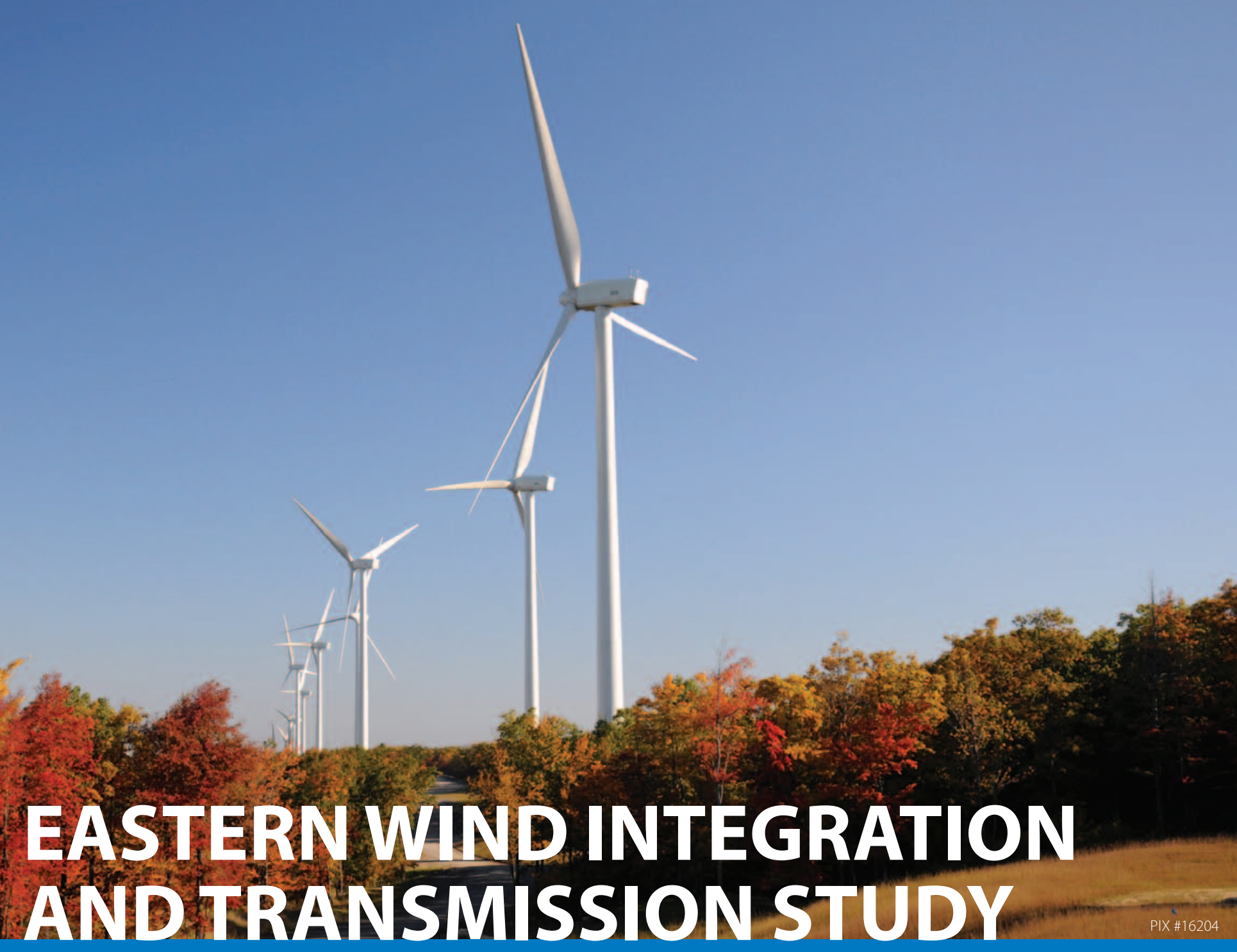

PREPARED FOR:

The National Renewable Energy Laboratory

A national laboratory of the U.S. Department of Energy

PREPARED BY:

EnerNex Corporation

REVISED FEBRUARY 2011 


\section{EASTERN WIND INTEGRATION AND TRANSMISSION STUDY}

Revised February 2011

Prepared for NREL by: EnerNex Corporation

Knoxville, Tennessee

NREL Technical Monitor: David Corbus

Prepared under Subcontract No. AAM-8-88513-01

Subcontract Report

NREL/SR-5500-47078

National Renewable Energy Laboratory

1617 Cole Boulevard, Golden, Colorado 80401

303-275-3000 • www.nrel.gov

NREL is a national laboratory of the U.S. Department of Energy

Office of Energy Efficiency and Renewable Energy

Operated by the Alliance for Sustainable Energy, LLC

Contract No. DE-AC36-08GO28308 


\section{NOTICE}

This report was prepared as an account of work sponsored by an agency of the United States government. Neither the United States government nor any agency thereof, nor any of their employees, makes any warranty, express or implied, or assumes any legal liability or responsibility for the accuracy, completeness, or usefulness of any information, apparatus, product, or process disclosed, or represents that its use would not infringe privately owned rights. Reference herein to any specific commercial product, process, or service by trade name, trademark, manufacturer, or otherwise does not necessarily constitute or imply its endorsement, recommendation, or favoring by the United States government or any agency thereof. The views and opinions of authors expressed herein do not necessarily state or reflect those of the United States government or any agency thereof.

Available electronically at http: / / www.osti.gov/ bridge

Available for a processing fee to U.S. Department of Energy and its contractors, in paper, from:

U.S. Department of Energy

Office of Scientific and Technical Information

P.O. Box 62

Oak Ridge, TN 37831-0062

phone: 865.576 .8401

fax: 865.576 .5728

email: mailto:reports@adonis.osti.gov

Available for sale to the public, in paper, from:

U.S. Department of Commerce

National Technical Information Service

5285 Port Royal Road

Springfield, VA 22161

phone: 800.553 .6847

fax: 703.605 .6900

email: orders@ntis.fedworld.gov

online ordering: http:/ / www.ntis.gov/ ordering.htm

Printed on paper containing at least 50\% wastepaper, including $10 \%$ post consumer waste. 


\section{TABLE OF CONTENTS}

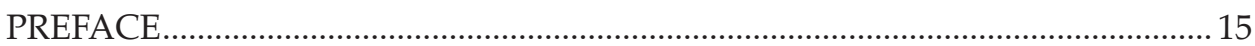

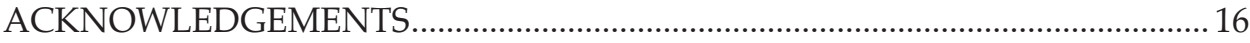

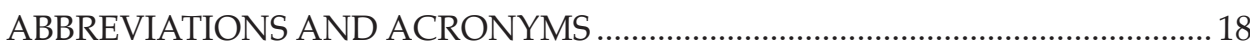

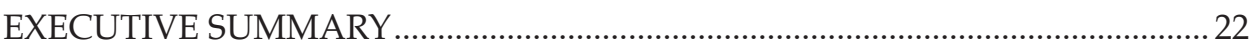

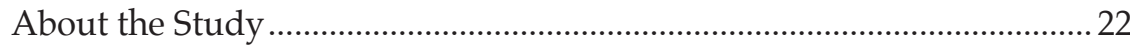

Scenario Development and Analysis .......................................................... 24

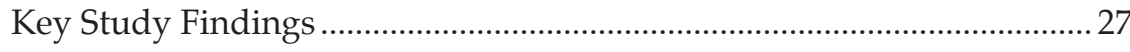

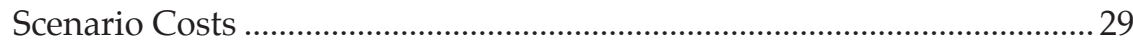

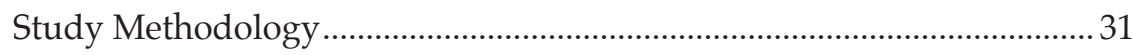

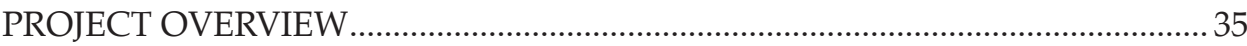

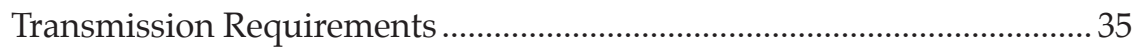

Wind Operational Impacts ............................................................................ 40

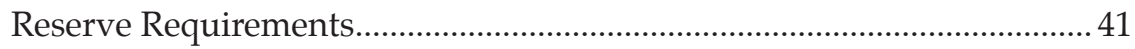

Production-Cost Modeling Results ............................................................... 44

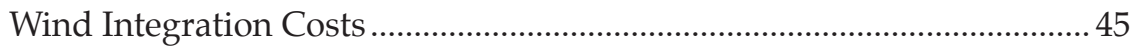

Carbon Sensitivity Analysis .......................................................................... 47

Contributions to Resource Adequacy ......................................................... 51

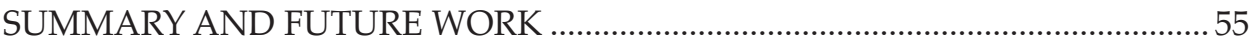

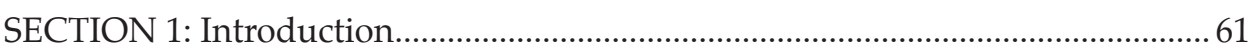

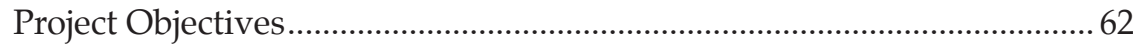

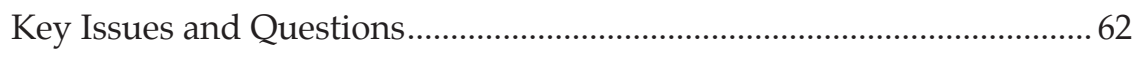

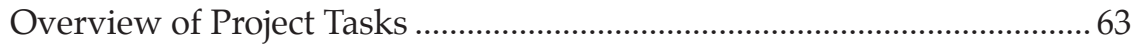

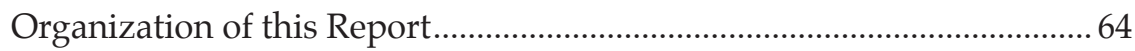

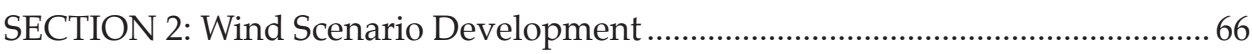

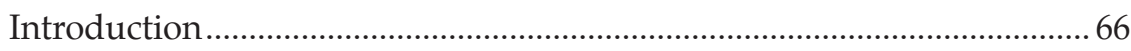

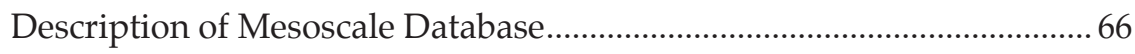

Scenario Development Process....................................................................... 70

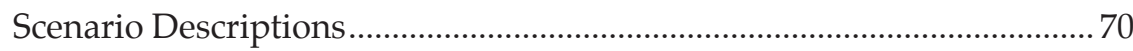

Regional wind Capacity and Energy ………............................................ 71

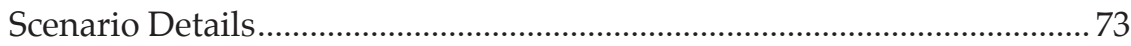

SECTION 3: Analytical Methodology: Data, Models, and Tools ............................ 81

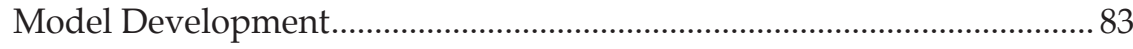

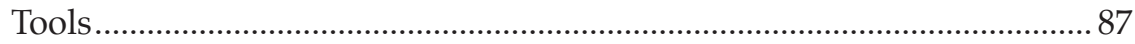

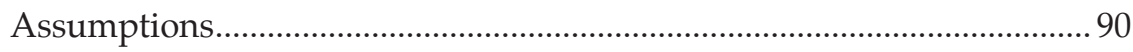

SECTION 4: Developing Economic Transmission Overlays ......................................98

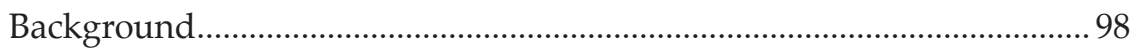

Application of Expansion Methodology ……………................................. 100

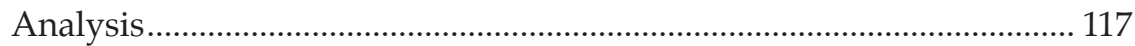

Design of HVDC Overlay Transmission ................................................... 120

SECTION 5: Power System Regulation and Balancing .......................................... 124

with Significant Wind Generation 
Power System Operation and Control..................................................... 124

Effects of Wind Generation on Power System Control ........................... 134

Modeling and Analysis for Assessing Wiind Integration Impacts......... 137

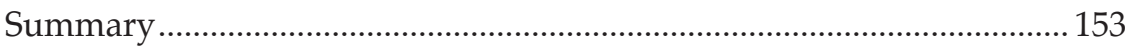

SECTION 6: Assessing Impacts on Power System Operation.................................. 156

Wind Integration Impacts and Costs ........................................................ 156

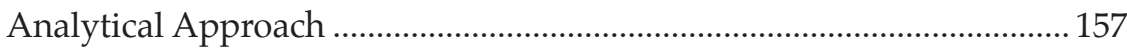

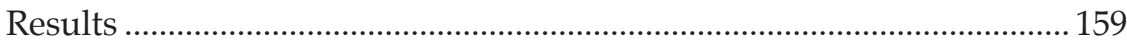

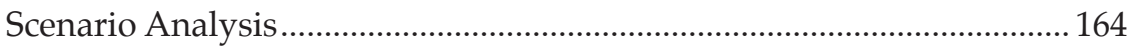

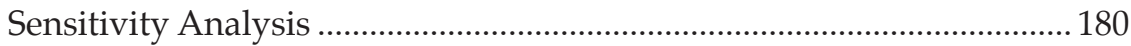

SECTION 7: Wind Generation Contributions to Resource ...................................... 194

Adequacy and Planning Margin

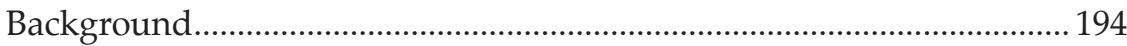

Analytical Approach …………............................................................. 194

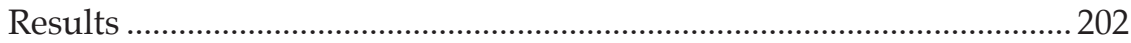

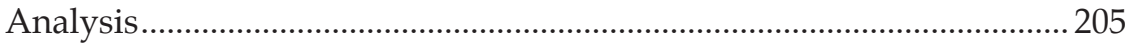

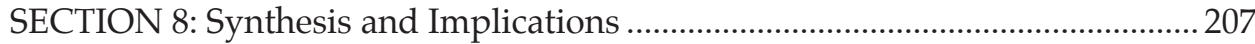

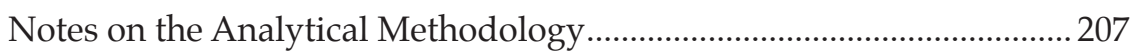

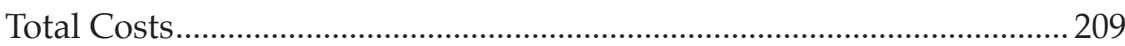

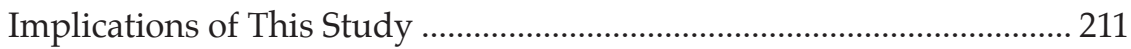

SECTION 9: Findings, Conclusions, and Recommendations................................ 214

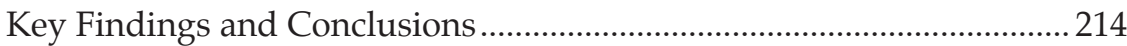

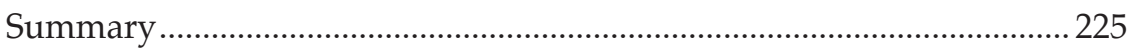

Recommendations for Future Study ....................................................... 226

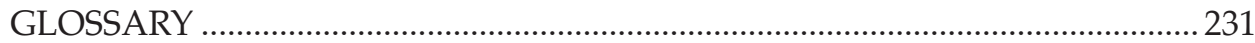

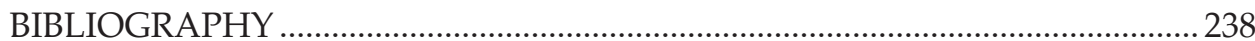

\section{LIST OF FIGURES}

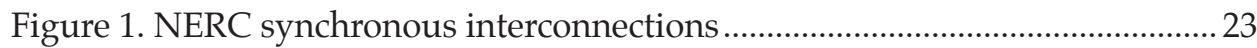

Figure 2. Summary of installed wind generation ................................................... 26

capacity by operating region for each scenario

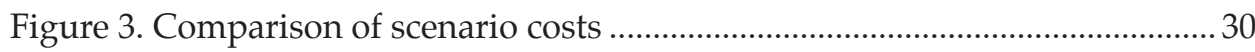

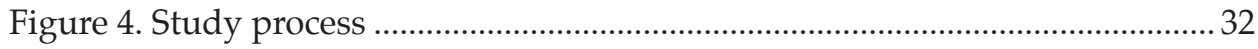

Figure 5. Assumed operational structure for the ..................................................... 34

Eastern Interconnection in 2004

Figure 6. Scenario2, annual generation differences between.....................................36 unconstrained case and constrained case

Figure 7. Scenario 2, annual generation weighted locational ..................................37 marginal price (LMP) for constrained case

Figure 8. Conceptual EHV transmission overlays for ............................................... 38 each study scenario

Figure 9. Regulating reserve requirements by region and scenario ........................ 42

Figure 10. Annual production-cost comparison ....................................................... 45 
Figure 11. Integration cost by scenario and year.

Figure 12. Generation expansion for the Scenario 2 ............................................. 48 carbon sensitivity case

Figure13. Generation expansion by scenario, including 49 the carbon sensitivity case

Figure 14. Carbon emissions for different scenarios 49

Figure 15. Generation utilization by unit and fuel. .50 type for Scenario 2 and carbon sensitivity case

Figure 16. Comparison of generation-weighted LMP by 50 region for Scenario 2 and carbon sensitivity case

Figure 17. Present value of accumulated costs for base .51 scenarios and carbon sensitivity

Figure 18. LOLE / ELCC results for high penetration .... .54 scenarios, with and without transmission overlays

Figure 2-1. LCOE for all wind facilities in database .68

Figure 2-2. Capacity factor for all wind in database 69

Figure 2-3. Aggregate capacity factor for all wind in database 69

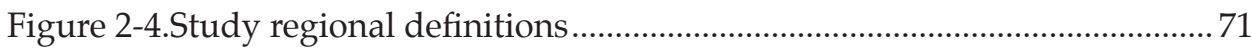

Figure 2-5. Annual energy production by region ....................................................... 72

Figure 2-6. Nameplate capacity by region.......................................................... 73

Figure 2-7. Wind plant size and location for Reference Case .................................. 74

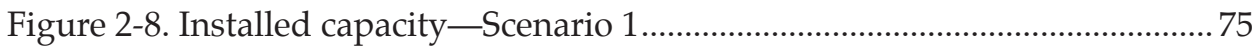

Figure 2-9. State map of nameplate capacity—Scenario 1 ........................................ 75

Figure 2-10. Installed capacity-Scenario 2 …………............................................ 76

Figure 2-11. State map of nameplate capacity-Scenario 2 2.................................. 77

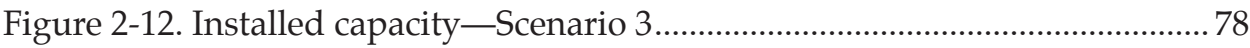

Figure 2-13. State map of nameplate capacity—Scenario 3 .................................... 78

Figure 2-14. Installed capacity —Scenario 4....................................................... 79

Figure 2-15. State map of nameplate capacity-Scenario 4 ...................................... 80

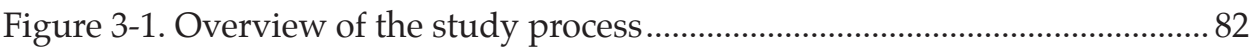

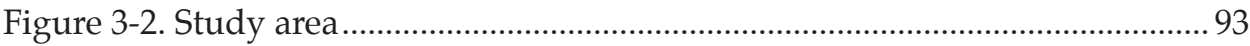

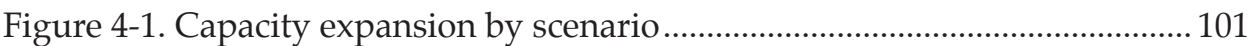

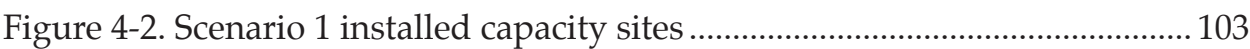

Figure 4-3. Scenario 2 installed capacity sites .......................................................... 103

Figure 4-4. Scenario 3 installed capacity sites ..................................................... 104

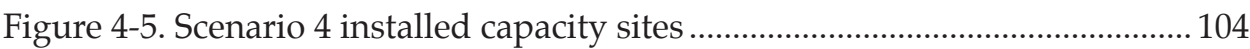

Figure 4-6. Scenario 2 annual generation-weighted............................................... 105

LMP for Scenario 2

Figure 4-7. Scenario 2 generation difference between ............................................. 106 unconstrained case and constrained case

Figure 4-8. Scenario 2 interface annual energy difference 107 between unconstrained case and constrained case

Figure 4-9. Transmission and substation costs per megawatt-mile....................... 109

Figure 4-10. SPP EHV conceptual transmission plan 110 
Figure 4-11. Midwest ISO RGOS, Phase I, Preliminary

Scenario T, 765-kV

Figure 4-12. EWITS Scenario 1 conceptual transmission plan. 112

Figure 4-13. EWITS Scenario 2 conceptual transmission plan................................ 112

Figure 4-14. EWITS Scenario 3 conceptual transmission plan. 113

Figure 4-15. EWITS Scenario 4 conceptual transmission plan 113

Figure 4-16. Scenario 1 annual generation-weighted. 118 LMP comparison 118

Figure 4-17. Scenario 2 annual generation-weighted. 118 LMP comparison

Figure 4-18. Scenario 3 annual generation-weighted. LMP comparison

Figure 4-19. Scenario 3 annual generation-weighted. LMP comparison

Figure 4-20. An example showing 800-kV HVDC lines 121 tied by $765-\mathrm{kV}$ lines and underlying $345-\mathrm{kV}$ lines

Figure 4-21. A postcontingency example showing five $800-\mathrm{kV}$ 122

HVDC lines example tied by $765-\mathrm{kV}$ lines and underlying $345-\mathrm{kV}$ lines

Figure 4-22. An example of the assumed distribution of 123 the flows on the underlying AC system

Figure 5-1. NERC reliability regions and balancing authorities 127 as of January 2005 and August 2007

Figure 5-2. U.S. RTOs. 128

Figure 5-3. Depiction of regulation and load-following 130 characteristics of demand

Figure 5-4. Normalized 10-minute variability for five different. 135 groups of wind generation. The $500 \mathrm{MW}$ scenario is part of the 5,000-MW scenario, which is part of the 15,000-MW scenario, and so on

Figure 5-5. Ten-minute variability of load and net load for... 136 MISO and PJM

Figure 5-6. Eastern Interconnection balancing authorities. 138

Figure 5-7. Illustration of short-term (next 10-minute interval) 144 forecasts of load and wind generation

Figure 5-8. Errors in short-term forecasts of load and wind. 144 generation; load error is assumed to be zero in the mathematical procedure

Figure 5-9. Illustration of short-term (10-minute ahead) wind 145 generation forecast errors as a function of average hourly production

Figure 5-10. Standard deviation of 1-hour persistence forecast error for PJM in Reference Case

Figure 5-11. Distributions of hourly regulating reserve requirements. 152 for PJM Scenario 3, for load only (ideal wind generation) and load net of wind generation 
Figure 6-1. Wind energy penetration levels by region using. 160 2004 hourly profiles

Figure 6-2. Annual average variable spinning reserve using 161 2004 hourly profiles

Figure 6-3. Annual APCs using 2004 hourly profiles 162

Figure 6-4. Annual steam turbine coal generation 163 summary with 2004 hourly profiles

Figure 6-5. Annual combined cycle and combustion 164 turbine gas generation with 2004 hourly profiles

Figure 6-6. Annual APC comparison for actual cases. 165

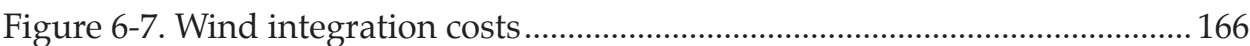

Figure 6-8. Wind integration costs (\$/MWh of annual ....................................... 167 wind energy in 2024)

Figure 6-9. Annual wind energy input summary for Scenario 1 168

Figure 6-10. Annual wind curtailment summary using 169 2004 hourly load and wind profiles

Figure 6-11. Annual wind curtailment summary using 169 2005 hourly load and wind profiles

Figure 6-12. Annual wind curtailment summary using 170 2006 hourly load and wind profiles

Figure 6-13. Annual generation energy by fuel type using 171 2004 hourly load and wind profiles

Figure 6-14. Annual generation energy by fuel type using 171 2005 hourly load and wind profiles

Figure 6-15. Annual generation energy by fuel type using 172 2006 hourly load and wind profiles

Figure 6-16. Annual generation energy by fuel type using 172 2004 hourly profiles

Figure 6-17. Annual generation energy by fuel type using 173 2005 hourly profiles

Figure 6-18. Annual generation energy by fuel type using 2006 hourly profiles

Figure 6-19. Change in annual generation from ideal to. 174 actual cases using 2004 hourly profiles

Figure 6-20. Change in annual generation from ideal to. 175 actual cases using 2005 hourly profiles

Figure 6-21. Change in annual generation from ideal to 175 actual cases using 2006 hourly profiles

Figure 6-22. Annual generation-weighted LMPs using 176 2004 hourly profiles

Figure 6-23. Annual generation-weighted LMPs using 2005 hourly profiles

Figure 6-24. Annual generation-weighted LMPs using 177 2006 hourly profiles 
Figure 6-25. Annual regional transaction energy using 2004 hourly profiles

Figure 6-26. Annual regional transaction energy using 179 2005 hourly profiles

Figure 6-27. Annual regional transaction energy using 179 2006 hourly profiles

Figure 6-28. Interface flow duration curve sample 181

Figure 6-29. APCs with 2005 hourly wind and load patterns 184

Figure 6-30. Integration cost summary with 2005 hourly 185 wind and load patterns

Figure 6-31. Annual generation-weighted LMPs with 185 2005 hourly wind and load patterns

Figure 6-32. Annual generation-weighted LMP comparison 187

Figure 6-33. Capacity expansion by scenario including 188 carbon sensitivity, 2008-2024

Figure 6-34. Carbon impact of modeled scenarios 189

Figure 6-35. Cost impact of modeled scenarios 189

Figure 6-36. Forecast generation locations for sensitivity 190 to scenario 2

Figure 6-37. Annual generation production by fuel type with 191 2005 hourly wind and load patterns

Figure 6-38. Annual generation energy changes from ideal 192 case to actual case

Figure 6-39. Annual generation-weighted LMP comparison 192

Figure 7-1. ELCC example system with and without resource. 195

Figure 7-2. ELCC example system at the same LOLE 195

Figure 7-3. Scenario 1, existing transmission system 198 August interface limits (MW)

Figure 7-4. Scenario 2, existing transmission system. 198 August interface limits (MW)

Figure 7-5. Scenario 3, existing transmission system 199 August interface limits (MW)

Figure 7-6. Scenario 4, existing transmission system 199 August interface limits (MW)

Figure 7-7. Scenario 1, conceptual transmission overlay 200 August interface limits (MW)

Figure 7-8. Scenario 2, conceptual transmission overlay 200 August interface limits (MW)

Figure 7-9. Scenario 3, conceptual transmission overlay August interface limits (MW)

Figure 7-10. Scenario 4, conceptual transmission overlay 201 August interface limits (MW)

Figure 7-11. ELCC results for existing and overlay transmission 203

Figure 7-12. Tie benefit results for existing and overlay transmission. .204 
Figure 8-1. Flow diagram for study analytical methodology …............................ 208

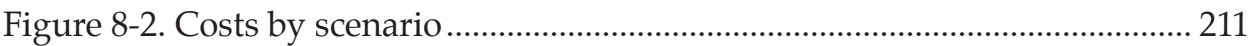

Figure 9-1. Comparison of production simulation results ................................... 219

(integration cost) for base unit-commitment algorithm and more sophisticated "bid-logic" approach

Figure 9-2. Comparison of LMPs for hurdle rate sensitivity ……………............. 220

Figure 9-3. Scenario 2, carbon case generation expansion ..................................... 221

Figure 9-4. Generation expansion by scenario, 2008-2024 …………………........ 221

Figure 9-5. Carbon emission comparison .............................................................. 222

Figure 9-6. Change in generation for carbon sensitivity …………………........... 223

Figure 9-7. Change in LMP for carbon sensitivity............................................... 223

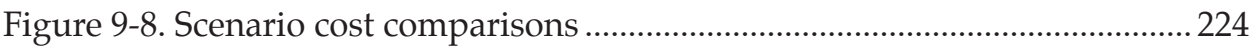

\section{LIST OF TABLES}

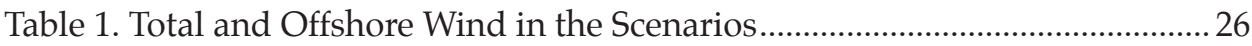

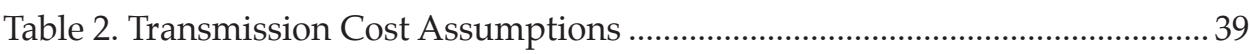

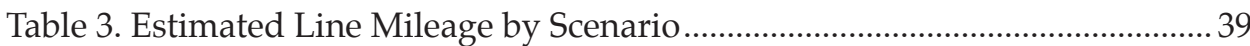

Table 4. Estimated Costs by Scenario (US \$2009, millions) ........................................ 39

Table 5. Reliability Zones for LOLE Analysis with Installed Wind ...........................53

Generation Capacity (Nameplate Wind in Megawatts)

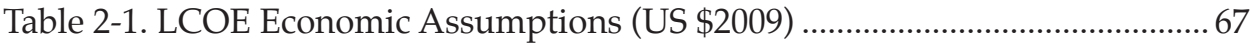

Table 2-2. Summary of Energy by Region for Scenarios.......................................... 72

Table 2-3. Reference Case, 6\% of 2024 Load Requirements....................................... 73

Table 2-4. Scenario 1-20\% High Capacity Factor, Onshore...................................... 74

Table 2-5. Scenario 2-20\% Hybrid with Offshore ................................................... 76

Table 2-6. Scenario 3-20\% Local, with Aggressive Offshore.................................. 77

Table 2-7. Scenario 4-30\% Aggressive Onshore and Offshore................................ 79

Table 3-1. Summary of Demand and Energy Assumptions Used............................ 84 within the Scenario Definitions

Table 3-2. Status Categories Applied to all Units Within the Database ................... 85

Table 3-3. Summary of Active Generation Capacity by Region ................................ 86 (Nameplate Capacities in Megawatts)

Table 3-4. Summary of Planned Generation Capacity by Region 86 through 2024 (Nameplate Capacities in Megawatts

Table 3-5. Summary of Generator Retirement Capacity by 87

Region through 2024 (Nameplate Capacities in Megawatts)

Table 3-6. Average Fuel Costs Modeled by System..................................................... 94

Table 3-7. Target Reserve Margins by Region ........................................................ 96

Table 3-8. Modeled Generator Prototype Data Values in US \$2008 ......................... 97

Table 3-9. Modeled Penetration of Demand Response by Region ......................... 97 (as percent age of peak)

Table 4-1. Top 24 Interfaces with the Largest Annual 108 Energy Difference

Table 4-2. Annual APC Savings for Each Scenario (US \$2024, millions) 109 
Table 4-3. Cost per Mile Assumption (US \$2024, millions) .................................... 114

Table 4-4. Estimated Line Mileage Summary (Miles) ............................................ 115

Table 4-5. Estimated Cost Summary (US \$2024, millions) ..................................... 115

Table 4-6. Benefit and Cost Comparison (US \$2024, millions)............................... 115

Table 4-7. Estimated Additional Transmission Investments................................... 116 for Scenario 1

Table 4-8. Estimated Additional Transmission Investments.................................. 116 for Scenario 2

Table 4-9. Estimated Additional Transmission Investments................................... 117 for Scenario 3

Table 4-10. Estimated Additional Transmission Investments. for Scenario 4

Table 4-11. Wind Curtailment Summary 120

Table 5-1. Excerpts from NERC Glossary of Terms Related to .............................. 129 Operating Reserves

Table 5-2. 2009 CPS2 bounds for Selected Eastern 132 Interconnection BAAs

Table 5-3. Mapping of Reserve Components in Categories for 140 Production Simulations

Table 5-4. Contingency Reserve Requirements by Operation 141 Region for 2024

Table 5-5. Summary of Reserve Methodology for Study Scenarios. 147

Table 5-6. Example Application of Reserve Methodology 149 to Hourly Data

Table 5-7. Adjustment of Spinning Reserve for Reduction 151 in Wind Generation

Table 5-8. Spinning Reserve Requirements by for the 152 Reference Case

Table 5-9. Spinning Reserve Requirements for Scenario 1. 152

Table 5-10. Spinning Reserve Requirements for Scenario 2 153

Table 5-11. Spinning Reserve Requirements for Scenario 3 153

Table 5-12. Spinning Reserve Requirements for Scenario 4 153

Table 6-1. Integration Costs (\$/MWh of Wind Energy in US\$ 2024).................... 162

Table 6-2. Integration Costs US\$ 2024 ………….................................................. 163

Table 6-3. Wind Curtailment Comparison for Sensitivity ..................................... 182

Case 1, Non Must-Run

Table 6-4. Wind Curtailment Comparison for Sensitivity 182 Case 2, Copper Sheet

Table 6-5. Wind Curtailment Comparison for Sensitivity 183 Case 3, Wind Energy Credit

Table 6-6. Annual Generation Energy Summary by Fuel Type ............................... 183

Table 6-7. Scenario 1, Hurdle Rate Sensitivity Results.............................................. 186

Table 6-8. Scenario 3, Hurdle Rate Sensitivity Results............................................ 186

Table 6-9. Scenario 2, Carbon Sensitivity Operational Impact Results................. 193 
Table 7-1. Reliability zones for LOLE analysis with installed wind

Generation Capacity (Nameplate wind in megawatts)

Table 7-2. ELCC Results for Isolated System (no ties) .............................................202

Table 7-3. ELCC Results for Existing Transmission System................................... 202

Table 7-4. ELCC Results for Overlay Transmission System.................................... 203

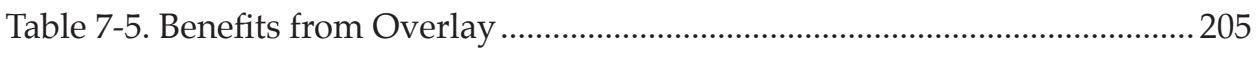

Table 8-1. Assumptions used in Scenario Cost Calculations ..................................209 


\section{PREFACE}

The Eastern Wind Integration and Transmission Study (EWITS) is the culmination of an effort that spanned two and one-half years. The study team began by modeling wind resources in a large part of the Eastern Interconnection and finished by conducting a detailed wind integration study and top-down transmission analysis. The study resulted in information that can be used to guide future work. A number of other studies have already examined similar wind integration issues, but the breadth and depth of the analysis in EWITS is unique. EWITS builds on the work of previous integration studies, which looked at considerably smaller geographic footprints, focused almost exclusively on wind integration, and did not include transmission. EWITS took the next step by expanding the study area and including conceptual transmission overlays.

Just a few years ago, $5 \%$ wind energy penetration was a lofty goal, and to some the idea of integrating 20\% wind by 2024 might seem a bit optimistic. And yet, we know from the European experience-where some countries have already reached wind energy penetrations of $10 \%$ or higher in a short period of time- that change can occur rapidly and that planning for that change is critically important. Because building transmission capacity takes much longer than installing wind plants, there is a sense of urgency to studying transmission. It is already starting to limit wind growth in certain areas.

The goal of the EWITS team was not to further any specific agenda or regional vision of the future, but to be as objective as possible while conducting a technical study of future high-penetration wind scenarios. To help guide the EWITS work, the U.S. Department of Energy's (DOE) National Renewable Energy Laboratory (NREL) convened a Technical Review Committee (TRC) composed of regional electric reliability council representatives, expert reviewers, transmission planners, utility administrators, and wind industry representatives. Over a period of 14 months while the study was in progress, the TRC held 6 full-day meetings along with numerous Webinars and conference calls to review study progress; comment on study inputs, methods, and assumptions; assist with collecting data; and review drafts of the study report.

Planning for the expansion of the electrical grid is a process that requires an immense amount of study, dialogue among regional organizations, development of technical methodologies, and communication and coordination among a multitude of important stakeholders. Keeping abreast of the changes is challenging because there are so many different developments, ideas, and viewpoints. It is my hope that the EWITS results will be helpful to all those involved in the planning of the future electrical grid and form a foundation for future studies.

David Corbus

Senior Engineer, NREL 


\title{
ACKNOWLEDGMENTS
}

The National Renewable Energy Laboratory (NREL) thanks the U.S. Department of Energy (DOE) for sponsoring EWITS; the Technical Review Committee (TRC) for such great participation and input; and the study team of EnerNex Corporation, the Midwest Independent System Operator (Midwest ISO), and Ventyx for carrying out the work. Thanks also go to Study Lead Robert Zavadil, along with Michael Brower of AWS Truewind, who conducted the wind modeling study.

\section{PROJECT MANAGER}

David Corbus

NREL

\section{STUDY TEAM}

EnerNex Corporation:

Jack King, Tom Mousseau, and Robert Zavadil

Midwest ISO: Brandon Heath, Liangying (Lynn) Hecker, John Lawhorn, Dale Osborn, and JT Smith

Ventyx: Rick Hunt and Gary Moland

\author{
TECHNICAL REVIEW COMMITTEE \\ John Adams \\ Mark Ahlstrom \\ Jared Alholinna \\ Steve Beuning \\ Clifton Black \\ Jay Caspary \\ Charlton Clark \\ Cathy Cole \\ David Corbus (co-chair) \\ Dan Fredrickson \\ Michael Goggin \\ Sasan Jalai (observer) \\ Brendan Kirby \\ Chuck Liebold \\ Michael Milligan \\ Jeff Mitchell \\ Nathan Mitchell \\ Don Neumeyer \\ New York Independent System Operator \\ (NYISO) \\ WindLogics \\ CapX 2020 (Great River Energy) \\ Xcel Energy \\ Southern Company \\ Southwest Power Pool (SPP) \\ DOE \\ Michigan Public Service Commission \\ NREL \\ Mid-Continent Area Power Pool (MAPP) \\ American Wind Energy Association (AWEA) \\ Federal Energy Regulatory Commission (FERC) \\ NREL \\ PJM Interconnection \\ NREL \\ North American Electric Reliability Corporation \\ (NERC; ReliabilityFirst) \\ American Public Power Association (APPA) \\ Organization of MISO States \\ (Wisconsin Public Service Commission)
}


Mark O’Malley

Dale Osborn

Dick Piwko

Matt Schuerger (co-chair)

Ken Schuyler

Richard Sedano

J. Charles Smith

Jason Smith

Dave Souder
University College Dublin

Midwest ISO

GE Energy

NREL

PJM Interconnection

Regulatory Assistance Project

Utility Wind Integration Group (UWIG)

SPP

PJM Interconnection

Finally, we thank René Howard (WordProse, Inc.), Kathy O'Dell (NREL), and Christina Thomas (Sage TechEdit Inc.) for their help in editing and production and Mark Schroder (Purple Sage Design) for designing this Executive Summary and Project Overview and the full report. 


\section{ABBREVIATIONS AND ACRONYMS}

ACE

AECI

AGC

AMRN

APC

ATC

BAA

BAAL

$\mathrm{B} / \mathrm{C}$

CAPX 2020 (GRE)

CC

$\mathrm{CC} / \mathrm{Seq}$

$\mathrm{CO} 2$

$\mathrm{CPM}$

CPS1

CPS2

CT

DCS

DOE

DR

ECAR

EERE

EGEAS

EHV

EHV AC

EHV DC

ELCC

EMS

EPJM

EPRI area control error

Associated Electric Cooperative, Inc.

automatic generation control

Ameren

adjusted production cost

American Transmission Company

balancing authority area

balancing authority ACE limit

benefit cost (analysis)

Capital Expansion Plan for 2020 (Great River

Energy)

combined cycle

combined cycle with sequestration

carbon dioxide

control performance measure

Control Performance Standard 1

Control Performance Standard 2

combustion turbine

Disturbance Control Standard

U.S. Department of Energy

demand response

East Central Area Reliability Coordinating

Agreement (a former NERC reliability region)

Office of Energy Efficiency and Renewable Energy

Electric Generation Expansion Analysis System

extra-high voltage

extra-high voltage AC

extra-high voltage DC

effective load-carrying capability

energy management system

East PJM

Electric Power Research Institute 


\begin{tabular}{|c|c|}
\hline ERAG MMWG & $\begin{array}{l}\text { Eastern Interconnection Reliability Assessment } \\
\text { Group Multi-Regional Modeling Working Group }\end{array}$ \\
\hline ERCOT & Electric Reliability Council of Texas \\
\hline ERO & Electric Reliability Organization \\
\hline ES\&D & electricity supply and demand \\
\hline EWIS & European Wind Integration Study \\
\hline EWITS & Eastern Wind Integration and Transmission Study \\
\hline EUE & expected unserved energy \\
\hline FERC & Federal Energy Regulatory Commission \\
\hline FRCC & Florida Reliability Coordinating Council \\
\hline GE-MARS & $\begin{array}{l}\text { GE Energy's Multi-Area Reliability Simulation } \\
\text { program }\end{array}$ \\
\hline GW & gigawatt \\
\hline GWh & gigawatt-hour \\
\hline HSIL & high-surge impedance loading \\
\hline HVDC & high-voltage DC \\
\hline $\mathrm{Hz}$ & hertz \\
\hline IGCC & integrated gasification combined cycle \\
\hline IGCC/Seq & $\begin{array}{l}\text { integrated gasification combined cycle with } \\
\text { sequestration }\end{array}$ \\
\hline IESO & Independent Electricity System Operator \\
\hline ISO & independent system operator \\
\hline ISO-NE & New England ISO \\
\hline JCSP & Joint Coordinated System Plan (2008) \\
\hline $\mathrm{km}$ & kilometer \\
\hline $\mathrm{kV}$ & kilovolt \\
\hline $\mathrm{kW}$ & kilowatt \\
\hline kWh & kilowatt-hour \\
\hline $\mathrm{LCOE}$ & levelized cost of energy \\
\hline LMP & locational marginal price \\
\hline LOLE & loss of load expectation \\
\hline LOLP & loss of load probability \\
\hline
\end{tabular}


MACC

MAIN

MAPP

MHEB

MISO

MBtu

MRO

MW

MWh

NBSO

NERC

NPCC

NREL

NWP

NYISO

O\&M

OMS

PHEV

PJM

PTC

REC

RET Coal

RFC

RGOS

RPS

RTO

SCUC

SERC

SLH

SPP

SPS

ST

TRC

TRE
Mid-Atlantic Area Council (a former NERC

reliability region)

Mid-American Interconnected Network

Mid-Continent Area Power Pool

Manitoba Hydro Electric Board

Midwest ISO

million British thermal units

Midwest Reliability Organization

megawatt

megawatt-hour

New Brunswick Security Operator

North American Electric Reliability Corporation

Northeast Power Coordinating Council

National Renewable Energy Laboratory

numerical weather prediction

New York ISO

operations and maintenance

Organization of MISO States

plug-in hybrid electric vehicle

PJM Interconnection

production tax credit

renewable energy credit

coal plant retirement

ReliabilityFirst Corporation

Regional Generation Outlet Study

renewable portfolio standard

regional transmission organization or regional

transmission operator

security-constrained unit commitment

Southeastern Electric Reliability Council

single largest hazard

Southwest Power Pool

Southwestern Public Service

steam turbine

Technical Review Committee

Texas Regional Entity 
TVA

TWh

UCTE

UWIG

V

W

WAPA

WECC

WI PSC

WWSIS
Tennessee Valley Authority

terawatt-hours

Union for the Co-ordination of Transmission of Electricity

Utility Wind Integration Group

volt

watt

Western Area Power Administration

Western Electricity Coordinating Council

Public Service Commission of Wisconsin

Western Wind and Solar Integration Study 


\section{EXECUTIVE SUMMARY}

The total installed capacity of wind generation in the United States surpassed 25 gigawatts (GW) at the end of 2008. Despite the global financial crisis, another $4.5 \mathrm{GW}$ was installed in the first half of 2009. Because many states already have mandates in place for renewable energy penetration, significant growth is projected for the foreseeable future.

In July 2008, the U.S. Department of Energy (DOE) published the findings of a year-long assessment of the costs, challenges, impacts and benefits of wind generation providing $20 \%$ of the electrical energy consumed in the United States by 2030 (EERE 2008). Developed through the collaborative efforts of a wide-ranging cross section of key stakeholders, that final report (referred to here as the $20 \%$ Report) takes a broad view of the electric power and wind energy industries. The $20 \%$ Report evaluates the requirements and outcomes in the areas of technology, manufacturing, transmission and integration, environmental impacts, and markets that would be necessary for reaching the $20 \%$ by 2030 target.

The 20\% Report states that although significant costs, challenges, and impacts are associated with a $20 \%$ wind scenario, substantial benefits can be shown to overcome the costs. In other key findings, the report concludes that such a scenario is unlikely to be realized with a business-as-usual approach, and that a major national commitment to clean, domestic energy sources with desirable environmental attributes would be required.

The growth of domestic wind generation over the past decade has sharpened the focus on two questions: Can the electrical grid accommodate very high amounts of wind energy without jeopardizing security or degrading reliability? And, given that the nation's current transmission infrastructure is already constraining further development of wind generation in some regions, how could significantly larger amounts of wind energy be developed? The answers to these questions could hold the keys to determining how much of a role wind generation can play in the U.S. electrical energy supply mix.

\section{ABOUT THE STUDY}

DOE commissioned the Eastern Wind Integration and Transmission Study (EWITS) through its National Renewable Energy Laboratory (NREL). The investigation, which began in 2007, was the first of its kind in terms of scope, scale, and process. The study was designed to answer questions posed by a variety of stakeholders about a range of important and contemporary technical issues related to a $20 \%$ wind scenario for the large portion of the electric load (demand for energy) that resides in the Eastern Interconnection (Figure 1). The Eastern Interconnection is one of the three synchronous grids covering the lower 
48 U.S. states. It extends roughly from the western borders of the Plains states through to the Atlantic coast, excluding most of the state of Texas.

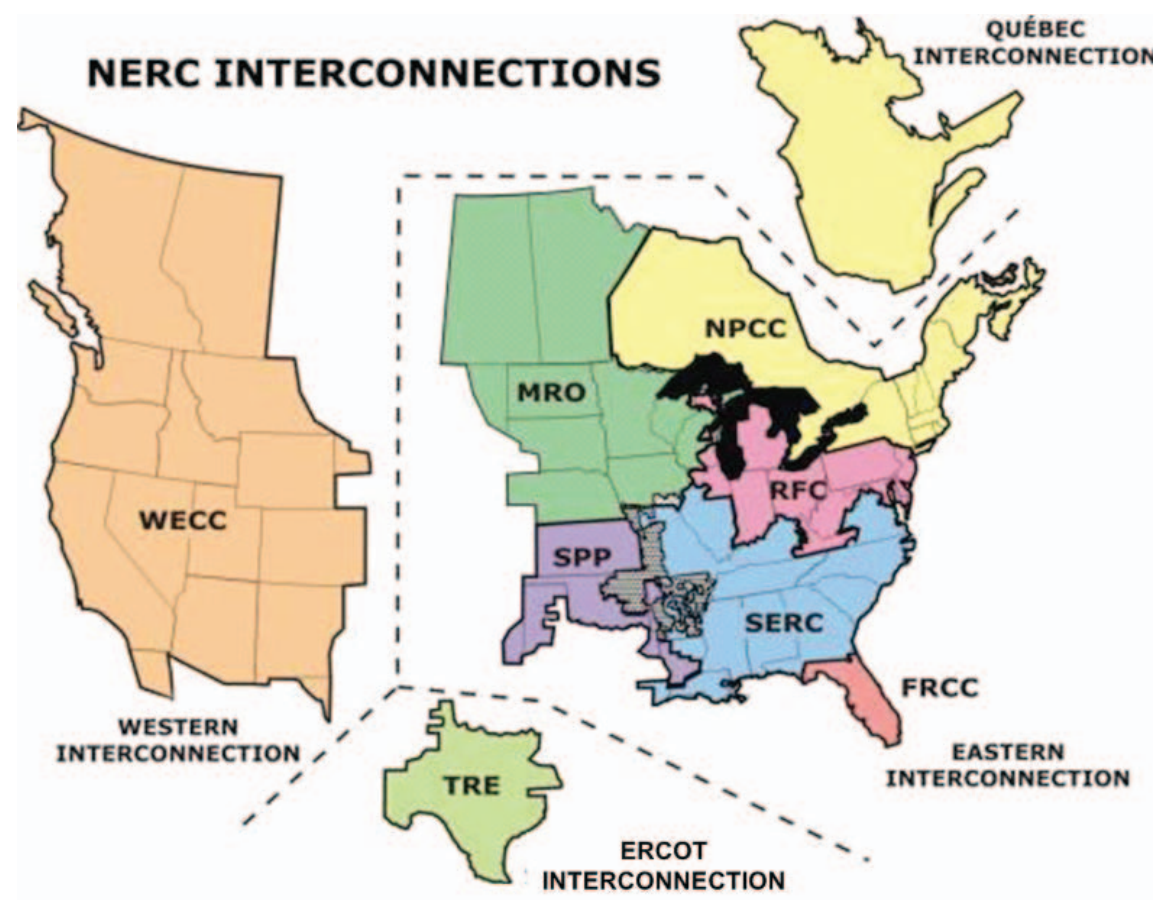

Figure 1. NERC synchronous interconnections

Notes: NERC $=$ North American Electric Reliability Corporation; $W E C C=$ Western Electricity Coordinating Council; TRE = Texas Regional Entity; ERCOT = Electric Reliability Council of Texas; $M R O=$ Midwest Reliability Organization; SPP = Southwest Power Pool; NPCC = Northeast Power Coordinating Council; RFC = ReliabilityFirst Corporation; SERC = Southeastern Electric Reliability Council; FRCC = Florida Reliability Coordinating Council

EWITS is one of three current studies designed to model and analyze wind penetrations on a large scale. The Western Wind and Solar Integration Study (WWSIS), also sponsored by DOE/NREL, is examining the planning and operational implications of adding up to $35 \%$ wind and solar energy penetration to the WestConnect footprint in the WECC. The European Wind Integration Study (EWIS) is an initiative established by the European associations of transmission system operators in collaboration with the European Commission. EWIS is aimed at developing common solutions to wind integration challenges in Europe and at identifying arrangements that will make best use of the panEuropean transmission network, allowing the benefits of wind generation to be delivered across Europe. 
EWITS was the first of its kind in terms of scope, scale, and process. Initiated in 2007, the study was designed to examine the operational impact of up to $20 \%$ to $30 \%$ wind energy penetration on the bulk power system in the Eastern Interconnection of the United States.

\section{SCENARIO DEVELOPMENT AND ANALYSIS}

To set an appropriate backdrop for addressing the key study questions, the EWITS project team-with input from a wide range of project stakeholders including the Technical Review Committee (TRC)—carefully constructed four high-penetration scenarios to represent different wind generation development possibilities in the Eastern Interconnection. Three of these scenarios delivered wind energy equivalent to $20 \%$ of the projected annual electrical energy requirements in 2024; the fourth scenario increased the amount of wind energy to $30 \%$.

In each scenario, individual wind plants from the Eastern Wind Data Study database (see sidebar) were selected to reach the target energy level. The wind data consisted of hourly and 10-minute wind plant data for each of three years: 2004, 2005, and 2006. Wind plants were available in all geographic locations within the Eastern Interconnection except off the shore of the southeastern United States and Canada (because of limitations

\section{The Eastern Wind Data Study}

A precursor to EWITS known as the Eastern Wind Data Study (AWS Truewind 2009) identified more than 700 GW of potential future wind plant sites for the eastern United States. All the major analytical elements of EWITS relied on the time series wind generation production data synthesized in this earlier effort. The data cover three historical years-2004, 2005, and 2006-at high spatial (2-kilometer [km]) and temporal (10-minute) resolution. On- and offshore resources are included, along with wind resources for all states. on the scope of work for the wind modeling). Approximately $4 \mathrm{GW}$ of new Canadian renewable generation was modeled to cover imports of new Canadian wind and hydro to the northeast.

A brief description of each scenario follows:

- Scenario 1, 20\% penetration - High Capacity Factor, Onshore: Utilizes high-quality wind resources in the Great Plains, with other development in the eastern United States where good wind resources exist.

- Scenario 2, 20\% penetration - Hybrid with Offshore: Some wind generation in the Great Plains is moved east. Some East Coast offshore development is included.

- Scenario 3, 20\% penetration - Local with Aggressive Offshore: More wind generation is moved east toward load centers, necessitating broader use of offshore resources. The offshore wind assumptions represent an uppermost limit of what could be developed by 2024 under an aggressive technology-push scenario. 
- Scenario 4, 30\% penetration - Aggressive On- and Offshore: Meeting the $30 \%$ energy penetration level uses a substantial amount of the higher quality wind resource in the NREL database. A large amount of offshore generation is needed to reach the target energy level.

The study team also developed a Reference Scenario to approximate the current state of wind development plus some expected level of near-term development guided by interconnection queues and state renewable portfolio standards (RPS). This scenario totaled about $6 \%$ of the total 2024 projected load requirements for the U.S. portion of the Eastern Interconnection.

\section{What Are ISOs and RTOs?}

In the mid-1990s, independent system operators (ISOs) and regional transmission operators (RTOs) began forming to support the introduction of competition in wholesale power markets. Today, two-thirds of the population of the United States and more than one-half of the population of Canada obtain their electricity from transmission systems and organized wholesale electricity markets run by ISOs or RTOs. These entities ensure that the wholesale power markets in their regions operate efficiently, treat all market participants fairly, give all transmission customers open access to the regional electric transmission system, and support the reliability of the bulk power system.

Source: Adapted from IRC (2009).
Figure 2 depicts the installed capacity by regional entity (either independent system operators [ISOs] or regional transmission operators [RTOs]; see sidebar) for each of the wind generation scenarios in EWITS. Table 1 shows the contribution of total and offshore wind to the scenarios.

Supplying $20 \%$ of the electric energy requirements of the U.S. portion of the Eastern Interconnection would call for approximately 225,000 megawatts (MW) of wind generation capacity, which is about a tenfold increase

above today's levels. To reach $30 \%$ energy from wind, the installed capacity would have to rise to 330,000 MW. 


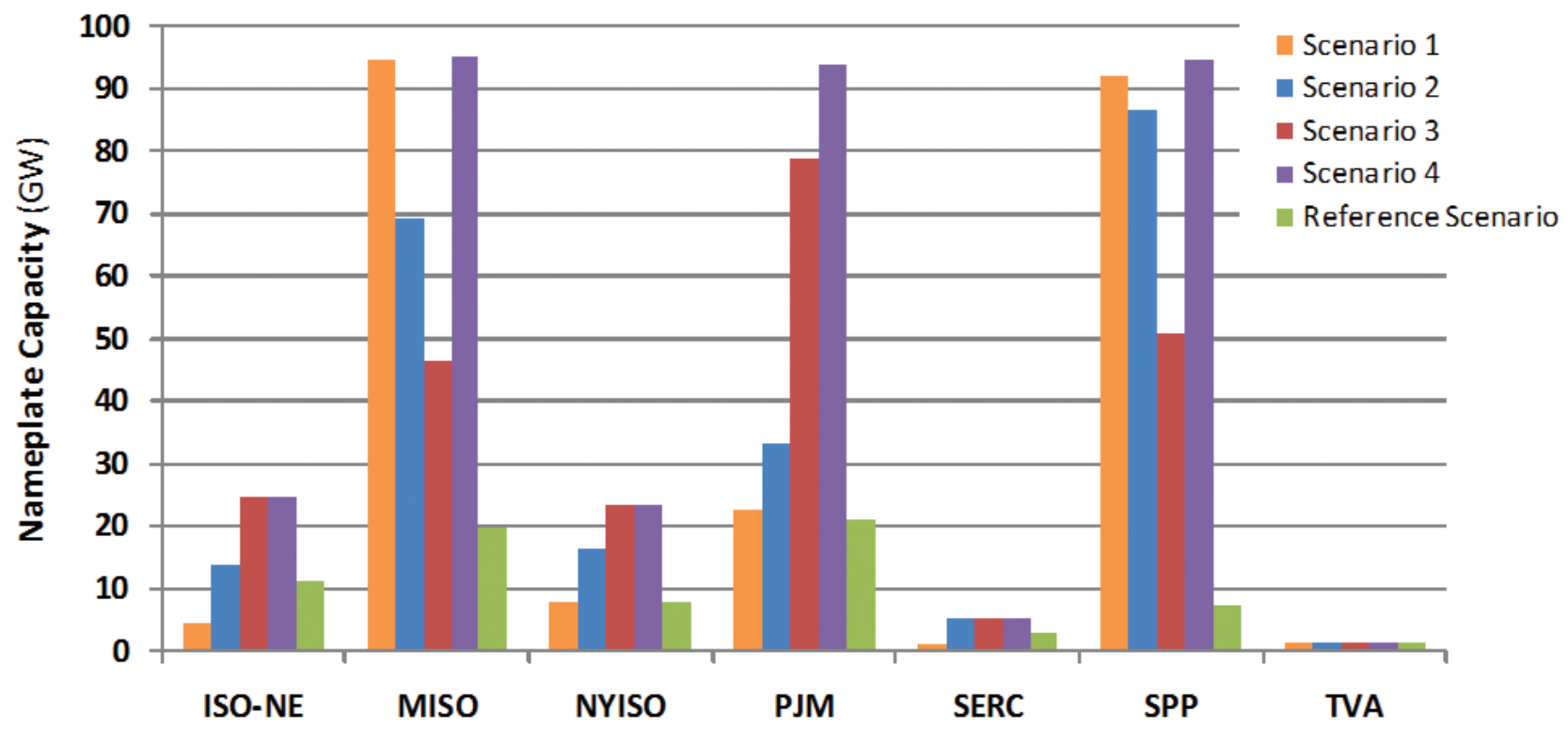

Figure 2. Summary of installed wind generation capacity by operating region

for each scenario (Notes: ISO-NE = New England Independent System Operator,

$M I S O=$ Midwest ISO, NYISO = New York ISO, PJM = PJM Interconnection,

SERC = Southeastern Electric Reliability Council, SPP = Southwest Power Pool,

TVA - Tennessee Valley Authority)

\begin{tabular}{|c|c|c|c|c|c|c|c|c|}
\hline \multirow[t]{2}{*}{ Region } & \multicolumn{2}{|c|}{$\begin{array}{c}\text { Scenario } 1 \\
\text { 20\% High Capacity Factor, } \\
\text { Onshore }\end{array}$} & \multicolumn{2}{|c|}{$\begin{array}{c}\text { Scenario } 2 \\
20 \% \text { Hybrid with Offshore }\end{array}$} & \multicolumn{2}{|c|}{$\begin{array}{c}\text { Scenario } 3 \\
\text { 20\% Local, } \\
\text { Aggressive Offshore }\end{array}$} & \multicolumn{2}{|c|}{$\begin{array}{l}\text { Scenario } 4 \\
\text { 30\% Aggressive } \\
\text { On- and Offshore }\end{array}$} \\
\hline & $\begin{array}{l}\text { TOTAL } \\
\text { (MW) }\end{array}$ & $\begin{array}{l}\text { Offshore } \\
\text { (MW) }\end{array}$ & $\begin{array}{l}\text { Total } \\
\text { (MW) }\end{array}$ & $\begin{array}{l}\text { Offshore } \\
\text { (MW) }\end{array}$ & $\begin{array}{l}\text { Total } \\
\text { (MW) }\end{array}$ & $\begin{array}{l}\text { Offshore } \\
\text { (MW) }\end{array}$ & $\begin{array}{l}\text { Total } \\
\text { (MW) }\end{array}$ & $\begin{array}{l}\text { Offshore } \\
\text { (MW) }\end{array}$ \\
\hline $\begin{array}{l}\text { MISO/ } \\
\text { MAPP }^{a}\end{array}$ & 94,808 & & 69,444 & & 46,255 & & 95,046 & \\
\hline SPP & 91,843 & & 86,666 & & 50,958 & & 94,576 & \\
\hline TVA & 1,247 & & 1,247 & & 1,247 & & 1,247 & \\
\hline SERC & 1,009 & & 5,009 & 4,000 & 5,009 & 4,000 & 5,009 & 4,000 \\
\hline PJM & 22,669 & & 33,192 & 5,000 & 78,736 & 39,780 & 93,736 & 54,780 \\
\hline NYISO & 7,742 & & 16,507 & 2,620 & 23,167 & 9,280 & 23,167 & 9.280 \\
\hline ISO-NE & 4,291 & & 13,837 & 5,000 & 24,927 & 11,040 & 24,927 & 11,040 \\
\hline TOTAL & 223,609 & 0 & 225,902 & 16,620 & 230,299 & 64,100 & 337,708 & 79,100 \\
\hline
\end{tabular}

${ }^{a}$ MAPP stands for Mid-Continent Area Power Pool. 


\section{KEY STUDY FINDINGS}

The EWITS technical work yielded detailed quantitative information on

- Wind generation required to produce $20 \%$ of the projected electrical energy demand over the U.S. portion of the Eastern Interconnection in 2024

- Transmission concepts for delivering energy economically for each scenario (new transmission for each scenario is based on economic performance for the conditions outlined in that scenario)

- Economic sensitivity simulations of the hourly operation of the power system defined by a wind generation forecast scenario and the associated transmission overlay

- The contribution made by wind generation to resource adequacy and planning capacity margin.

The specific numeric results of the analysis are sensitive to the many assumptions that were required to define the 2024 study year. The study assumptions were developed in close coordination with the TRC. Changes in the assumptions, such as the cost of various fuels, the impact of regulation and policy, or the costs associated with new construction, would have a major influence. Other assumptions, such as the electrical energy demand and its characteristicspenetration and capabilities of demand response, influence of smart grid technologies, or the very nature of the load itself (as in an aggressive plug-in hybrid electric vehicle [PHEV] scenario)—would be likely to have a measurable impact on the results.

In general, though, the study shows the following:

- High penetrations of wind generation-20\% to $30 \%$ of the electrical energy requirements of the Eastern Interconnection-are technically feasible with significant expansion of the transmission infrastructure.

- New transmission will be required for all the future wind scenarios in the Eastern Interconnection, including the Reference Case. Planning for this transmission, then, is imperative because it takes longer to build new transmission capacity than it does to build new wind plants.

- Without transmission enhancements, substantial curtailment (shutting down) of wind generation would be required for all the $20 \%$ scenarios.

- Interconnection-wide costs for integrating large amounts of wind generation are manageable with large regional operating pools and significant market, tariff, and operational changes.

- Transmission helps reduce the impacts of the variability of the wind, which reduces wind integration costs, increases reliability of the electrical grid, and helps make more efficient use of the available generation resources. Although costs for aggressive expansions of the existing grid are significant, they make up a relatively small portion of the total annualized costs in any of the scenarios studied. 
- Carbon emission reductions in the three $20 \%$ wind scenarios do not vary by much, indicating that wind displaces coal in all scenarios and that coal generation is not significantly exported from the Midwest to the eastern United States; carbon emissions are reduced at an increased rate in the $30 \%$ wind scenario as more gas generation is used to accommodate wind variability. Wind generation displaces carbon-based fuels, directly reducing carbon dioxide $\left(\mathrm{CO}_{2}\right)$ emissions. Emissions continue to decline as more wind is added to the supply picture. Increasing the cost of carbon in the analysis results in higher total production costs.

The scenarios developed for EWITS do not in any way constitute a plan; instead, they should be seen as an initial perspective on a top-down, high-level view of four different 2024 futures. The transition over time from the current state of the bulk power system to any one of the scenarios would require additional technical and economic evaluation, including detailed modeling of power flows and a study of the effects on the underlying transmission systems. A more thorough evaluation of the sensitivity of the EWITS results to the range of assumptions made would also be required to guide the development of any specific bottom-up plans.

The significant amount of analytical work performed in EWITS, though, answers the questions posed at the outset of the project:

1. What impacts and costs do wind generation variability and uncertainty impose on system operations? With large balancing areas and fully developed regional markets, the cost of

\section{Why Regional Markets?}

Because they span large geographic areas, regional markets optimize the power grid by promoting efficiency through resource sharing. These organized markets are designed so that an area with surplus electricity can benefit by sharing megawatts with another region in the open market. This allows participants and operators to see the big picture when it comes to dispatching electricity in the most efficient manner. Source: Adapted from www.isorto.org. Accessed November 2009. integration for all scenarios is about \$5 (US\$ 2009) per megawatt-hour (MWh) of wind, or about $\$ 0.005$ per kilowatt-hour (kWh) of electricity used by customers.

2. What benefits accrue from long-distance transmission that accesses multiple and geographically diverse wind resources? The study results show that long-distance (and high-capacity) transmission can assist smaller balancing areas with wind integration, allowing penetration levels that would not otherwise be feasible. Furthermore, all scenarios, including the Reference Case, made use of major transmission upgrades to better interlock Eastern Interconnection markets for assisting with wind integration. 
3. What benefits are realized from long-distance transmission that moves large quantities of remote wind energy to urban markets? Long-distance transmission, along with assumed modifications to market and system operations, contributes substantially to integrating large amounts of wind that local systems would have difficulty managing. In addition, long-distance transmission has other value in terms of system robustness that was not completely evaluated in EWITS.

4. How do remote wind resources compare to local wind resources? In the Eastern Interconnection, the Eastern Wind Data Study database (AWS Truewind 2009) shows that the higher quality winds in the Great Plains have capacity factors that are about $7 \%-9 \%$ higher than onshore wind resources near the high-load urban centers in the East. Offshore plants have capacity factors on par with Great Plains resources but the cost of energy is higher because capital costs are higher.

5. How much does geographical diversity, or spreading the wind out across a large area, help reduce system variability and uncertainty? Quite substantially.

6. What is the role and value of wind forecasting? With significant wind generation, forecasting will play a key role in keeping energy markets efficient and reducing the amount of reserves carried while maintaining system security.

7. What benefit does balancing area cooperation or consolidation bring to wind variability and uncertainty management? This and other recent studies (see Bibliography) reinforce the concept that large operating areas-in terms of load, generating units, and geography-combined with adequate transmission, are the most effective measures for managing wind generation.

8. How does wind generation capacity value affect reliability (i.e., supply resource adequacy)? Wind generation can contribute to system adequacy, and additional transmission can enhance that contribution.

\section{SCENARIO COSTS}

EWITS looks at a "snapshot" in time for a single year in the future. A transformation of the bulk power system in the Eastern Interconnection to the degree suggested by the study scenarios would result if many capital investments were made from the present through 2024. Consequently, economic analysis of the scenarios brings to light complicated questions that cannot be answered precisely without a detailed timeline of capital expenditures. 
Because the study scenarios need to be compared on an economic basis, total costs for each scenario are approximated by identifying the fixed (investment) and variable (production) cost components. These costs are then summed, allowing the study team to view some measure of economic performance for each scenario side by side.

Study analysts calculated costs for each scenario as the sum of production-related costs (e.g., fuel costs) plus annualized amounts for capital investments in new conventional generation, wind plants, and transmission. The results for the Reference Case and the four high-penetration scenarios (Figure 3, in millions of US\$2009) show that Scenario 1 is the least costly of the $20 \%$ scenarios, and that the increased cost of offshore wind adds to the costs in Scenarios 3 and 4.

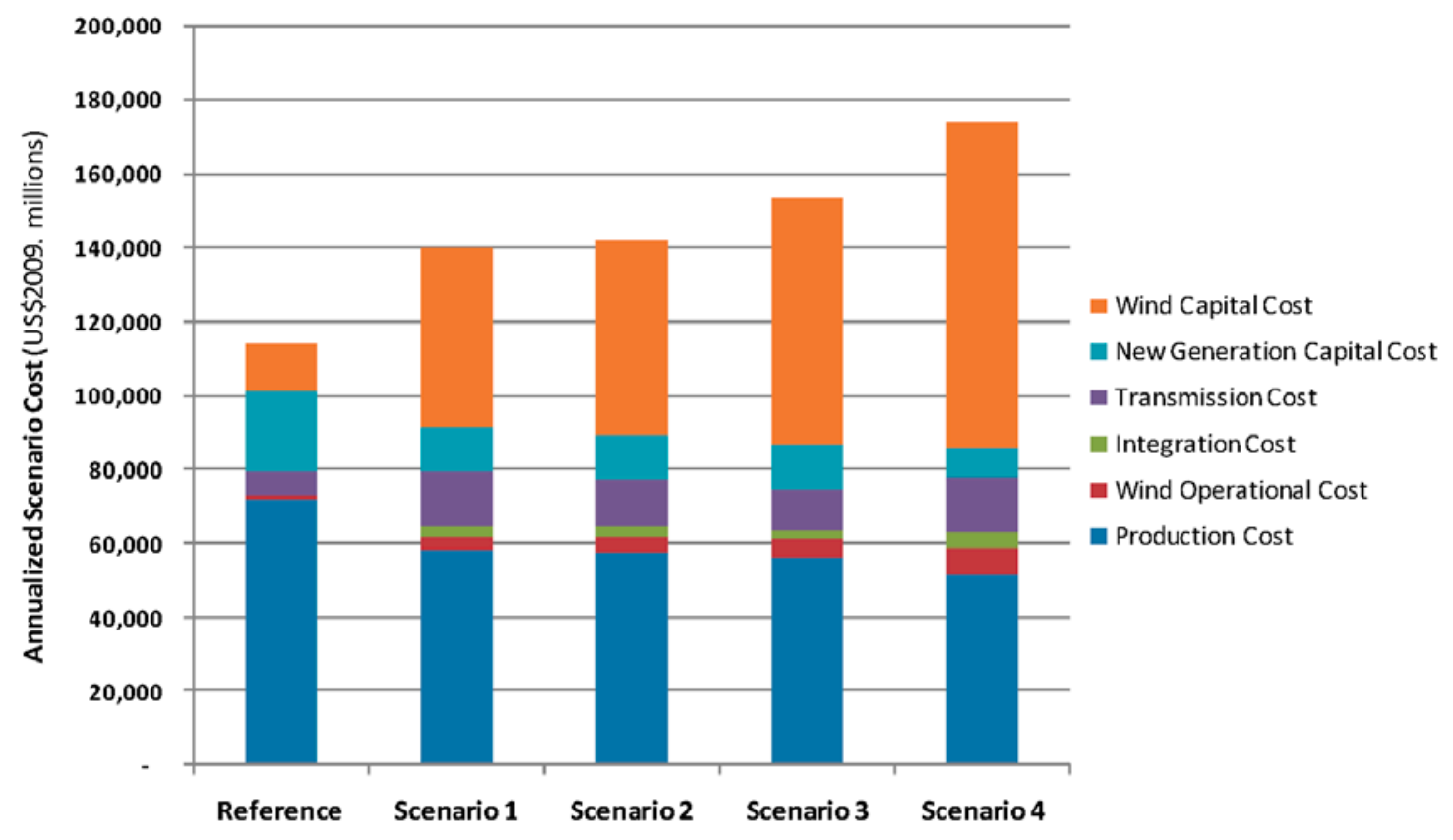

Figure 3. Comparison of scenario costs

Although production-related costs constitute a large fraction of the total costs for all scenarios, these decline as the amount of wind generation increases. In scenarios 3 and 4 , capital costs for wind generation increase because of slightly lower capacity factors and the much higher capital cost of offshore construction.

Transmission costs are a relatively small fraction for all scenarios, with only a small absolute difference seen across the $20 \%$ cases. Wind integration costs are measurable but very small relative to the other factors.

None of the initial scenarios include any costs associated with carbon, which increases production costs significantly. The carbon price was addressed in a sensitivity analysis for Scenario 2, as described later in this Executive Summary and Project Overview. 


\section{STUDY METHODOLOGY}

The EWITS project consisted of three major tasks: (1) wind plant output data development, (2) transmission requirements analysis, and (3) wind integration analysis. In wind integration studies, it is important to use concurrent load and

\section{The Role of Weather and Wind Forecasting}

Using numerical weather prediction models, also known as mesoscale models, is an accepted method for producing a time series of wind plant output data. Essentially, physics-based, numerical simulations on supercomputers, integrated with observational data sets, re-create the weather of historical years and generate a four-dimensional gridded wind-speed data set. A wind speed time series data set can be extracted and converted to wind power output. This approach produces a temporally, spatially, and physically consistent wind data set. For EWITS, this was done for hundreds of wind plants and the study team used these data sets in the modeling of the different scenarios.

Wind forecast data modeling is an increasingly common tool used by utilities and ISOs to schedule generation units. Wind integration studies typically include the effect of wind forecast errors on integration costs. wind data to capture the correlations between load and wind (i.e., weather; see sidebar).

The project team developed the quantitative information through a multistage analytical process, shown graphically in Figure 4. Methods developed and refined in previous integration studies formed the basis for the technical analysis, but were necessarily extended because the scope and size of this effort surpassed that of earlier studies. Focus on transmission requirements for the substantial amount of wind generation required to meet the $20 \%$ and 30\% energy targets was a new and significant part of the study scope. 


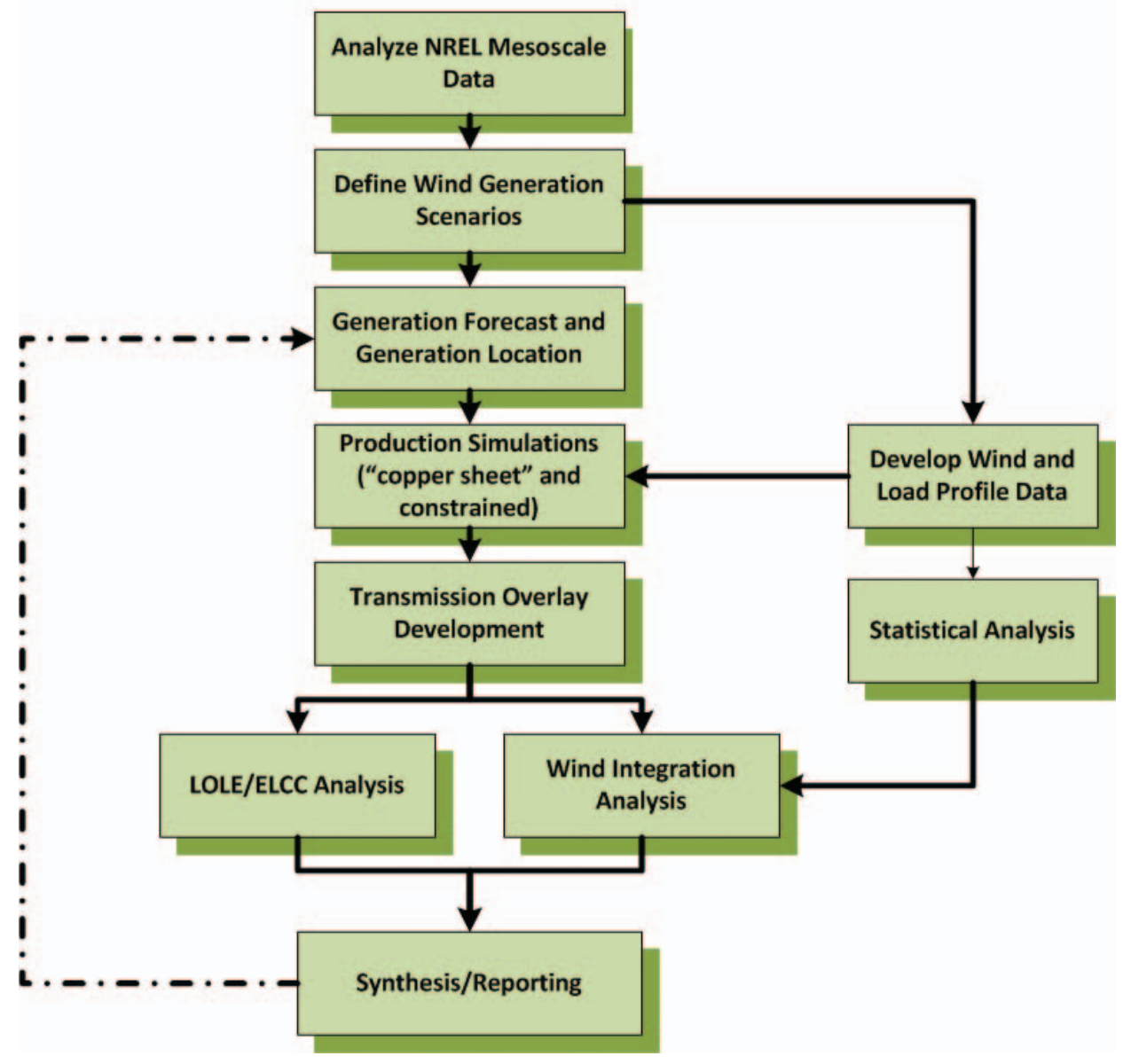

Notes: A copper sheet simulation assumes no transmission constraints or congestion. $L O L E=$ loss of load expectation and ELCC = effective load-carrying capability

Figure 4. Study process

Current transmission expansion planning is based on a decision-making process that starts with the present and looks forward through time. The existing bulk power grid in the United States is the result of such a bottom-up approach. In EWITS, the project team used top-down economic methods to develop the conceptual transmission capacity needed to deliver energy to load. These topdown methods tend to create designs with more transmission than bottom-up methods. The primary reason is that the total economic potential of increasing the economic efficiency of the generation fleet-including wind generation in the Eastern Interconnection-is used to justify transmission expansion. The combination of capturing the economic potential of both nonwind and wind generation loads the transmission lines more efficiently (i.e., the lines are not just being used for wind). The transmission requirements are mainly off peak for the wind generation and on peak for the nonwind generation.

Although the study assumptions were touched on previously, a more detailed look is helpful at this point. Peak demand and energy for all study regions was based on 2004-2006 Federal Energy Regulatory Commission (FERC) data 
combined with 2006 power flow data. These data had been compiled for a previous study, and were reviewed by all stakeholders at that time. To preserve correlation with the wind generation profile data, load data for EWITS were mapped to conform to actual wind profiles representing calendar years 2004, 2005, and 2006.

Because of the very large amount of wind generation studied, it was important to establish a framework for the day-to-day operations of the Eastern Interconnection in 2024. Results from past integration studies have shown that operational structure plays a major role in determining the difficulty or ease with

\section{Operating the Grid}

\section{Balancing Authority}

A balancing authority is the responsible entity that maintains load resource balance within a given, predefined area (the balancing authority area). The authority develops integrated resource plans, matches generation with load, maintains scheduled interchanges with other balancing authority areas, and supports interconnection frequency of the electric power systems in real time.

\section{Reliability-Related Services}

In the NERC Functional Model, which defines the set of functions that must be performed to ensure the reliability of the bulk electric system, these include the range of services, other than the supply of energy for load, that are physically provided by generators, transmitters, and loads in order to maintain reliability. In wholesale energy markets, they are commonly described as "ancillary services."

Source: Adapted from http://www.nerc.com/files/opman_12-13Mar08.pdf. Accessed November 2009. which wind generation is integrated. Small balancing areas, which were the original building blocks of today's major interconnections, can be significantly challenged by large amounts of wind generation. Large effective balancing areas (see sidebar) have more supply resources to deploy and benefit substantially from diversity in both load and wind generation.

Extrapolating from trends that have been seen for the past decade, the study team-with input from the TRC-assumed that by 2024 operations in the Eastern Interconnection (at least the significant fraction modeled explicitly in EWITS) would be conducted under the auspices of seven large balancing areas, which are shown in Figure 5. The structure as it existed in August 2007 was

used for comparison. Five of the seven correspond to existing RTOs in the Eastern Interconnection.

The project team also assumed that operations in each area would conform to the same structure. For example, on the day before the operating day, all generating units bid competitively to serve load, and after market clearing, operators perform a security-constrained unit commitment to ensure that adequate capacity will be available to meet forecast load. During the operating day, generators are dispatched frequently to follow short-term demand trends under a fast, subhourly market structure. A competitive ancillary services market 
supplies regulation, balancing, and unused generation capacity to cover large events such as the loss of major generating facilities.

The assumptions made about operating structure are very significant given the current operations in the Eastern Interconnection. The assumed market mechanisms, however, are actually in use today, albeit not uniformly, and have been shown in previous studies to be of substantial value for wind integration. There is some probability that developments in market operation over the next decade could further enhance the ability to integrate wind energy.

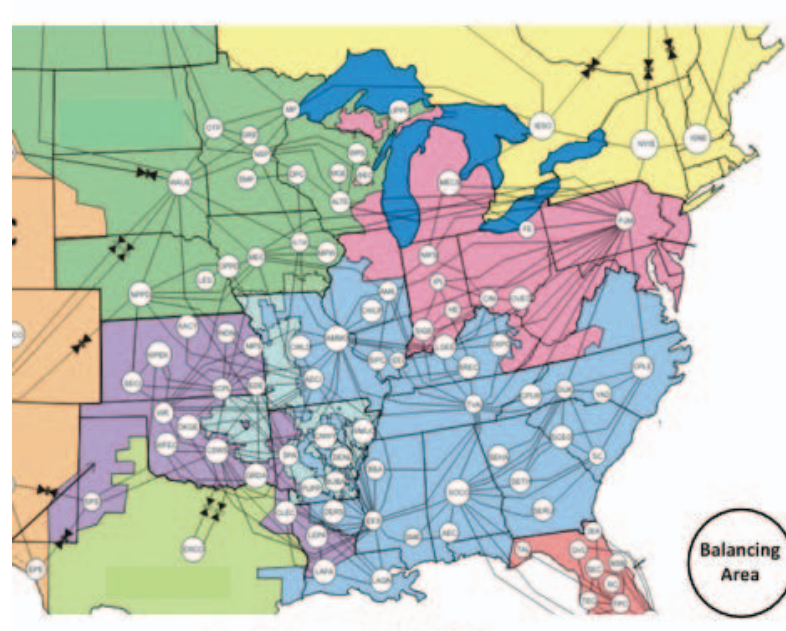

As of August 1, 2007

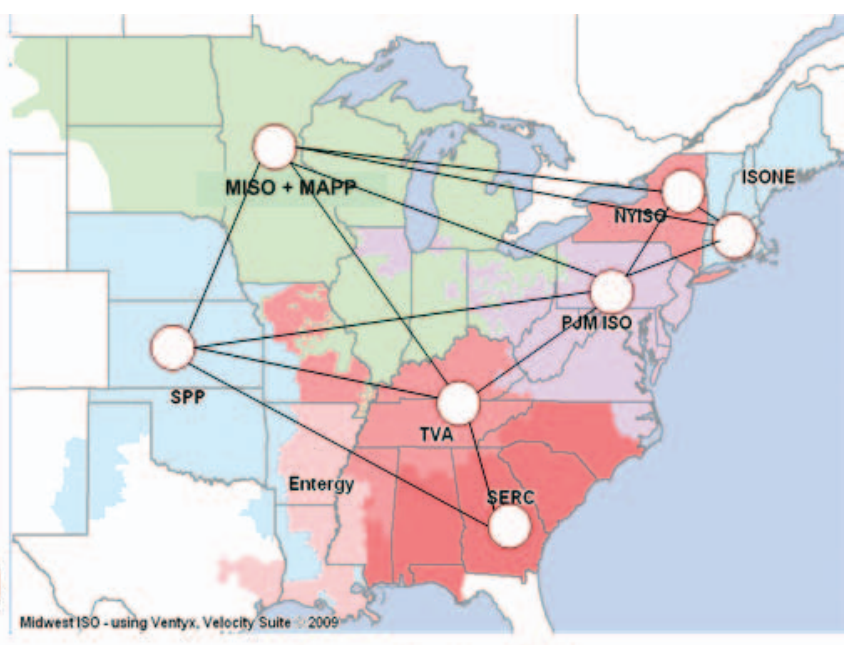

Assumption for 2024

Figure 5. Assumed operational structure for the Eastern Interconnection in 2024 (white circles represent balancing authorities; Entergy is operated as part of SERC) 


\section{PROJECT OVERVIEW}

This section describes the transmission requirements, wind operational impacts, production-cost modeling results, wind integration costs, carbon sensitivity analysis, and the wind contribution to resource adequacy for EWITS.

\section{TRANSMISSION REQUIREMENTS}

EWITS uses a deterministic, chronological production-cost model (PROMOD $\left.\mathrm{IV}^{\circledR}\right)^{1}$ for evaluating transmission requirements. The study process began with locating wind generation across the interconnection, and then determining what additional nonwind capacity would be required in each region to maintain reliability for the projected energy demand in the study year. No new transmission was considered at this stage. This step allowed the study analysts to identify the locations of electrical energy supply and locate the loads or demand for the energy. To develop the transmission overlays, then, the project team used economic signals to connect the "sources" (supply) to the "sinks" (loads).

The study team used an economics-based expansion planning methodology to develop transmission requirements for each scenario based on the output of the different production simulations. Before each set of simulations, the additional nonwind capacity required to reliably serve the projected load was determined using traditional generation expansion methodologies. Wind generation was assigned a firm capacity value of $20 \%$. Next, wind generation and the indicated conventional expansion were added to the production-cost model that contained the existing transmission network.

After simulating system operation over an entire year of hourly data, study analysts then compared the results of this modeling simulation to those from a similar simulation in which constraints on the transmission system were removed. The comparison indicates how regional or interconnection-wide production costs increase because of transmission congestion, or put another way, what value could be achieved by eliminating or reducing transmission constraints. Differences between the "constrained" case and the "unconstrained" case yield the following information:

- The areas of economic energy sources and sinks

- The interface flow changes to determine the incremental transfer capacity needs

- The total benefit savings, which in turn gives a rough estimate of a potential budget for building transmission to relieve constraints and reduce congestion costs

1 PROMODIV (developed by Ventyx) is an integrated electric generation and transmission market simulation system that incorporates extensive details of generating unit operating characteristics and constraints, transmission constraints, generation analysis, unit commitment/operating conditions, and market system operations. PROMOD IV performs an 8,760-hour commitment and dispatch recognizing both generation and transmission impacts at the bus-bar level. (Bus-bar refers to the point at which power is available for transmission.) 
Transmission flows between regions in EWITS are determined in part by the differences between production simulations using a "copper sheet" (i.e., no transmission constraints, no congestion) versus the existing transmission system. Transmission capacity is designed to deliver $80 \%$ of the desired energy flow. Figure 6 shows the annual generation differences between the unconstrained and constrained cases for Scenario 2. This helps to define the energy source and sink areas and gives insight into the optimal locations for potential transmission lines and substations. Red represents the energy source areas; blue signifies the energy sink areas. As Figure 7 illustrates, the price signal drives energy from low-cost source areas to high-cost sink areas if the transmission system is not constrained across the study footprint.

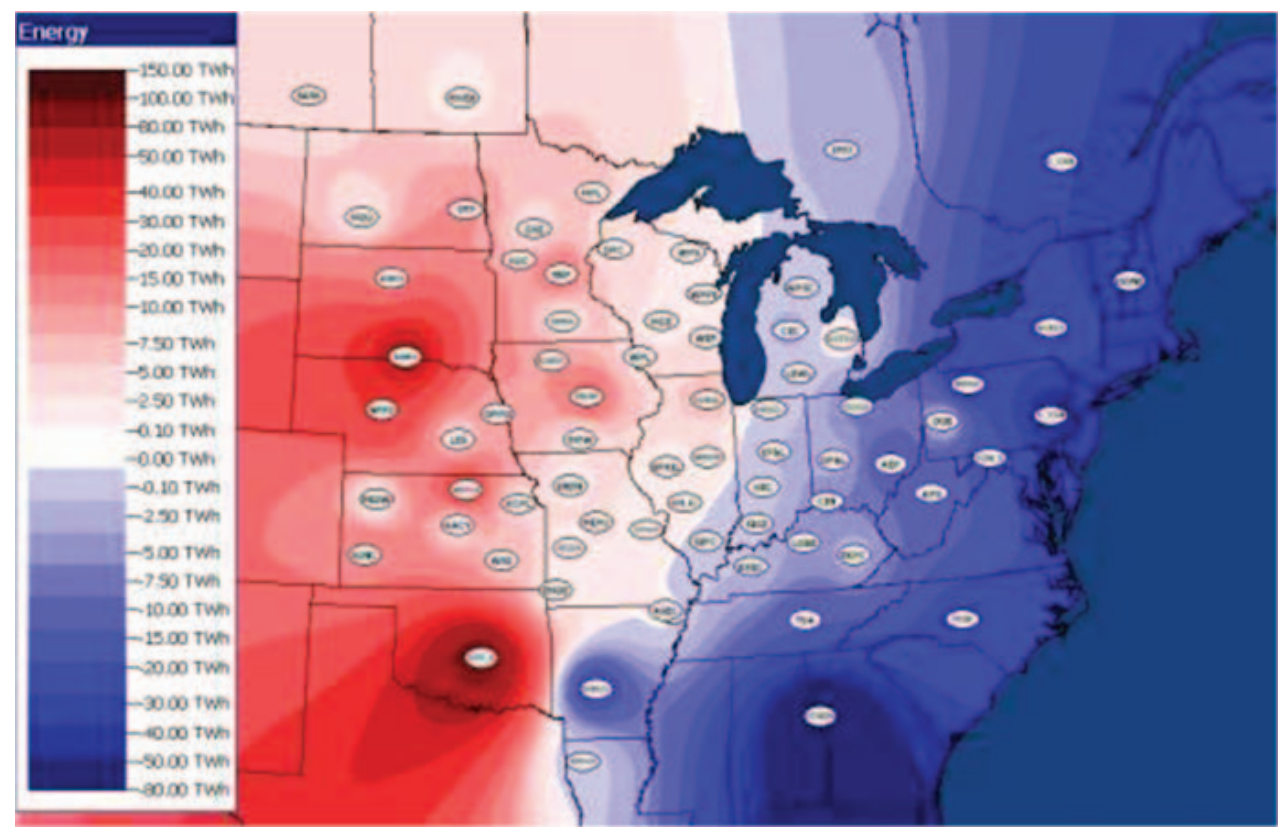

Figure 6. Scenario 2, annual generation differences between unconstrained case and constrained case (Note: Because price contours developed from defined pricing hubs, they do not correspond exactly to geography.) 


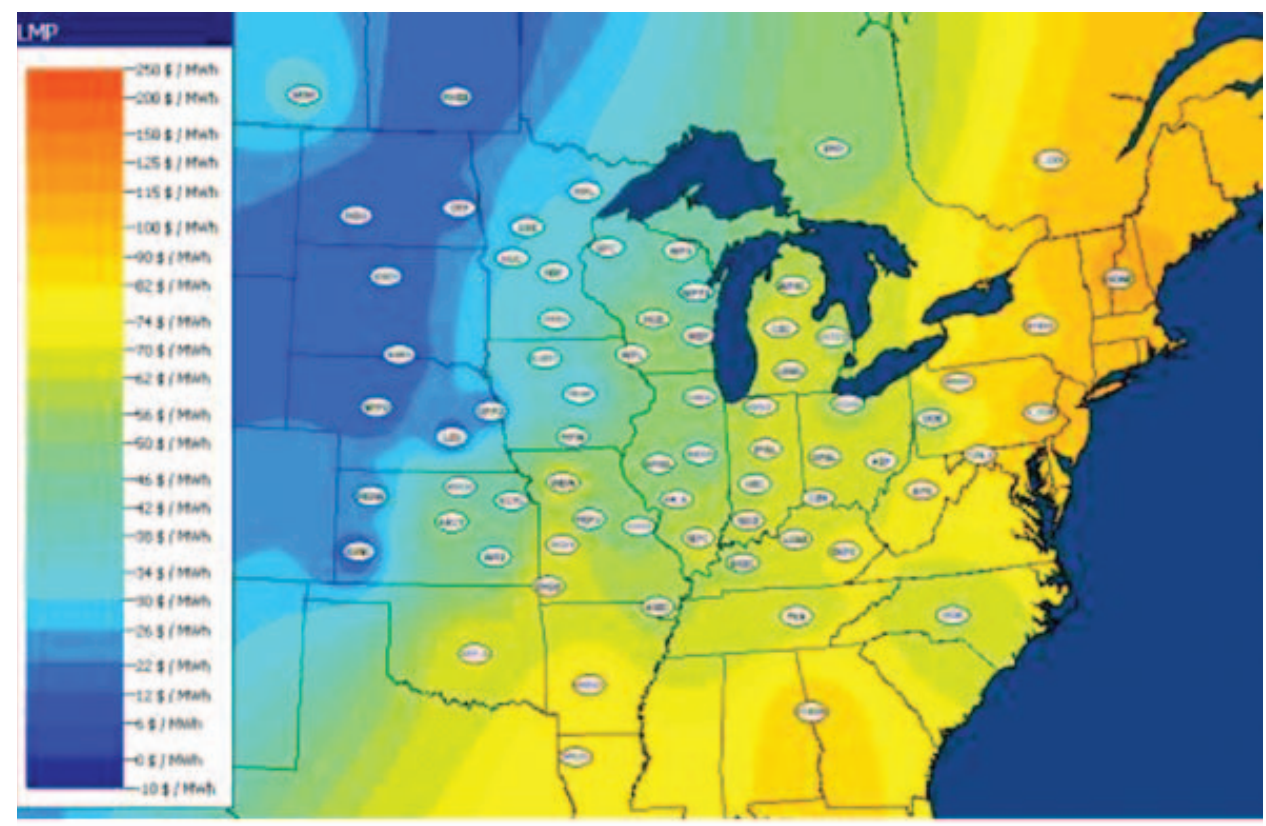

Figure 7. Scenario 2, annual generation weighted locational marginal price (LMP) for constrained case

Using these comparative results as a guide, and with input from the TRC, the study team developed transmission overlays for each scenario.

The conceptual transmission overlays, shown in Figure 8, consist of multiple 800-kilovolt $(\mathrm{kV})$ high-voltage direct current (HVDC) and extra-high voltage (EHV) AC lines with similar levels of new transmission and common elements for all four scenarios. Tapping the most high-quality wind resources for all three $20 \%$ scenarios, the project team arrived at a transmission overlay for Scenario 1 that consists of nine 800-kV HVDC lines and one 400-kV HVDC line. For Scenario 2, analysts moved some wind generation eastward, resulting in a reduced transmission overlay with seven 800-kV HVDC lines and one 400$\mathrm{kV}$ HVDC line. As more wind generation is moved toward the east and more offshore resources are used in Scenario 3, the resulting transmission overlay has the fewest number of HVDC lines, with a total number of five $800-\mathrm{kV}$ HVDC lines and one 400-kV HVDC line. To accommodate the aggressive $30 \%$ wind target and deliver a significant amount of offshore wind along the East Coast in Scenario 4, the overlay must be expanded to include ten 800-kV HVDC lines and one 400-kV HVDC line. 


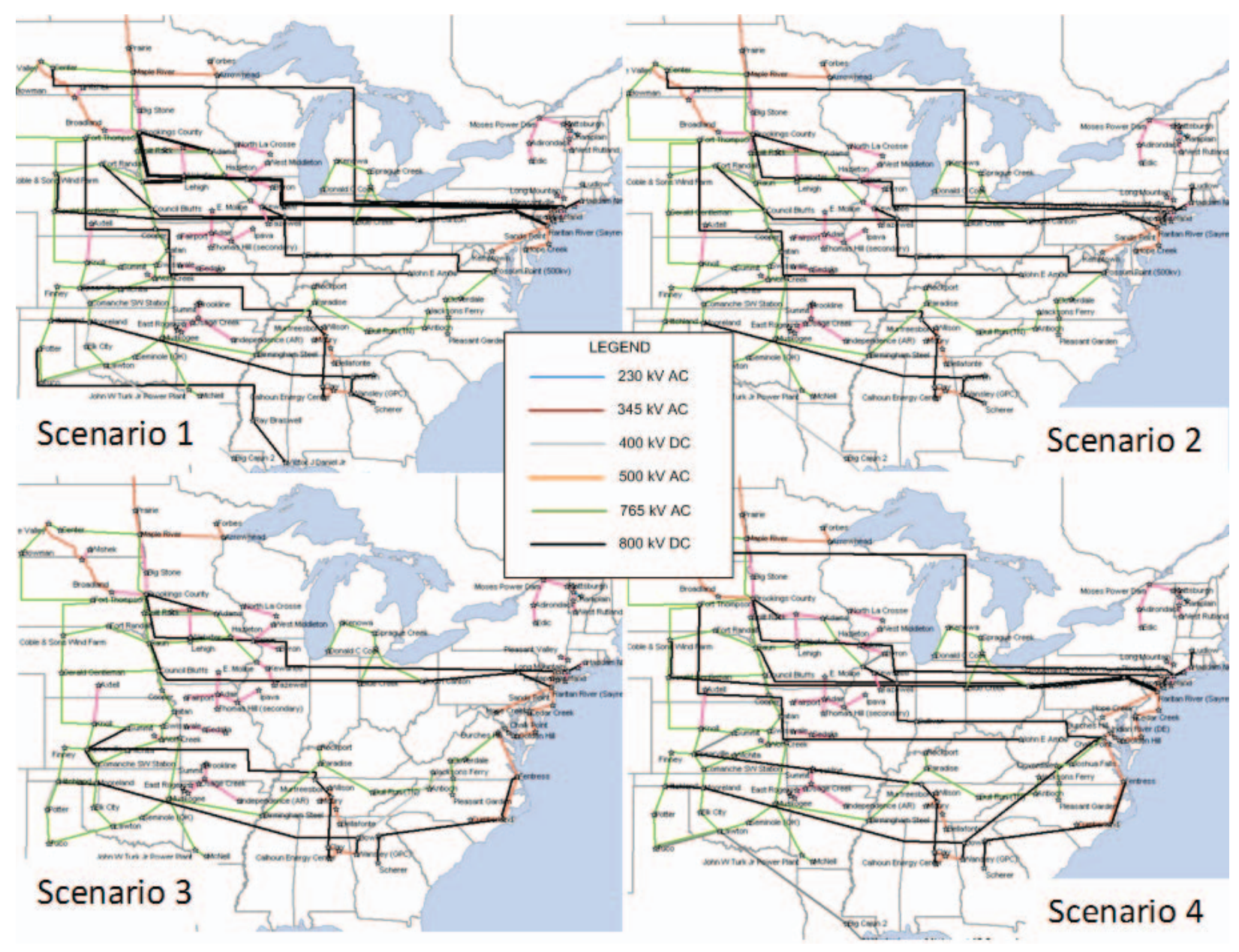

\section{Figure 8. Conceptual EHV transmission overlays for each study scenario}

Tables 2 through 4 summarize the transmission and construction cost-permile assumptions by voltage level, the estimated total line miles by voltage level, and the estimated cost in US\$2024 for the four wind scenario conceptual overlays, respectively. In Table 4, the total AC line costs include a 25\% margin to approximate the costs of substations and transformers. In addition, the total HVDC line costs include those for terminals, communications, and DC lines. Costs associated with an offshore wind collector system and those for some necessary regional transmission upgrades are not included in the total estimated cost and would increase total transmission costs. With approximately 22,697 miles of new EHV transmission lines, the transmission overlay for Scenario 1 has the highest estimated total cost at $\$ 93$ billion (US\$2009). 


\begin{tabular}{|c|c|c|c|c|c|c|c|}
\hline \multicolumn{8}{|c|}{ COST-PER-MILE ASSUMPTION } \\
\hline VOLTAGE LEVEL & $345 \mathrm{KV}$ & $\begin{array}{l}345 \mathrm{KV} \text { AC } \\
\text { (DOUBLE } \\
\text { UNIT) }\end{array}$ & $500 \mathrm{KV}$ & $\begin{array}{l}500 \mathrm{KV} \text { AC } \\
\text { (DOUBLE } \\
\text { CIRCUIT) }\end{array}$ & $765 \mathrm{KV}$ & $400 \mathrm{KV}$ DC & $800 \mathrm{KV}$ DC \\
\hline US\$2024 (MILLIONS) & $2,250,000$ & $3,750,000$ & $2,875,00$ & $4,792,00$ & $5,125,000$ & $3,800,000$ & $6,000,000$ \\
\hline US\$2009 (MILLIONS) & $1,440,000$ & $2,410,000$ & $1,850,00$ & $3,080,00$ & $3,290,000$ & $2,440,000$ & $3,850,000$ \\
\hline
\end{tabular}

\begin{tabular}{|c|c|c|c|c|c|c|c|c|}
\hline \multicolumn{9}{|c|}{ ESTIMATED LINE MILEAGE SUMMARY } \\
\hline $\begin{array}{l}\text { VOLTAGE } \\
\text { LEVEL }\end{array}$ & $345 \mathrm{KV}$ & $\begin{array}{l}345 \text { KV AC } \\
\text { (DOUBLE } \\
\text { CIRCUIT) }\end{array}$ & $500 \mathrm{KV}$ & $\begin{array}{l}500 \mathrm{KV} \text { AC } \\
\text { (DOUBLE } \\
\text { CIRCUIT) }\end{array}$ & $765 \mathrm{KV}$ & $400 \mathrm{KV}$ DC & $800 \mathrm{KV}$ DC & TOTAL \\
\hline REFERENCE & 3,106 & 292 & 593 & 494 & 2,624 & 470 & 2,400 & 9,979 \\
\hline SCENARIO 1 & 1,977 & 247 & 1,264 & 243 & 7,304 & 560 & 11,102 & 22,697 \\
\hline SCENARIO 2 & 1,977 & 247 & 1,264 & 243 & 7,304 & 560 & 8,352 & 19,947 \\
\hline SCENARIO 3 & 1,977 & 247 & 1,264 & 742 & 7,304 & 769 & 4,747 & 17,050 \\
\hline SCENARIO 4 & 1,977 & 247 & 1,264 & 742 & 7,304 & 560 & 10,573 & 22,667 \\
\hline
\end{tabular}

\begin{tabular}{|c|c|c|c|c|c|c|c|c|}
\hline \multicolumn{9}{|c|}{ Estimated Cost Summary (US \$2024, millions) } \\
\hline $\begin{array}{l}\text { VOLTAGE } \\
\text { LEVEL }\end{array}$ & $345 \mathrm{KV}$ & $\begin{array}{l}345 \mathrm{KV} \text { AC } \\
\text { (DOUBLE } \\
\text { CIRCUIT) }\end{array}$ & $500 \mathrm{KV}$ & $\begin{array}{l}500 \mathrm{KV} \text { AC } \\
\text { (DOUBLE } \\
\text { CIRCUIT) }\end{array}$ & $765 \mathrm{KV}$ & $400 \mathrm{KV}$ DC & $800 \mathrm{KV}$ DC & TOTAL \\
\hline Reference & 5,607 & 880 & 1,367 & 1,900 & 10,790 & 1,383 & 9,243 & 31,170 \\
\hline Scenario 1 & 3,569 & 743 & 2,916 & 935 & 30,033 & 1,539 & 53,445 & 93,179 \\
\hline Scenario 2 & 3,569 & 743 & 2,916 & 935 & 30,033 & 1,539 & 40,206 & 79,941 \\
\hline Scenario 3 & 3,569 & 743 & 2,916 & 935 & 30,033 & 1,898 & 22,852 & 64,865 \\
\hline Scenario 4 & 3,569 & 743 & 2,916 & 935 & 30,033 & 1,539 & 50,898 & 92,551 \\
\hline
\end{tabular}

Specific findings and conclusions from development of the transmission overlays for each scenario include the following:

- The 800-kV HVDC and EHV AC lines are preferred if not required because of the volumes of energy that must be transported across and around the interconnection, as well as the distances involved.

- Similar levels of new transmission are needed across the four scenarios, and certain major facilities appear in all the scenarios. This commonality is influenced by the top-down method used and the location of the wind generation in each scenario. The study focuses on four possible 2024 "futures." Determining a path for realizing one or more of those futures was outside the study scope. Large amounts of transmission are also required in the Reference Case.

- The modeling indicates that significant wind generation can be accommodated as long as adequate transmission capacity is available and market/operational rules facilitate close cooperation among the operating regions. 
- Transmission offers capacity benefits in its own right, and enhances wind generation's contribution to reliability by a measurable and significant amount.

- The EHV DC transmission that constitutes a major portion of the overlays designed for the scenarios in EWITS has benefits beyond those evaluated here. For example, it would be possible to schedule reserves from one area to another, effectively transporting variability resulting from wind and load to areas that might be better equipped to handle it. And the transfer capability of the underlying $\mathrm{AC}$ network could be enhanced by using the DC terminals to mitigate limitations caused by transient stability issues.

\section{WIND OPERATIONAL IMPACTS}

Reliable delivery of electrical energy to load centers entails a continuous process of scheduling and adjusting electric generation in response to constantly changing demand. Sufficient amounts of wind generation increase the variability and uncertainty in demand that power system operators face from day to day or even from minute to minute. Quantifying how the amounts of wind generation in each of the study scenarios would affect daily operations of the bulk system and estimating the costs of those effects were major components of EWITS.

Using detailed chronological production simulations for each scenario, the study team assessed impacts on power system operation. The objective of these simulations was to mimic how day-to-day operations of the Eastern Interconnection would be conducted in 2024 with the prescribed amounts of wind generation in each scenario, new conventional generation per the expansion study, and the transmission overlays the study team developed. Ways to manage the increased variability and uncertainty attributable to wind generation, along with the resulting effect on operational costs, were of primary interest.

EWITS uses a deterministic production-cost model to run hourly power system operational simulations using the transmission overlays for each scenario and the wind plant outputs and actual load data for 2004, 2005, and 2006. The model takes the wind generation at each "injection bus" (i.e., the closest transmission connection to the wind plant) and dispatches nonwind generation units accordingly for each market region while solving at the model node for the LMP. The tool simulates actual power system operations by first solving the unitcommitment problem (i.e., what conventional generators will be dispatched to meet load), then using the wind power and load forecasts, and finally dispatching the units based on the actual modeled wind and load data. Obtaining realistic results is necessary because unit-commitment decisions must actually be made well in advance, allowing generators sufficient time to start up and synchronize to the grid. A hurdle rate accounts for hourly transactions among eight different market regions. The simulation is done over the entire study region and the wind plant and load time series data capture geographic diversity. 


\section{RESERVE REQUIREMENTS}

With large amounts of wind generation, additional operating reserves (see sidebar) are needed to support interconnection frequency and maintain balance between generation and load. Because the amounts of wind generation in any of the operating areas, for any of the scenarios, dramatically exceed the levels for which appreciable operating experience exists, the study team conducted statistical and mathematical analyses of the wind generation and load profile data to estimate the additional

\section{Types of Reserves}

In bulk electric system operations, different types of generation reserves are maintained to support the delivery of capacity and energy from resources to loads in accordance with good utility practice.

\section{Contingency Reserves}

Reserves to mitigate a "contingency," which is defined as the unexpected failure or outage of a system component, such as a generator, a transmission line, a circuit breaker, a switch, or another electrical element. In the formal NERC definition, this term refers to the provision of capacity deployed by the balancing authority to meet the disturbance control standard (DCS) and other NERC and regional reliability organization contingency requirements.

\section{Operating Reserves}

That capability above firm system demand required to provide for regulation, load forecasting error, forced and scheduled equipment outages, and local area protection. This type of reserve consists of both generation synchronized to the grid and generation that can be synchronized and made capable of serving load within a specified period of time.

\section{Regulating Reserves}

An amount of reserve that is responsive to automatic generation control (AGC) and is sufficient to provide normal regulating margin. Regulating reserves are the primary tool for maintaining the frequency of the bulk electric system at $60 \mathrm{~Hz}$.

\section{Spinning Reserves}

The portion of operating reserve consisting of (1) generation synchronized to the system and fully available to serve load within the disturbance recovery period that follows a contingency event; or (2) load fully removable from the system within the disturbance recovery period after a contingency event. requirements. These were used as inputs to the production-cost modeling. The analysis focused on the major categories of operating reserves, which included needs for regulation, load following, and contingencies.

In the production simulations for each scenario, study analysts took into account the additional uncertainty and variability resulting from wind generation by

- Incorporating the increased operating reserves as constraints on the commitment and dispatch of generating resources in each operating area

- Committing generating units for operation based on forecasts of load and wind generation, then dispatching the available units against actual quantities.

The levels of wind generation considered in EWITS increase the amount of operating reserves required to support interconnection frequency and balance the system in real time. Contingency reserves are not directly affected, but the amount of spinning reserves assigned to regulation duty must increase because of the additional variability and short-term uncertainty of the balancing area demand. 
The assumption of large balancing areas does reduce the requirement, however. Under the current operational structure in the Eastern Interconnection, the total amount of regulation that would need to be carried would be dramatically higher.

Using the methodology developed for EWITS, the study team calculated regulating reserve requirements for each region and each scenario from hourly load data and 10-minute wind production data. The result is an hourly profile that varies with both the amount of load and the level of wind generation. The calculations account for important characteristics of the wind generation scenario, such as the amount of geographic diversity and its influence on the aggregate short-term variability.

Figure 9 summarizes the regulating reserve requirements for each region and each scenario. The value indicated by the bar is the average of the annual hourly profile. The load-only case is a reference for calculating the incremental requirement resulting from wind generation.

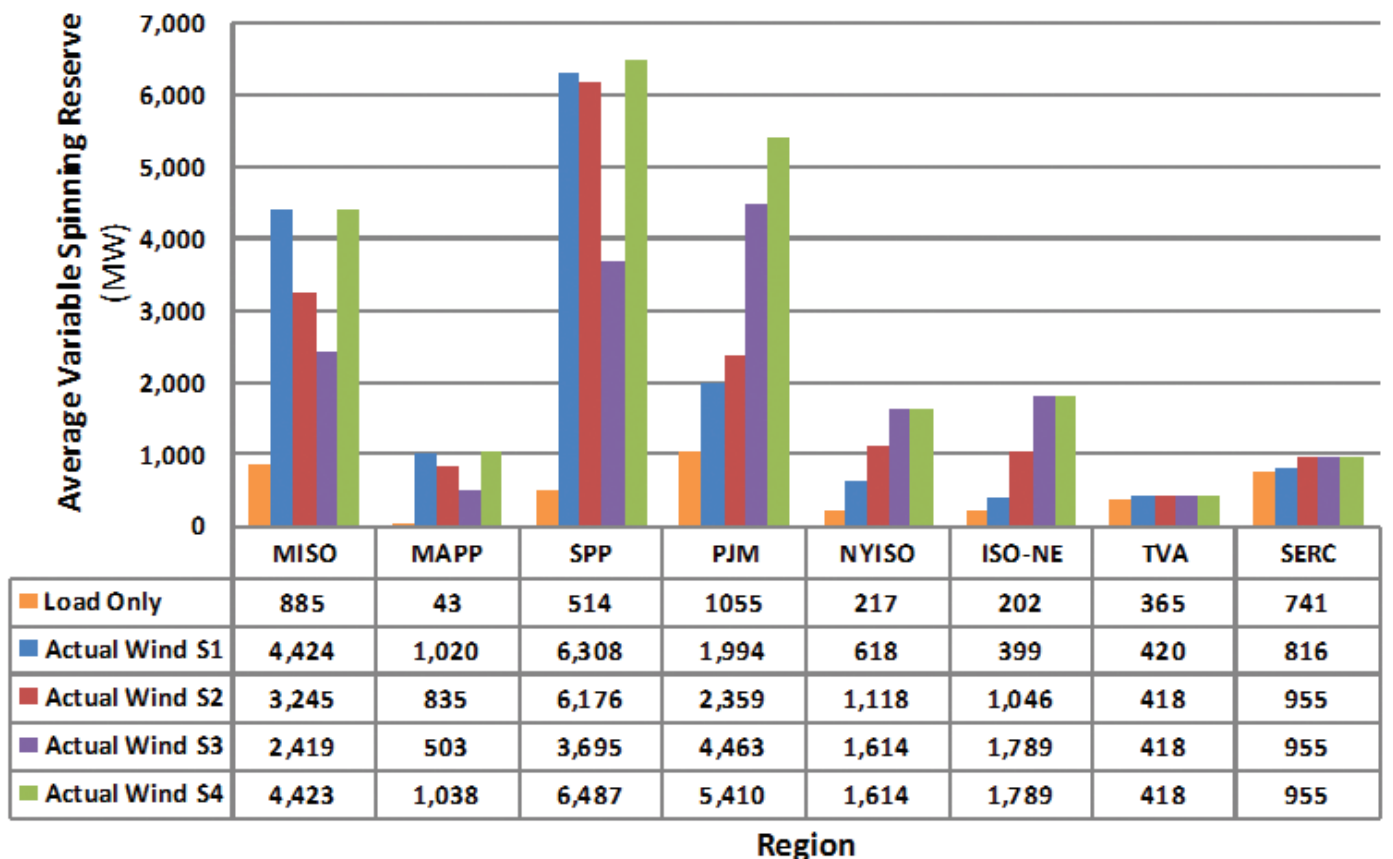

Figure 9. Regulating reserve requirements by region and scenario. The incremental amount resulting from wind generation is the difference between the scenario number and the load-only value.

Current operating experience offers little guidance on managing the incremental variability and uncertainty associated with large amounts of wind generation in the operating footprints defined for EWITS. The statistical analysis conducted on the time series data from the scenarios, however, forms a highly reasonable 
analytical foundation for the assumptions and reserve requirement results that the study team carried forward to the production simulations.

The team's analysis of reserve requirements with substantial amounts of wind generation resulted in the following findings and conclusions:

- The assumptions made about how the Eastern Interconnection will be operated in 2024 played an important role in minimizing the additional amounts of spinning reserve that would be required to manage the variability of large amounts of wind generation.

- The large size of the market areas assumed in the study allows substantial benefits of geographic diversity to be realized.

- The pooling of larger amounts of load and discrete generating resources via regional markets also realizes diversity benefits. The per-unit variability of load declines as the amount of load increases; larger markets also have more discrete generating units of diverse fuel types and capabilities for meeting load and managing variability.

- With real-time energy markets, changes in load and wind that can be forecast over a short interval-10 minutes in EWITS, 15 to 20 minutes in current practice-are compensated for through economic movements of participating generating units. Because load changes over 10-minute intervals can be accurately forecast, they can be cleared in a subhourly market.

- The fastest changes in balancing area demand-on time scales from a few to tens of seconds-are dominated by load, even with very large amounts of wind generation.

- Incremental regulating reserve requirements are driven by errors in short-term (e.g., 10 to 20 minutes ahead) wind generation forecasts.

- Data from the Eastern Wind Data Study can be used to characterize both variability and uncertainty for a defined scenario. With more wind generated over a larger geographic area, percentages of aggregate wind variability and uncertainty decrease. These quantitative characterizations are useful for estimating incremental reserve requirements.

- Current energy market performance shows that, on average, subhourly market prices do not command a premium over prices in the day-ahead market. Consequently, the hourly production simulation will capture most of the costs associated with units moving in subhourly markets, and the spinning reserve requirements for regulation and contingency will appropriately constrain the unit commitment and dispatch.

The EWITS analysis addresses these requirements only; as wind displaces marginal conventional generation, those nonwind resources deliver less energy and thus realize less revenue. With large amounts of wind generation such as those considered in EWITS, additional costs could be associated with those displaced marginal units that are not captured in the production modeling. 


\section{PRODUCTION-COST MODELING RESULTS}

The project team ran annual production simulations for all three wind and load years and all scenarios. The raw results included hourly operations and costs for each generator and flows on each transmission element in the model, but because of the sheer volume of data generated, the project team had to analyze summary information.

The detailed production modeling of a system of such size and scope reduces the number of assumptions and approximations required. Although the large volume of results is a disadvantage, the results do contain information from which conclusions can be drawn — with relatively high confidence-about wind generation impacts on other system resources. Specifically,

- Generation displacement depends on the location and amount of wind generation.

- Because of its low dispatch price, wind generation will reduce LMPs. The effect in a particular region is greater with local wind resources.

- The addition of overlay transmission works to equalize LMPs across the footprint. Because of transfer limits, there are still price differences across the footprint, but the magnitude of the difference is reduced with the overlays.

- Offshore wind has more effect on LMPs in eastern load centers because of its proximity to large load centers otherwise served by generation with higher costs.

Figure 10 shows total production costs for each of the high-penetration wind scenarios and for the Reference Case. The primary effect of wind generation is to displace production from conventional sources; as the amount of wind generation increases, so does the magnitude of the displacement. The location of wind generation, however, also has an influence. Under the baseline assumptions used for the study, energy prices are higher in the East and lower in the western portion of the interconnection. Consequently, production costs are reduced more by wind in areas with higher costs; the production costs shown in Figure 10 do not account for the capital costs of the wind or infrastructure required to deliver wind energy to load. 


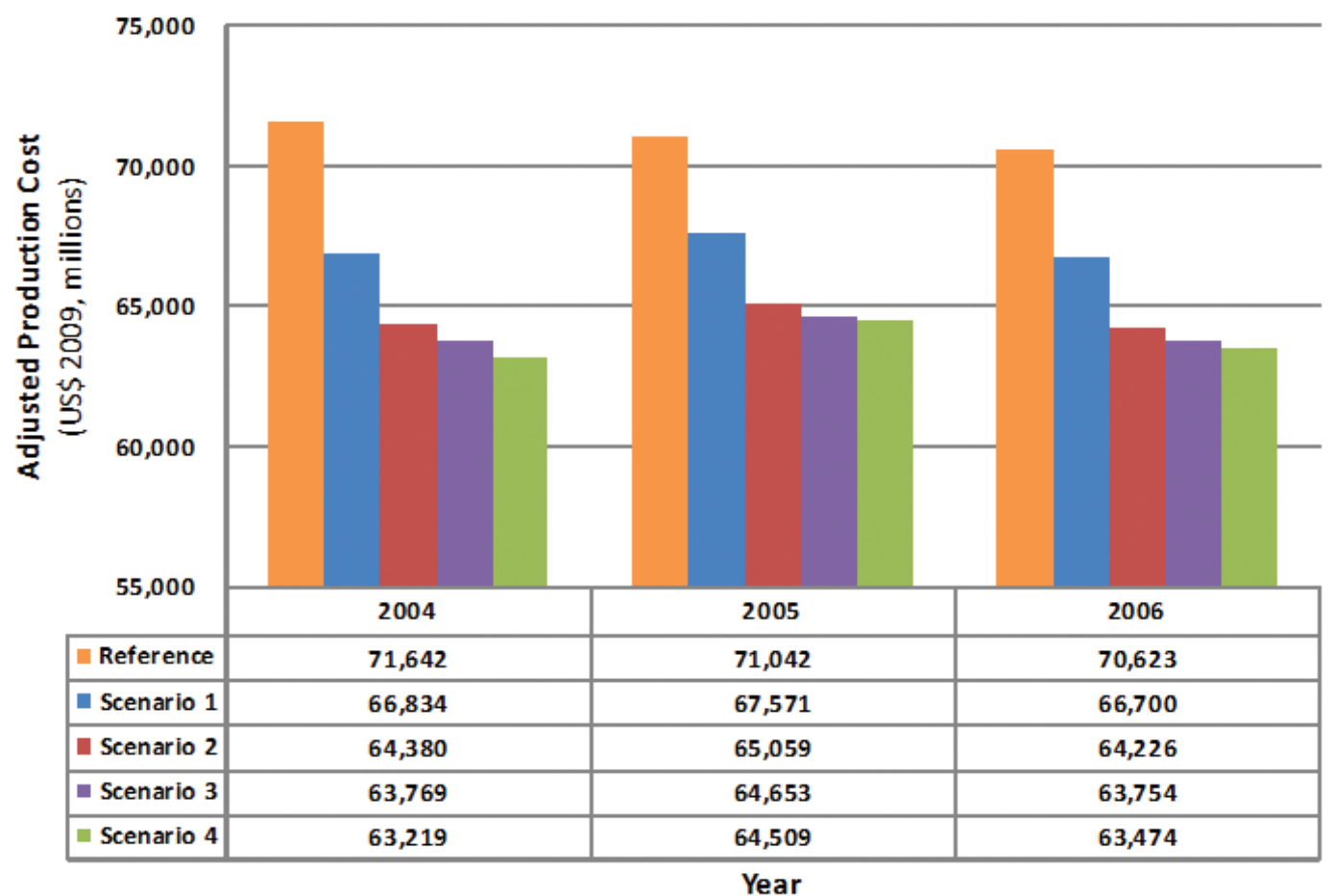

Figure 10. Annual production-cost comparison (US\$2009, millions)

\section{WIND INTEGRATION COSTS}

Assessing the costs for integrating large amounts of wind generation was another key aspect of EWITS. Team members used methods and analytical approaches employed in earlier integration studies as their starting point. As interim results became available, nuances in and challenges to applying that methodology to a large, multiarea production model became apparent. This project significantly bolstered the knowledge base and perspective on the components of the total cost associated with managing wind energy delivery.

The study team computed the cost of managing the delivery of wind energy (i.e., the integration cost) by running a set of comparative production simulations. In these cases, analysts assumed that wind energy did not require carrying additional regulating reserves for managing variability and short-term uncertainty. They also assumed that the hourly wind energy delivery was known perfectly in the unit-commitment step of the simulation. The differences in production costs among these cases and the corresponding cases where wind generation is not ideal can be attributed to the incremental variability and uncertainty introduced by the wind resource.

Figure 11 shows the calculated integration cost for each scenario. Costs vary by scenario and by year, but all are less than $10 \%$ of the bus-bar cost of the wind energy itself. 


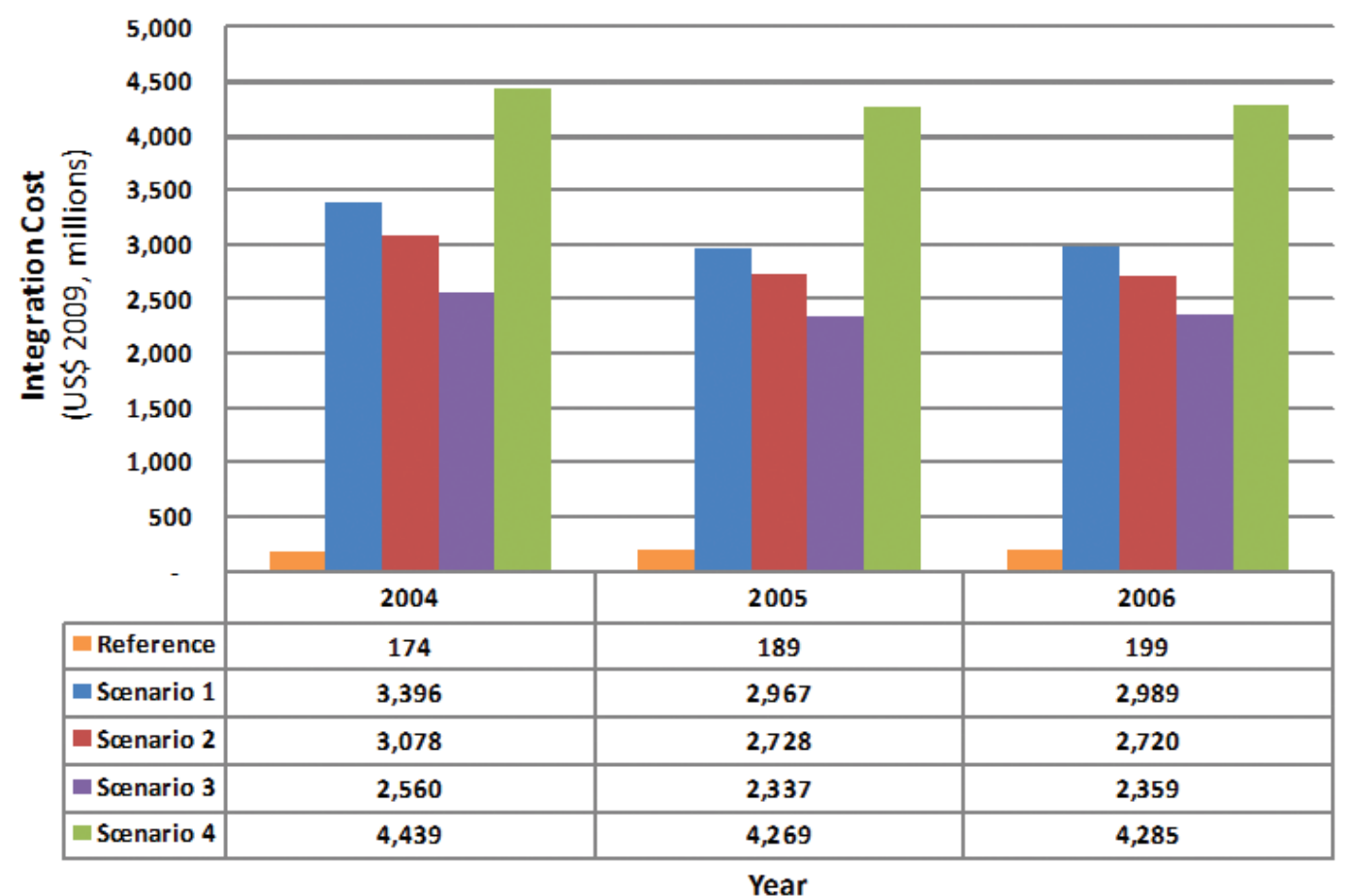

Figure 11. Integration cost by scenario and year (US\$2009)

Salient points from the integration impacts and costs analysis include the following:

- Because the production simulation model contains multiple operating areas, and because transactions between and among these areas are determined on an economic basis, variability from wind in a given area is carried through economic transactions to other areas. In earlier integration studies, wind impacts were isolated in the subject area by restricting transactions to predefined shapes based on historical contracts.

- Costs for integrating wind across the interconnection vary by scenario. For the 20\% cases, Scenario 1 shows the highest cost at \$5.13/MWh (US\$2009) of wind energy; Scenario 3 shows the lowest integration cost at \$3.10/MWh (US\$2009).

- Integration costs average $\$ 4.54$ /MWh (US\$2009) for the 30\% scenario, which is roughly a combination of scenarios 1 and 3 .

- Results for the $20 \%$ scenarios show that spreading the wind more evenly over the footprint reduces integration costs. This is particularly noticeable in the East, where there is more load and a larger number of resources to manage variability.

The project team also analyzed production simulation results to assess curtailment of wind generation resulting from transmission congestion or other binding constraints. Such constraints include excess electricity supply relative to demand and must-run generation ("minimum generation" limits), limitations in ramping capability, or availability of adequate operating reserves. 
Varying amounts of wind generation curtailment were observed in the production simulation results. Findings include the following:

- Wind generation was assigned a very low dispatch price in the production simulations, allowing other sources to be redispatched first to relieve congestion. Even so, study analysts observed a modest amount of curtailment in some operating areas. This is likely the result of local or subregional transmission congestion.

- After conducting a sensitivity analysis consisting of additional production simulation runs, the study team determined that transmission congestion caused most of the curtailment. In these results, minimum generation

\section{Ramp Rates}

For a generator, the ramp rate (typically expressed in megawatts per minute) is the rate at which a generator changes its output. For an interchange, the ramp rate or ramp schedule is the rate, also expressed in megawatts per minute, at which the interchange schedule is attained during the ramp period.

Because wind is variable and results in ramping, it is important to understand these ramp rates and maintain reserves to cover them as needed. levels, reserve constraints, and ramp limitations accounted for less than $1 \%$ of the curtailed energy.

- In developing the conceptual transmission overlays, facilities were sized to accommodate a large fraction-though not $100 \%$ - of the transaction energy from the unconstrained production simulation case. Consequently, a certain amount of wind generation curtailment was a likely outcome.

\section{CARBON SENSITIVITY ANALYSIS}

The entire analytical methodology, except for the loss of load expectation (LOLE) analysis (see the next section for more information on LOLE), was run for a scenario that considered a carbon price of $\$ 100 /$ metric ton. The study team determined that the high price was necessary to bring about a significant change in the type of new generation built during the expansion modeling process. In addition, because it was a sensitivity analysis, choosing a high price helped to illustrate sensitivities. Figure 12 shows the results of the expansion, and Figure 13 compares the expansion for the carbon sensitivity case to the base scenarios and the existing Eastern Interconnection queue.

Results from the production simulations show that the impact on carbon emissions is substantial. Even though the carbon sensitivity case was based on Scenario 2, in which wind generation provides $20 \%$ of the energy in the Eastern Interconnection, carbon emissions are lower than those from Scenario 4, in which wind generation delivers $30 \%$ of that energy (Figure 14). 
Little impact was observed on wind generation curtailment or integration cost. Relative to the original Scenario 2 (Figure 15), fossil-fuel generation is reduced; nuclear generation increases because the nuclear share of the new generation expansion is larger. Energy from combined-cycle plants also increases because it became the preferred resource for managing variability.

With the high cost of carbon, energy prices increase across the footprint (Figure 16). The present value of the accumulated costs more than doubles from the base scenarios (Figure 17).

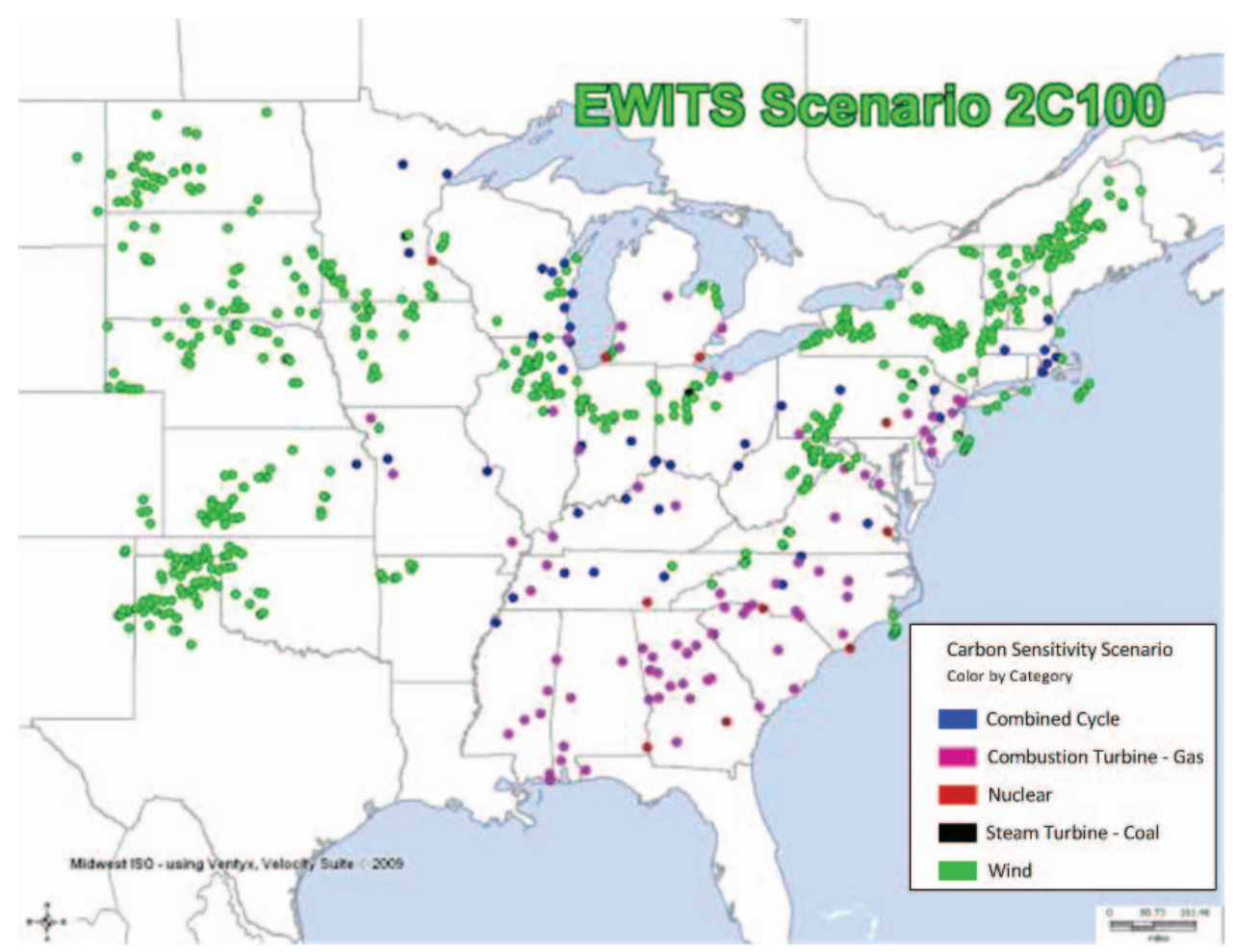

Figure 12. Generation expansion for the Scenario 2 carbon sensitivity case 


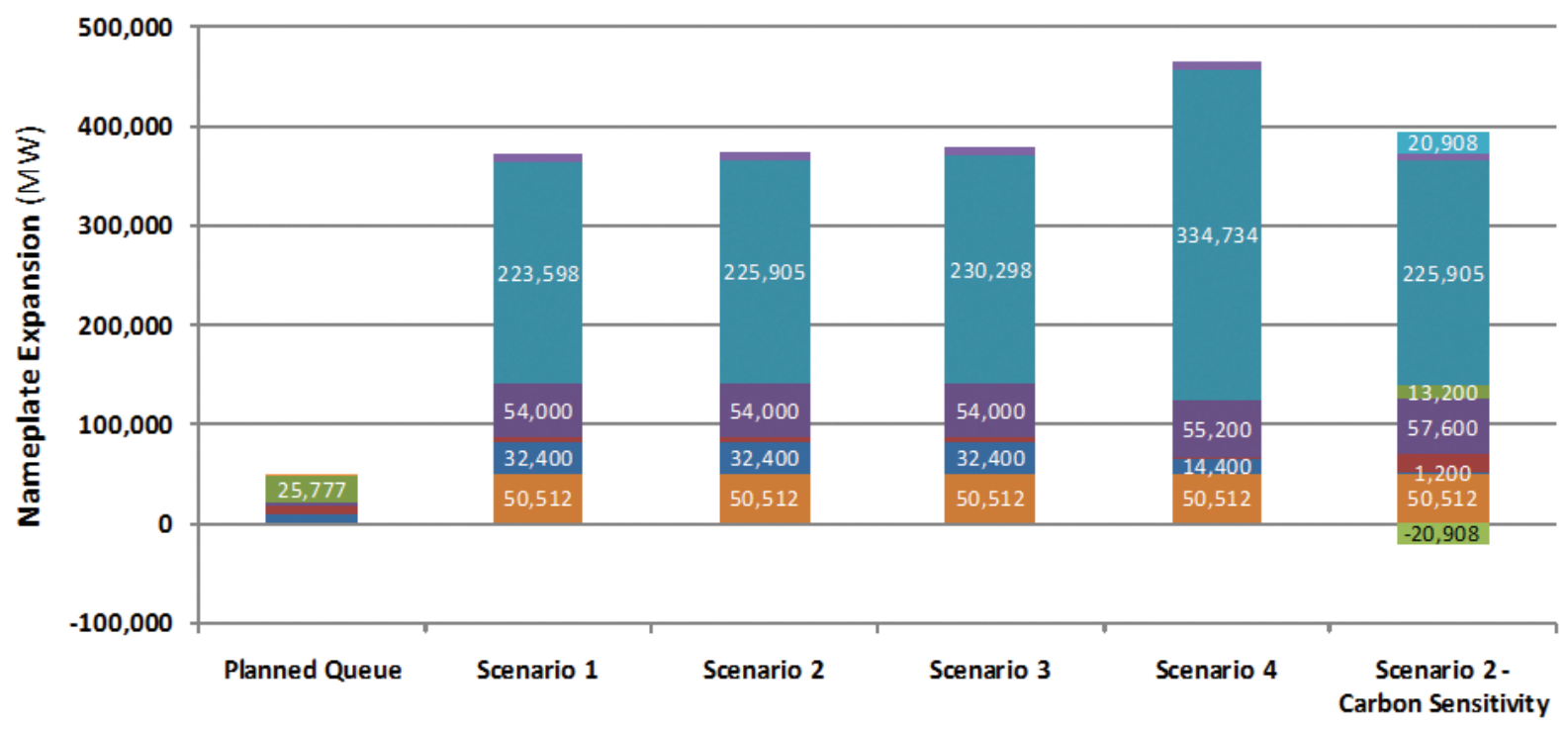

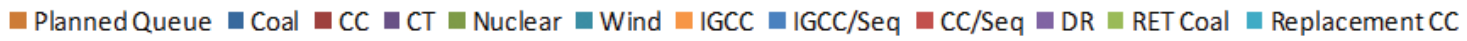

$C C=$ combined cycle; $C T=$ combustion turbine; $D R=$ demand response $/$ IGCC $=$ integrated gas combined cycle; IGCC/Seq = integrated gas combined cycle with sequestration; CC/Seq = combined cycle with sequestration; $R E T$ Coal = coal plant retirements; Replacement $C C=$ replacement combined cycle

Figure13. Generation expansion by scenario, including the carbon sensitivity case

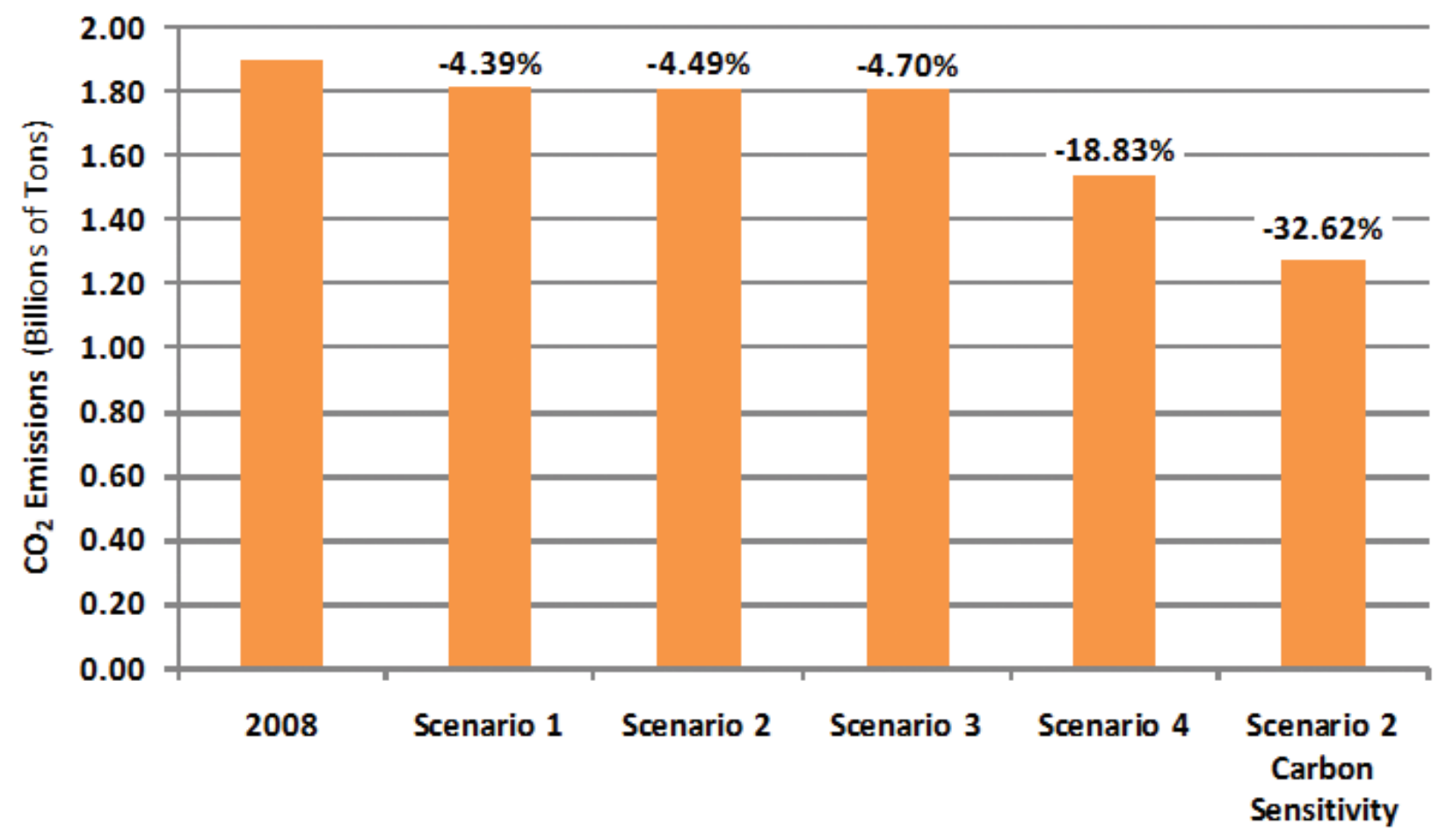

Figure 14. Carbon emissions for different scenarios (carbon price applies only to carbon scenario) 


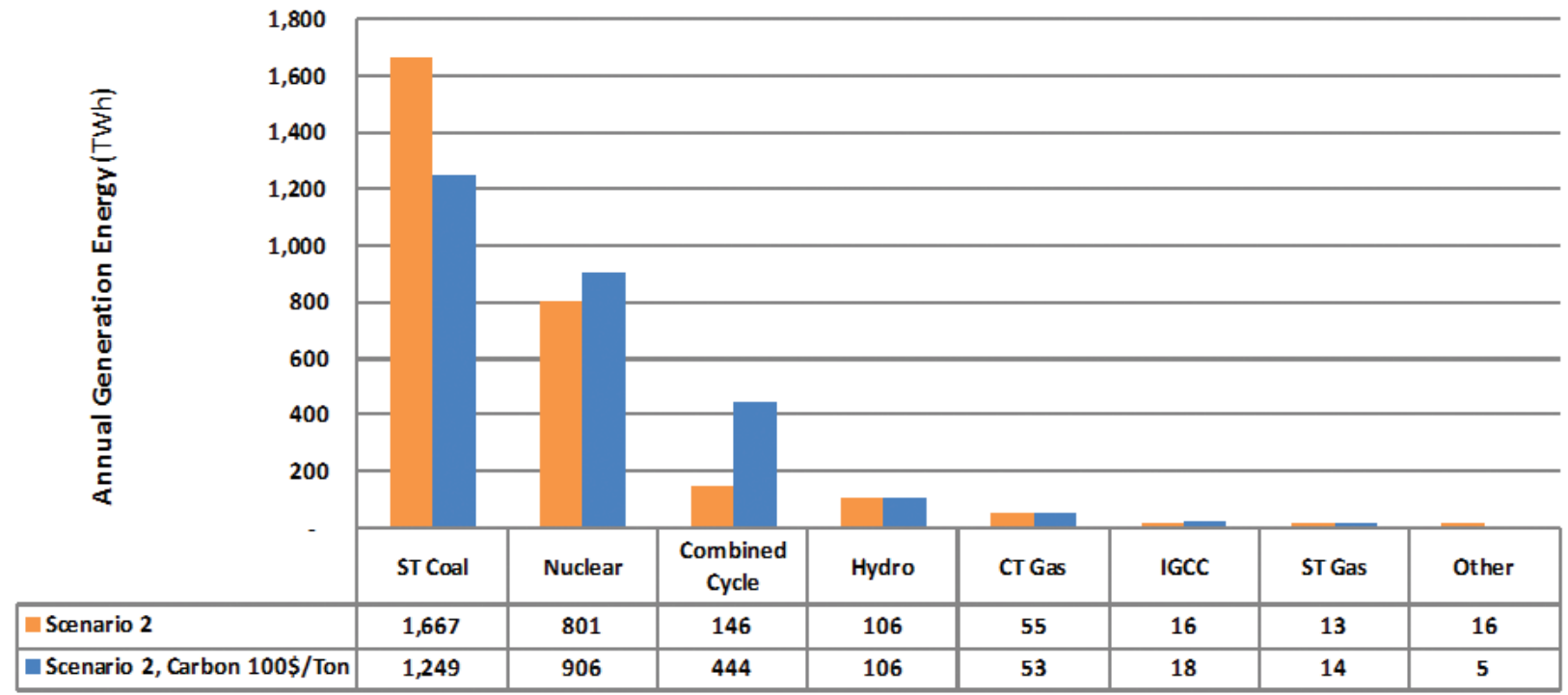

Figure 15. Generation utilization by unit and fuel type for Scenario 2 and carbon sensitivity case

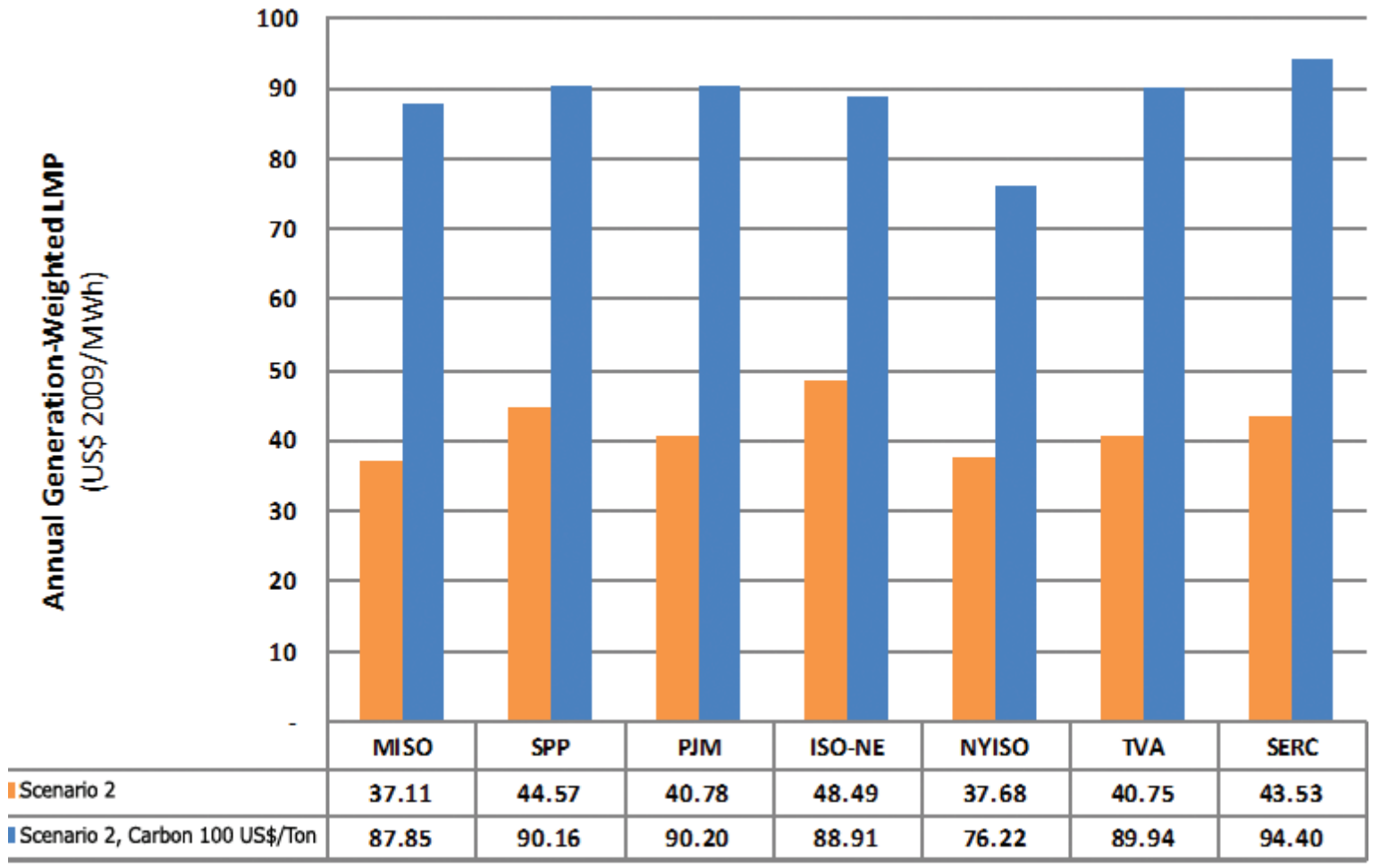

Figure 16. Comparison of generation-weighted LMP by region for Scenario 2 and carbon sensitivity case 


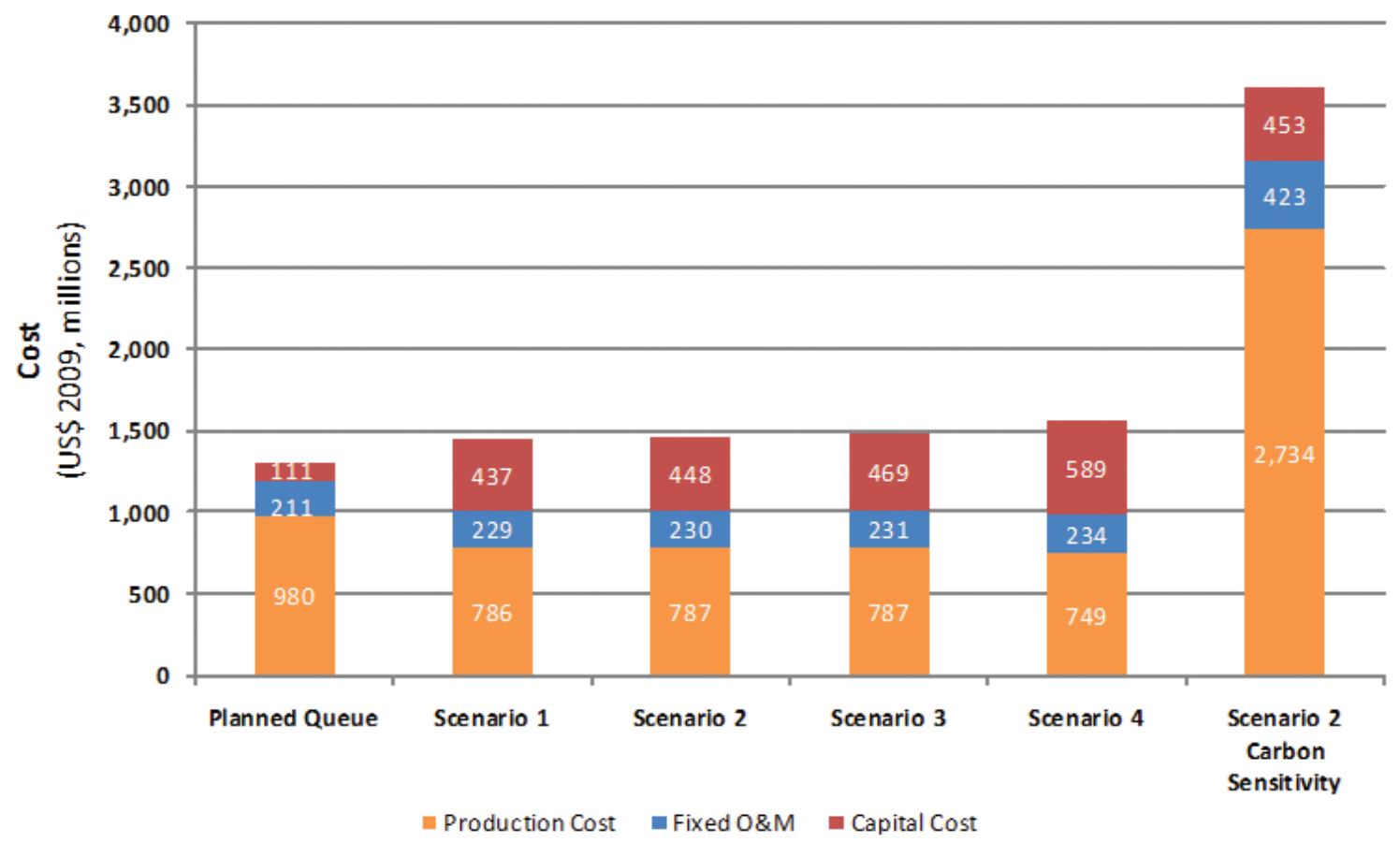

Figure 17. Present value of accumulated costs for base scenarios and carbon sensitivity (US\$2009)

\section{CONTRIBUTIONS TO RESOURCE ADEQUACY}

Having sufficient generation capacity to meet forecast load is an important aspect of bulk power system reliability.

\section{Reliability of the Grid}

EWITS: The EWITS results represent a first detailed look at several "snapshots" of the Eastern Interconnection as it could exist in 2024 and is therefore not intended to provide a complete analysis of the reliability impacts to the present bulk power system. EWITS is aimed at characterizing the operational impacts for future scenarios, primarily through economicsbased transmission expansion planning, resource adequacy studies, and hourly modeling simulations. Important technical aspects in the study related to Bulk-Power System reliability were not studied or were represented approximately or by means of best engineering judgments. A variety of comprehensive power system engineering analyses and studies still need to be conducted (see Summary and Future Work Section) to determine what additional situations should be addressed to maintain system reliability from the present to the 2024 study year when integrating large quantities of renewable generation. Although wind generation cannot be dispatched to meet peak loads, EWITS shows some probability that wind generation would be available during periods of system stress (i.e., it needs additional energy to meet demand). Unlike conventional generating units, only a small fraction of the nameplate capacity rating of a wind plant can be counted on to be available for serving peak loads. With the amounts of wind generation considered in EWITS, though-more than 200,000 MW—understanding the small fraction in quantitative detail is important because it equates to billions of dollars of capital investment. 
The fraction of the nameplate rating of a wind plant that can be counted as dependable or firm capacity, expressed as a percentage, is known as the capacity value.

To estimate a 2024 capacity value for wind, the study analysts used the 2004, 2005, and 2006 effective load-carrying capability (ELCC) of wind at the future penetration level. The team analyzed each of the highpenetration wind scenarios that were explored in the operational analysis.

The EWITS team examined three different levels of transmission sensitivities. The level of transmission being modeled varied from no ties between areas to the different transmission levels of each existing and conceptual overlay scenario. These transmission sensitivities were

- Isolated system, stand-alone zone (no zone-to-zone interfaces modeled)

- Existing transmission system (constrained case and interface limits)

- Conceptual transmission overlay (increased zone-to-zone interface limits and new ties).

Data from the operational simulations were conditioned into the correct format for implementation into the LOLE model. Because that model uses a transportation representation for the transmission network, the study team ran a large number of additional production simulations to estimate the import capacity for each reliability zone. Predefined regional and planning areas were used as the modeling zones. Table 5 lists these zones along with the total nameplate amount of wind generation for each EWITS scenario. 


\begin{tabular}{|c|c|c|c|c|}
\hline Zone & Scenario 1 & Scenario 2 & Scenario 3 & Scenario 4 \\
\hline MISO West & 59,260 & 39,953 & 23,656 & 59,260 \\
\hline MISO Central & 12,193 & 11,380 & 11,380 & 12,193 \\
\hline MISO East & 9.091 & 6,456 & 4,284 & 9,091 \\
\hline MAPP USA & 13,809 & 11,655 & 6,935 & 14,047 \\
\hline SPP North & 48,243 & 40,394 & 24,961 & 50,326 \\
\hline SPP Central & 44,055 & 46,272 & 25,997 & 44,705 \\
\hline PJM & 22,669 & 33,192 & 78,736 & 93,736 \\
\hline TVA & 1,247 & 1,247 & 1,247 & 1,247 \\
\hline SERC & 1,009 & 5,009 & 5,009 & 5,009 \\
\hline NYISO & 7,742 & 16,507 & 23,167 & 23,167 \\
\hline ISO-NE & 4,291 & 13,837 & 24,927 & 24,927 \\
\hline Entergy & 0 & 0 & 0 & 0 \\
\hline IESO $^{\mathrm{a}}$ & 0 & 0 & 0 & 0 \\
\hline MAPP Canada & 0 & 0 & 0 & 0 \\
\hline FULL STUDY SYSTEM & 223,609 & 225,902 & 230,299 & 337,708 \\
\hline
\end{tabular}

a Independent Electricity System Operator

Results of the ELCC analysis, shown graphically in Figure 18 for the cases with existing and overlay transmission, indicate that the transmission network has a significant positive impact on the capacity value of wind generation. For the calendar year with the smallest contribution, the aggregate capacity value of wind generation by scenario ranges from $53 \mathrm{GW}$ to almost $65 \mathrm{GW}$.

Although the influence of transmission on wind generation capacity value is intuitive, the magnitude of the contribution is striking. Considering both the existing and the overlay transmission concepts developed for EWITS, the aggregate wind generation capacity value is increased by more than $20 \mathrm{GW}$ in the $20 \%$ cases, and by nearly $30 \mathrm{GW}$ at $30 \%$ wind penetration.

The capacity value results vary depending on the year, which is consistent with observations in previous studies (see Bibliography). The magnitude of the interannual variation is actually smaller than that seen in some of the earlier results. This could be a consequence of both the scale of the model and the large volume of wind generation.

Assessing the capacity value of wind generation has been a staple of most of the integration studies conducted over the past several years. The approach taken in the EWITS project likely represents the most thorough and detailed investigation to date because of the size and scope of the model, the process by which area transfer limits were determined, and the sensitivities evaluated. The wind capacity values 
calculated in EWITS are significantly higher than those found in previous studies. The study team recognizes that the results represent a macro view, in which some important intraregional transmission constraints are not considered. Because the project focuses on transmission, though, the results represent a target resource adequacy contribution that could be achieved for the wind generation scenarios studied.

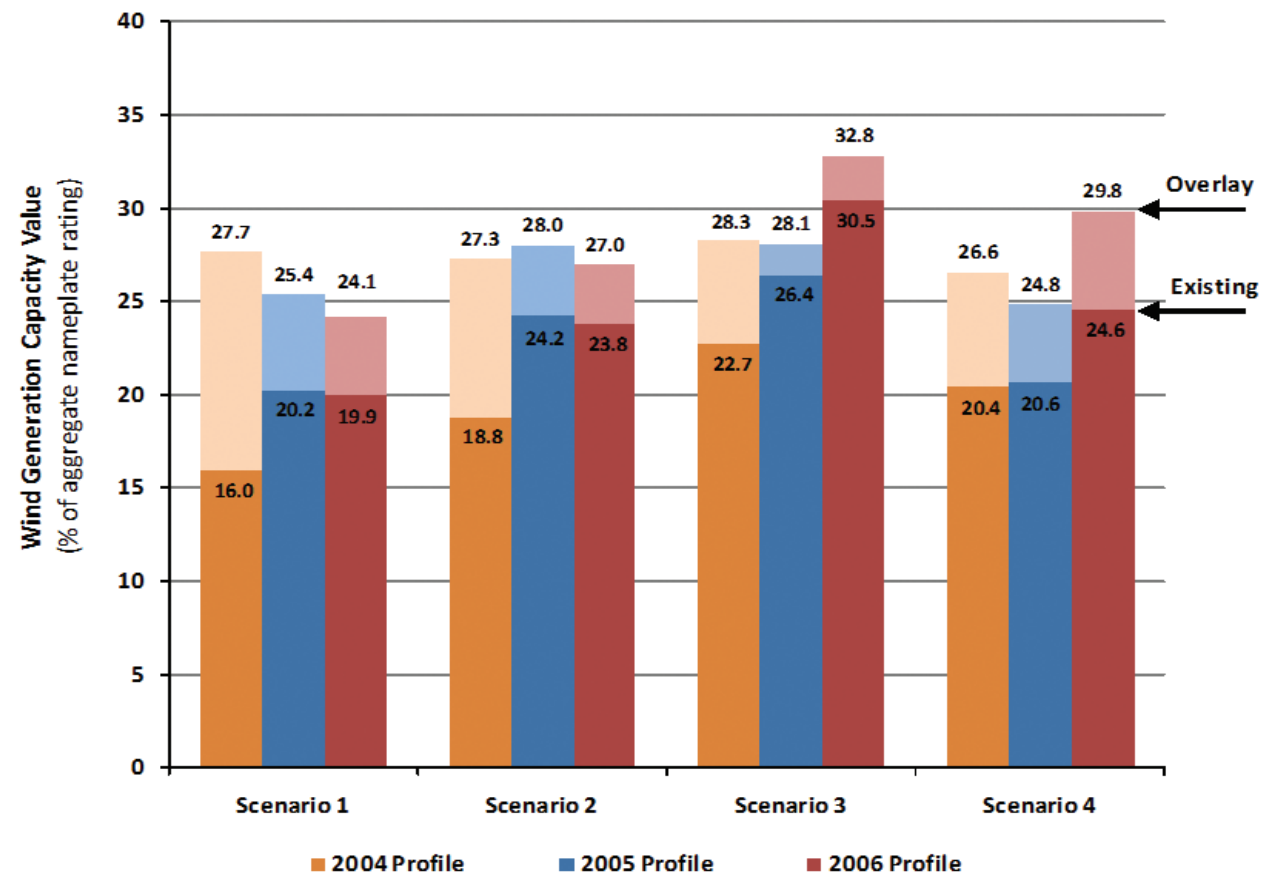

Figure 18. LOLE/ELCC results for high penetration scenarios, with and without transmission overlays

Specific findings and conclusions include the following:

- The LOLE analysis performed for EWITS shows that the existing transmission network in the Eastern Interconnection contributes roughly $50,000 \mathrm{MW}$ of capacity benefits. With the transmission overlays developed for the EWITS wind scenarios, the benefit is increased by up to 8,500 MW.

- The LOLE analysis of the Eastern Interconnection with wind generation and the transmission overlays shows that the ELCC of the wind generation ranges from $24.1 \%$ to $32.8 \%$ of the rated installed capacity.

- The transmission overlays increase the ELCC of wind generation anywhere from a few to almost 10 percentage points (e.g., $18 \%$ to $28 \%$ ).

- The ELCC of wind generation can vary greatly by geographic region depending on which historical load and wind profiles are being studied. Although interannual variations were observed, they are much smaller than those seen in previous studies (see, for example, EnerNex Corporation [2006]).

- Characteristics of the zonal ELCC differences among profiles tended to be the same across all four scenarios. 


\section{SUMMARY AND FUTURE WORK}

The EWITS results represent a first detailed look at a handful of future snapshots of the Eastern Interconnection as it could exist in 2024. The analysis was driven primarily by economic considerations, with important technical aspects related to bulk power system reliability represented approximately or through engineering judgments.

EWITS is an important step in the uncertain world of long-range planning because it addresses questions such as feasibility and total ultimate costs, and begins to uncover important additional questions that will require answers. Although the TRC's representation from the Eastern Interconnection is extensive, the study team also recognizes that additional key stakeholders must be involved to further develop an interconnection-wide view of transmission system plans.

A complete evaluation of any of the scenarios would require a significant amount of additional technical analysis. The framework established by the scenario definitions and transmission overlay concepts, however, forms a foundation for conducting conventional power system planning to further evaluate the feasibility of these high-penetration scenarios and to improve the cost estimates.

Production simulation results from EWITS could be used to identify times of binding constraints or other periods of interest, such as large changes in wind production, minimum load periods, and conditions where loss of significant generation would raise questions about the security of the system. The state of the system during these periods-loads, committed generation and dispatch levels, and wind generation levels, among others-would be transferred to an appropriate AC power system model. A variety of power system engineering analyses could then be conducted to determine what additional equipment or operating limitations would be necessary to maintain system reliability. These analyses would include the following.

- An AC analysis that examines in more detail the power transfer limitations assumed in the production modeling. For EWITS, the team conducted production simulations using a DC power flow that does not consider the wide range of issues associated with voltage control and reactive power dispatch. An AC analysis would involve power flows that look at voltage and reactive compensation issues, dynamic and transient stability, and HVDC terminal control. Local and regional transmission needs could then be analyzed in much greater detail.

- Longer term dynamic analysis, where the actions of AGC, load tap changing on transformers, and capacitor or reactor switching for voltage control can be simulated and analyzed in much greater detail. Such dynamic analysis could examine subhourly market operation and 
the response of generation to either AGC or market dispatch instructions while considering the limitations caused by prime mover or governor response, HVDC control actions, or special protective schemes. This analysis could be used to zoom in on system operation in real time, resulting in a higher confidence estimate of the operating reserve requirements and policies needed to maintain performance and reliability.

The analysis suggested for the large footprint considered in EWITS would require that many entities across the interconnection participate and collaborate. Personnel engaged in running similar studies with a regional focus would need to be involved, at a minimum, in a review capacity and for interpreting results. National entities such as NERC would also need to be engaged to oversee the development of the data sets and models. And because the size and scope of the system models might also require computational power beyond what is used today in the power industry, these suggested analyses could involve universities or national laboratories with appropriate resources.

The top-down views of the interconnection that EWITS yields constitute, in essence, the starting point for a substantially significant amount of subsequent engineering analysis. The analysis would paint a more accurate picture of the total transmission investment necessary, and illuminate measures necessary to preserve the security of the bulk power system. As with EWITS, such an effort would be beyond the scope of previous attempts, and would require cooperation and coordination at many levels to succeed.

Although EWITS is a technical study that examines future wind scenarios, the results pose some interesting policy and technology development questions:

- Could the levels of transmission, including the Reference Case, ever be permitted and built, and if so, what is a realistic time frame?

- Could the level of offshore wind energy infrastructure be ramped up fast enough to meet the aggressive offshore wind assumption in the EWITS scenarios?

- Would a different renewable profile or transmission overlay arise from a bottom-up process with more stakeholders involved?

- How can states and the federal government best work together on regional transmission expansion and the massive development of onshore and offshore wind infrastructure?

- What is the best way for regional entities to collaborate to make sure wind is optimally and reliably integrated into the bulk electrical grid?

- What is the difference between applying a carbon price instead of mandating and giving incentives for additional wind? 
As is expected in a study of this type, especially when a wide variety of technical experts and stakeholders are giving ongoing input, a number of important variations on the 2024 future scenario can be envisioned. In addition, several technical areas in the study present opportunities for further technical investigation that could deepen understanding or reveal new insights:

- Further analysis of production-cost simulation results: The output from the many annual production simulations performed in EWITS contains detail on every generator and monitored transmission interface in the Eastern Interconnection. Because of scope and schedule constraints, the EWITS analysis was necessarily limited to summary results. Further analysis of these output data would likely generate additional valuable insights on impacts of wind generation on nonwind generation, and help define more detailed analyses that could be conducted in the future.

- Smart grid implications and demand response sensitivities: The Eastern Interconnection load considered in EWITS was based on regional projections out to the study year (2024). For the most part, load was considered "static." Major industry initiatives are currently exploring means by which at least a portion of the load might respond like a supply resource, thereby relaxing the constraints on scheduling and dispatch of conventional generating units. The implications for wind generation are potentially very significant, which is why alternative 2024 scenarios that consider the range of smart grid implications for the bulk electric system merit further consideration (scope limitations prevented these from inclusion in this phase of EWITS).

- Nighttime charging of PHEVs: Widespread adoption of electric vehicles has the potential to alter the familiar diurnal shape of electric demand. Because the wind resource is abundant at night and during the low-load seasons, increases in electric demand during these times could ease some of the issues associated with integration.

- Commitment/optimization with high amounts of wind: The approach for scheduling and dispatching generating resources used in the production simulations is based on current practice. In the future, new operating practices and energy market structures might be implemented that take advantage of the fact that uncertainty declines as the forecast horizon is shortened (for both load and wind generation). Intraday energy markets that allow reoptimization of the supply resources more frequently could offer some advantage for accommodating large amounts of variable and uncertain wind energy.

- Fuel sensitivity: In this phase of EWITS, the study team considered a single future for prices of other fuels used for electric generation. As history attests, there is much uncertainty and volatility inherent in some fuel markets, especially for natural gas. Alternate scenarios that explore the impacts of other fuel price scenarios on integration impacts and overall costs would be valuable. 
- The role and value of electrical energy storage: With the substantial transmission overlays and the assumption of large regional markets, the EWITS results show that large amounts of wind generation can be accommodated without deploying additional energy storage resources. The ability to store large amounts of electrical energy, though, could potentially obviate the need for some of the transmission and reduce wind integration impacts. Analysis of bulk energy storage scenarios with generic storage technologies of varying capabilities would quantify the costs and benefits of an alternate means for achieving high penetrations of renewable energy.

- Transmission overlay enhancement: As described earlier, the analytical methodology was based on a single pass through what is considered to be an iterative process. Further analysis of the existing results could be used to refine the transmission overlays, which would then be tested in additional production simulations and LOLE analyses, along with AC power flow and stability analyses. This could reduce the estimated costs of the overlay and bolster the view of the required regional transmission expansion that would be needed to deliver the large amounts of wind energy to load.

- Sequencing of overlay development: EWITS focused on a snapshot of a 2024 scenario using a top-down perspective. The resulting transmission overlays and substantial amounts of wind generation would be developed over many years. An analysis over time-beginning now and extending to 2024-would yield important insights into the overall feasibility and costs of an aggressive transmission development future.

- Wind generation curtailment: Using wind generation curtailment selectively and appropriately could have high operational value. Although wind plants cannot increase their output at will without first spilling wind generation, downward movement is easily accomplished with today's wind generation technology. This could have very high economic value under certain circumstances. Wind generation is very capable of "regulating down"; for example, in an ancillary services market where the regulation service is bifurcated (i.e., regulation up and regulation down are separate services). Additional analysis of the scenarios studied in EWITS could help quantify what such a service would be worth to wind plant operators.

The current installed capacity of wind generation in many areas of the United States, coupled with prospective development over the next several years, requires that assessments of the bulk electric power system take a much broader view than has been typically employed. In addition, the unique characteristics of wind generation as an electrical energy supply resource are leading the power industry to new approaches for planning and analyzing the bulk electric power system. 
Several of these techniques were demonstrated in EWITS, and are also being used in other large-scale wind integration analyses. The data sets compiled for the study represent the most detailed view to date of high-penetration wind energy futures and potential transmission. Given the significant changes coursing through the electric power industry, many alternative scenarios for the Eastern Interconnection in 2024 can be postulated. In that sense, EWITS is a solid first step in evaluating possibilities for the twenty-first century grid in the United States, with many more to follow. 


\section{SECTION 1: INTRODUCTION}

As the penetration of bulk wind energy continues to grow, evaluating its effect on the operation of regional electrical systems becomes increasingly important. Evaluating wind energy's interaction with the utility grid allows for a better understanding of how to manage the wind resource during both planning and day-to-day operations. Quantifying the actual effect of wind energy on specific regional electrical systems will produce information critical to transmission planning.

Many states are adopting regional mandates on renewable energy penetration into the electrical grid, and these mandates could be adopted for the nation as a whole. Meeting the growing need for wind power in the United States will require careful analysis and modeling of how large amounts of wind power will be integrated into the electrical grid. Analyzing future scenarios of wind power penetration using state-of-the-art production-cost models, transmission power flow and power simulation models, and related methodologies is an important step in the energy and transmission planning process. Because new transmission will most likely be necessary for much of the future wind power that will be installed in the United States, it is imperative to plan for this transmission. The lead times for building transmission are significantly longer than those for building wind plants.

The U.S. Department of Energy (DOE) commissioned the work described in this report through its National Renewable Energy Laboratory (NREL). Known as the Eastern Wind Integration and Transmission Study (EWITS), the project was designed to consider a range of important and contemporary questions about integrating high-penetration wind energy into the grid. The technical work conducted for this study produced detailed quantitative information on the following:

- Wind scenarios that reach wind energy penetrations equivalent to $20 \%$ of the electrical energy delivered in the Eastern Interconnection in 2024

- Transmission concepts for delivering energy economically for each scenario (new transmission for each scenario is based on economic performance for the conditions of the generation scenario)

- Economic sensitivity simulations of the hourly operation of the power system defined by a wind generation forecast scenario and the associated transmission overlay

- The contribution made by wind generation to resource adequacy and planning capacity margin.

As part of this study, NREL convened a Technical Review Committee (TRC) with representation from regional electric reliability councils, expert reviewers, 
the study subcontractor, transmission planners, utilities, and wind industry representatives. The TRC met 6 times over 14 months during the project to review study progress; comment on study inputs, methods, and assumptions; assist with collecting data; and review drafts of the study report.

The Eastern Wind Data Study (AWS Truewind 2009), a precursor to this study, identified more than 700 gigawatts $(\mathrm{GW})$ of potential future wind plant sites for the eastern United States. The hourly time series data produced in that study were used as primary inputs to this study's analytical methods. EWITS focuses on the integration of wind power into the majority of the Eastern Interconnection, a region covering much of the eastern half of the United States.

\section{PROJECT OBJECTIVES}

For this project, the study team evaluated the power system impacts, costs, and conceptual transmission overlays attendant with increasing wind generation capacity to $20 \%$ and $30 \%$ of retail electric energy sales in 2024 for the study area, which encompasses portions of the Eastern Interconnection under the auspices of the following entities:

- New England Independent System Operator (ISO-NE)

- New York ISO (NYISO)

- PJM Interconnection

- Tennessee Valley Authority (TVA)

- Portions of the Southeastern Electric Reliability Council (SERC)

- Southwest Power Pool (SPP)

- Midwest ISO

- Mid-Continent Area Power Pool (MAPP)

EWITS builds on the methods developed in previous wind integration studies and related technical work (see Bibliography), and coordinates with ongoing interregional power system investigations. Ultimately, the EWITS team's objective was to produce meaningful, broadly supported results through a technically rigorous and inclusive study process.

\section{KEY ISSUES AND QUESTIONS}

In the years preceding this study, numerous wind integration studies had been conducted for individual or regional entities (see Bibliography). When many of those studies were performed, the "outside world" (i.e., the operation of the grid outside the study confines) could be ignored or easily approximated from operating history. Now that the installed capacity of wind generation is approaching $30 \mathrm{GW}$ in the United States (and concentrated in certain areas), and many states have passed legislation mandating that an appreciable fraction of electrical energy be produced by certain renewable resources, interest has grown past the confines of a single operating area. 
Many of the key questions to be answered in this study are similar to those posed in previous wind integration studies, but the scope and scale are entirely different. The existing transmission infrastructure in the Eastern Interconnection has a limited capacity for accommodating additional wind generation; transmission congestion is already an issue in some areas, including those with the potential for tenfold or greater development in wind capacity. Consequently, evaluating transmission needs was also a major aspect of this study.

Key questions posed at the outset of the project include the following:

1. What impacts and costs do wind generation variability and uncertainty impose on system operations?

2. What benefits accrue from long-distance transmission that accesses multiple and geographically diverse wind resources?

3. What benefits are realized from long-distance transmission that moves large quantities of remote wind energy to urban markets?

4. How do remote wind resources compare to local wind resources?

5. How much does geographical diversity, or spreading the wind out across a large area, help reduce system variability and uncertainty?

6. What is the role and value of wind forecasting?

7. What benefit does balancing area cooperation or consolidation bring to wind variability and uncertainty management?

8. How does wind generation capacity value affect supply resource adequacy?

\section{OVERVIEW OF PROJECT TASKS}

Evaluating the impacts of large-scale wind generation development across the Eastern Interconnection in the United States required three major tasks: developing wind plant power outputs, conducting transmission analysis, and studying the implications of high-penetration wind integration. The last two tasks are formally part of the study documented in this report.

A reasonably accurate, physically consistent depiction of what wind generation would look like to power system operators has been the critical input to all previous integration studies. Expanding the area of interest to include nearly half of the land area of the lower continental United States posed a significant challenge in this respect. The precursor effort (AWS Truewind 2009), though, resulted in an extensive database of synthesized, high-resolution, correlated 
wind energy profiles for a significant portion of the Eastern Interconnection. A quality control process was applied to the raw data, followed by construction of more than $700 \mathrm{GW}$ of wind power plant temporal data, down to a resolution of 10 minutes for a consecutive 3-year period (2004, 2005, and 2006).

From that starting point, the EWITS team began this project by defining four wind generation scenarios for 2024, three with $20 \%$ of the projected electrical energy demand across the Eastern Interconnection and one that stretched the wind generation penetration to $30 \%$.

The wind generation profile data set the stage for some analytical work that represents the leading edge of engineering and economic methods combined with computational horsepower. With the tools and analytical methods described in this report, the study team designed extensive top-down transmission overlays that span the interconnection, and then rigorously analyzed the operating and planning reserve impacts.

EWITS is one of three to conduct this type of analysis on such a large scale. The Western Wind and Solar Integration Study (WWSIS) is examining the planning and operational implications of adding up to $30 \%$ penetration by energy of wind generation and solar energy to the WestConnect footprint in the Western Electricity Coordinating Council (WECC). The European Wind Integration Study (EWIS) is an initiative established by the European associations of transmission system operators in collaboration with the European Commission. EWIS is aimed at developing, where possible and appropriate, common solutions to wind integration challenges in Europe. The study also seeks to identify arrangements that will make the best use of the pan-European transmission network, allowing the benefits of wind generation to be delivered across Europe.

And as the amount of wind generation continues to increase, these studies are unlikely to be the last.

\section{ORGANIZATION OF THIS REPORT}

Section 2 describes the data the team used and the process employed to create the four wind generation scenarios. Characteristics of the wind resource on a regional basis are also described.

Section 3 discusses the data and analysis methods used to develop the scenarios for the 2024 study year. The section also describes the tools used for the detailed assessments of wind generation operational impacts and resource adequacy contributions.

Section 4 explains how the transmission overlays were developed for each scenario. The large amounts of wind generation considered here will increase the 
variability of the net demand and introduce some heightened uncertainty into operational considerations.

Section 5 discusses the approach for assessing how operating reserves would be affected by these large amounts of wind generation, and presents results by scenario and operating region.

Section 6 presents the range of operational impacts as determined from chronological hourly production simulations of the entire Eastern Interconnection.

Section 7 summarizes the analytical effort to determine how wind generation contributes to resource adequacy, an important element of power system reliability.

Section 8 explores the broader implications of the EWITS results.

Section 9 presents findings and conclusions drawn from the study's quantitative results. It also gives recommendations for future work should this effort be continued. These recommendations are drawn from comments and discussions among members of the project team and the TRC, along with project sponsors. 


\section{SECTION 2: WIND SCENARIO DEVELOPMENT}

\section{INTRODUCTION}

Through a collaborative process, the Eastern Wind Integration and Transmission (EWITS) researchers developed four wind scenarios for analysis. The idea behind multiple scenarios was to examine the effect of different geographic positioning of the wind resources at $20 \%$ of the expected load for 2024 and to understand the effect of increasing the wind penetration to $30 \%$.

This section briefly explains the process of developing the scenarios, and then describes the resulting four wind scenarios. Because of the large volume of data, both for the entire database and for the scenarios used in this study, the documentation in this report is necessarily in the form of summary charts, graphs, and tables that depict relevant characteristics of the time series data.

\section{DESCRIPTION OF MESOSCALE DATABASE}

The mesoscale database, which now resides at the National Renewable Energy Laboratory (NREL), contains 1,325 separate wind production plants, most hypothetical and others corresponding to the locations of existing operating wind plants. These plants are aggregations of the 2-kilometer $(\mathrm{km})$ wind simulation grid data from meteorological simulations done by AWS Truewind (2009). The nameplate capacity of these plants varies from 100 megawatts (MW) to greater than 1,400 MW. The total installed nameplate capacity is approximately 700 gigawatts (GW).

The project that produced these data modeled the atmosphere over the study area using mesoscale modeling tools. Mesoscale refers to atmospheric phenomena (temperature, pressure, precipitation, and wind, for example) on scales of several kilometers to several hundred kilometers. By using known meteorological measurement data for historical years, the model can be guided to reproduce what the wind speeds and air density would have been at many points, both on the ground and at wind turbine hub height. Those wind speeds are used, along with local geographic information (e.g., mountains, lakes, and ridgelines), to estimate an area's wind power production over the time frame of the numerical weather simulation.

The simulation modeled wind in the Eastern Interconnection for 2004, 2005, and 2006. For each plant, the data span 3 years of 10-minute power production data. For each site, several hourly resolution forecast vectors were calculated, including a day-ahead horizon (18 to 42 hours), a 6-hour-ahead forecast, and a 4-hour-ahead forecast. 
The wind data calculated for this study are roughly distributed according to the geographic quality of the wind resources across the eastern United States. Some heavier weighting was given to eastern states because high-capacity wind resources are concentrated in the western states. States like Nebraska and Minnesota have large amounts of high-quality wind; states like New Jersey, Maryland, and Ohio have relatively small amounts. The EWITS team made an effort to represent wind resources from all states with any reasonable wind resources in the data set.

One important measure of wind-resource quality is the levelized cost of energy (LCOE) for each facility in the database and for the wind database as a whole. The LCOE allows for direct comparisons among the lifetime costs—on an energy-delivered basis - of facilities with different capital and maintenance costs. Table 2-1 gives the economic parameters used for the calculations, and Figure 2-1 shows the LCOE for all the wind plants in the database (plotted by increasing cost against the accumulating nameplate capacity of the plants).

\begin{tabular}{|l|r|r|}
\hline \multicolumn{3}{|l|}{ TABLE 2-1. LCOE ECONOMIC ASSUMPTIONS (US \$2009) } \\
\hline ASSUMPTION & \multicolumn{1}{|l|}{ ONSHORE } & \multicolumn{1}{l|}{ OFFSHORE } \\
\hline Fixed Charge Rate (\%) & 11.92 & 11.92 \\
\hline Capital Cost (\$/kW) & 1,875 & 3,700 \\
\hline Fixed O\&M (\$/kW/yr) & 11.50 & 15.00 \\
\hline Variable O\&M (\$/MWh) & 4.79 & 14.50 \\
\hline
\end{tabular}

Notes: $k W=$ kilowatt; O\&M = operations and maintenance; $M W h=$ megawatt-hour. Source: 2008 data from NREL and Lawrence Berkeley National Laboratory. See also Wiser and Bolinger (2009). Note that these costs are not the same as those used for the resource expansion planning documented later in this report. The values here reflect updated information that was not available when the study team explored expansion planning. 


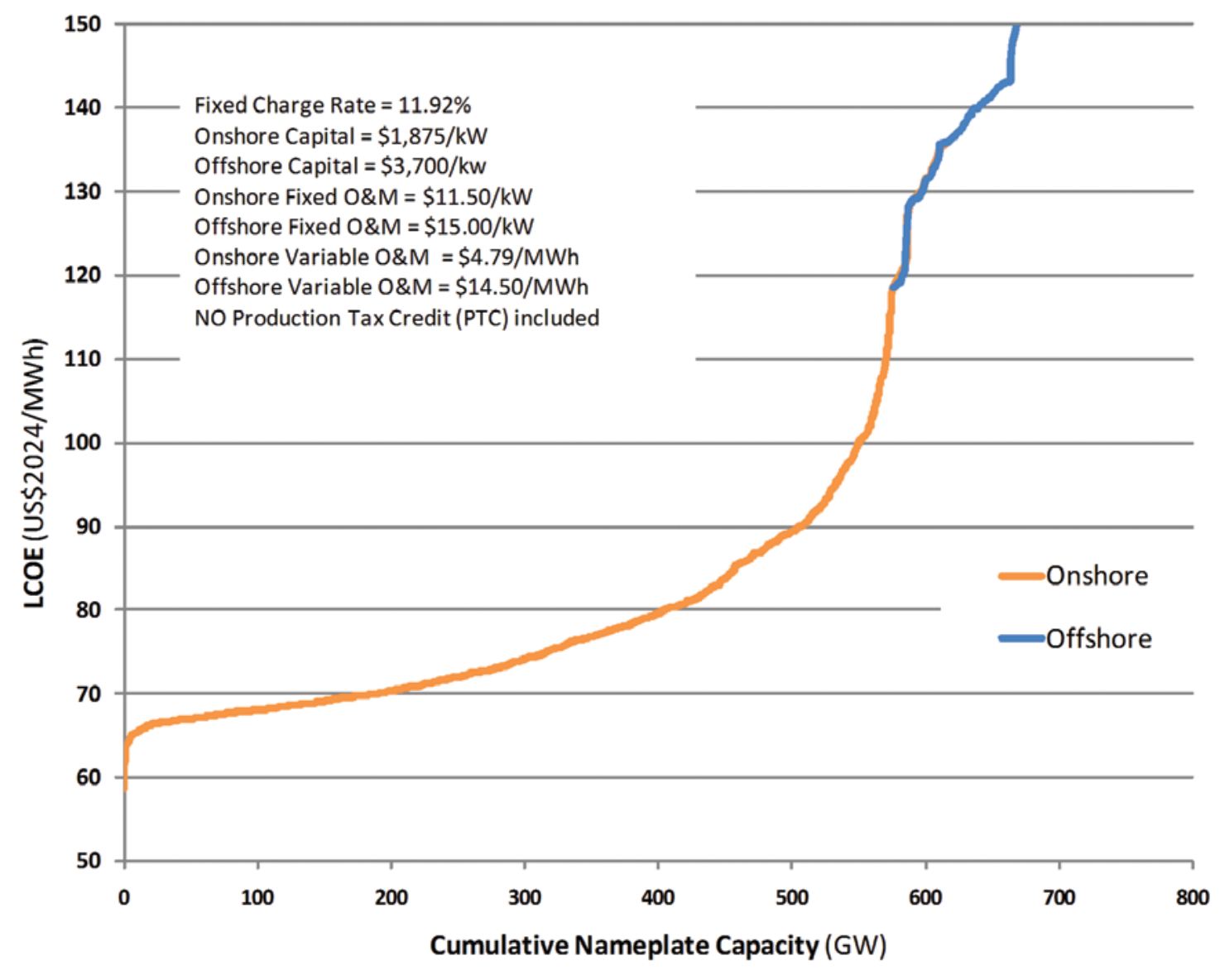

Figure 2-1. LCOE for all wind facilities in database

The plants with the lowest costs typically have the highest capacity factor.

Offshore wind plants tend to have the highest LCOE because of their high capital and maintenance costs-even though their capacity factors are generally quite high. The data in Figure 2-1 reflect approximately 580 GW of onshore wind nameplate capacity and about $100 \mathrm{GW}$ of offshore wind nameplate capacity in the Great Lakes and off the eastern seaboard. Offshore wind is located in waters up to 30 meters $(\mathrm{m})$ deep.

Another useful way to look at the overall data is in terms of capacity factor versus cumulative nameplate capacity. Capacity factor can be seen as a reasonable proxy for return on construction, carrying, and operations costs. Figure 2-2 shows the incremental capacity factor for all plants in the database with and without considering offshore plants. The horizontal axis shows the total capacity in the database having a capacity factor equal to or greater than the capacity factor indicated on each curve. Capacity factors shown on this graph (and on Figure 2-3) are net, but curtailment (shutting down wind) is not taken into account. 


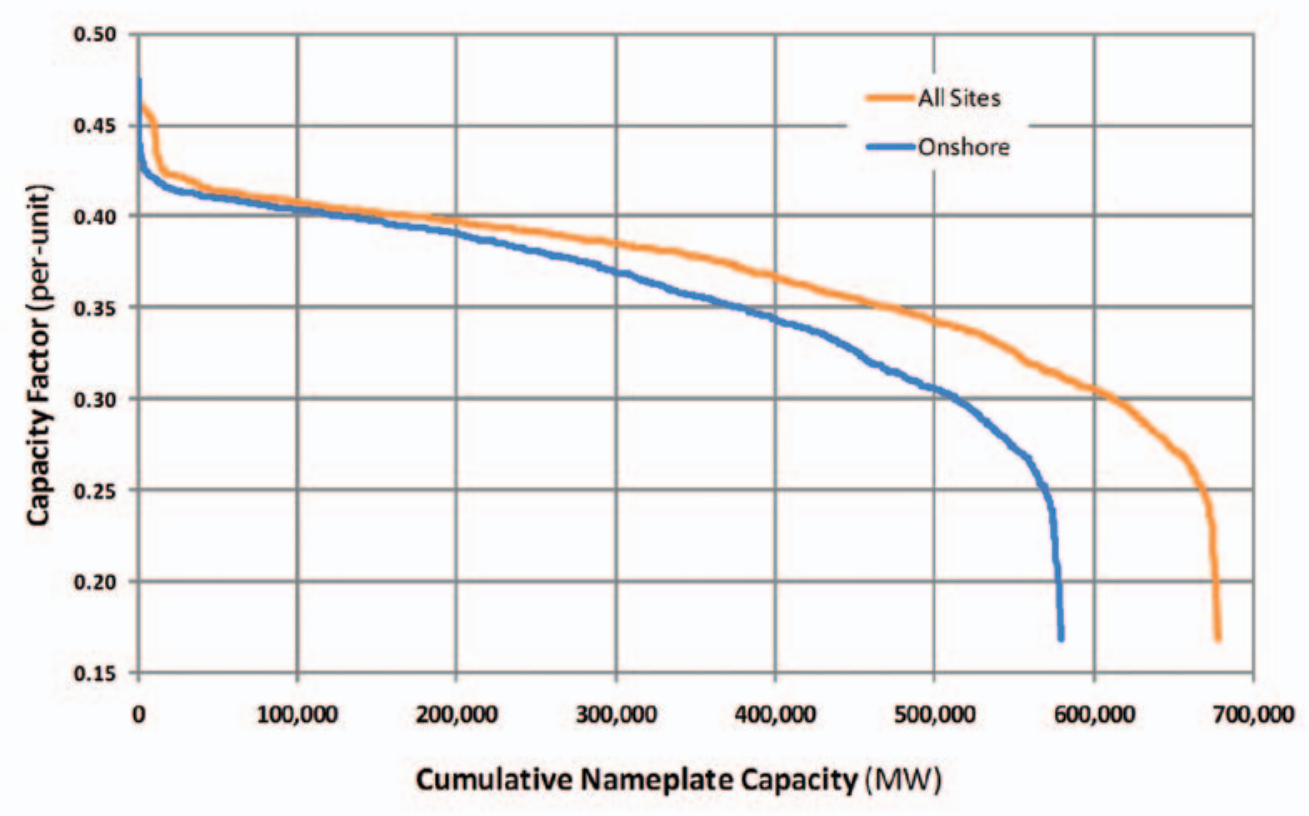

Figure 2-2. Capacity factor for all wind in database

Figure 2-3 shows the same data as Figure 2-2 except that the capacity factor is an aggregate of all units less than a selected capacity value. Figure 2-3 shows the total effective capacity factor for the total capacity selected on the capacity axis.

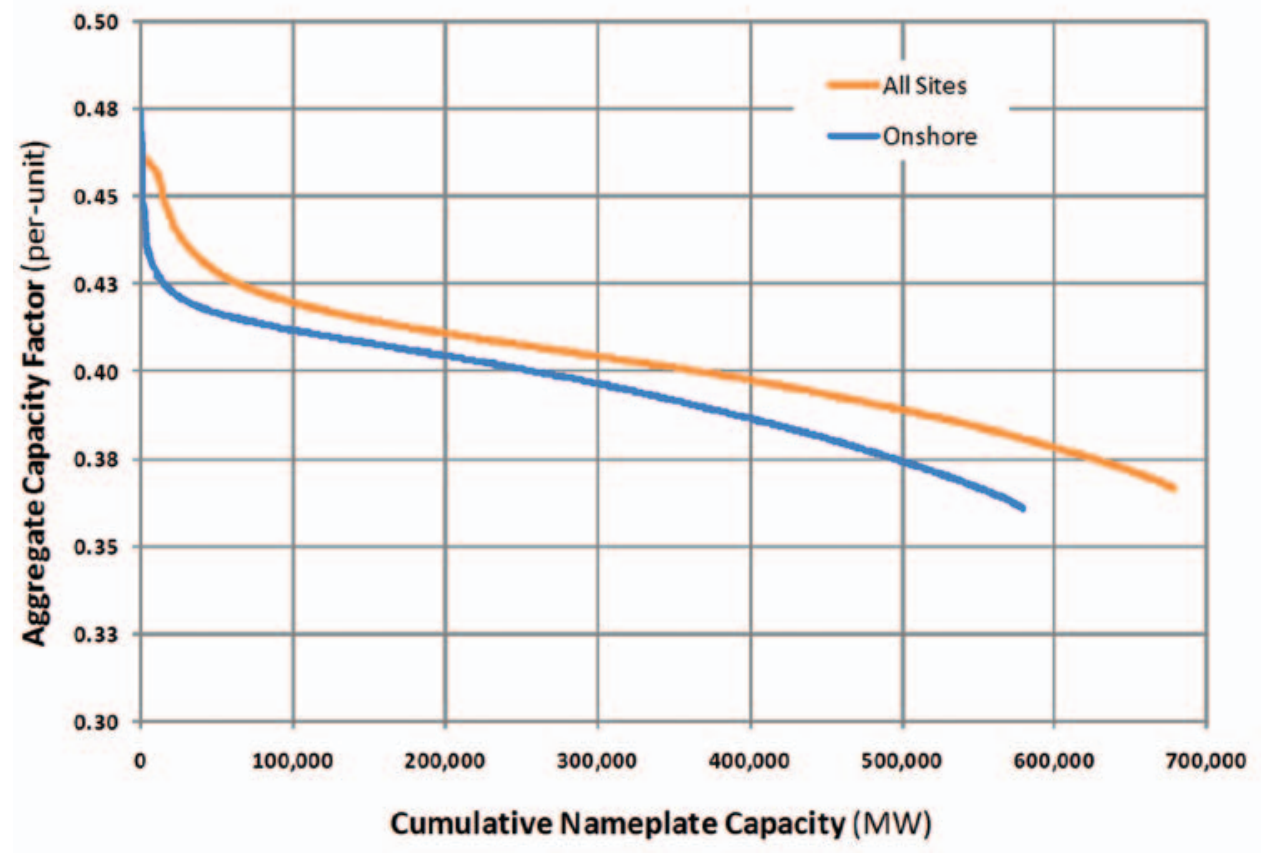

Figure 2-3. Aggregate capacity factor for all wind in database 


\section{SCENARIO DEVELOPMENT PROCESS}

Once the project team defined the scenario goals, attention turned to developing the wind scenarios from the database described earlier. Four scenarios were constructed—three with $20 \%$ wind energy penetration and one with $30 \%$.

For each of the scenarios, the study team took state renewable portfolio standard (RPS) goals and existing interconnection wind queues into account, and gave some consideration to distributing wind to all states with usable resources.

To yield data required for selection among all the resources calculated and stored in the database, some calculations were required. The study team analyzed the production time series data to determine annual and average capacity factor and energy production for 2004, 2005, and 2006 for each of the 1,325 sites.

Once the regional allocations were decided, the project team worked with NREL to segregate wind resources from the database by geographic region. Next, the team analyzed these data, and made the appropriate selections. Because this study is based on energy penetration criteria, these allocations are specified in the annual wind production target.

For regionally focused scenarios (all except Scenario 1), selections were based first on the regional allocations. Within the regions, the plants with the highest capacity factors were selected first. Plants were added to the scenarios by decreasing capacity factor until the target annual energy penetration was reached. The study team used 3-year average capacity factor and energy production values for this process.

After the quantitative process was complete, the allocations were manually checked to ensure that diversity and local siting goals were met. For instance, some adjustments were made to the scenarios to site some wind generation in all states with RPS in place or pending.

\section{SCENARIO DESCRIPTIONS}

Once the scenarios had been defined, the project team conducted various analyses on the scenario data. This section gives an overview of these analyses.

The five scenarios are as follows:

- Reference Scenario (also called Reference Case)_Existing RPS

- Scenario 1, 20\% penetration-High Capacity Factor, Onshore

- Scenario 2, 20\% penetration-Hybrid with Offshore

- Scenario 3, 20\% penetration-Local with Aggressive Offshore

- Scenario 4, 30\% penetration-Aggressive On- and Offshore. 


\section{REGIONAL WIND CAPACITY AND ENERGY}

The scenario data were tabulated based on the independent system operator (ISO) / market region footprints for ease of aggregation and comparison. The regions were defined in 2009 (Figure 2-4) and the roughly described footprints follow:

ISO-NE: New England ISO

MISO + MAPP: Midwest ISO ${ }^{1}$ and Mid-Continent Area Power Pool

NYISO: New York ISO

PJM: PJM Interconnection

SPP: Southwest Power Pool (includes Nebraska Power Association and Entergy ${ }^{2}$ loads)

TVA: Tennessee Valley Authority

SERC: SERC Reliability Corporation without TVA and Entergy

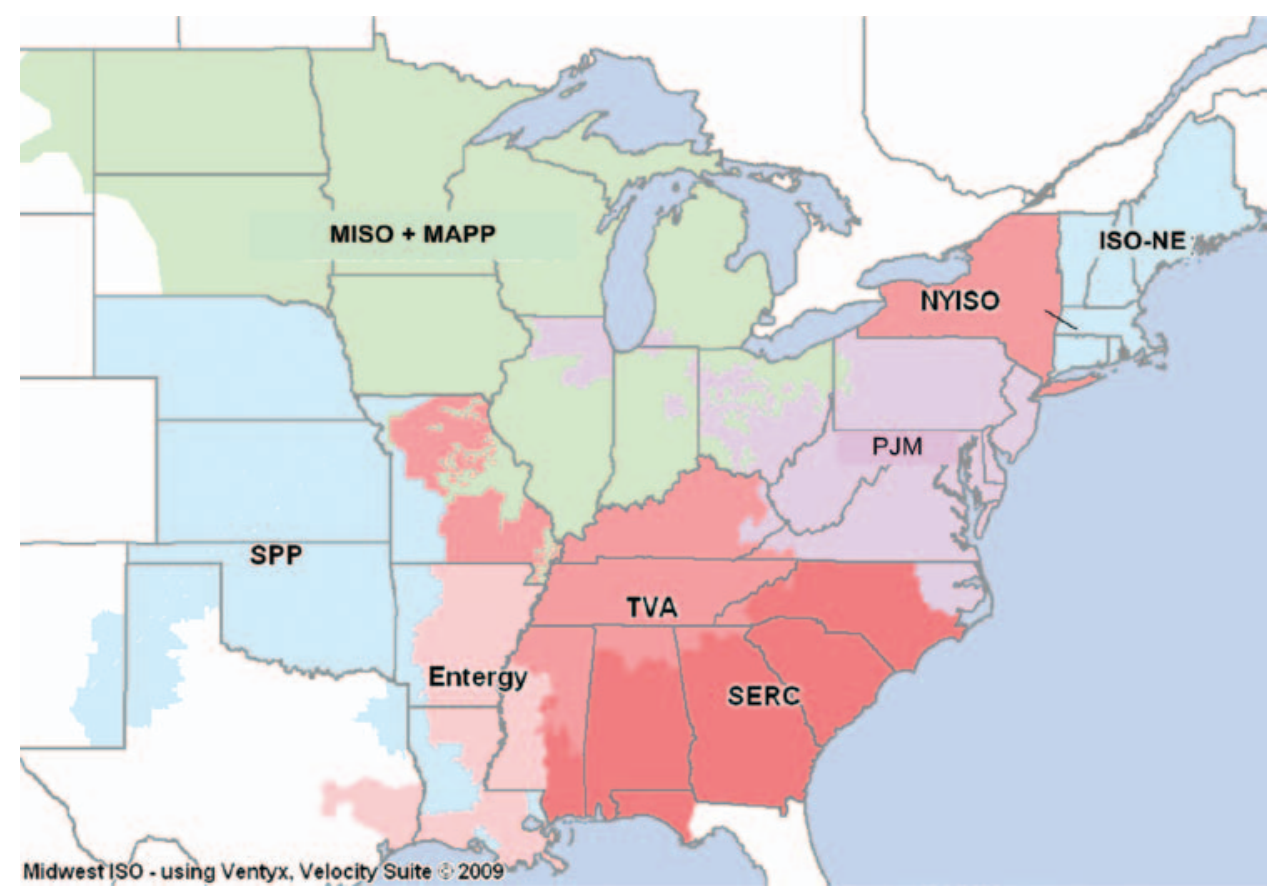

Figure 2-4.Study regional definitions

The scenarios were developed for the different energy targets. Table 2-2 and Figure 2-5 show the energy production allocation (in terawatt-hours [TWh]) by region for each of the four energy scenarios and for the Reference Scenario. The 20\% energy scenarios (1 through 3 ) vary slightly because of the different resources used to achieve the targets.

1 Because of space considerations, Midwest ISO is shortened to MISO in tables and figures. Similarly, PJM Interconnection is shortened to PJM.

2 Entergy is operated as part of SERC. 


\begin{tabular}{|c|r|r|r|r|r|}
\hline \multirow{2}{*}{ TABLE 2-2. SUMMARY OF ENERGY BY REGION FOR SCENARIOS } \\
\hline & \begin{tabular}{l} 
ANNUALNERGY (TWH) \\
REFERENCE \\
\cline { 2 - 7 }
\end{tabular} SCENARIO & SCENARIO 1 & SCENARIO 2 & SCENARIO 3 & SCENARIO 4 \\
\hline ISO-NE & 33 & 13 & 46 & 82 & 82 \\
\hline $\begin{array}{c}\text { MISO + } \\
\text { MAPP }\end{array}$ & 63 & 404 & 288 & 189 & 405 \\
\hline NYISO & 20 & 22 & 48 & 71 & 71 \\
\hline PJM & 65 & 64 & 97 & 244 & 295 \\
\hline SERC & 13 & 3 & 16 & 16 & 16 \\
\hline SPP & 26 & 234 & 245 & 139 & 243 \\
\hline TVA & 4 & 4 & 4 & 4 & 4 \\
\hline TOTAL & $\mathbf{2 2 4}$ & $\mathbf{7 4 4}$ & $\mathbf{7 4 5}$ & $\mathbf{7 4 6}$ & $\mathbf{1 1 1 6}$ \\
\hline
\end{tabular}

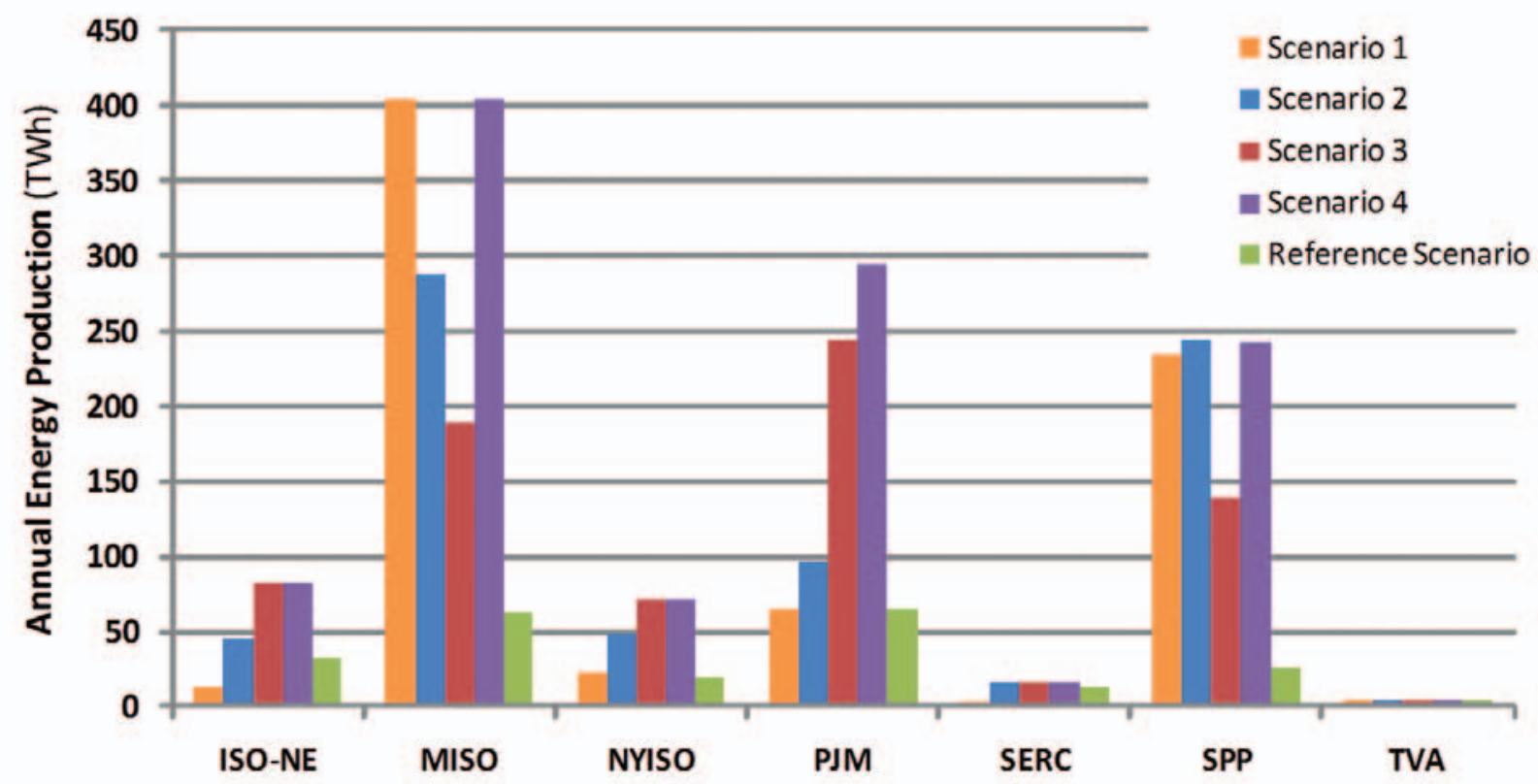

Figure 2-5. Annual energy production by region

Figure 2-6 shows the allocation of nameplate capacity for each region by scenario. 


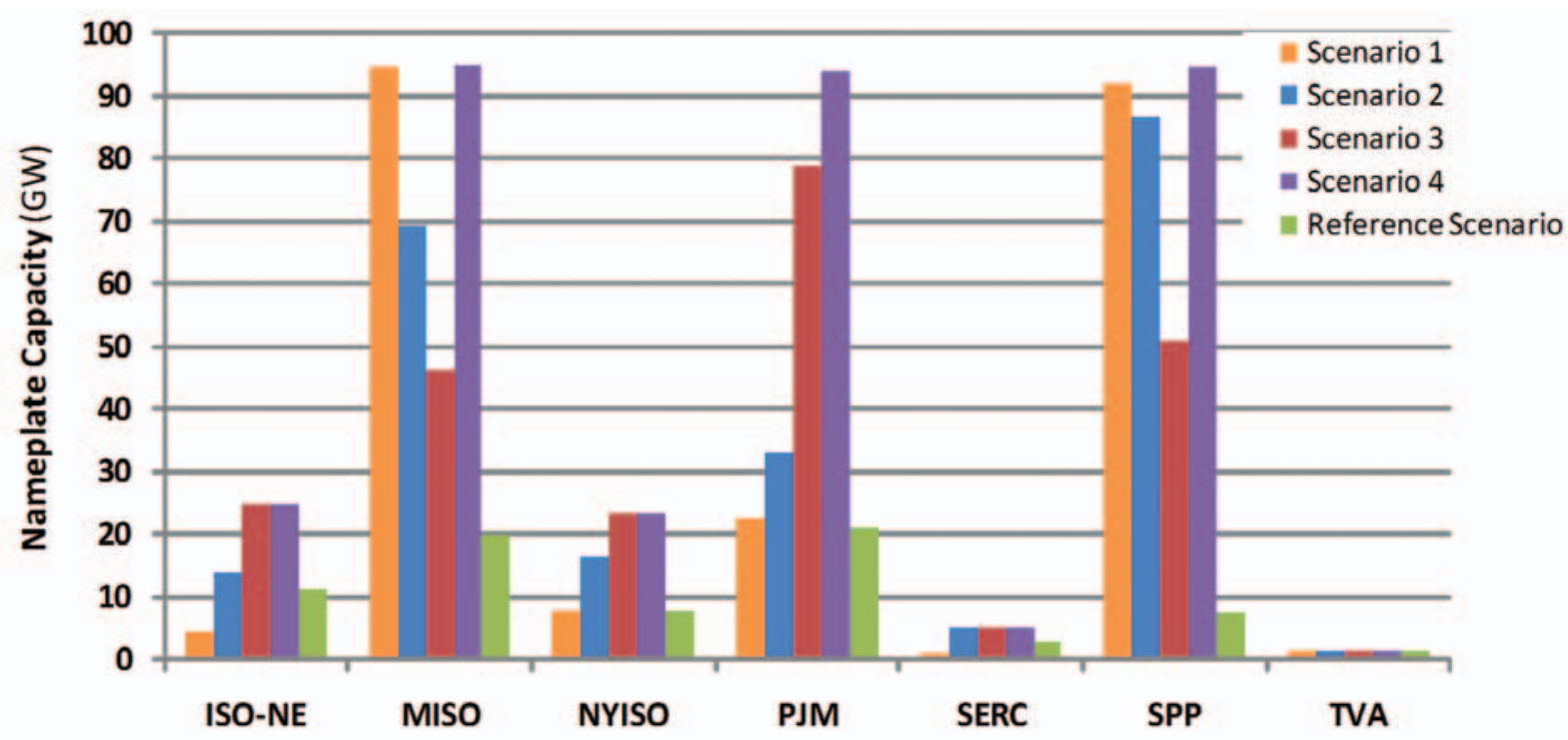

Figure 2-6. Nameplate capacity by region

\section{SCENARIO DETAILS}

The following sections give additional details for the five scenarios, including installed capacity by operating region, sizes and locations of plants, and state-bystate capacity.

\section{REFERENCE CASE}

This scenario is designed to approximate the current state of wind development plus some expected near-term development guided by interconnection queues and state RPS. This scenario totaled about $6 \%$ of the total 2024 projected load requirements for the Eastern Interconnection.

Table 2-3 lists capacity by operating region. Locations and sizes of individual plants are shown in Figure 2-7.

\begin{tabular}{|l|r|r|r|r|}
\hline \multicolumn{2}{|l|}{ TABLE 2-3. REFERENCE CASE, 6\% OF 2024 LOAD REQUIREMENTS } \\
\hline REGION & $\begin{array}{l}\text { ONSHORE } \\
\text { (MW) }\end{array}$ & $\begin{array}{l}\text { OFFSHORE } \\
\text { (MW) }\end{array}$ & $\begin{array}{l}\text { TOTAL } \\
\text { (MW) }\end{array}$ & $\begin{array}{l}\text { ANNUAL } \\
\text { ENERGY (TWH) }\end{array}$ \\
\hline ISO-NE & 8,310 & 3,000 & 11,310 & 33 \\
\hline MISO + SAPP & 19,732 & & 19,732 & 63 \\
\hline NYISO & 4,932 & 3,000 & 7,932 & 20 \\
\hline PJM & 19,402 & 1,620 & 21,022 & 65 \\
\hline SERC & 1,009 & 2,000 & 3,009 & 13 \\
\hline SPP & 7,419 & & 7,419 & 26 \\
\hline TVA & 1,247 & & 1,247 & 4 \\
\hline TOTAL & $\mathbf{6 2 , 0 5 1}$ & $\mathbf{9 , 6 2 0}$ & $\mathbf{7 1 , 6 7 1}$ & $\mathbf{2 2 4}$ \\
\hline
\end{tabular}




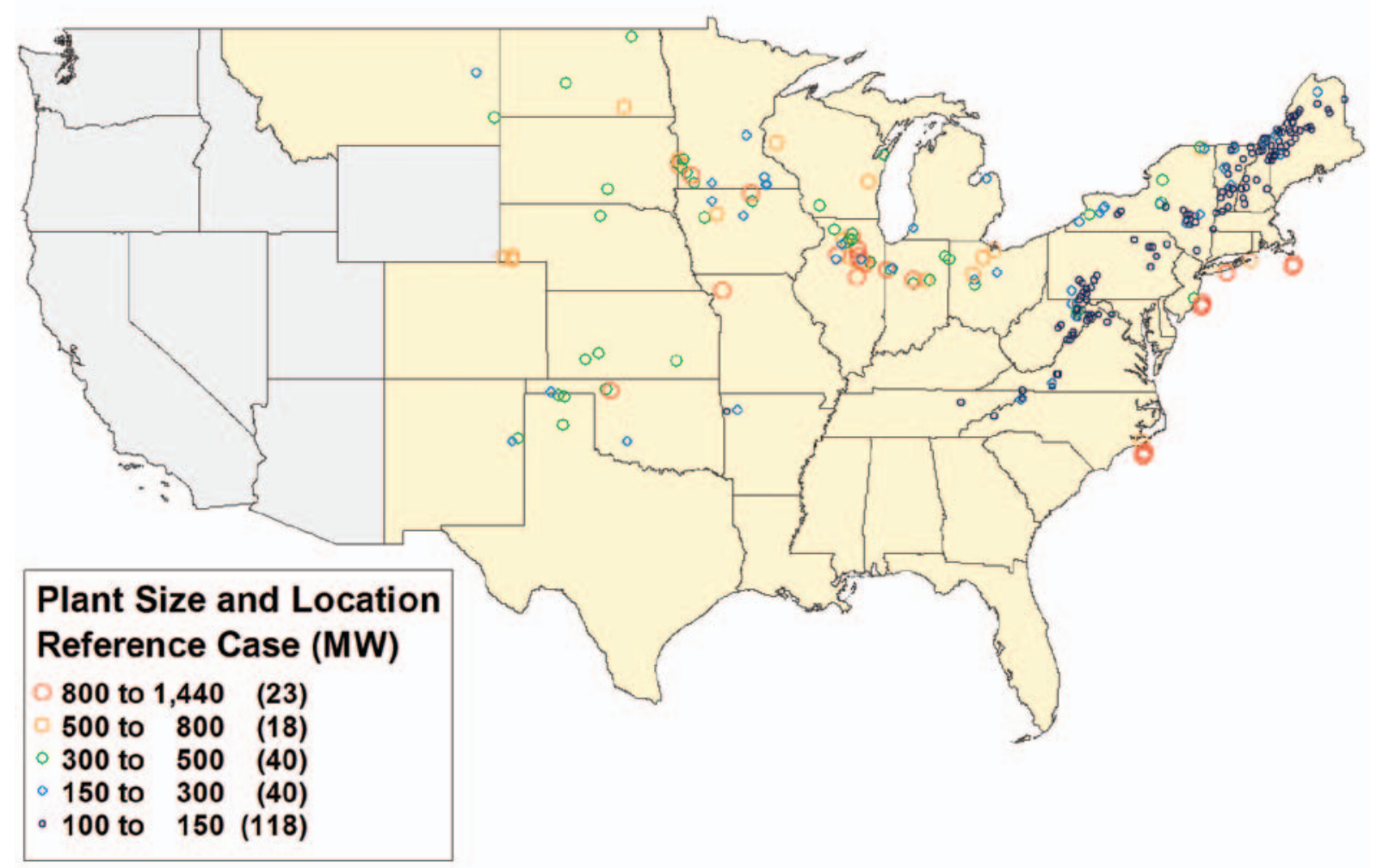

Figure 2-7. Wind plant size and location for Reference Case

\section{SCENARIO 1}

In general, this scenario exploits the onshore wind resources with high capacity factors across the interconnection. Consequently, it has the largest Great Plains wind capacity of the three $20 \%$ scenarios and takes advantage of the best onshore resources in the East.

Table 2-4 shows capacity by operating region. Locations and sizes of individual plants are shown in Figure 2-8. Figure 2-9 is a better visual illustration of stateby-state installed capacity.

\begin{tabular}{|l|r|l|l|r|}
\hline \multicolumn{7}{|l|}{ TABLE 2-4. SCENARIO 1-20\% HIGH CAPACITY FACTOR, ONSHORE } \\
\hline REGION & $\begin{array}{l}\text { ONSHORE } \\
\text { (MW) }\end{array}$ & $\begin{array}{l}\text { OFFSHORE } \\
\text { (MW) }\end{array}$ & $\begin{array}{l}\text { TOTAL } \\
\text { (MW) }\end{array}$ & $\begin{array}{l}\text { ANNUAL } \\
\text { ENERGY (TWH) }\end{array}$ \\
\hline ISO-NE & 4,291 & 0 & 4,291 & 13 \\
\hline MISO + SAPP & 94,808 & 0 & 94,808 & 404 \\
\hline NYISO & 7,742 & 0 & 7,742 & 22 \\
\hline PJM & 22,669 & 0 & 22,669 & 64 \\
\hline SERC & 1,009 & 0 & 1,009 & 3 \\
\hline SPP & 91,843 & 0 & 91,843 & 234 \\
\hline TVA & 1,247 & 0 & 1,247 & 4 \\
\hline TOTAL & $\mathbf{2 2 3 , 6 0 9}$ & $\mathbf{0}$ & $\mathbf{2 2 3 , 6 0 9}$ & $\mathbf{7 4 4}$ \\
\hline
\end{tabular}




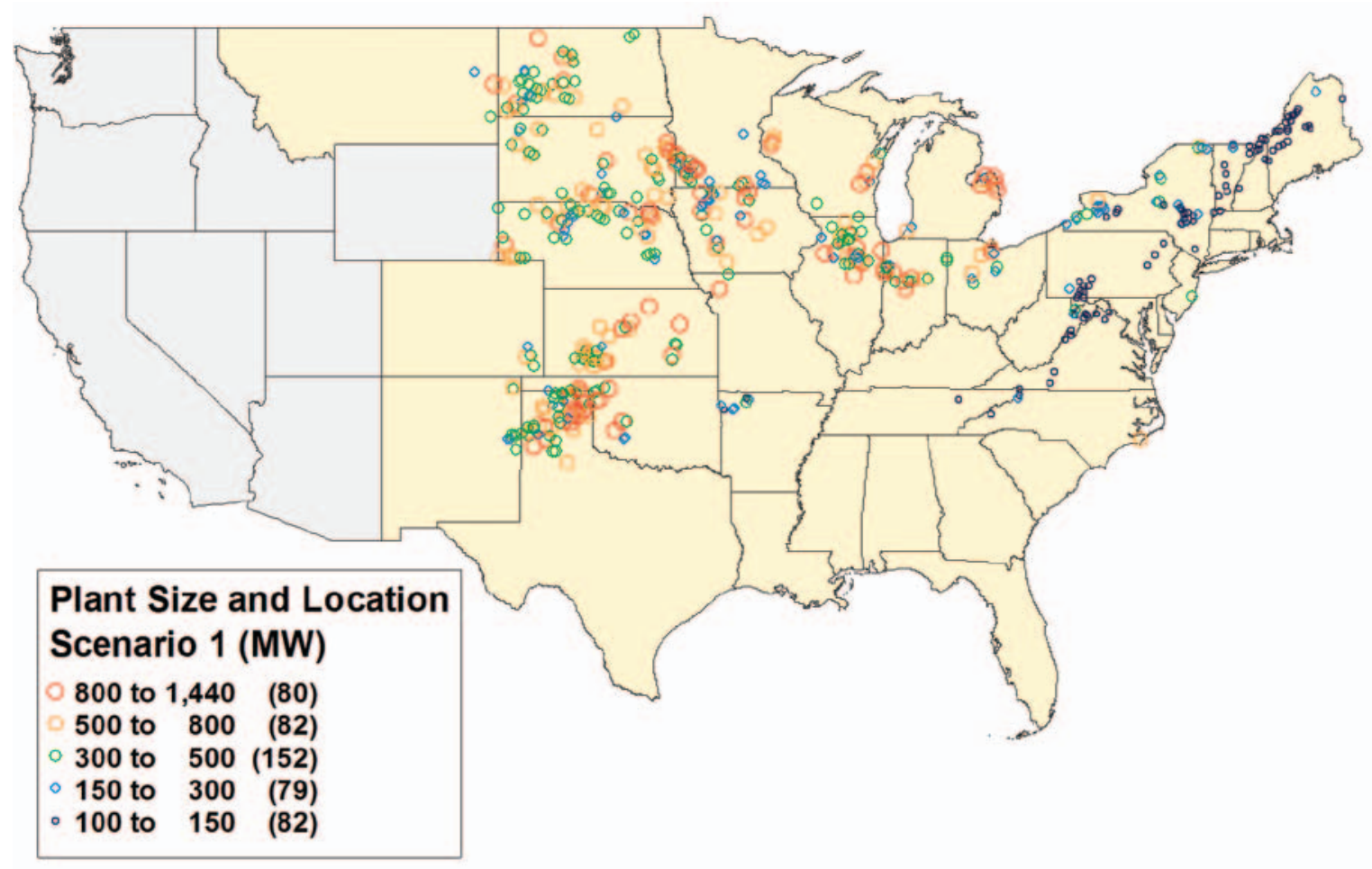

Figure 2-8. Installed capacity-Scenario 1

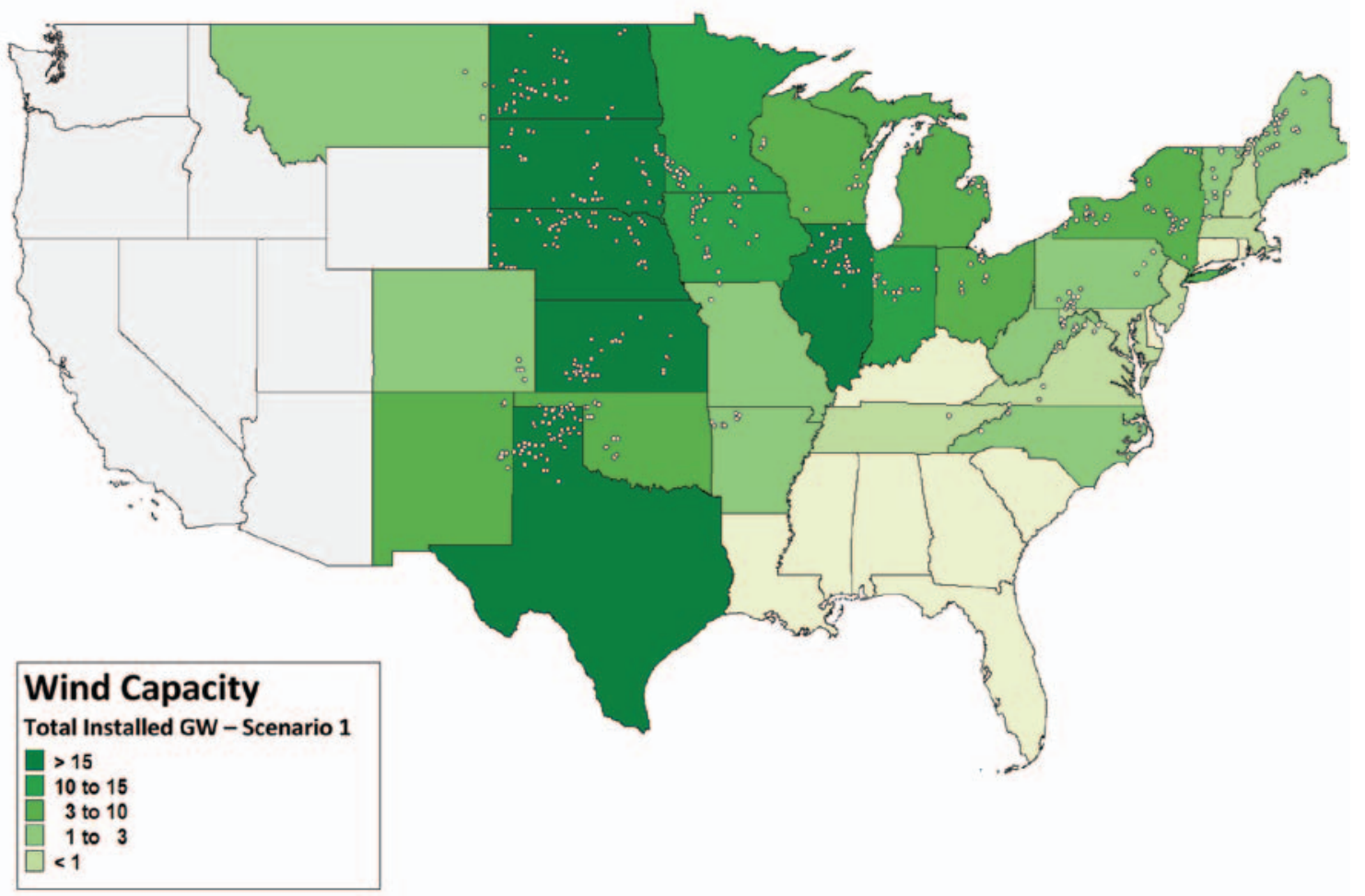

Figure 2-9. State map of nameplate capacity-Scenario 1 


\section{SCENARIO 2}

In Scenario 2, some of the wind generation from the Great Plains is moved eastward. In addition, a modest amount of offshore development is assumed off the East Coast.

This scenario corresponds most closely to a $20 \%$ scenario studied in a recent collaborative planning effort (JCSP 2008).

Table $2-5$ shows capacity by operating region. Figure $2-10$ shows locations and sizes of individual plants, and Figure 2-11 shows state-by-state installed capacity.

\begin{tabular}{|l|r|r|r|r|}
\hline \multicolumn{7}{|l|}{ TABLE 2-5. SCENARIO 2-20\% HYBRID WITH OFFSHORE } \\
\hline REGION & $\begin{array}{l}\text { ONSHORE } \\
\text { (MW) }\end{array}$ & $\begin{array}{l}\text { OFFSHORE } \\
\text { (MW) }\end{array}$ & $\begin{array}{l}\text { TOTAL } \\
\text { (MW) }\end{array}$ & $\begin{array}{l}\text { ANNUAL } \\
\text { ENERGY (TWH) }\end{array}$ \\
\hline ISO-NE & 8,837 & 5,000 & 13,837 & 46 \\
\hline MISO + SAPP & 69,444 & 0 & 69,444 & 288 \\
\hline NYISO & 13,887 & 2,620 & 16,507 & 48 \\
\hline PJM & 28,192 & 5,000 & 33,192 & 97 \\
\hline SERC & 1,009 & 4,000 & 5,009 & 16 \\
\hline SPP & 86,666 & 0 & 86,666 & 245 \\
\hline TVA & 1,247 & 0 & 1,247 & 4 \\
\hline TOTAL & $\mathbf{2 0 9 , 2 8 2}$ & $\mathbf{1 6 , 6 2 0}$ & $\mathbf{2 2 5 , 9 0 2}$ & $\mathbf{7 4 5}$ \\
\hline
\end{tabular}

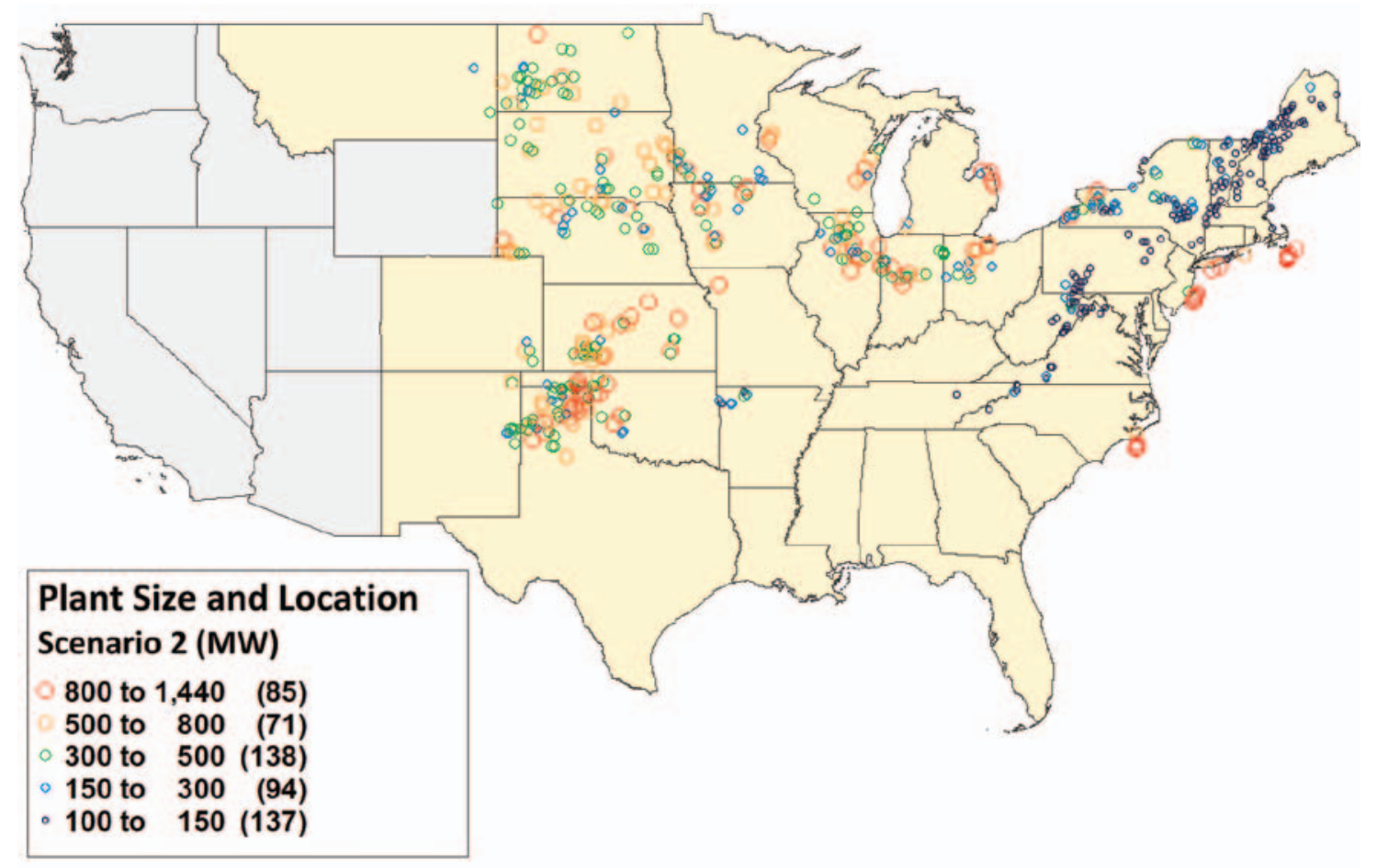

Figure 2-10. Installed capacity-Scenario 2 


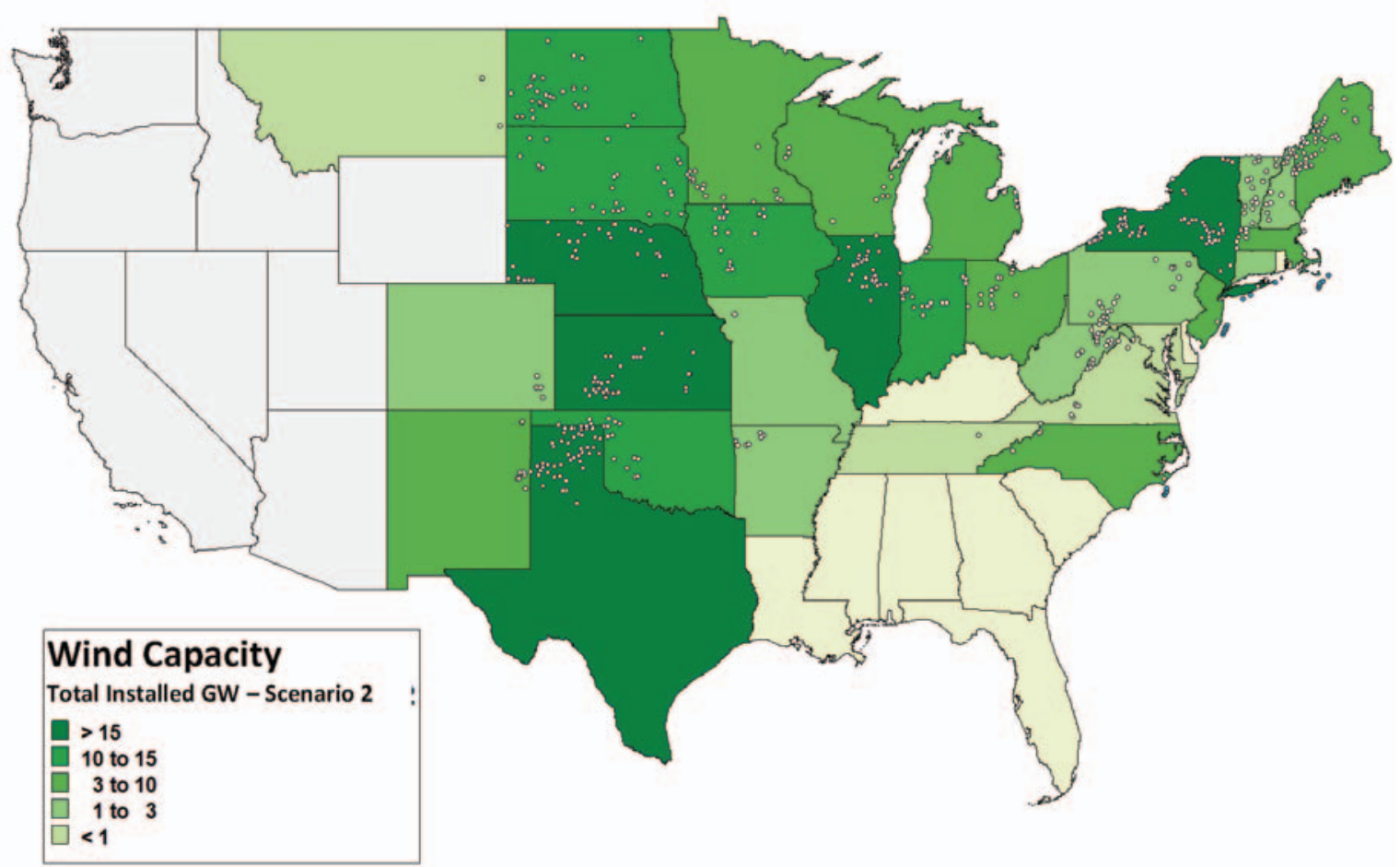

Figure 2-11. State map of nameplate capacity-Scenario 2

\section{SCENARIO 3}

To create a contrast with Scenario 1, a large amount of wind generation is moved from the Great Plains nearer to the East Coast load centers. To bring about this shift, a large amount of offshore wind generation is required.

Table 2-6 shows capacity by operating region. Locations and sizes of individual plants are shown in Figure 2-12, with the state-by-state illustration in Figure 2-13.

\begin{tabular}{|l|r|r|l|r|}
\hline TABLE 2-6. SCENARIO 3-20\% LOCAL, WITH AGGRESSIVE OFFSHORE \\
\hline REGION & $\begin{array}{l}\text { ONSHORE } \\
\text { (MW) }\end{array}$ & $\begin{array}{l}\text { OFFSHORE } \\
\text { (MW) }\end{array}$ & $\begin{array}{l}\text { TOTAL } \\
\text { (MW) }\end{array}$ & $\begin{array}{l}\text { ANNUAL } \\
\text { ENERGY (TWH) }\end{array}$ \\
\hline ISO-NE & 13,887 & 11,040 & 24,927 & 82 \\
\hline MISO + SAPP & 46,255 & 0 & 46,255 & 189 \\
\hline NYISO & 13,887 & 9,280 & 23,167 & 71 \\
\hline PJM & 38,956 & 39,780 & 78,736 & 244 \\
\hline SERC & 1,009 & 4,000 & 5,009 & 16 \\
\hline SPP & 50,958 & 0 & 50,958 & 139 \\
\hline TVA & 1,247 & 0 & 1,247 & 4 \\
\hline TOTAL & $\mathbf{1 6 6 , 1 9 9}$ & $\mathbf{6 4 , 1 0 0}$ & $\mathbf{2 3 0 , 2 9 9}$ & $\mathbf{7 4 6}$ \\
\hline
\end{tabular}




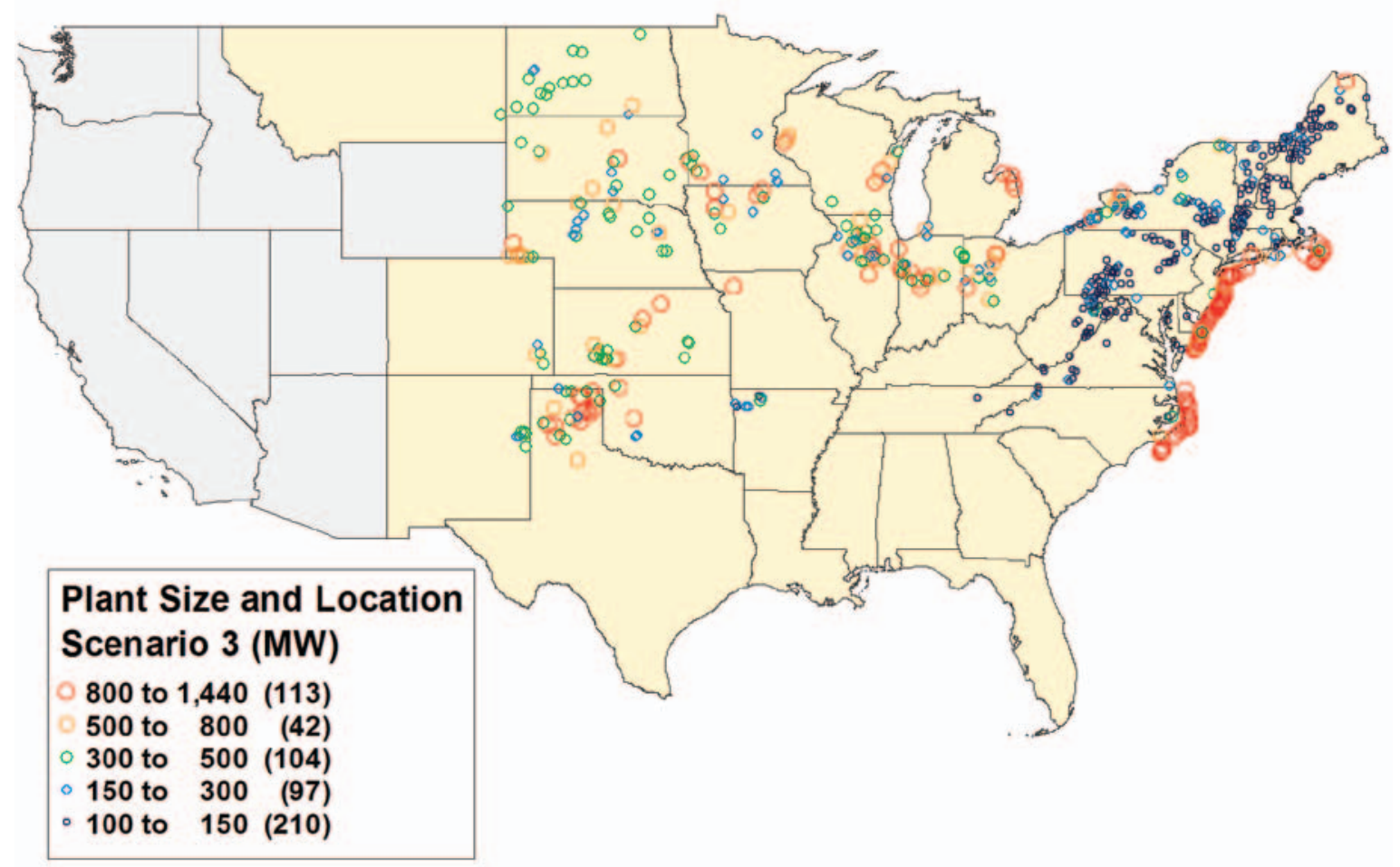

Figure 2-12. Installed capacity-Scenario 3

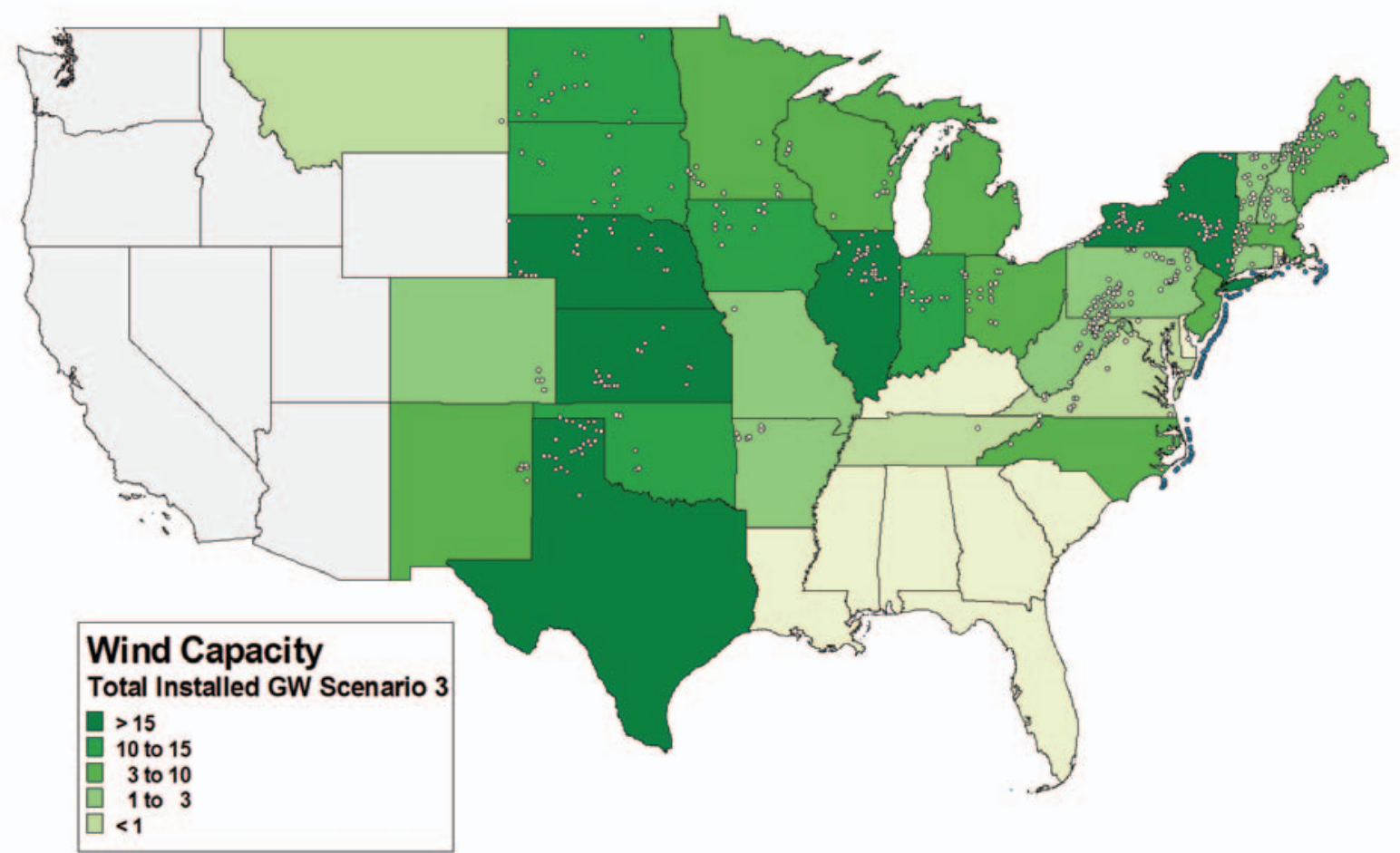

Figure 2-13. State map of nameplate capacity-Scenario 3 


\section{SCENARIO 4}

Reaching 30\% energy penetration requires more than $300 \mathrm{GW}$ of wind generation, and therefore uses a significant portion of the higher quality wind resources in the NREL database. A large amount of offshore wind is required, and the amounts in the Great Plains are comparable to Scenario 1.

Table 2-7 shows capacity by operating region. Locations and sizes of individual plants are shown in Figure 2-14, with the state-by-state illustration in Figure 2-15.

\begin{tabular}{|l|l|l|l|r|}
\hline \multicolumn{2}{|l|}{ TABLE 2-7. SCENARIO 4-30\% AGGRSSIVE ONSHORE AND OFFSHORE } \\
\hline REGION & $\begin{array}{l}\text { ONSHORE } \\
\text { (MW) }\end{array}$ & $\begin{array}{l}\text { OFFSHORE } \\
\text { (MW) }\end{array}$ & $\begin{array}{l}\text { TOTAL } \\
(\mathrm{MW})\end{array}$ & $\begin{array}{l}\text { ANNUAL } \\
\text { ENERGY (TWH) }\end{array}$ \\
\hline ISO-NE & 13,887 & 11,040 & 24,927 & 82 \\
\hline MISO + SAPP & 95,046 & 0 & 95,046 & 405 \\
\hline NYISO & 13,887 & 9,280 & 23,167 & 71 \\
\hline PJM & 38,956 & 54,780 & 93,736 & 295 \\
\hline SERC & 1,009 & 4,000 & 5,009 & 16 \\
\hline SPP & 94,576 & 0 & 94,576 & 243 \\
\hline TVA & 1,247 & 0 & 1,247 & 4 \\
\hline TOTAL & $\mathbf{2 5 8 , 6 0 8}$ & $\mathbf{7 9 , 1 0 0}$ & $\mathbf{3 3 7 , 7 0 8}$ & $\mathbf{1 , 1 1 6}$ \\
\hline
\end{tabular}

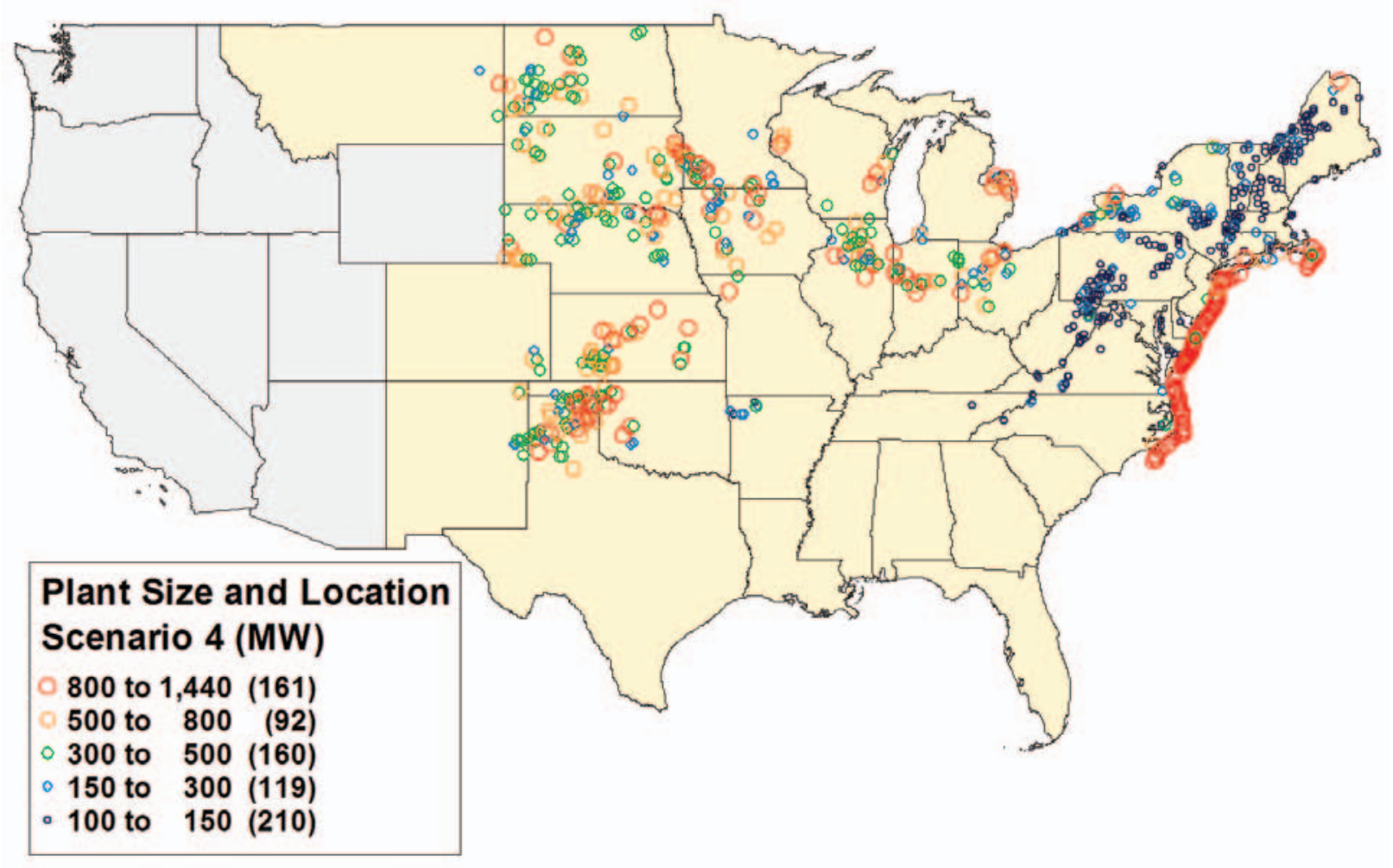

Figure 2-14. Installed capacity -Scenario 4 


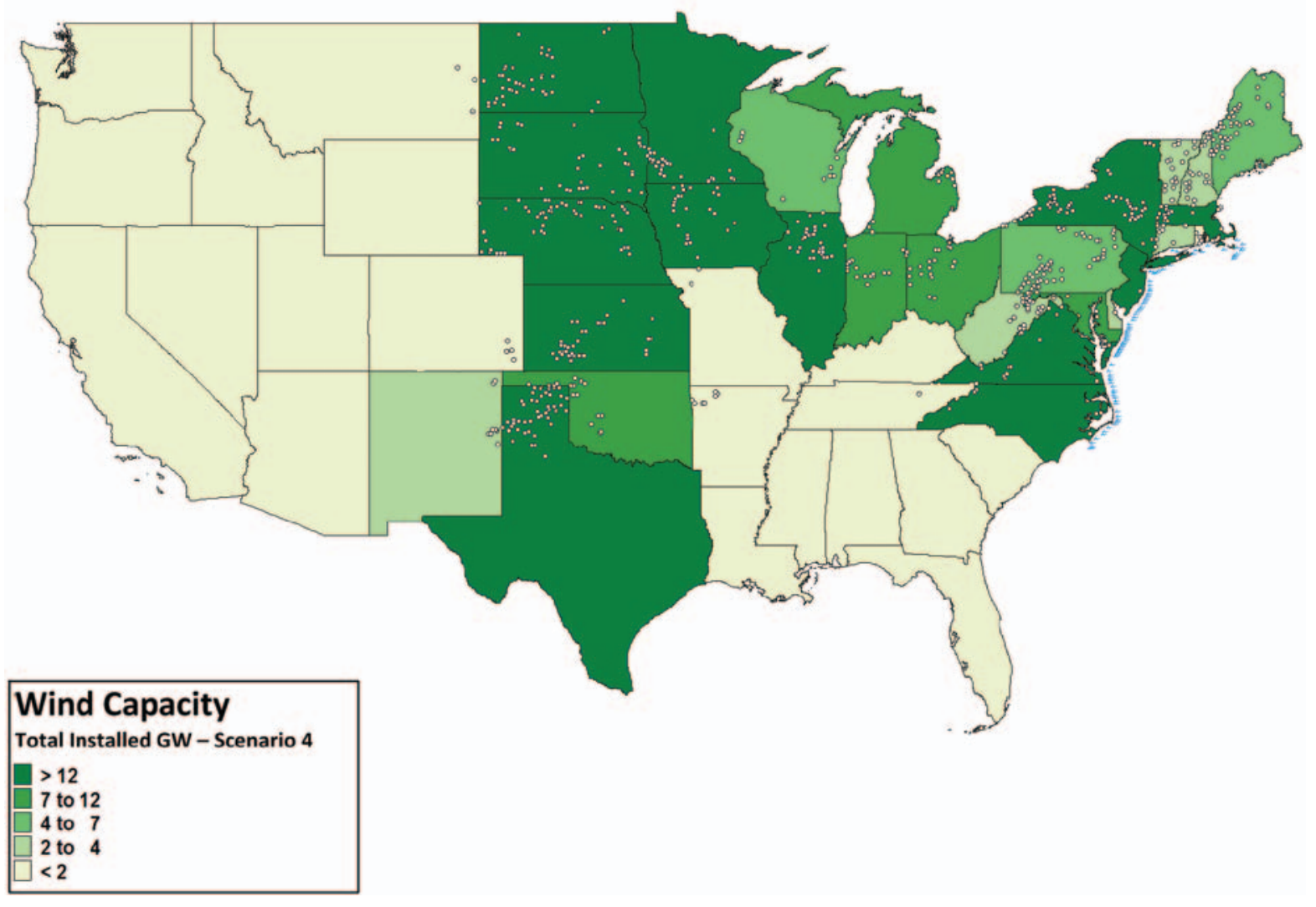

Figure 2-15. State map of nameplate capacity-Scenario 4 


\section{SECTION 3: ANALYTICAL METHODOLOGY: DATA, MODELS, AND TOOLS}

The study analysis focused on three major areas:

1. Developing conceptual transmission to accommodate the levels of wind generation as defined in the four scenarios described in Section 2.

2. Assessing the impacts of the wind generation in each scenario on grid operations in the Eastern Interconnection.

3. Determining the level to which wind generation in each scenario contributes to resource adequacy (i.e., its capacity value).

The analytical methods used in this study build on those established in previous integration studies conducted over the past 10 years (see, for example, EnerNex Corporation and Wind Logics 2004; Bai et al. 2007; GE Energy 2008).

A chronological data set of wind generation and load data is the critical input for EWITS. Load and wind data must be physically correlated because meteorology influences load patterns and is a critical factor for wind energy production.

Hourly load data from across the interconnection for years corresponding to the National Renewable Energy Laboratory's (NREL) mesoscale data were obtained as the starting point for developing a representation of Eastern Interconnection loads in 2024. The basic resolution for both load and wind data is 1 hour, although higher resolution (10-minute average) data are available from the mesoscale data for wind generation, and samples of higher resolution data were collected from operating entities in the Eastern Interconnection.

Figure 3-1 is an overview of the process and methodology used in EWITS. All the analytical methods use the chronological wind generation and load data over a 3-year period as inputs. Brief descriptions of the methods follow:

- Statistical analysis of wind generation and load data, separately and in combination, to assess impacts on operating reserves

- Chronological production simulations, which, if correctly structured, are used to simulate scheduling and operation of the power system

- Monte Carlo-based chronological resource adequacy assessment, which uses annual or multiannual hourly data for load and wind generation to determine the probability that available supply resources would not be able to meet demand. 


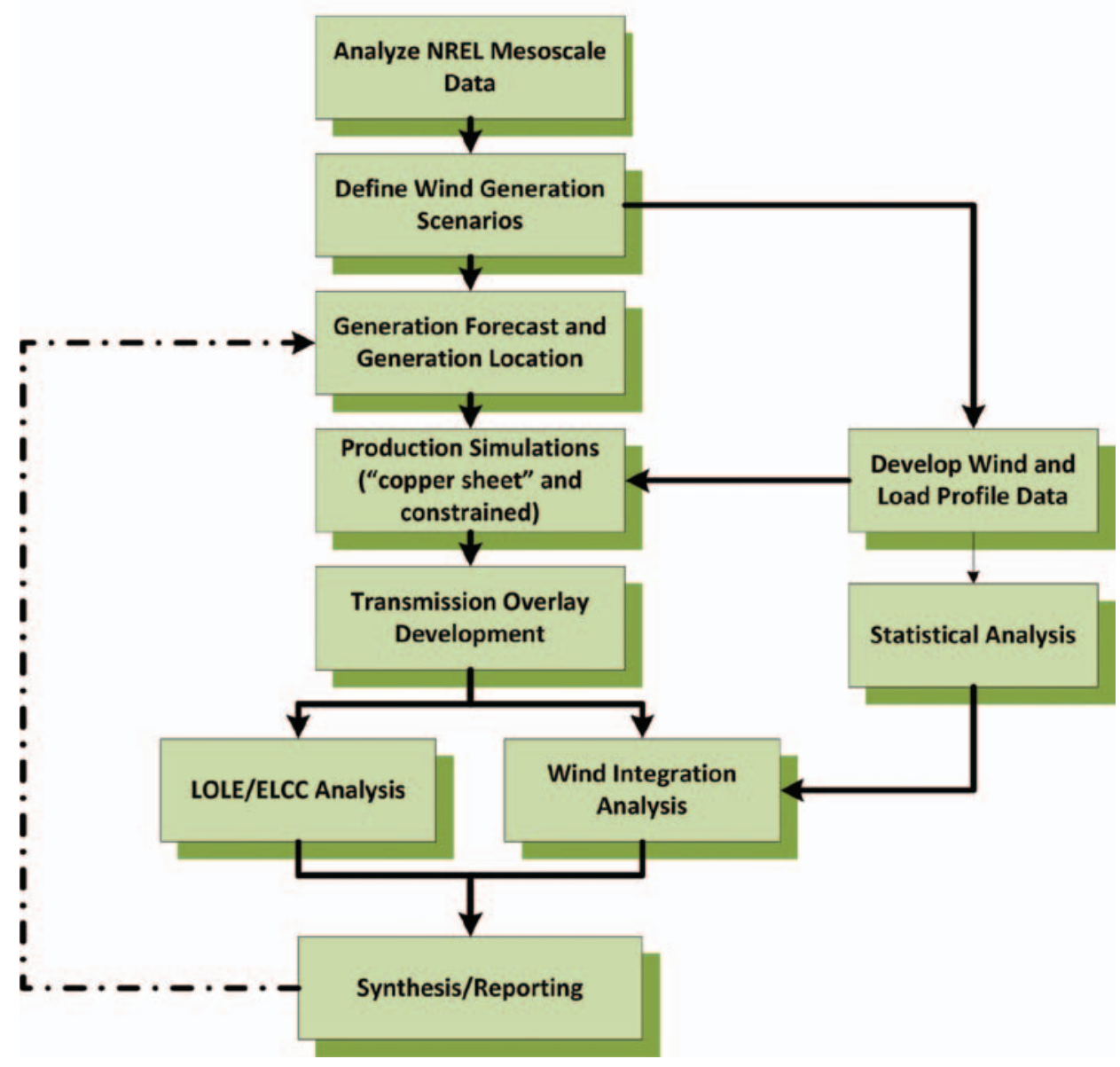

Notes: $L O L E=$ loss of load expectation; ELCC = effective load-carrying capability.

Figure 3-1. Overview of the study process

The consensus approach for assessing wind integration impacts is to simulate the scheduling and operation of the power system with wind generation over an extended period of time. If the hourly load and wind data that drive the simulation extend over a sufficient time frame, the range of conditions evaluated can be considered statistically valid. In other words, all combinations of wind and load and their respective variability and uncertainty characteristics are represented in the input data. This prevents focusing only on severe events, like major wind ramps, that would be expected infrequently.

The EWITS team used chronological production simulations in several aspects of the analysis:

- Development of the transmission overlays, where production simulations for the current system determine both the locations and the economic value of new transmission 
- Evaluation of operational impacts (where scheduling and real-time system operations are mimicked as closely as possible and details such as incremental operating reserves required to manage wind generation and increased uncertainty caused by wind generation forecast errors are considered directly)

- Determination of new area import limits with expanded transmission for evaluation of wind generation and new transmission contributions to resource adequacy.

The chronological wind and load data also support the preferred approach for assessing wind generation contributions to resource adequacy. With a chronological, Monte Carlo-based, probilistic resource adequacy assessment tool, the effects of wind generation on planning capacity margin can be calculated directly. Comparing these results to one without wind generation determines the specific contribution of the defined wind generation.

\section{MODEL DEVELOPMENT}

EWITS focuses on calendar year 2024. All the analytical elements are based on a model of what the Eastern Interconnection would look like in that year.

\section{ELECTRICAL REPRESENTATION OF THE EASTERN INTERCONNECTION}

The EWITS analysis depended on three sets of data that represent the electrical infrastructure of the Eastern Interconnection: load, transmission network, and generation. The Joint Coordinated System Plan (JCSP 2008) was an earlier effort to produce analytics of the electrical infrastructure that ignored regional transmission organization (RTO) and balancing authority seams while working under a common set of assumptions. The JCSP process included open stakeholder involvement in developing assumptions and verifying the base data. This open process gave all stakeholders the opportunity to review the information and make appropriate changes to the data to better reflect the system. This reviewed data set consists of forecast loads, along with planned and existing generation, and incorporates existing transmission development plans (or concepts) to supplement the existing transmission infrastructure.

Because a large amount of effort went into compiling and reviewing these data, the data were an appropriate starting point for this study.

\section{$\angle O A D$}

Demand for all study regions was originally based on the information within the PowerBase ${ }^{\mathrm{TM}}$ (a Ventyx product) database, which is based on the 2006 Federal Energy Regulatory Commission (FERC) Form 714, 2006 North American Electric Reliability Corporation (NERC) electricity supply and demand (ES\&D) information, and 2006 power flow data. The load data for all regions were 
benchmarked against various reporting entities within each region and were also given to all stakeholders during the JCSP participant review process. Through this process, some areas specifically adjusted demand and energy projections. Most areas, however, deemed the PowerBase data to be suitable for the study.

The PowerBase database contains annual peak demand for each company within an area or region. This demand value is applied to an hourly load profile for each company, developed from filed historical load data. The EWITS study team used hourly profiles representing 2004, 2005, and 2006. In the PowerBase database, each company has its own unique hourly profile, with each company experiencing its peak demand at different times of the year. The PROMOD IV® economic energy model uses company-specific detail for demand and energy; however, because the Electric Generation Expansion Analysis System (EGEAS; from the Electric Power Research Institute [EPRI]) expansions are performed on a regional basis (see Section 3.3), the EWITS team had to aggregate each individual company's peak demand and determine a peak coincident factor for each study region. This was accomplished by summing the individual hourly peaks for each company for all 8,760 hours in the year, using the 2004 annual profiles. The maximum sum of the individual hourly peaks is the coincident peak for the year. Dividing the coincident peak by the sum of the individual company peaks gives a regional coincident factor, as seen in Table 3-1.

Just like the demand assumptions, annual energy values are also available from the PowerBase database. The EWITS team reviewed and checked the values to determine whether they needed update or verification.

\begin{tabular}{|c|c|c|c|c|c|c|}
\hline REGION & $\begin{array}{l}\text { STUDY } \\
\text { REGION } \\
\text { COINCIDENCE } \\
\text { FACTOR }\end{array}$ & $\begin{array}{l}2008 \\
\text { NONCOINCI- } \\
\text { DENT PEAK } \\
\text { DEMAND } \\
(\mathrm{MW})\end{array}$ & $\begin{array}{l}2008 \\
\text { COINCIDENT } \\
\text { PEAK } \\
\text { DEMAND } \\
(\mathrm{MW})\end{array}$ & $\begin{array}{l}2008 \\
\text { ANNUAL } \\
\text { ENERGY } \\
\text { (GWH) }\end{array}$ & $\begin{array}{l}\text { REFERENCE } \\
\text { ANNUAL } \\
\text { DEMAND } \\
\text { ESCALATION } \\
(\%)\end{array}$ & $\begin{array}{l}\text { REFERENCE } \\
\text { ANNUAL } \\
\text { ENERGY } \\
\text { ESCALATION } \\
(\%)\end{array}$ \\
\hline ENTERGY & 0.9947 & 27,712 & 27,565 & 142,362 & 1.80 & 1.66 \\
\hline ISO-NE & 0.9892 & 28,227 & 27,923 & 1335,776 & 2.27 & 1.69 \\
\hline MISO & 0.9343 & 115,862 & 108,254 & 590,662 & 1.28 & 1.50 \\
\hline MAPP & 0.9608 & 9,915 & 9,526 & 49,941 & 1.20 & 1.61 \\
\hline NYISO & 0.9428 & 35,064 & 33,057 & 171,054 & 0.92 & 0.77 \\
\hline PJM & 0.9497 & 142,826 & 135,637 & 717,468 & 1.90 & 1.65 \\
\hline SERC & 0.9828 & 96,071 & 94,421 & 472,752 & 2.37 & 2.04 \\
\hline SPP & 0.9798 & 47,478 & 46,519 & 220,543 & 1.34 & 1.77 \\
\hline TVA & 0.9858 & 47,633 & 46,955 & 257,337 & 2.27 & 0.89 \\
\hline
\end{tabular}

Notes: $M W=$ megawatts; GWh = gigawatt-hours; ISO-NE = New England ISO; NYISO = New York ISO; MISO = Midwest ISO (shortened to MISO in figures and tables because of space considerations); MAPP = Mid-Continent Area Power Pool; PJM = PJM Interconnection (shortened to PJM because of space considerations); SERC = Southeastern Electric Reliability Council; SPP = Southwest Power Pool; TVA = Tennessee Valley Authority. 


\section{NETWORK}

The EWITS study relies on the 2018 power flow model that was developed during the participant review process for a previous study of the Eastern Interconnection (JCSP 2008). The Eastern Interconnection Reliability Assessment Group Multi-Regional Modeling Working Group (ERAG MMWG) 2007 Series 2018 summer peak power flow model was used as the starting point for the development. To better represent the latest and most accurate transmission system for the study, the power flow model was reviewed and updated by study stakeholders to incorporate planned or proposed transmission projects.

\section{GENERATION}

The EWITS study used the PowerBase software as its platform for existing unit generator information. In addition to benchmarking its generator data, some asset owners supplied additional information, and the study team added the information to the database before model population. Stakeholders gave comments on adjusted capacities, ownership, in-service dates, and unit operational status. Building on the generators in the default PowerBase database, change cases were created to reflect the existing and future generation fleet. Each generator in the database or in a queue was assigned a status of active, planned, future, or canceled, as described in Table 3-2.

\begin{tabular}{|l|l|}
\hline \multicolumn{2}{|l|}{ TABLE 3-2. STATUS CATEGORIES APPLIED TO ALL UNITS WITHIN THE DATABASE } \\
\hline STATUS & GENERATOR STATUS DESCRIPTION \\
\hline ACTIVE & $\begin{array}{l}\text { Existing online generation, including committed and uncommitted units. Does not include generation } \\
\text { that has been mothballed or decommissioned. }\end{array}$ \\
& $\begin{array}{l}\text { A generator that is not online, has a future in-service date, is not suspended or postponed, and has } \\
\text { proceeded to a point where construction is almost certain. Examples would include generators for } \\
\text { which an Interconnection Agreement has been signed, all permits have been approved, all study } \\
\text { work has been completed, state or administrative law approval has been obtained, and so on. One } \\
\text { exception to this rule is the inclusion of recently proposed nuclear expansions throughout the Eastern } \\
\text { Interconnection. Although the units do not qualify as "planned" units, JCSP participants felt strongly } \\
\text { that the units be considered as part of the planned generation fleet. These units are used in the model } \\
\text { to meet future demand requirements before the economic expansions. All units coming online between } \\
\text { August 2007 and July 2008 show up as newly installed in 2008. }\end{array}$ \\
\hline FUTURE & $\begin{array}{l}\text { Generators with a future online date that do not meet the criteria of the planned status. Generators } \\
\text { with a future status typically fall under one of the following categories: proposed, feasibility studies in } \\
\text { progress, applications for permits submitted, and so on. These generators are not used in the models } \\
\text { but are considered in the siting of future generation. }\end{array}$ \\
\hline CANCELED & \begin{tabular}{l} 
Generators that have been suspended, canceled, retired, or mothballed. \\
\hline
\end{tabular} \\
\hline
\end{tabular}

Table 3-3 summarizes active generation with the nameplate capacity described by region and generator unit type. Table 3-4 gives a summary of capacity additions planned between 2010 and 2024. Finally, Table 3-5 summarizes the generation that is planned to retire before 2024 . 


\begin{tabular}{|c|c|c|c|c|c|c|c|c|c|c|c|}
\hline 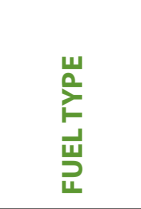 & 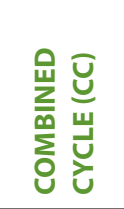 & 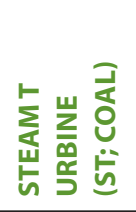 & 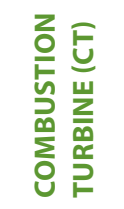 & 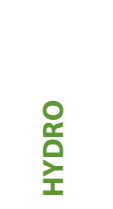 & U్ & 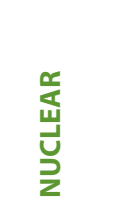 & $\frac{n}{n}$ & 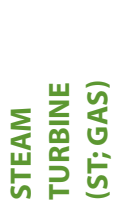 & 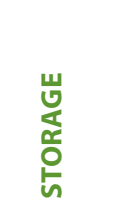 & $\frac{\mathrm{Q}}{\mathrm{z}}$ & $\stackrel{\frac{1}{6}}{\circ}$ \\
\hline ENTERGY & 13,422 & 5,919 & 3,446 & 691 & & 5,182 & 95 & 15,760 & 28 & & 44,543 \\
\hline ISO-NE & 12,610 & 3,195 & 2,614 & 1,734 & & 4,389 & 935 & 6,932 & 1,675 & 70 & 34,154 \\
\hline MISO & 10,709 & 69,843 & 27,398 & 1,408 & 282 & 10,282 & 286 & 3,918 & 2,475 & 2,862 & 129,462 \\
\hline MAPP & 1,077 & 7,319 & 2,142 & 2,449 & & 891 & & 24 & & 498 & 14,400 \\
\hline NYISO & 8,699 & 3,092 & 5,994 & 4,356 & & 5,069 & 289 & 11,898 & 1,280 & 42 & 40,716 \\
\hline PJM & 24,484 & 70,656 & 30,974 & 2,647 & & 30,769 & 669 & 9,253 & 3,625 & 514 & 173,590 \\
\hline SERC & 17,501 & 44,948 & 23,638 & 6,261 & & 17,151 & 147 & 1,169 & 3,844 & & 114,659 \\
\hline SPP & 11,059 & 23,426 & 8,932 & 2,570 & & 2,056 & 56 & 12,943 & 296 & 2,001 & 63,338 \\
\hline TVA & 7,761 & 27,189 & 11,641 & 5,074 & & 7,117 & & & 1,712 & 79 & 60,574 \\
\hline TOTAL & 197,322 & 255,587 & 116,779 & 27,191 & 282 & 82,906 & 2,473 & 61,896 & 14,935 & 6,065 & 675,435 \\
\hline
\end{tabular}

${ }^{a}$ GCC $=$ integrated gasification combined cycle

\begin{tabular}{|c|c|c|c|c|c|c|c|c|c|c|c|}
\hline 嵌 & U & 七 & 七 & 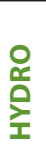 & U্ত & 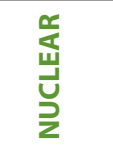 & $\frac{n}{\frac{n}{n}}$ & $\frac{\sqrt[n]{0}}{\sqrt[0]{n}}$ & 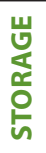 & $\stackrel{0}{z}$ & 홍 \\
\hline ENTERGY & 18,00 & 1,585 & & & & 3,000 & & & & & 6,385 \\
\hline ISO-NE & 110 & & 70 & & & & 50 & & & 607 & 837 \\
\hline MISO & 2,235 & 3,972 & 374 & & & 4,163 & & & & 597 & 11,340 \\
\hline MAPP & & & & & & & & & & 90 & 90 \\
\hline NYISO & 640 & & 1,100 & & & 1,600 & & & & 460 & 3,800 \\
\hline PJM & 1,127 & 92 & & & 2,071 & 4,706 & & & & 862 & 8,858 \\
\hline SERC & 1,652 & 500 & 280 & & & 8,848 & & & & & 11,280 \\
\hline SPP & 500 & 2,995 & 1,407 & & & & & & & 2,748 & 7,380 \\
\hline TVA & 660 & 549 & 340 & & 677 & 3,460 & & & & 50 & 5,736 \\
\hline TOTAL & 8,724 & 9,692 & 3,571 & & 2,748 & 25,777 & 50 & & & 5,144 & 55,705 \\
\hline
\end{tabular}




\begin{tabular}{|c|c|c|c|c|c|c|c|c|c|c|c|}
\hline 岀 & u & 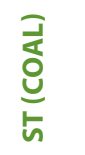 & 七 & 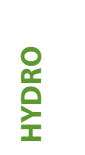 & $\underline{\underline{U}}$ & 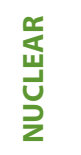 & $\begin{array}{l}\tilde{y} \\
\frac{\tilde{c}}{\infty} \\
\frac{0}{\infty}\end{array}$ & $\begin{array}{l}\bar{n} \\
\underline{\underline{v}} \\
5\end{array}$ & 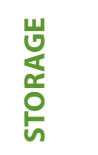 & $\stackrel{0}{3}$ & $\begin{array}{l}\text { 모 } \\
\text { 음 }\end{array}$ \\
\hline ENTERGY & & & & & & & & & & & 0 \\
\hline ISO-NE & & & & & & & & & & & 0 \\
\hline MISO & & 561 & & & & & & & & & 561 \\
\hline MAPP & & & & & & & & & & & 0 \\
\hline NYISO & & 177 & 825 & & & & & & & & 1,002 \\
\hline PJM & & 615 & 868 & & & & & & & & 1,483 \\
\hline SERC & & & 62 & & & & & & & & 62 \\
\hline SPP & & & & & & & & & & & 0 \\
\hline TVA & & & & & & & & & & & 0 \\
\hline TOTAL & c & 1,353 & 1,755 & 0 & c & ( & & 0 & 0 & 0 & 3,108 \\
\hline
\end{tabular}

\section{TOOLS}

The project team used three software tools to support the various analytical elements of the study. All are established tools in the electrical energy industry; their basic purpose and functions are described next.

\section{PROMOD IV OVERVIEW}

PROMOD IV is an integrated electric generation and transmission market simulation system that incorporates extensive details of generating unit operating characteristics and constraints, transmission constraints, generation analysis, unit commitment/operating conditions, and market system operations. It performs an 8,760-hour commitment and dispatch recognizing both generation and transmission impacts at the bus-bar (nodal) level. PROMOD IV forecasts hourly energy prices, unit generation, fuel consumption, bus-bar energy market prices, regional energy interchange, transmission flows, and congestion prices. It uses an hourly chronological dispatch algorithm that minimizes costs while simultaneously adhering to a variety of operating constraints, including generating unit characteristics, transmission limits, fuel and environmental considerations, spinning reserve requirements, and customer demand.

\section{TRANSMISSION SYSTEM REPRESENTATION}

PROMOD IV captures the constraints and limitations inherent in electrical power transmission using a DC load flow algorithm. All major transmission equipment is modeled-voltage transformers, phase-angle regulators, DC ties, generation and load buses, and transmission lines with reactance and resistance inputs. The transmission topology data are fully integrated with the commitment and dispatch algorithm so that generators are scheduled, started, and cycled while transmission constraints are enforced. PROMOD IV simultaneously optimizes the transmission, generation commitment, and unit dispatch for all 8,760 hours under security- 
constrained unit commitment (SCUC) and economic-dispatch rules. PROMOD IV also models transmission interfaces, enforcing bidirectional limits on groups of lines.

The PROMOD IV tool includes both summer and winter normal-state ratings on power flow branches and interfaces to enforce normal flow limits on the transmission system. In addition, PROMOD IV recognizes contingency constraints, so that the dispatch will still be feasible if the system experiences any of a set of contingency events or combination of events. A single defined contingency can represent multiple transmission lines or generator outages (e.g., $\mathrm{N}-1, \mathrm{~N}-2$, and more contingencies). Emergency ratings (summer and winter) on power flow branches and interfaces can be used to define additional energy that can flow on lines during contingency events. There are no program-imposed limitations on the number of contingencies or monitored lines.

An iterative approach is used to include the effects of marginal transmission losses in markets that have loss components in their locational marginal price (LMP) calculations. In each hour, actual dynamic losses are calculated line by line using a nonlinear solution, generators are penalized based on their incremental contribution to losses, and the simulation is repeated until the convergence tolerance is satisfied. PROMOD IV calculates the incremental loss at each bus and incorporates that marginal loss component into the bus LMP.

\section{UNIT DISPATCH}

PROMOD IV calculates dispatch lambdas for each unit capacity segment based on its variable costs, which include fuel (commodity, handling, and transportation); emissions; and operations and maintenance (O\&M). Based on the reactance of the connected transmission lines, shift factors are calculated for each bus, so that injected generation will flow into the system while adhering to the physical characteristics of the grid. PROMOD IV incorporates each generator's costs, shift factors, and ramp rate limits into a linear program to optimize the dispatch across the entire system for each hour, honoring transmission constraints within a full security-constrained economic dispatch.

\section{UNIT COMMITMENT}

A multipass process is employed to establish day-ahead unit commitment for each generator based on forecast energy prices at the generator injection bus. Unit characteristics captured in the commitment and dispatch include multisegment operation, minimum capacity, ramp-up and ramp-down limits, start-up costs, minimum runtime and downtime constraints, and operating reserve contribution. The unit-commitment process also captures system operational effects, including transmission congestion, marginal losses, phase angle regulators, DC line operation, regional interchange, and tariffs. PROMOD IV also co-optimizes spinning reserve decisions within hourly dispatch. The following paragraphs describe the steps in the unit-commitment and dispatch solution. 
First, a preliminary unit dispatch is performed without enforcing unit runtime and downtime constraints, ramp rates, and start-up cost effects. This preliminary solution is designed to create a starting point for the price of energy in each hour that is not subject to multihour commitment constraints. This dispatch incorporates a full view of transmission congestion and other detailed operations. Wind units can be set up to be dispatched in the preliminary solution by designating them as "Firm" resources, or they can be excluded in the preliminary price formation by designating them as "Non-Firm." The preliminary dispatch is performed for a 7-day period, starting Monday at 1:00 a.m. and ending Sunday at 12:00 p.m. (midnight). This gives each generation injection site (bus) a unique 168-hour forecast for energy prices. The 168-hour look-ahead from Monday to Sunday is designed to be long enough to account for unit-commitment decisions based on multiday constraints (e.g., 48-hour minimum downtime).

The second step in the unit-commitment process is to optimize the operation of each generator given the price forecast at its bus, subject to unit-specific operating constraints and unit bid (or cost) inputs. A mixed-integer program is used to optimize unit profit. If energy prices are higher than the unit bid in a given hour, it is assumed the unit must be committed in that hour for load or reliability, and the program optimizes the run schedule for the surrounding hours to meet runtime constraints and maximize profits or minimize losses. If a unit runs at a loss for any day (including start-up cost), a new unit bid is calculated by determining the price increase needed to allow the unit to break even over the given run period. This new bid is added to the unit cost from the preliminary unit dispatch for the next dispatch pass. Each unit is processed individually based on the forecast prices at its injection bus. The unit commitment is done for the entire week without knowing if any forced outages will occur. If a forced outage does transpire during the week, the rest of the week is re-optimized from the hour in which the unit returns to service.

When all units have been processed, a second complete dispatch pass is done with all unit constraints in place and all commitment bid adders applied. The second dispatch results in a new forecast of bus prices and the commitment is reoptimized for each unit within the mixed-integer program to reflect the effect of unit operating constraints and bids on bus prices. This final commitment is then "locked in" for the final dispatch pass.

During the final dispatch, the commitment schedule from the final mixed-integer solution for each unit is honored. The final dispatch also includes any Non-Firm resources that were not included in the preliminary passes. The dispatch process itself is a linear program optimization that includes a DC load flow solution to monitor flows on transmission lines, calculates and applies marginal loss factors at each generation node, recognizes market import-export tariffs, and cooptimizes for spinning reserve requirements. 
In the EWITS Reference Scenario, the day-ahead wind forecast profiles are input as Firm resources, thus affecting the nodal prices used for unit commitment. The wind error profiles are input as Non-Firm, causing them to be used only in the final dispatch, changing the wind profiles to match the actual wind vectors. This modeling creates the disconnect between day-ahead unit commitment and final hourly dispatch based on the uncertainty of the wind forecast. A similar approach is used to model the effects of load uncertainty.

\section{GE-MARS}

The study team used GE Energy's Multi-Area Reliability Simulation (GE-MARS) program to calculate reliability indices. GE-MARS is a transportation-style model based on a sequential Monte Carlo simulation that steps through time chronologically and produces a detailed representation of the hourly loads and hourly wind profiles in comparison with the available generation, in addition to interfacing between the interconnected areas.

GE-MARS calculates, by area or area group, the standard reliability indices of daily or hourly loss of load expectation (LOLE, in days per year or hours per year) and expected unserved energy (EUE, in megawatt-hours per year). For EWITS, the study team used the daily LOLE index to determine the effective load-carrying capability (ELCC) of wind generation.

The basic calculations are done at the area level, which is how much of the data are specified and aggregated. Loads, wind profiles, and generation are assigned to areas, and transfer limits are specified between areas. All the core data assumptions for the GE-MARS model come from PROMOD IV but are aggregated into the LOLE study areas.

\section{EGEAS}

The EGEAS software is used for long-term regional resource forecasting. EGEAS performs capacity expansions based on long-term, least-cost optimizations with multiple input variables and alternatives. Optimizations can be performed on a variety of constraints such as resource adequacy (loss-of-load hours), reserve margins, or emissions constraints. The EWITS study optimization is based on minimizing the 20-year capital and production costs, with a reserve margin requirement indicating when new capacity is required.

\section{ASSUMPTIONS}

To fully define the scenarios for the study year, the EWITS study team had to make a number of assumptions. And because any assumptions about a scenario 15 years in the future would be subject to differences of opinion and debate, many of the EWITS assumptions were drawn from the previous stakeholderdriven assessment of the Eastern Interconnection (JSCP 2008), which looked at the same year. Doing this allows EWITS to benefit from the significant amount 
of discussion and interaction that took place in that earlier effort to reach some agreement on what the Eastern Interconnection might look like in 2024.

\section{OPERATIONS IN THE EASTERN INTERCONNECTION}

Because the wind generation in the scenarios is not distributed evenly across the interconnection, either geographically or in a load-weighted sense, portions of the interconnection in the study scenarios have very high penetrations. These penetrations are well beyond the boundaries of actual experience with wind generation, resulting in effects on power system operation and control.

Previous wind integration studies (see Bibliography) offer some important conclusions relevant to defining the framework for operating the interconnection with these large penetrations of wind generation. One finding is that larger operating footprints allow the significant effects of geographic diversity on wind generation variability and uncertainty to be exploited. A second relevant finding is that the rules and processes that govern power system operations are an important factor in wind integration; structures that aggregate large amounts of load and generating resources into a single operational framework and encourage flexibility allow wind generation to be more easily integrated.

Currently, operations in a large portion of the Eastern Interconnection are under the auspices of five wholesale energy markets. For the 2024 study year, the study team assumed that these market footprints would remain, and that the other portions of the Eastern Interconnection explicitly represented in the model-TVA and portions of SERC — would operate in a manner similar to the market footprints.

A further assumption was made about the details of scheduling and operations processes in each of the operating areas. For purposes of production modeling, the team assumed that operations in each area had three major elements:

- A day-ahead unit-commitment process, where forecasts of load and wind generation for the next operating day are assessed through a SCUC evaluation. Currently, this step is performed some time following the day-ahead energy market clearing.

- A real-time or subhourly energy market, where participating units are economically dispatched on a frequent basis (5- to 10-minute intervals) based on short-term forecasts of net load (i.e., load minus wind generation).

- An ancillary services market that draws on many resources for the spinning and nonspinning reserves required for frequency support, balancing, and system security.

At present, not all of the operating areas in the study footprint operate in this manner. With the study horizon of 2024 and the strong trends in the industry in these directions, however, the assumption is appropriate for this type of study. 


\section{CAPACITY EXPANSION MODEL ASSUMPTIONS}

Performing energy flow analysis in an out-year model requires that the load and generation balance meet generation fleet resource adequacy requirements. Existing area generation queues do not typically have planned capacity beyond a 5- to 10-year window. This results in gaps for resource adequacy for modeling years further into the future. Therefore, these gaps need to be filled in with proxy capacity that supplements and supports the existing fleet and generation queues. This ensures not only a reliable generation fleet but also enough capacity to be dispatched within the economic energy model.

A regional resource forecast model estimates, on a consistent least-cost basis, the type and timing of new generation and energy efficiency resources that need to be incorporated into the planning models to maintain adequate reserves. For this purpose, the study team used EPRI's EGEAS model to develop regional resource forecasts for the 11 regions in the Eastern Interconnection. ${ }^{3}$ The Canadian provinces do participate in the PROMOD IV economic models, but do not require capacity expansion analysis because they have adequate resource availability. Appropriate resource adequacy is needed for all of these areas to avoid generation biases from one region to another, which would skew economic energy movement.

The study analyzed nine designated regions within the Eastern Interconnection, shown in Figure 3-2. All regions were studied as a whole with the exception of the Midwest ISO, which was divided into three study regions because the EGEAS software has a limitation of 1,000 thermal generating units and the Midwest ISO's footprint exceeds this limitation. The study adhered to the three existing Midwest ISO transmission expansion planning regions (Central, East, and West). The planning regions are the same as the existing regions. Each area is planned to have sufficient generation with the exception of specified interchange schedules and wind interchanges. From a capacity viewpoint, each area can supply its own needs.

3 The regions are MISO (which is divided into three regions), MAPP, SPP, TVA, PJM, SERC, Entergy, NYISO, and ISO$N E$. 


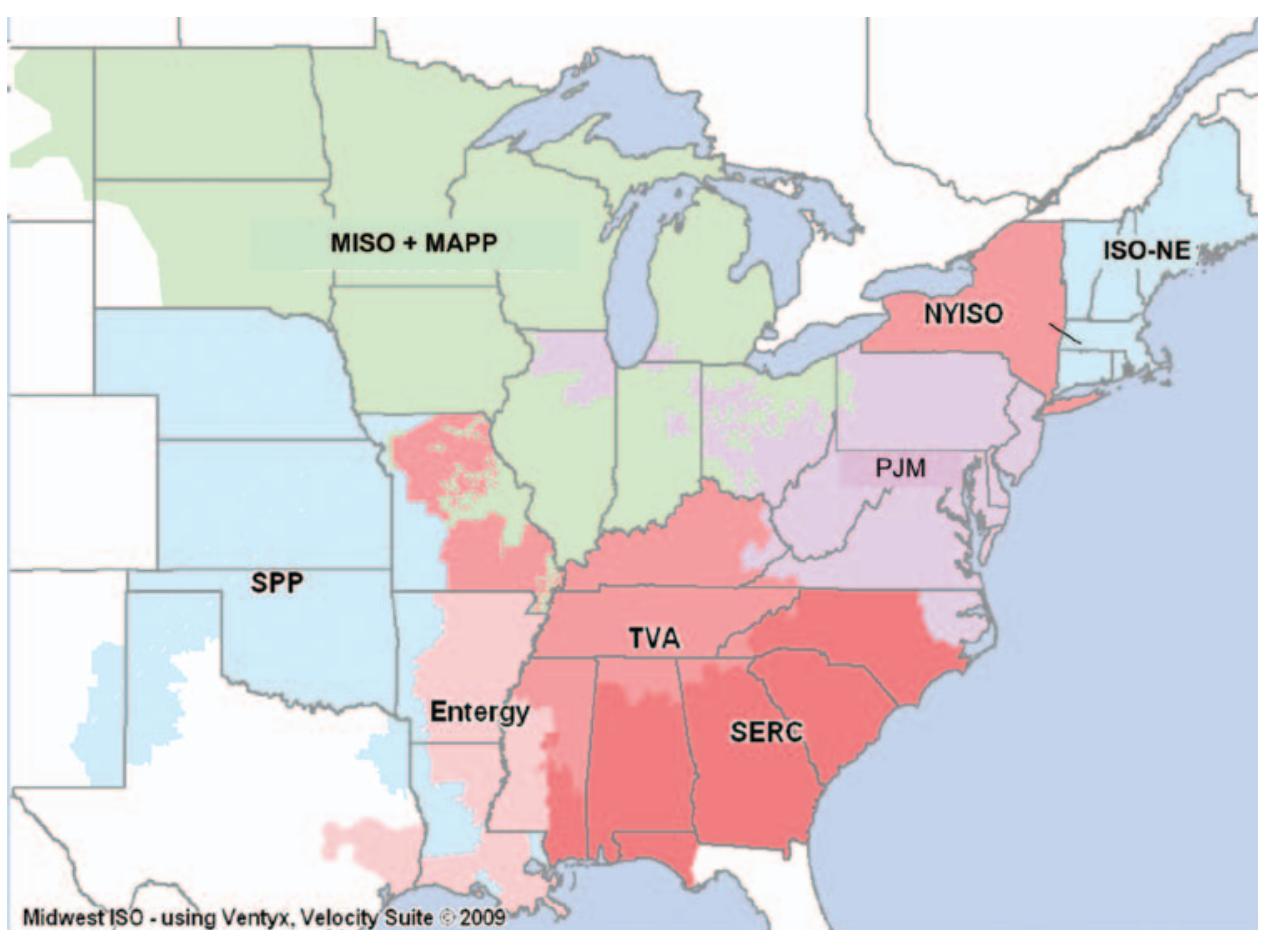

Figure 3-2. Study area

\section{FUTURE FUEL COSTS}

The economic models used with the EWITS study represent the generation fleet-unit by unit—for all regions. This modeling requires fuel cost projections for the entire fleet. Table 3-6 shows the 2008 average fuel costs modeled by region as well as the 2024 average cost. The fuel costs are a primary driver in the dispatch of generation within the energy models. The fuel cost assumptions were vetted through an earlier participant process. 


\begin{tabular}{|c|c|c|c|c|c|c|}
\hline SYSTEM & YEAR (UNIT) & COAL & $\begin{array}{l}\text { NATURAL } \\
\text { GAS }\end{array}$ & URANIUM & OIL HEAVY & OIL LIGHT \\
\hline \multirow{3}{*}{ ISO-NE } & $2008(\$ / M B T U)^{a}$ & 2.51 & 9.21 & 0.6 & 12.61 & 17.94 \\
\hline & 2024 (\$/MBTU) & 3.45 & 16.53 & 0.82 & 23.61 & 33.61 \\
\hline & ANNUAL GROWTH RATE (\%) & 2.01 & 3.72 & 1.97 & 4.00 & 4.00 \\
\hline \multirow{3}{*}{ MISO } & 2008 (\$/MBTU) & 1.61 & 8.35 & 0.66 & 12.61 & 17.94 \\
\hline & 2024 (\$/MBTU) & 2.2 & 15.67 & 0.91 & 23.61 & 33.61 \\
\hline & ANNUAL GROWTH RATE (\%) & 1.97 & 4.01 & 2.03 & 4.00 & 4.00 \\
\hline \multirow{3}{*}{ MAPP } & 2008 (\$/MBTU) & 1.13 & 8.06 & 0 & 12.61 & 17.94 \\
\hline & 2024 (\$/MBTU) & 1.55 & 15.38 & 0 & 23.61 & 33.61 \\
\hline & ANNUAL GROWTH RATE (\%) & 1.99 & 4.12 & 0 & 4.00 & 4.00 \\
\hline \multirow{3}{*}{ NYISO } & 2008 (\$/MBTU) & 2.19 & 8.98 & 0.52 & 12.61 & 17.94 \\
\hline & $2024(\$ / M B T U)$ & 3.01 & 16.3 & 0.71 & 23.61 & 33.61 \\
\hline & ANNUAL GROWTH RATE (\%) & 2.01 & 3.80 & 1.97 & 4.00 & 4.00 \\
\hline \multirow{3}{*}{ TVA } & 2008 (\$/MBTU) & 1.78 & 8.65 & 0.53 & 12.61 & 17.94 \\
\hline & 2024 (\$/MBTU) & 2.44 & 15.96 & 0.73 & 23.61 & 33.61 \\
\hline & ANNUAL GROWTH RATE (\%) & 1.99 & 3.90 & 2.02 & 4.00 & 4.00 \\
\hline \multirow{3}{*}{ SERC } & 2008 (\$/MBTU) & 2.14 & 8.5 & 0.5 & 12.61 & 17.94 \\
\hline & 2024 (\$/MBTU) & 2.94 & 15.81 & 0.68 & 23.61 & 33.61 \\
\hline & ANNUAL GROWTH RATE (\%) & 2.00 & 3.95 & 1.94 & 4.00 & 4.00 \\
\hline \multirow{3}{*}{ SPP } & 2008 (\$/MBTU) & 1.24 & 8.01 & 0 & 12.61 & 17.94 \\
\hline & 2024 (\$/MBTU) & 1.71 & 15.33 & 0 & 23.61 & 33.61 \\
\hline & ANNUAL GROWTH RATE (\%) & 2.03 & 4.14 & 0 & 4.00 & 4.00 \\
\hline \multirow{3}{*}{ PJM } & 2008 (\$/MBTU) & 2 & 8.81 & 0.54 & 12.61 & 17.94 \\
\hline & 2024 (\$/MBTU) & 2.74 & 16.12 & 0.74 & 23.61 & 33.61 \\
\hline & ANNUAL GROWTH RATE (\%) & 1.99 & 3.85 & 1.99 & 4.00 & 4.00 \\
\hline \multirow{3}{*}{ ENTERGY } & 2008 (\$/MBTU) & 1.47 & 8.29 & 0.55 & 12.61 & 17.94 \\
\hline & $2024(\$ / M B T U)$ & 2.02 & 15.54 & 0.76 & 23.61 & 33.61 \\
\hline & ANNUAL GROWTH RATE (\%) & 2.01 & 4.01 & 2.04 & 4.00 & 4.00 \\
\hline
\end{tabular}

${ }^{a}$ Millions of British thermal units

\section{PRODUCTION COST AND OTHER ECONOMIC ASSUMPTIONS}

The variable cost associated with supply of the energy to load is an important metric in EWITS. Production-related costs encompass fuel and O\&M, among others. With a large model consisting of multiple operating areas, the balance of energy transfers (imports and exports) in a given region may not sum to zero over the year. Consequently, the net "position" for the area is a function of more than just the raw cost of production.

Adjustments must be made to account for this transaction balance. Adjusted production cost (APC) for an annual period is defined as 
Annual APC $=$

$$
\begin{aligned}
& \sum_{i=l}^{8760} \sum_{j-l}^{M} C_{i j}+\sum_{i-l}^{8760} \text { Load_Weighted_LMP } P_{i} * \text { Purchase }_{i} \\
& -\sum_{i=1}^{8760} \text { Generator_Weighted_LMP } * \text { Sale }_{i}
\end{aligned}
$$

where

i represents each hour in a year of the study.

$\mathrm{C}_{\mathrm{ij}} \quad$ is the production cost of generator $\mathrm{j}$ during hour $\mathrm{i}$.

$\mathrm{M}$ is the number of total generators in the region.

Load_Weighted_LMP ${ }_{i}$ is load-weighted LMP during hour i.

Generator_Weighted_LMP ${ }_{\mathrm{i}}$ is generator weighted LMP during hour i.

Purchase $_{i}$ is a company's purchase of megawatts during hour i.

Sale $_{i}$ is a company's sale of megawatts during hour $i$.

EWITS was performed using US\$2024. Where possible, the assumed escalation rate of 3\% was used to translate results into US\$2009. Care must be taken with some of the results, however, because prices for individual fuels were escalated at different rates for different regions. For this reason, only some of the results in later sections are shown in US\$2009.

A 15\% annualized revenue requirement is used to determine the annual cost of the conceptual transmission plan. This is obviously subject to change in actual construction, depending on the cost structure of the constructing transmission owners.

\section{RESOURCE ADEQUACY ASSESSMENT}

Capacity additions in the model are based on reserve margin requirements. Reserve margin is calculated as the difference in available capacity and peak coincident demand divided by the peak coincident demand.

\section{Reserve Margin = Available Capacity-Peak Coincident Demand Peak Coincident Demand}

Peak demand is determined using the noncoincident annual peaks applied to hourly load profile curves. The coincident peak occurs at the time the hourly load demand reaches its peak for the system (refer to Table 3-1 for demand assumptions). The available capacity is the maximum capacity available during the peak coincident demand from net transactions, interruptible load, and firm generation. Firm generation is the percentage of a generator's maximum capacity that is counted toward calculation of the reserve margin. For example, wind units contribute $20 \%$ of their maximum capacity toward reserve margin calculations. Table 3-7 shows the modeled reserve targets. 


\begin{tabular}{|l|r|}
\hline TABLE 3-7. TARGET RESERVE MARGINS BY REGION \\
\hline REGION & RESERVE TARGET (\%) \\
\hline ENTERGY & 15.0 \\
\hline ISO-NE & 15.0 \\
\hline MAPP & 15.0 \\
\hline MISO & 15.0 \\
\hline NYISO & 15.0 \\
\hline PJM & 15.5 \\
\hline SERC & 15.0 \\
\hline SPP & 15.0 \\
\hline TVA & 15.0 \\
\hline
\end{tabular}

\section{GENERATION EXPANSION ALTERNATIVES}

EGEAS has five primary alternatives for region expansion: coal-fired steam turbines, natural-gas-fired combined cycles, natural-gas-fired combustion turbines, nuclear facilities, and wind facilities. Before using the capacity expansion model, the project team eliminated other alternatives such as integrated gasification and combined cycle (IGCC) units with sequestration, biomass, and hydro facilities as options because they were not economically competitive with the conventional resources under the assumptions applied to the analysis.

Table 3-8 shows the attributes for the generation alternatives. It should be noted that the capital costs for wind generation in this table are lower than what is assumed later in the report when total costs are tabulated. These lower values were artifacts of an earlier planning study. Because of the approach used here, however-the amount of wind generation is predetermined by the scenario definitions-the lower numbers have no influence on the expansion results.

Wind is given a $20 \%$ capacity credit against the required planning margin; all other units produce $100 \%$ of available capacity at peak system hours. Because of the wind modeling technique, resource adequacy calculations take into account existing fleet, planned fleet, and modeled wind expansions before estimating the need for additional capacity. 


\begin{tabular}{|c|c|c|c|c|c|}
\hline 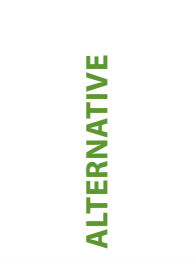 & 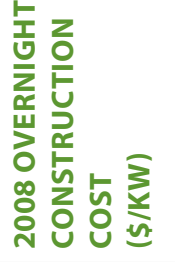 & 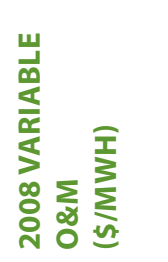 & 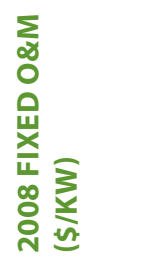 & 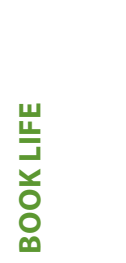 & 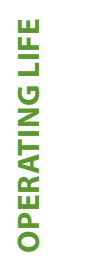 \\
\hline COAL & 1,833 & 4.60 & 28.22 & 40 & 60 \\
\hline CC & 857 & 5.17 & 34.01 & 30 & 30 \\
\hline CT & 597 & 4.62 & 17.72 & 30 & 30 \\
\hline $\begin{array}{l}\text { WIND } \\
\text { (ONSHORE) }\end{array}$ & 1,750 & 5.70 & 11.93 & 25 & 25 \\
\hline $\begin{array}{l}\text { WIND } \\
\text { (OFFSHORE) }\end{array}$ & 2,440 & 18.67 & 15.55 & 25 & 25 \\
\hline NUCLEAR & 2,928 & 4.63 & 69.57 & 40 & 60 \\
\hline
\end{tabular}

${ }^{a}$ All costs escalated at $3 \%$ annually during study period. Notes: $k W=$ kilowatt; $M W h=$ megawatt-hour

Energy efficiency is not modeled beyond what is embedded in the modeled energy projections available through the PowerBase database. Demand response, however, is added to the individual areas to maintain existing penetration percentages through the study period, as shown in Table 3-9. The demand response units are modeled much like high-cost combustion turbines to limit capacity factors to values less than $1 \%$.

TABLE 3-9. MODELED PENETRATION OF DEMAND RESPONSE BY REGION (AS
PERCENTAGE OF PEAK)
\begin{tabular}{|l|r|r|r|}
\hline STUDY REGION & $\begin{array}{l}\text { NONCOINCIDENT } \\
\text { PEAK DEMAND } \\
\text { (MW) }\end{array}$ & $\begin{array}{l}\text { MODELED DEMAND } \\
\text { RESPONSE } \\
(\mathrm{MW})\end{array}$ & $\begin{array}{l}\text { RATIO OF DEMAND } \\
\text { RESPONSE TO PEAK } \\
\text { DEMAND (\%) }\end{array}$ \\
\hline ENTERGY & 22,712 & 50 & 0.18 \\
\hline ISO-NE & 28,227 & 2,400 & 8.50 \\
\hline MISO + MAPP & 125,777 & 4,362 & 3.47 \\
\hline NYISO & 35,064 & 2,014 & 5.74 \\
\hline PJM & 142,826 & 3,239 & 2.27 \\
\hline SERC & 96,071 & 1,745 & 1.82 \\
\hline SPP & 47,478 & 736 & 1.55 \\
\hline TVA & 47,633 & 2,309 & 4.85 \\
\hline
\end{tabular}




\section{SECTION 4: DEVELOPING ECONOMIC TRANSMISSION OVERLAYS}

The amounts of wind generation defined for study in this project exceed the current installed capacity by nearly an order of magnitude. Transmission issues are already limiting wind energy development in some regions, so it is a near certainty that significant new transmission would be necessary to accommodate the much higher amounts of wind generation represented in the Eastern Wind Integration and Transmission Study (EWITS) scenarios.

This section describes the methodology and results of the transmission assessment for the four scenarios examined in EWITS.

\section{BACKGROUND}

The transmission facilities that make up today's Eastern Interconnection were developed through a planning process that had two basic objectives: (1) to connect specific new generating units to load, and (2) to maintain or enhance the reliability of the bulk power system in the face of growing demand. By building transmission facilities to interconnect with neighbors, capacity resources could be shared in emergencies, reducing the amount of excess capacity an individual utility must maintain to serve load reliably. Opportunities for economic exchanges of energy under nonemergency conditions were a side benefitthough not usually the driver-of the process.

Because it is primarily a source of energy, not capacity, wind generation does not fit well into conventional resource adequacy-based transmission planning processes. In conventional planning, the focus will typically be concentrated on certain system conditions-peak or minimum load hours, or operation of the system with a major facility out of service. The status of conventional generating units during these periods is usually a given. With large amounts of wind generation, the disposition of other conventional generating units may not be so easily ascertained; in addition, high amounts of wind generation are likely in offpeak hours or seasons that might not be of special interest for reliability issues.

A transmission planning method based on economics has been developed, demonstrated, and even adopted by one Eastern Interconnection regional transmission organization (RTO) for insight into transmission needs for significant wind generation development, which conventional methods have more difficulty addressing. It was first used in the Joint Coordinated System Plan (JCSP), a collaborative planning process among the Midwest ISO, the Southwest 
Power Pool (SPP), the PJM Interconnection (PJM), the Tennessee Valley Authority (TVA), the Mid-Continent Area Power Pool (MAPP), and other interested parties to develop conceptual interregional transmission plans required for a $5 \%$ wind energy scenario and a $20 \%$ wind energy scenario.

The method takes a top-down view by defining what transmission would be needed and possibly justified by benefits exceeding cost for a future year, given the locations of both loads and the sources of energy. In EWITS, the objective is to evaluate the transmission that would be needed to facilitate $20 \%$ and $30 \%$ wind penetration levels across the Eastern Interconnection. To ensure economic energy delivery across a large geographical area, energy-based regional transmission planning is necessary to incorporate comprehensive economic assessment using production-cost simulations. By linking the markets across the entire Eastern Interconnection with large energy price differences, the benefits of such a regional transmission plan could outweigh its cost.

Because the JCSP also focused on a $20 \%$ scenario, the results from that effort served as an appropriate starting point for EWITS. Other regional transmission plans such as the Midwest ISO's Regional Generation Outlet Study: Phase I Executive Summary Report (Midwest ISO 2009; known as RGOS; Phase I of a 765-kV [kilovolt] wind outlet transmission overlay) and the SPP's Draft 2008 SPP EHV Overlay Report (SPP 2008) were considered to help facilitate the collection of the high-quality wind resources in the Great Plains and Upper Midwest. A similar level of regional detail was not available for other parts of the Eastern Interconnection.

The transmission development methodology is a sequential process that focuses on a snapshot of a single future year. The steps in the process follow:

1. Defining the location of "sinks" for energy (loads) in the year of interest.

2. Determining what generation capacity would be necessary to reliably serve the defined loads given the existing transmission infrastructure. This is accomplished through a formal generation expansion process that begins with the present and ends in the target year. Wind generation is accounted for by assigning an estimated capacity value, which is the fractional amount of nameplate rating that can be considered firm capacity for planning purposes. The expansion program then considers the new generation that must be built to meet regional planning margin requirements given the growth in loads and possible retirements of existing generators. Projected capital and operating costs over the planning horizon are used to optimize the expansion by minimizing total costs while maintaining resource adequacy. 
3. Testing the result of the generation expansion step by running annual or multiannual hourly production simulations with the existing transmission network. Two cases are run:

a. A "copper sheet" case, where limits on all transmission facilities are removed, so that energy flows from sources to sinks based purely on production economics. In this case, the price for energy in any hour is the same across the entire system.

b. A constrained case, where transmission limits are applied. Congestion will result in unequal prices caused by less-thanoptimal use of the generation fleet and likely curtailment of wind generation.

4. Comparing results of the copper sheet and constrained cases. Costs of congestion across major transmission lines and interfaces are totaled for the annual period.

5. Using the accumulated congestion charges as a guide for developing new transmission.

The EWITS project team carried out steps 1 through 5 for each of the four wind generation scenarios, and this process is described in the following sections.

\section{APPLICATION OF EXPANSION METHODOLOGY}

To begin the transmission development process, the study team used the Electric Generation Expansion Analysis System (EGEAS) tools described in Section 3 to conduct a regional capacity expansion analysis for each wind scenario. The objective was to maintain an approximate 15\% reserve margin across the Eastern Interconnection in the 2024 study year. Based on analysis of the hourly wind production and regional load data, wind generation was assigned a uniform capacity value of $20 \%$ in the EGEAS runs.

\section{EGEAS GENERATION EXPANSION}

Each region identified in the assumptions was analyzed independently from the other regions. This assumes that regions will build capacity to be self-sufficient and will not depend on capacity in other regions for resource adequacy needs. For wind, however, the EWITS team assumed that a region would be given capacity credit for the wind needed to meet the scenario specifications of energy served and no more, whether located internally or not.

Figure 4-1 shows the nameplate capacity expansions required to meet the resource adequacy needs for each region. The information is, however, for the aggregate Eastern Interconnection. The first column represents generation capacity with a status of planned. This includes the signed Interconnection Agreement generation from the various Eastern Interconnection generation 
queues as well as a significant increase in nuclear capacity that has been recently proposed throughout the Eastern Interconnection.

The effect of wind on the capacity expansion model can be seen by comparing the three $20 \%$ wind energy scenarios to the $30 \%$ wind energy scenario. The added energy produced from the wind resources tends to be more competitive with the base-load generation in the off-peak hours. As a result, when increased wind resources are forced into the expansion model, the economic result is to remove base-load capacity (e.g., coal and nuclear) from the expansion and leave the more flexible peaking and intermediate capacity less affected.

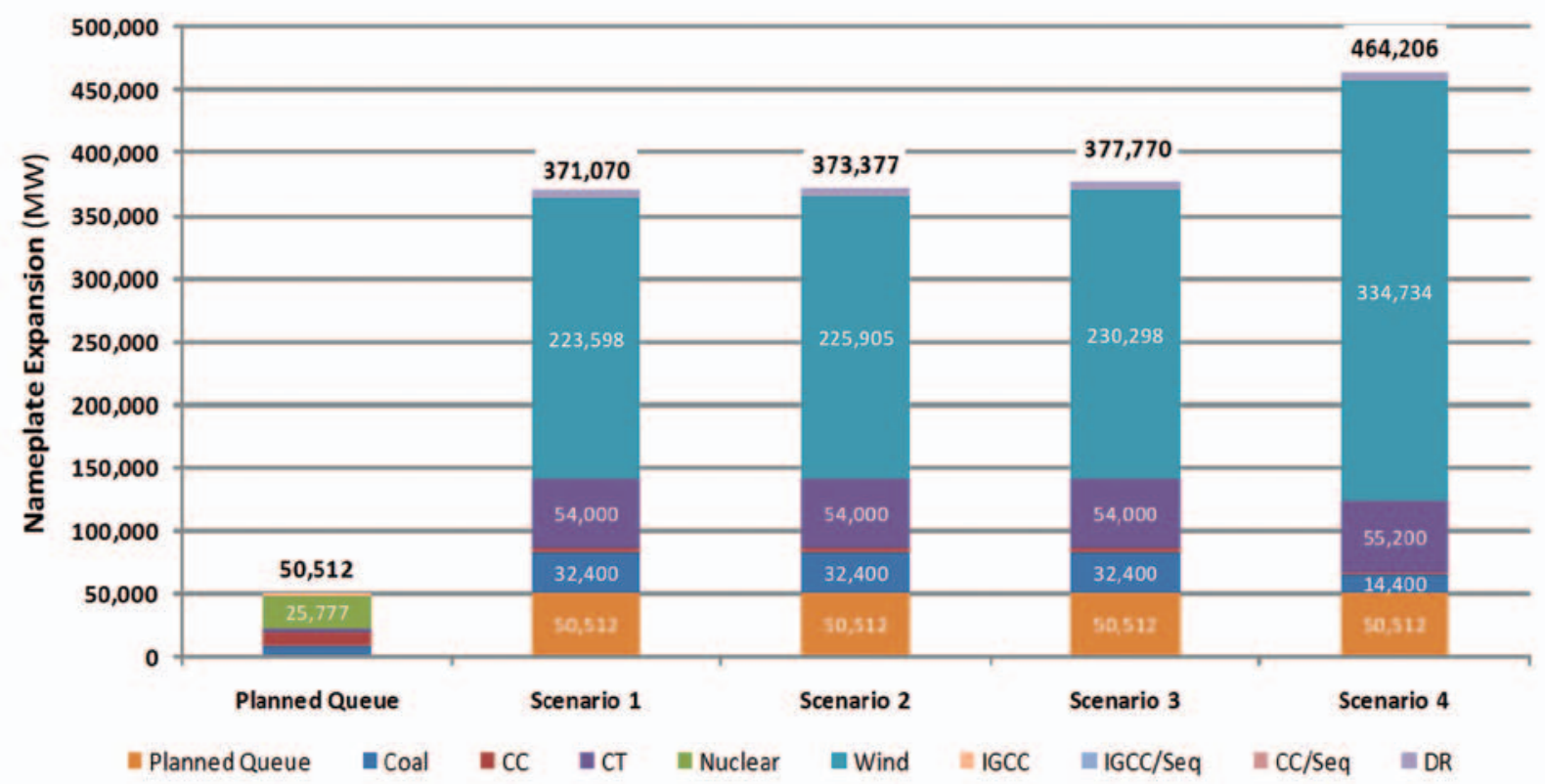

Notes: $C C=$ combined cycle; $C T=$ combustion turbine; IGCC = integrated gas combined cycle; IGCC/Seq = integrated gas combined cycle with sequestration; CC/Seq = combined cycle with sequestration; $R E T$ Coal = coal plant retirements; Replacement $C C=$ replacement combined cycle $D R=$ demand response.

\section{Figure 4-1. Capacity expansion by scenario}

\section{SITING OF CAPACITY}

The resources forecast from the expansion model for each of the scenarios are specified by fuel type and timing; these resources are not, however, site-specific at this point. A siting methodology to tie each resource to a specific bus in the PROMOD IV models is required to complete the process. The study team used a philosophy- and rule-based methodology, and industry expertise, to site the forecast generation.

The wind locations were dictated by the scenario definitions and the NREL wind data (AWS Truewind 2009). The thermal capacity was locally sited at various queue and brownfield locations. 
It is important to note that the scenario definitions result in some areas being selfsufficient in wind capacity (wind energy requirements being met with local wind energy production) but others require support from wind located in external regions.

Areas that meet the target energy on a regional basis, by scenario, are as follows:

- Scenario 1: Midwest ISO, MAPP, SPP

- Scenario 2: Midwest ISO, MAPP, SPP, New England ISO (ISO-NE), New York ISO (NYISO)

- Scenario 3: MAPP, SPP, PJM, ISO-NE, NYISO

- Scenario 4: Midwest ISO, MAPP, SPP, PJM, ISO-NE, NYISO

Areas with less than the target amounts by scenario include the following:

- Scenario 1: ISO-NE, NYISO, PJM, Southeastern Electric Reliability Council (SERC), TVA, Entergy (operated as part of SERC)

- Scenario 2: SERC, TVA, PJM, Entergy

- Scenario 3: Midwest ISO, SERC, TVA, Entergy

- Scenario 4: SERC, TVA, Entergy

\section{RESULTS}

Figures 4-2 through 4-5 illustrate the final generation siting locations for Scenarios 1 through 4, respectively. With the same $20 \%$ wind penetration level, Scenarios 1, 2, and 3 have exactly the same thermal generation capacity and siting locations. With the increased 30\% wind energy penetration in Scenario 4, base-load capacity decreases and gas-fired combustion turbine capacity increases because of its more flexible nature and lower capital cost. 


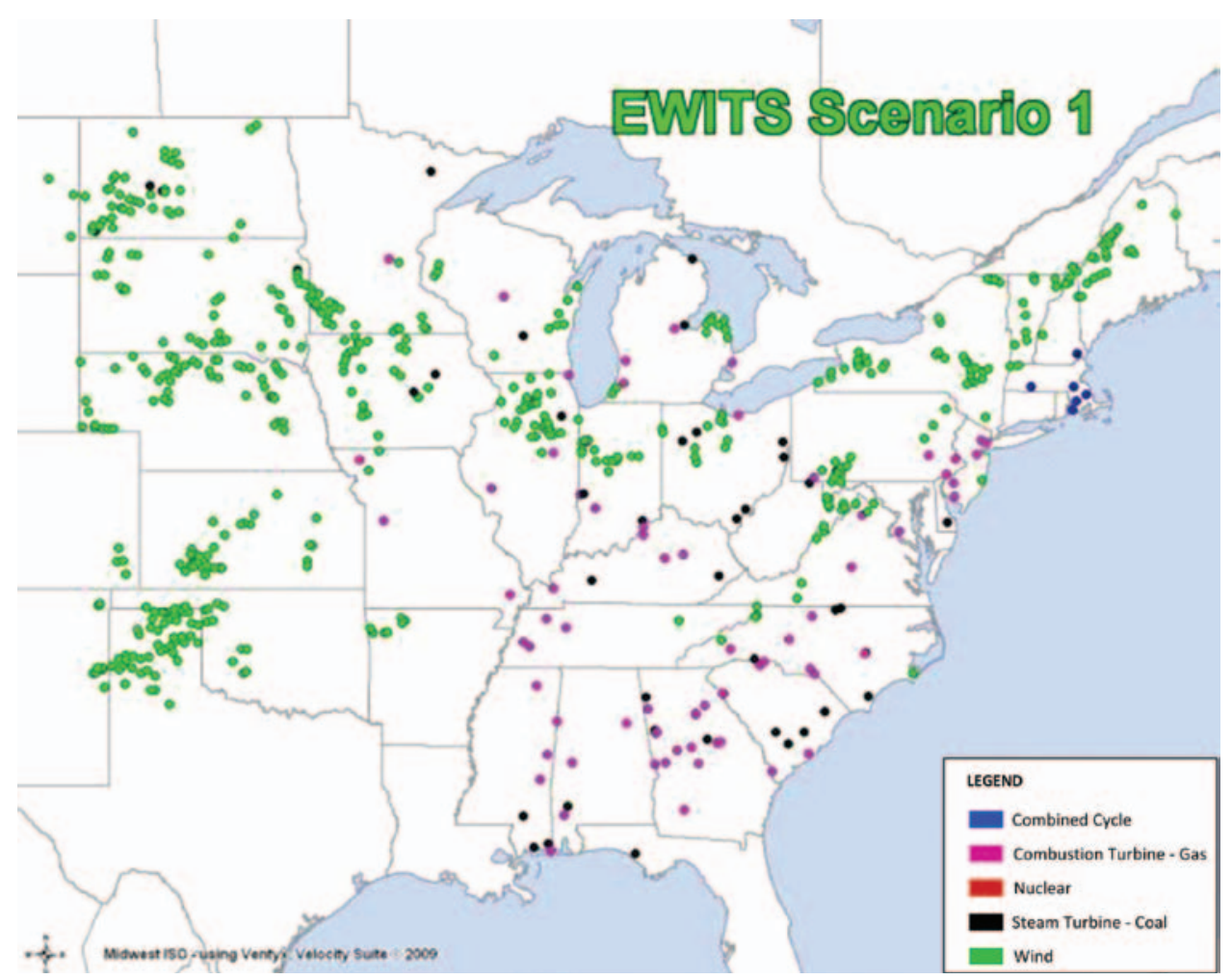

Figure 4-2. Scenario 1 installed capacity sites

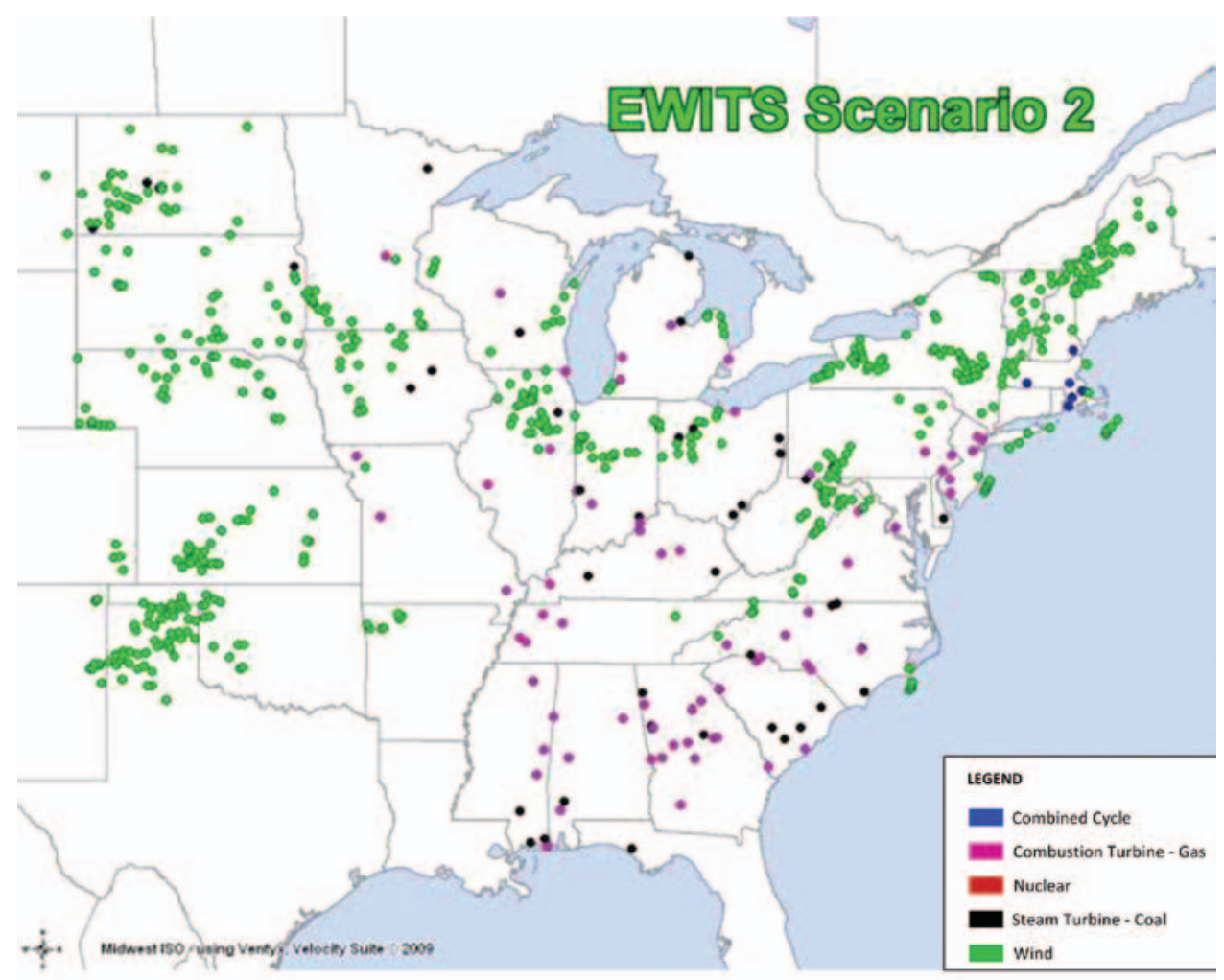

Figure 4-3. Scenario 2 installed capacity sites 


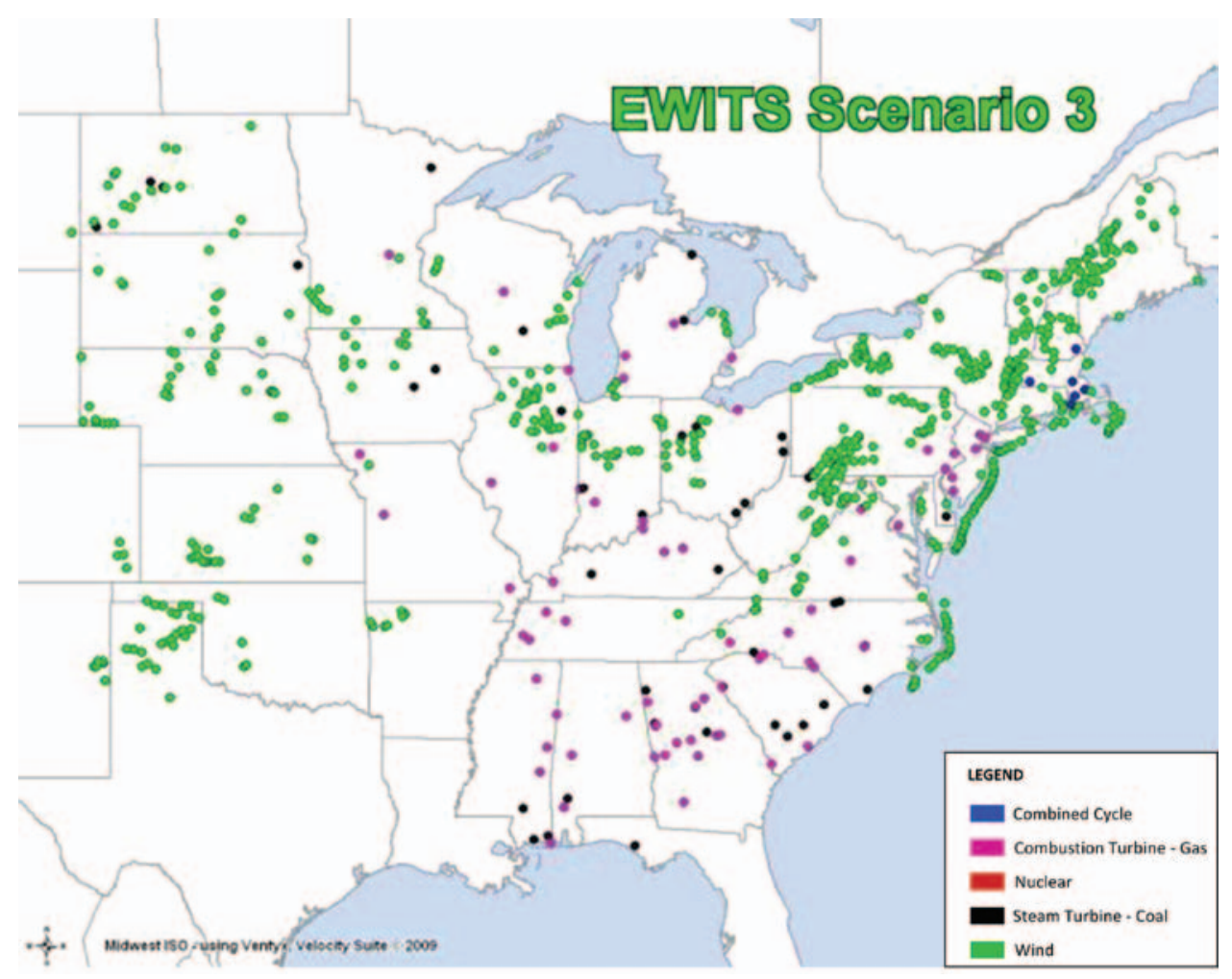

Figure 4-4. Scenario 3 installed capacity sites

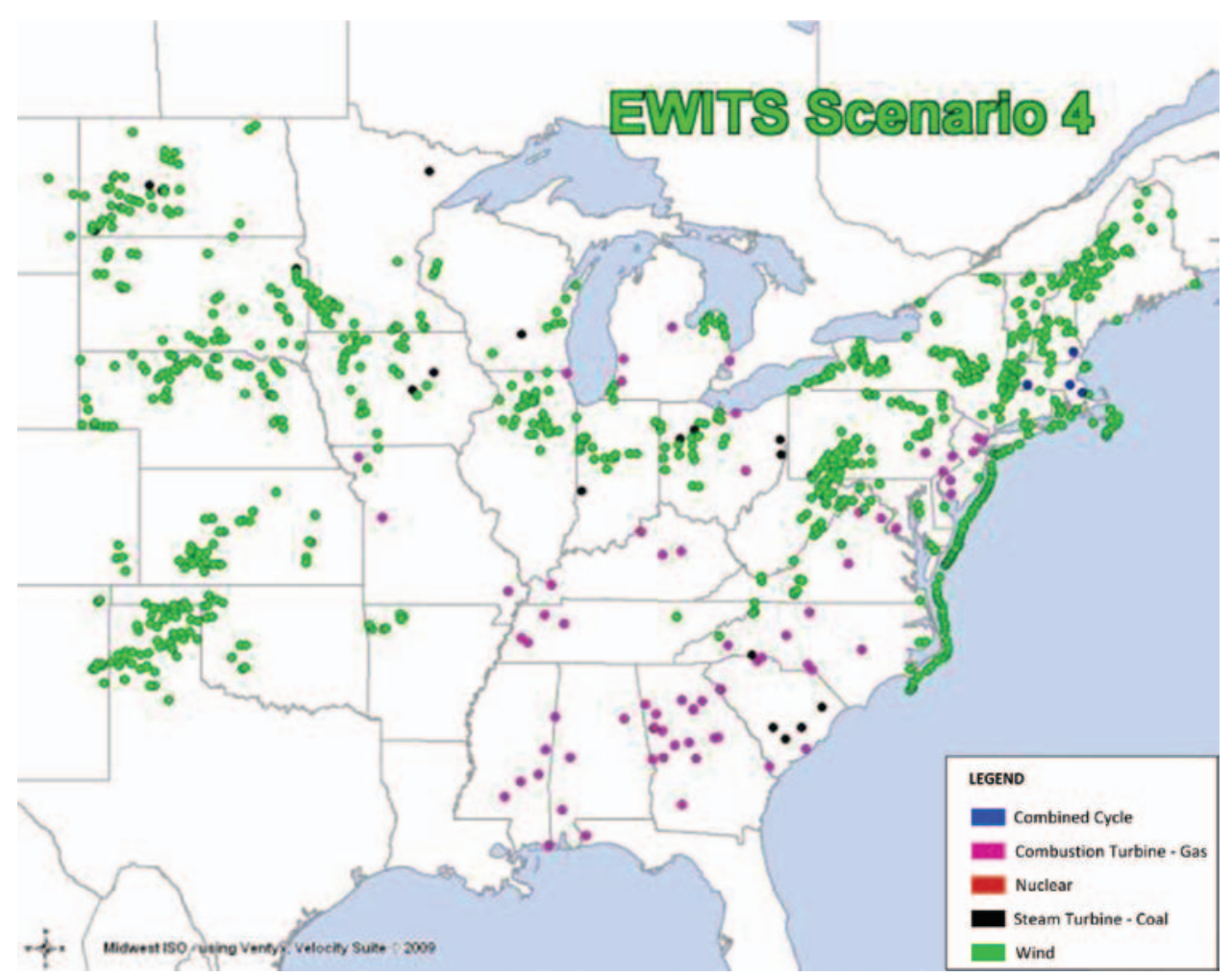

4-5. Scenario 4 installed capacity sites 


\section{TRANSMISSION OVERLAY DEVELOPMENT}

The following sections describe the interim steps of the transmission expansion methodology along with results for the study scenarios.

\section{PRE-OVERLAY ECONOMIC ANALYSIS}

The pre-overlay economic analysis results are the input information necessary for developing the conceptual extra high voltage (EHV) transmission overlay.

The study team first considered two PROMOD IV economic simulations, the constrained base case and the unconstrained case assuming no transmission constraints. Examining the differences between the two cases reveals the following:

- The areas of economic energy sources and sinks

- The interface flow changes to determine the incremental transfer capacity needs

- The total benefit savings, which gives a rough estimate for the potential budget.

Figure 4-6 shows the annual generation-weighted locational marginal pricing (LMP) contour map across the system for the constrained case in the $20 \%$ wind Scenario 2. The highest prices are on the East Coast. The price differentials are driven by a combination of transmission constraints and the cost of natural gas. Under economic market operation, energy tends to flow from low-cost areas to high-cost areas. The LMP contour map shows the direction where the energy would be likely to flow. To obtain the value from a transmission plan, the transmission should link the lower cost areas to the higher cost areas and relieve the transmission constraints. The more areas that are linked with the appropriately sized transmission, the greater the value the transmission can achieve.

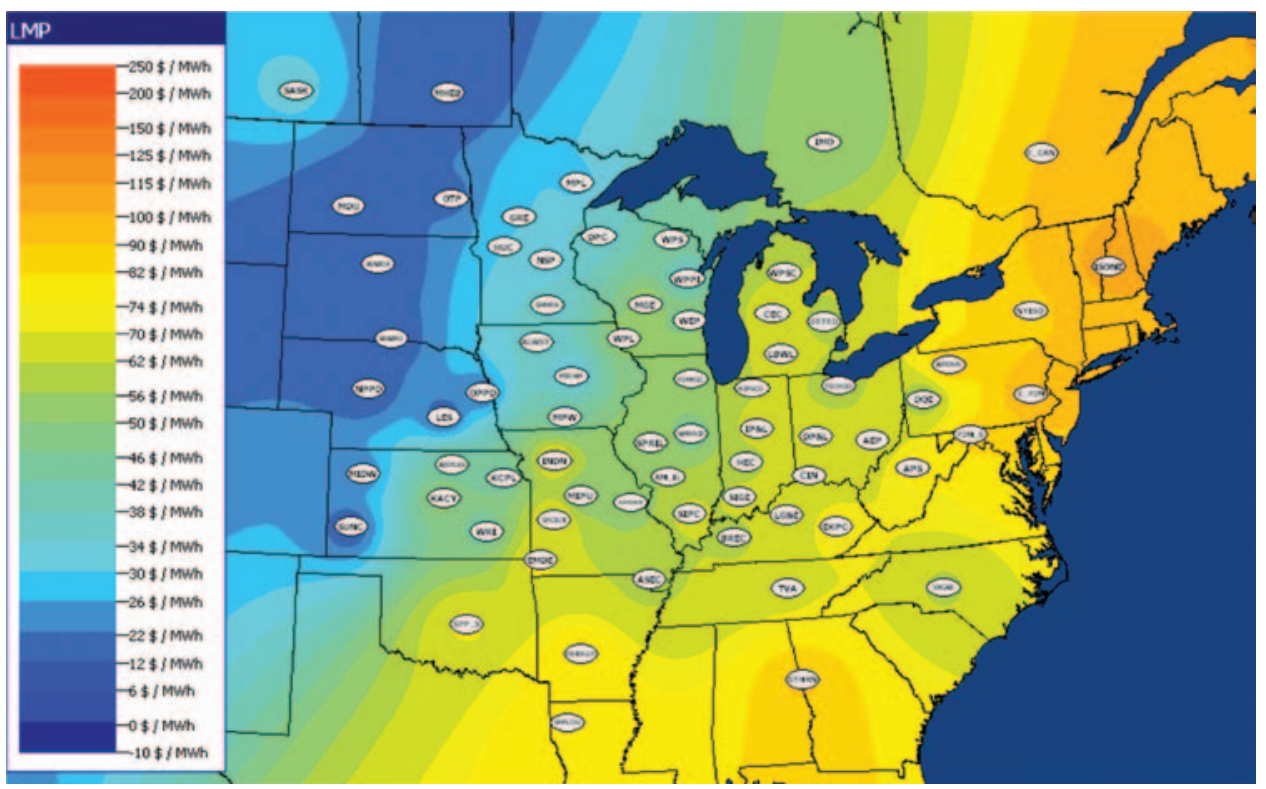

Figure 4-6. Scenario 2 annual generation-weighted LMP for Scenario 2 
Figure 4-7 shows the annual generation difference between the unconstrained and constrained cases for Scenario 2. This helps define the energy source (red) and energy sink (blue) areas and gives insight into where the potential transmission lines and substations should be located. As seen in Figure 4-7, the price signal drives energy from low-cost source areas to high-cost sink areas if the transmission system is not constrained across the study footprint.

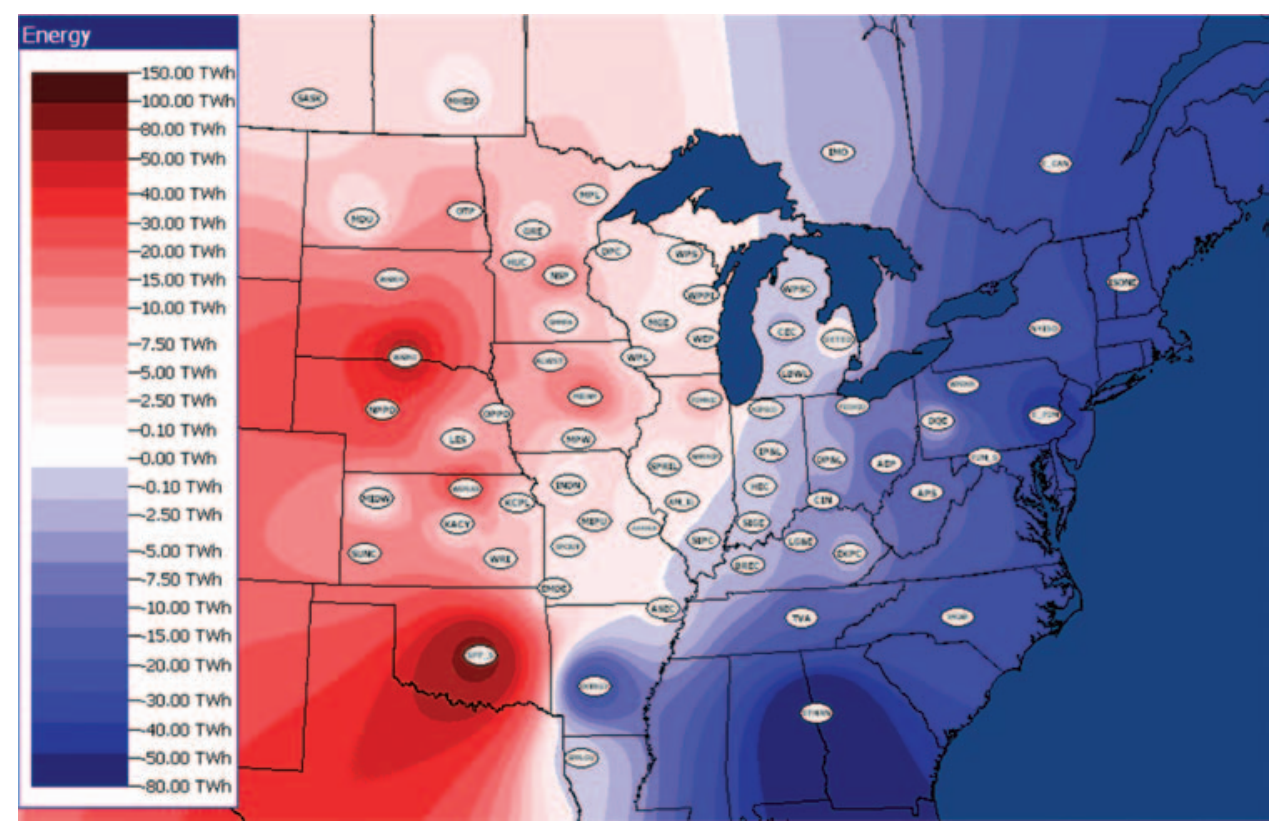

Figure 4-7. Scenario 2 generation difference between unconstrained case and constrained case

Designing an economically beneficial transmission plan requires considering the amount of energy that flows from sources to sinks in addition to the price difference. Figure 4-8 shows the annual energy differences between the unconstrained and constrained cases on each interface for Scenario 2; it shows the direction and magnitude of the interface flow changes. The red indicates the largest incremental flow change on the interface and the blue represents the smallest. The interface flows that tend toward red indicate where energy would flow more economically if there were no constraints in the system, and these are the candidate locations for overlay lines to increase power transfer. 


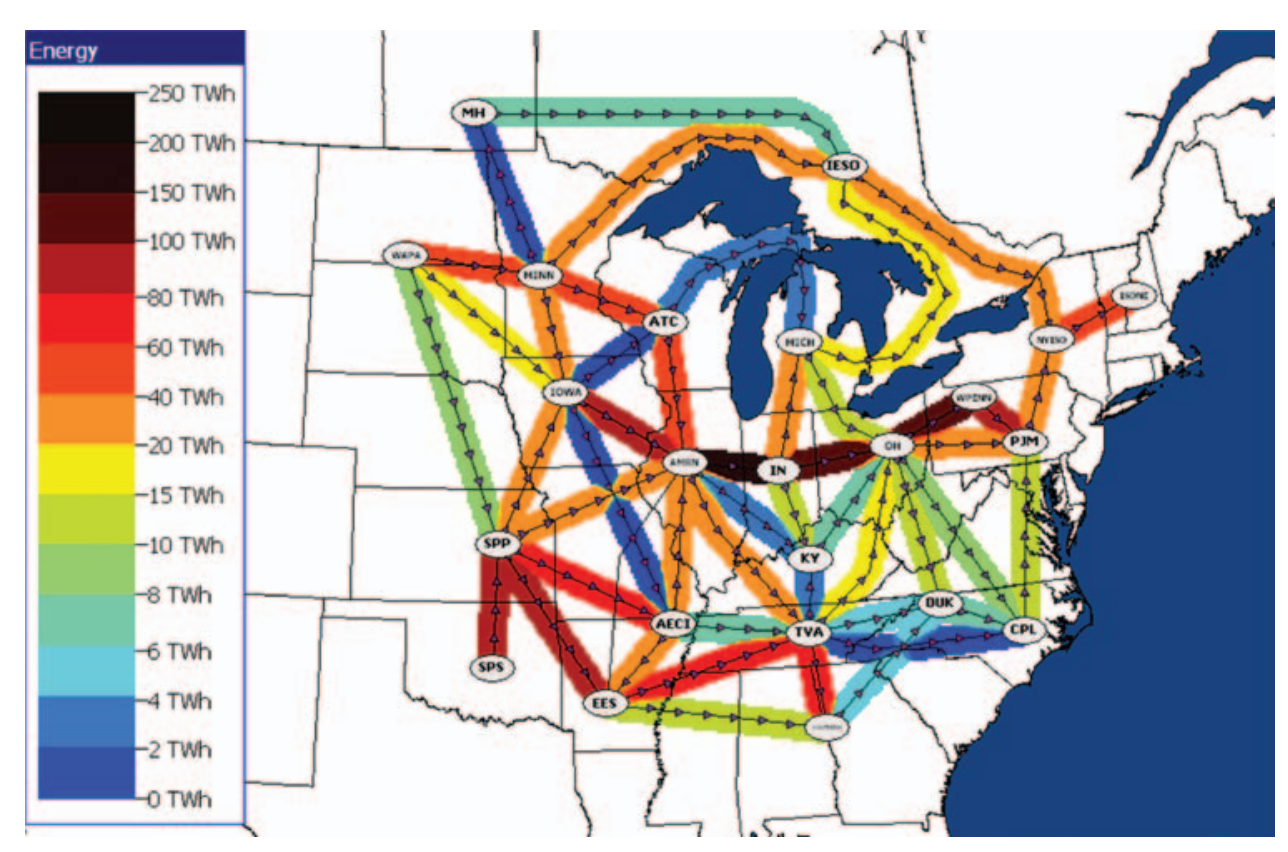

Figure 4-8. Scenario 2 interface annual energy difference between unconstrained case and constrained case

Table 4-1 lists the top 24 interfaces with the largest annual energy differences between the unconstrained and constrained cases for each wind scenario; it essentially shows in tabular form the same information depicted in Figure 4-8. The additional transfer needs are calculated to deliver $80 \%$ of the annual energy differences on each interface between the unconstrained and constrained cases. This information can be used to determine the type and size of the transmission lines and transformers. 


\begin{tabular}{|c|c|c|c|c|c|}
\hline \multirow[t]{2}{*}{ INTERFACE ${ }^{\mathrm{a}}$} & $\begin{array}{l}\text { JCSP 20\% } \\
\text { WIND }\end{array}$ & $\begin{array}{l}\text { EWITS } \\
\text { SCENARIO } 1\end{array}$ & $\begin{array}{l}\text { EWITS } \\
\text { SCENARIO } 2\end{array}$ & $\begin{array}{l}\text { EWITS } \\
\text { SCENARIO } 3\end{array}$ & $\begin{array}{l}\text { EWITS } \\
\text { SCENARIO } 4\end{array}$ \\
\hline & $\begin{array}{l}\text { ADDITIONAL } \\
\text { TRANSFER } \\
\text { NEEDS } \\
\text { (MEGAWATTS } \\
{[\mathrm{MW}] \text { ) }}\end{array}$ & $\begin{array}{l}\text { ADDITIONAL } \\
\text { TRANSFER } \\
\text { NEEDS (MW) }\end{array}$ & $\begin{array}{l}\text { ADDITIONAL } \\
\text { TRANSFER } \\
\text { NEEDS (MW) }\end{array}$ & $\begin{array}{l}\text { ADDITIONAL } \\
\text { TRANSFER } \\
\text { NEEDS (MW) }\end{array}$ & $\begin{array}{l}\text { ADDITIONAL } \\
\text { TRANSFER } \\
\text { NEEDS (MW) }\end{array}$ \\
\hline AMRN - IN & 26,878 & 28,856 & 22,901 & 13,223 & 24,609 \\
\hline IN - OH & 19,334 & 20,843 & 16,594 & 9,633 & 17,081 \\
\hline OH - EPJM & 16,126 & 18,662 & 14,378 & 8,715 & 12,928 \\
\hline SPS - SPP & 7,174 & 13,482 & 13,983 & 7,743 & 13,399 \\
\hline SPS - EES & 12,567 & 12,551 & 11,598 & 6,417 & 12,160 \\
\hline $\begin{array}{l}\text { IOWA- } \\
\text { AMRN }\end{array}$ & 12,204 & 15,173 & 11,150 & 6,040 & 14,084 \\
\hline EES-TVA & 9,472 & 10,173 & 9,039 & 4,879 & 9,205 \\
\hline $\begin{array}{l}\text { TVA- } \\
\text { SOUTHERN }\end{array}$ & 8,860 & 9,045 & 8,202 & 5,476 & 8,744 \\
\hline SPP-AECI & 7,866 & 8,565 & 7,930 & 4,134 & 8,283 \\
\hline $\begin{array}{l}\text { NYISO- } \\
\text { ISONE }\end{array}$ & 10,331 & 9,128 & 7,405 & 6,202 & 6,967 \\
\hline PJM-NYISO & 8,430 & 8,457 & 7,086 & 6,115 & 6,631 \\
\hline $\begin{array}{l}\text { WAPA- } \\
\text { MINN }\end{array}$ & 1,865 & 9,243 & 6,633 & 2,443 & 9,164 \\
\hline ATC-AMRN & 8,068 & 8,771 & 6,586 & 3,878 & 7,663 \\
\hline MINN-ATC & 6,575 & 8,647 & 6,260 & 3,186 & 8,148 \\
\hline SPP-IOWA & 2,926 & 3,978 & 4,355 & 2,606 & 4,227 \\
\hline AECI-AMRN & 4,618 & 4,585 & 4,300 & 2,142 & 4,512 \\
\hline SPP-AMRN & 3,922 & 4,556 & 3,973 & 2,134 & 4,368 \\
\hline AMRN-TVA & 4,691 & 4,571 & 3,925 & 2,367 & 4,224 \\
\hline IN-MICH & 4,568 & 4,937 & 3,846 & 2,254 & 3,990 \\
\hline IESO-NYISO & 8,678 & 4,971 & 3,817 & 2,630 & 3,499 \\
\hline MICH-IESO & 4,184 & 4,070 & 3,238 & 2,349 & 2,801 \\
\hline AECI-EES & 3,976 & 3,607 & 3,088 & 2,042 & 3,584 \\
\hline MINN-IOWA & 3,424 & 4,102 & 2,866 & 1,425 & 3,931 \\
\hline WAPA-IOWA & 2,392 & 4,343 & 2,847 & 994 & 4,262 \\
\hline
\end{tabular}

a Interface and state names are abbreviated in this column because of space considerations. Please refer to the Abbreviations and Acronyms list.

Adjusted production cost (APC) savings are calculated by taking the differences between the unconstrained and constrained cases for all four high-penetration wind scenarios. Table 4-2 lists the detailed APC savings for each region plus the entire Eastern Interconnection study footprint. The APC savings, which represent proxy estimates of potential budgets available for transmission development, are used as the economic benefit value metric for the transmission overlay. 


\begin{tabular}{|l|r|r|r|r|}
\hline \multicolumn{6}{|l|}{ TABLE 4-2. ANNUAL APC SAVINGS FOR EACH SCENARIO (US\$2024, MILLIONS) } \\
\hline REGION & SCENARIO 1 & SCENARIO 2 & SCENARIO 3 & \multicolumn{1}{|c|}{ SCENARIO 4 } \\
\hline PJM & 4,682 & 3,169 & 1,588 & 2,768 \\
\hline MISO & 2,529 & 1,832 & 1,288 & 2,883 \\
\hline TVASUB & 789 & 661 & 590 & 1,500 \\
\hline MAPP & 8,234 & 5,275 & 2,264 & 6,290 \\
\hline SPP & 6,534 & 6,765 & 4,071 & 5,691 \\
\hline SERCNI & 5,728 & 5,655 & 5,494 & 11,166 \\
\hline E_CAN & 2,652 & 2,306 & 2,389 & 1,823 \\
\hline IMO & 1,144 & 1,068 & 1,048 & 1,157 \\
\hline ISO-NE & 3,794 & 2,117 & 1,079 & 1,432 \\
\hline MHEB & 730 & 629 & 599 & 603 \\
\hline NYISO & 4,851 & 3,424 & 1,872 & 2,499 \\
\hline ENTIRE EI & 41,667 & 32,902 & 22,282 & 37,812 \\
\hline
\end{tabular}

Notes: SERCNI, E-CAN and TVASUB are monikers used in EWITS for subregions in the PROMODIV model. $I M O=$ the independent electricity market operator that covers Ontario; $M H E B=$ Manitoba Hydro Electric Board; El = Eastern Interconnection.

\section{TRANSMISSION DESIGN CONSIDERATIONS FOR EHV OVERLAY}

Figure 4-9 demonstrates simple decisions that enable the transmission lines to be selected. If the lines can be loaded economically close to their power transfer limit, the cost to deliver energy is lower with the higher voltage lines. For large amounts of energy transfer, $765-\mathrm{kV}$ (kilovolt) AC and 800-kV high-voltage DC (HVDC) lines are the low-cost options.

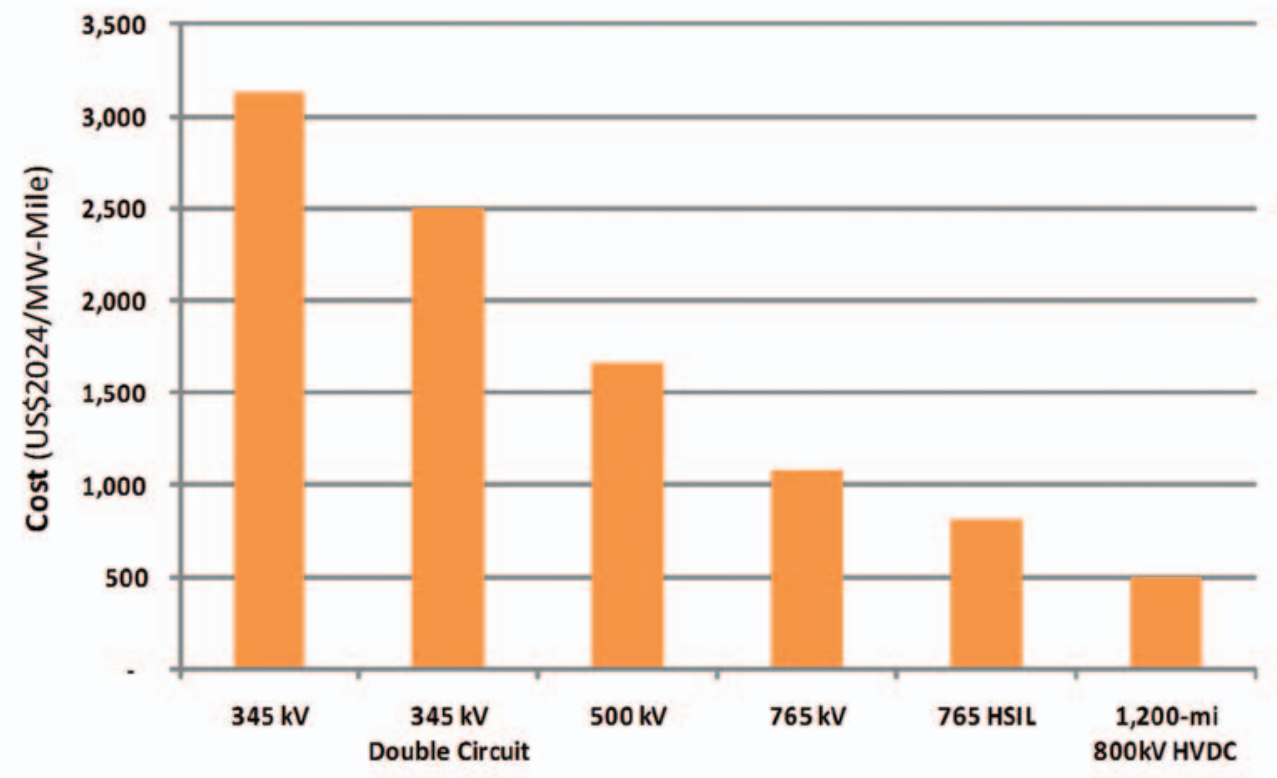

Note: $H S I L$ = high-surge impedance loading

Figure 4-9. Transmission and substation costs per megawatt-mile 
The architecture with a mix of multiple HVDC and EHV AC lines is necessary because of the high-penetration wind levels across the Eastern Interconnection. The 800-kV HVDC lines with bipolar configuration need to be used in groups of three or more to deliver energy more than 600 miles to remote load centers. EHV AC lines connected to the HVDC terminals are used for contingency backup, to collect energy from multiple wind resources that are geographically diverse, and to deliver energy to HVDC terminals. Because of the volumes of transaction energy and the distances between source and sink areas, HVDC was determined to be the least costly and was used in all the EWITS transmission overlays.

\section{IDENTIFYING AND LOCATING NEW TRANSMISSION FACILITIES}

The study team developed the conceptual transmission overlays for all four wind scenarios using the pre-overlay economic analysis results and input from the Technical Review Committee (TRC). Local and regional knowledge represented by the TRC members was used to locate terminals for new transmission facilities in the Eastern Interconnection system model.

Regional transmission plans in the western part of the interconnection were incorporated into the overlay design. Two existing conceptual plans with a regional focus were integrated into the overlays. Figure 4-10 shows a conceptual EHV plan developed by SPP and updated when Nebraska utility companies became part of the SPP RTO in 2008. RGOS Phase I transmission, which was initiated by the Midwest ISO, its state regulators, and stakeholders to develop transmission portfolios required to meet the renewable portfolio standards (RPS) or goals, is depicted in Figure 4-11.

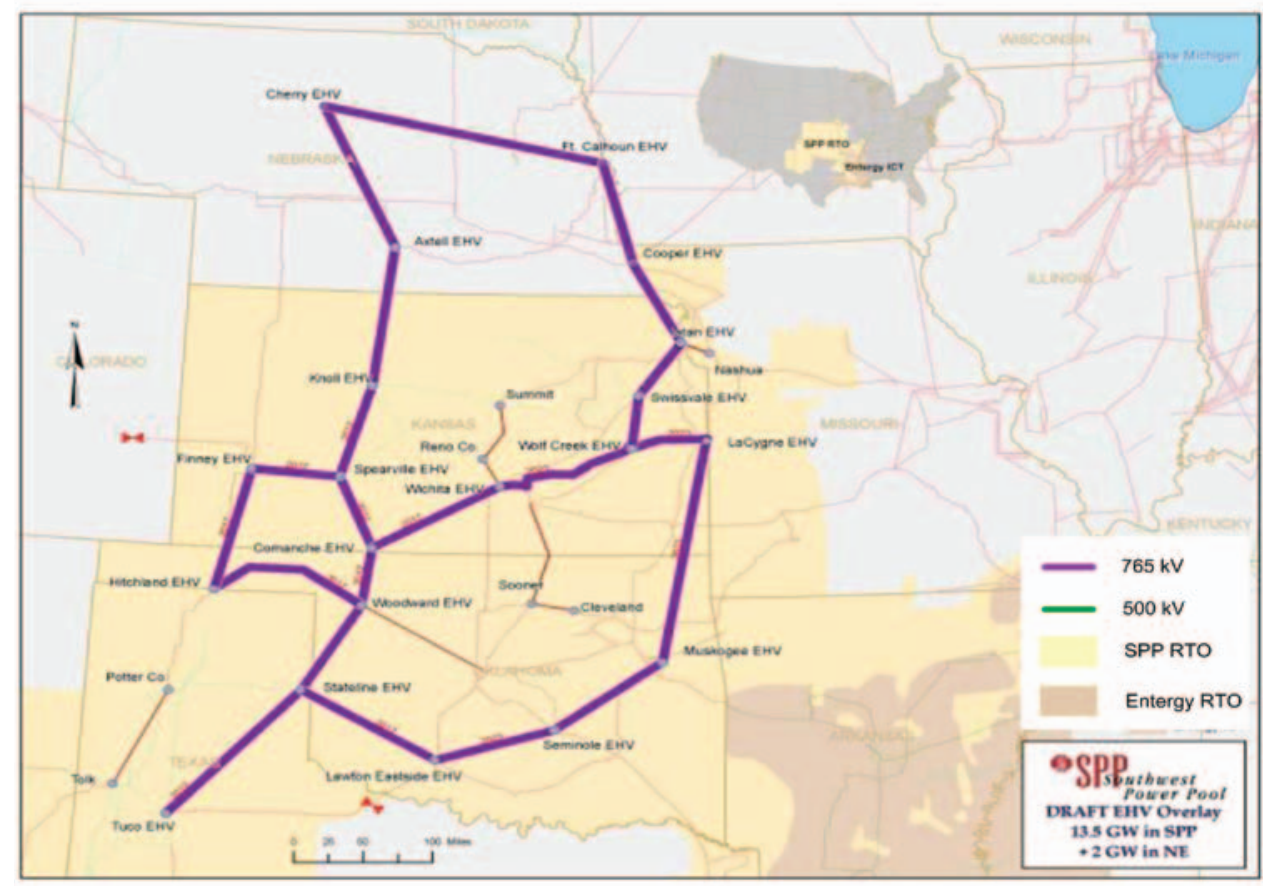

Figure 4-10. SPP EHV conceptual transmission plan 


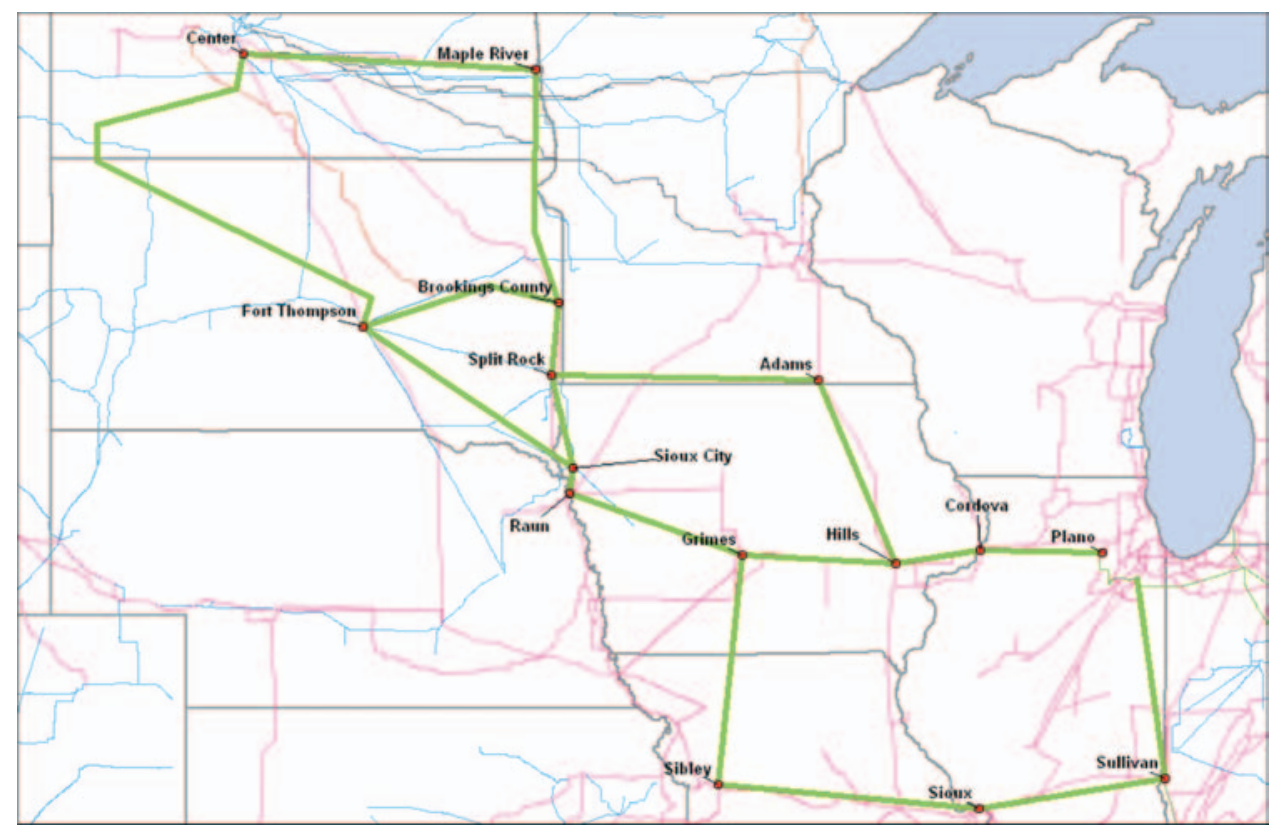

Figure 4-11. Midwest ISO RGOS, Phase I, Preliminary Scenario T, 765-kV (green)

Building on previous energy-driven transmission planning efforts, the inputs from the TRC were incorporated to create initial conceptual overlays for the three $20 \%$ wind scenarios and the $30 \%$ wind scenario. To improve benefits and relieve congestion, the study team made some additional refinements. The resulting conceptual transmission overlays for the four wind scenarios are shown in Figures 4-12 through 4-15.

All of the overlays are structured to allow a general west-to-east energy transfer. There are several reasons for such a bias. First, in all the scenarios, the western part of the interconnection has large amounts of wind generation and minimal load. Second, issues with loop flows in portions of the existing transmission system in roughly the geographical center of the interconnection favor west-toeast lines over more north-south orientations of long-distance facilities.

A third major reason for the general west-to-east orientation of the overlays involves the representation of Canadian provinces in this study. No wind generation data were available for Canada, which precluded detailed study of energy transactions between border regions of the United States and the provinces to the north. In this study, a firm import of 5 gigawatts (GW) over an asynchronous tie between New England and Quebec, represented as a market transaction, was the only consideration of wind generation outside the United States. 
Canada has significant wind energy potential in addition to hydroelectric resources, and its proximity to the northeastern U.S. load centers in particular offers the northeastern portion of the United States access to wind generation that is relatively local compared to wind generation in the Great Plains. The TRC recommended that such a scenario be considered in the future, if and when compatible wind data are available for those provinces.

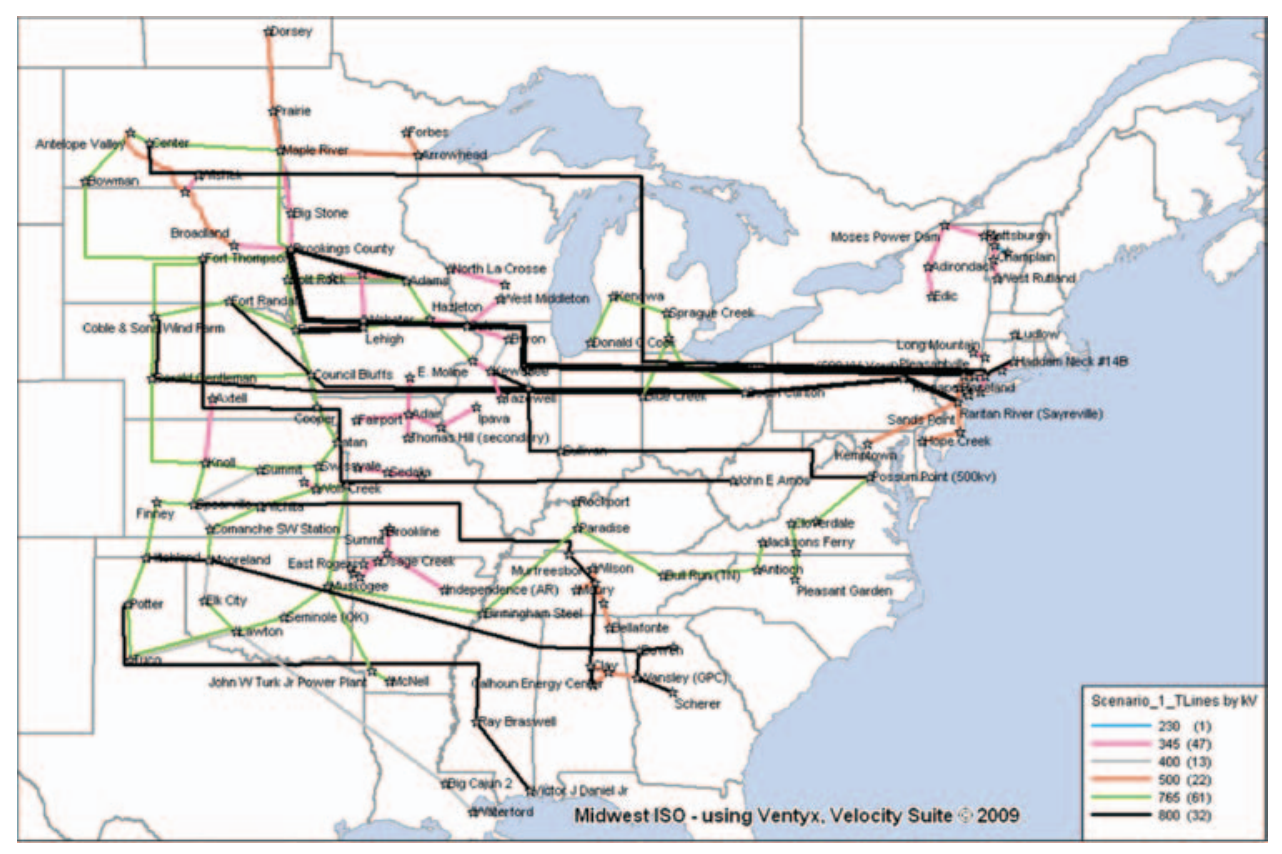

Figure 4-12. EWITS Scenario 1 conceptual transmission plan

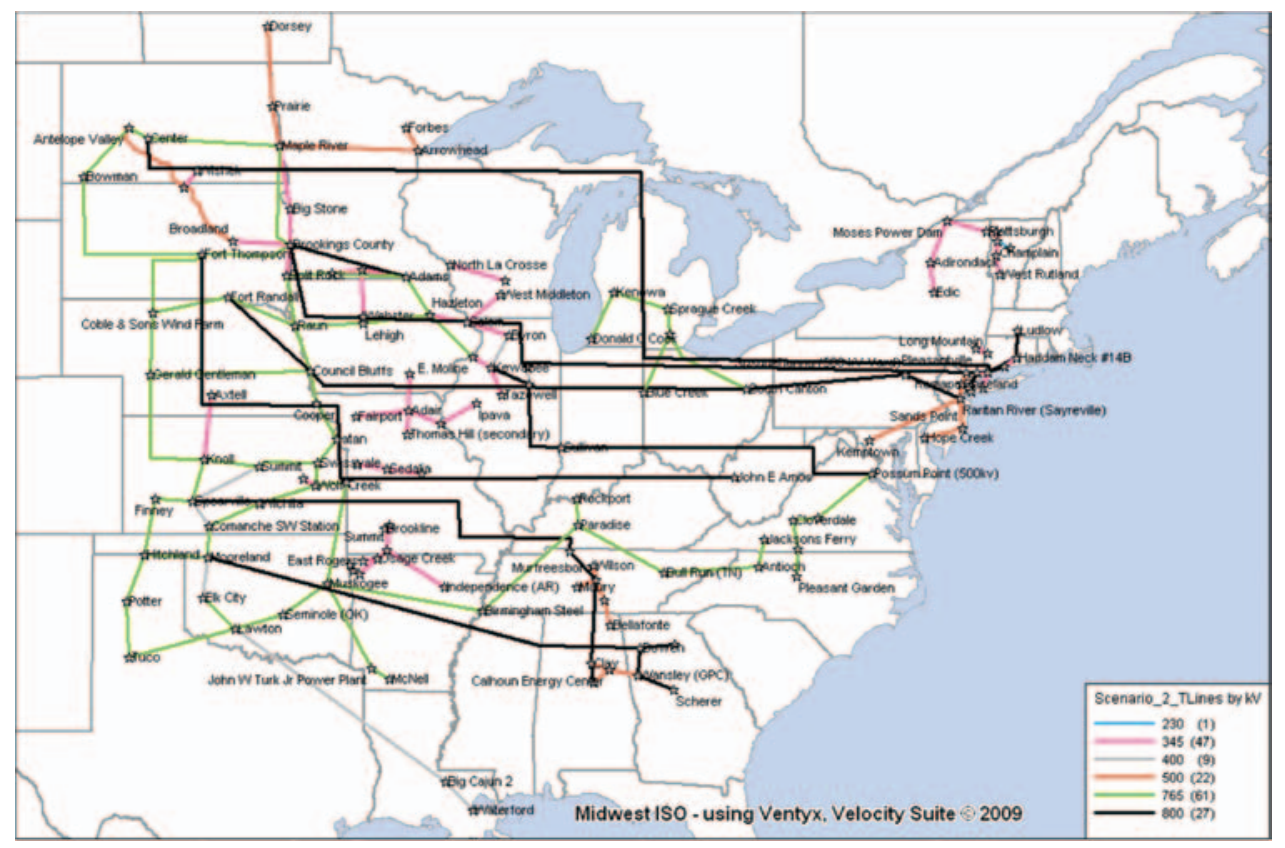

Figure 4-13. EWITS Scenario 2 conceptual transmission plan 


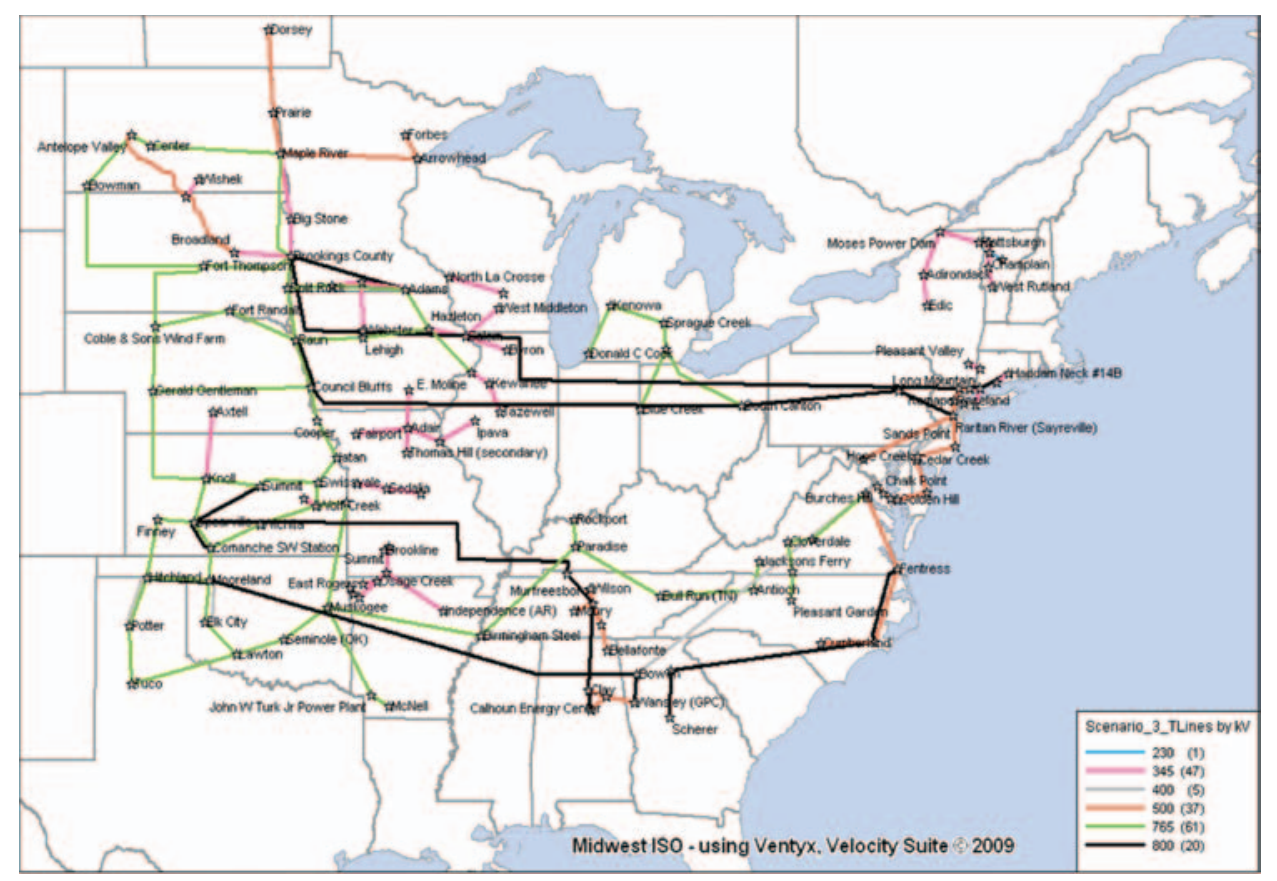

Figure 4-14. EWITS Scenario 3 conceptual transmission plan

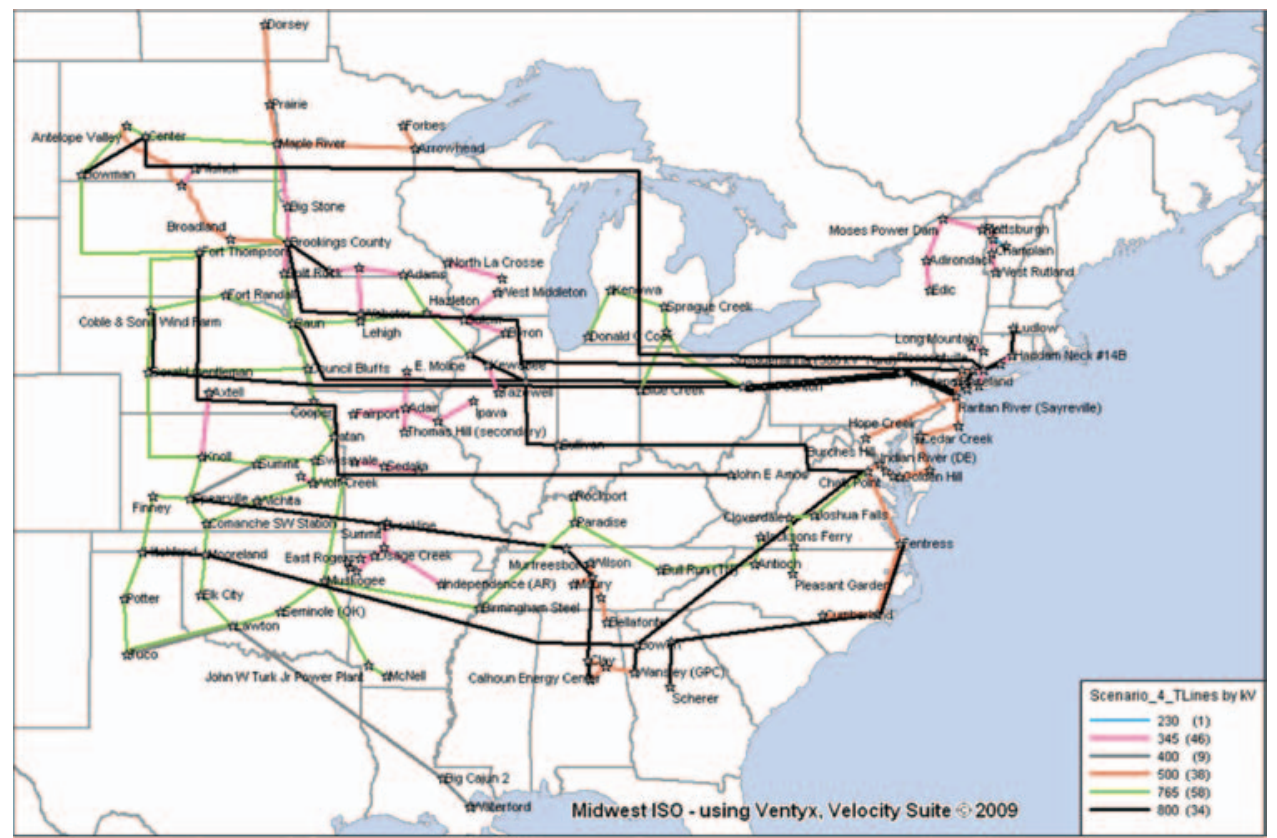

Figure 4-15. EWITS Scenario 4 conceptual transmission plan 


\section{POST-OVERLAY ECONOMIC ASSESSMENT}

Tables 4-3 through 4-5 summarize the EWITS transmission construction costper-mile assumptions by voltage level and region, the estimated total line miles by voltage level, and the estimated cost in millions of US\$2024 for the four wind scenario conceptual overlays. In Table 4-5, the total AC line costs include a 25\% adder to approximate the costs of substations and transformers; the total HVDC line costs include terminals, communications, and DC line costs. The costs associated with an offshore wind collector system or some subregional transmission upgrades that would be required, which could be substantial, are not included in the total estimated cost. With approximately 21,666 miles of new EHV transmission, the transmission overlay for Scenario 4 has the highest estimated total cost at $\$ 158$ billion.

The conceptual transmission overlays consist of multiple 800-kV HVDC and EHV AC lines for all four scenarios with similar levels of new transmission and common elements. In the three $20 \%$ wind energy scenarios, the highest quality wind resources in the western portion of the interconnection were used. The Scenario 1 transmission overlay has nine 800-kV HVDC lines and one 400-kV HVDC line. A reduced transmission overlay with seven 800-kV HVDC lines and one 400-kV HVDC line is applied for Scenario 2 (with some wind moving eastward). Because more wind is moved eastward and more offshore resources are used in Scenario 3, the transmission overlay has the least amount of HVDC lines: five 800-kV HVDC lines and one 400-kV HVDC line. To accommodate the aggressive 30\% wind mandate and deliver a significant amount of offshore wind along the East Coast in Scenario 4, the overlay must be expanded to include ten 800-kV HVDC lines and one 400-kV HVDC line.

Compared to the JCSP 20\% wind scenario overlay, more 765-kV lines are included in the four EWITS scenarios to ensure easy access to the high-quality wind resources in the Great Plains and Upper Midwest. Approximately $85 \%$ of the line miles are associated with at least 500-kV AC or HVDC lines for all four wind scenarios.

\begin{tabular}{|l|r|l|r|r|r|r|r|}
\hline TABLE 4-3. COST PER MILE ASSUMPTION (US \$2024, MILLIONS) \\
\hline REGION & $345 \mathrm{kV}$ & $\begin{array}{l}\text { 345 } \\
\text { kV AC } \\
\text { (double } \\
\text { circuit) }\end{array}$ & $500 \mathrm{kV}$ & $\begin{array}{l}\text { 500 } \\
\text { kV AC } \\
\text { (double } \\
\text { circuit) }\end{array}$ & $\begin{array}{l}765 \mathrm{kV} \\
\mathbf{4 0 0} \mathbf{k V} \\
\text { DC }\end{array}$ & $\begin{array}{l}800 \mathrm{kV} \\
\text { DC }\end{array}$ \\
\hline MISO & 3.2 & 3.9 & 5.6 & 9.4 & 7.1 & 3.8 & 6.0 \\
\hline SPP & 1.9 & 3.2 & 3.0 & 4.3 & 4.5 & 3.8 & 6.0 \\
\hline PJM & 7.2 & 12.0 & 9.2 & 15.4 & 16.0 & 3.8 & 6.0 \\
\hline $\begin{array}{l}\text { ISO-NE/ } \\
\text { NYISO }\end{array}$ & 5.5 & 9.1 & 7.0 & 11.7 & 16.0 & 3.8 & 6.0 \\
\hline
\end{tabular}




\begin{tabular}{|c|c|c|c|c|c|c|c|c|}
\hline SCENARIO & $345 \mathrm{kV}$ & $\begin{array}{l}345 \\
\text { kV AC } \\
\text { (double } \\
\text { circuit) }\end{array}$ & $500 \mathrm{kV}$ & $\begin{array}{l}500 \\
\text { kV AC } \\
\text { (double } \\
\text { circuit) }\end{array}$ & 765 kV & $\begin{array}{l}400 \mathrm{kV} \\
\mathrm{DC}\end{array}$ & $\begin{array}{l}800 \mathrm{kV} \\
\mathrm{DC}\end{array}$ & TOTAL \\
\hline REFERENCE & 3,054 & 299 & 567 & 494 & 2,631 & 1,188 & 1,968 & 10,203 \\
\hline SCENARIO 1 & 1,978 & 236 & 1,100 & 243 & 6,701 & 560 & 11,102 & 21,920 \\
\hline SCENARIO 2 & 1,978 & 236 & 1,100 & 243 & 6,674 & 560 & 8,352 & 19,143 \\
\hline SCENARIO 3 & 1,978 & 236 & 1,148 & 726 & 6,674 & 769 & 4,747 & 16,278 \\
\hline SCENARIO 4 & 1,886 & 236 & 1,240 & 726 & 6,445 & 560 & 10,573 & 21,666 \\
\hline
\end{tabular}

\begin{tabular}{|c|c|c|c|c|c|c|c|c|}
\hline SCENARIO & 345 kV & $\begin{array}{l}345 \\
\text { kV AC } \\
\text { (double } \\
\text { circuit) }\end{array}$ & $500 \mathrm{kV}$ & $\begin{array}{l}500 \\
\text { kV AC } \\
\text { (double } \\
\text { circuit) }\end{array}$ & 765 kV & $\begin{array}{l}400 \mathrm{kV} \\
\mathrm{DC}\end{array}$ & $\begin{array}{l}800 \mathrm{kV} \\
\mathrm{DC}\end{array}$ & TOTAL \\
\hline REFERENCE & 12,308 & 1,820 & 2,356 & 5,912 & 27,789 & 4,403 & 11,752 & 66,340 \\
\hline SCENARIO 1 & 7,409 & 1,563 & 7,242 & 4,575 & 49,798 & 2,397 & 83,265 & 156,249 \\
\hline SCENARIO 2 & 7,409 & 1,563 & 7,242 & 4,575 & 49,640 & 2,397 & 62,640 & 135,466 \\
\hline SCENARIO 3 & 7,409 & 1,563 & 7,789 & 12,131 & 49,663 & 2,957 & 35,603 & 117,115 \\
\hline SCENARIO 4 & 7,040 & 1,563 & 8,436 & 12,131 & 47,520 & 2,397 & 79,298 & 158,385 \\
\hline
\end{tabular}

An annual revenue requirement of $15 \%$ of the total overlay cost was used to calculate the annual cost of the overlay. All the dollar values represent the year 2024 only. Table 4-6 gives the annual transmission costs, APC savings, and benefit/cost (B/C) ratios for all transmission overlays. The transmission overlays and associated $\mathrm{B} / \mathrm{C}$ ratios are indicative, and a further comprehensive $\mathrm{B} / \mathrm{C}$ analysis of potential alternatives would be required before making any recommendations.

\begin{tabular}{|l|l|r|r|}
\hline \multicolumn{4}{|l|}{ TABLE 4-6. BENEFIT AND COST COMPARISON (US \$2024, MILLIONS) } \\
\hline SCENARIO & $\begin{array}{l}\text { 2024 ANNUAL } \\
\text { TRANSMISSION } \\
\text { COST }\end{array}$ & 2024 APC SAVINGS & 2024 B/C RATIO \\
\hline 1 & 23,437 & 28,648 & 1.22 \\
\hline 2 & 20,320 & 22,194 & 1.09 \\
\hline 3 & 17,567 & 13,095 & 0.75 \\
\hline 4 & 23,758 & 18,676 & 0.79 \\
\hline
\end{tabular}

The EWITS team used an iterative process to target the development of conceptual transmission overlays that meet both economic and resource adequacy needs. The transmission overlay developed in EWITS entails more development of wind collector systems in the western portion of the interconnection and addresses more of the underlying system and the associated impacts. Because of time constraints, however, additional congestion problems remain to be tackled. 
Tables 4-7 through 4-10 give more details on the estimated investments needed to mitigate the additional constraints for each scenario and fix the overloading lines. Further iterative refinement and more detailed resource adquacy analysis must be performed to ensure that the conceptual transmission overlays lower energy costs while meeting adequacy needs in the most efficient way.

\begin{tabular}{|c|c|c|c|c|c|}
\hline \multirow[t]{2}{*}{ VOLTAGE } & \multicolumn{2}{|c|}{ TRANSMISSION OVERLAY } & \multicolumn{2}{|c|}{ EXISTING 500 KV ABOVE } & \multirow{2}{*}{$\begin{array}{l}\text { TOTAL } \\
\text { ESTIMATED } \\
\text { COST } \\
\text { (US\$2024, } \\
\text { MILLIONS) }\end{array}$} \\
\hline & $\begin{array}{l}\text { NUMBER OF } \\
\text { LINES }\end{array}$ & $\begin{array}{l}\text { LINE } \\
\text { MILEAGE }\end{array}$ & $\begin{array}{l}\text { NUMBER OF } \\
\text { LINES }\end{array}$ & $\begin{array}{l}\text { LINE } \\
\text { MILEAGE }\end{array}$ & \\
\hline $345 \mathrm{kV}$ & 3 & 67 & 0 & 0 & 188 \\
\hline $\begin{array}{l}345 \mathrm{kV} \mathrm{AC} \\
\text { (double } \\
\text { circuit) }\end{array}$ & 2 & 49 & 0 & 0 & 230 \\
\hline $500 \mathrm{kV}$ & 0 & 0 & 13 & 574 & 2,063 \\
\hline $\begin{array}{l}500 \mathrm{kV} \mathrm{AC} \\
\text { (double } \\
\text { circuit) }\end{array}$ & 0 & 0 & 0 & 0 & 0 \\
\hline $765 \mathrm{kV}$ & 9 & 1,619 & 0 & 0 & 10,372 \\
\hline TOTAL & 14 & 1,735 & 13 & 574 & 12,853 \\
\hline
\end{tabular}

TABLE 4-8. ESTIMATED ADDITIONAL TRANSMISSION INVESTMENTS FOR SCENARIO 2

\begin{tabular}{|c|c|c|c|c|c|}
\hline \multirow{2}{*}{ VOLTAGE } & \multicolumn{2}{|c|}{ TRANSMISSION OVERLAY } & \multicolumn{2}{|c|}{ EXISTING 500 KV ABOVE } & \multirow{2}{*}{$\begin{array}{l}\text { TOTAL } \\
\text { ESTIMATED } \\
\text { COST } \\
\text { (US\$2024, } \\
\text { MILLIONS) } \\
\end{array}$} \\
\hline & $\begin{array}{l}\text { NUMBER OF } \\
\text { LINES }\end{array}$ & $\begin{array}{l}\text { LINE } \\
\text { MILEAGE }\end{array}$ & $\begin{array}{l}\text { NUMBER OF } \\
\text { LINES }\end{array}$ & $\begin{array}{l}\text { LINE } \\
\text { MILEAGE }\end{array}$ & \\
\hline $345 \mathrm{kV}$ & 2 & 54 & 0 & 0 & 152 \\
\hline $\begin{array}{l}345 \mathrm{kV} \text { AC } \\
\text { (double } \\
\text { circuit) }\end{array}$ & 2 & 49 & 0 & 0 & 230 \\
\hline $500 \mathrm{kV}$ & 0 & 0 & 12 & 660 & 2,372 \\
\hline $\begin{array}{l}500 \mathrm{kV} \text { AC } \\
\text { (double } \\
\text { circuit) }\end{array}$ & 0 & 0 & 0 & 0 & 0 \\
\hline 765 kV & 11 & 1,861 & 0 & 0 & 11,922 \\
\hline TOTAL & 15 & 1,964 & 12 & 660 & 14,676 \\
\hline
\end{tabular}




\begin{tabular}{|l|r|r|r|r|r|}
\hline \multirow{2}{*}{ TABLE 4-9. ESTIMATED AD ITIONAL TRANSISION INVESTMENTS FOR SCENARIO 3 } \\
\hline
\end{tabular}

TABLE 4-10. ESTIMATED ADDITIONAL TRANSMISSION INVESTMENTS FOR SCENARIO 4

\begin{tabular}{|c|c|c|c|c|c|}
\hline \multirow[t]{2}{*}{ VOLTAGE } & \multicolumn{2}{|c|}{ TRANSMISSION OVERLAY } & \multicolumn{2}{|c|}{ EXISTING 500 KV ABOVE } & TOTAL \\
\hline & $\begin{array}{l}\text { NUMBER OF } \\
\text { LINES }\end{array}$ & $\begin{array}{l}\text { LINE } \\
\text { MILEAGE }\end{array}$ & $\begin{array}{l}\text { NUMBER OF } \\
\text { LINES }\end{array}$ & $\begin{array}{l}\text { LINE } \\
\text { MILEAGE }\end{array}$ & $\begin{array}{l}\text { ESTIMATED } \\
\text { COST } \\
\text { (US\$2024, } \\
\text { MILLIONS) }\end{array}$ \\
\hline $345 \mathrm{kV}$ & 2 & 54 & 0 & 0 & 152 \\
\hline $\begin{array}{l}345 \mathrm{kV} \text { AC } \\
\text { (double } \\
\text { circuit) }\end{array}$ & 1 & 20 & 0 & 0 & 94 \\
\hline $500 \mathrm{kV}$ & 0 & 0 & 21 & 795 & 2,857 \\
\hline $\begin{array}{l}500 \mathrm{kV} \text { AC } \\
\text { (double } \\
\text { circuit) }\end{array}$ & 3 & 295 & 0 & 0 & 1,767 \\
\hline $765 \mathrm{kV}$ & 7 & 1,202 & 10 & 10 & 7,764 \\
\hline TOTAL & 13 & 1,571 & 31 & 805 & 12,634 \\
\hline
\end{tabular}

\section{ANALYSIS}

Transmission overlays were added to the production simulation model for each scenario to test their impact.

\section{REGIONAL GENERATION-WEIGHTED LMP CHANGES}

Figure 4-16 shows the comparison of the annual generation-weighted LMPs across the study footprint for Scenario 1. The diagram on the left represents the hub LMPs for the constrained base case, and the one on the right represents the hub LMPs for the overlay case. 


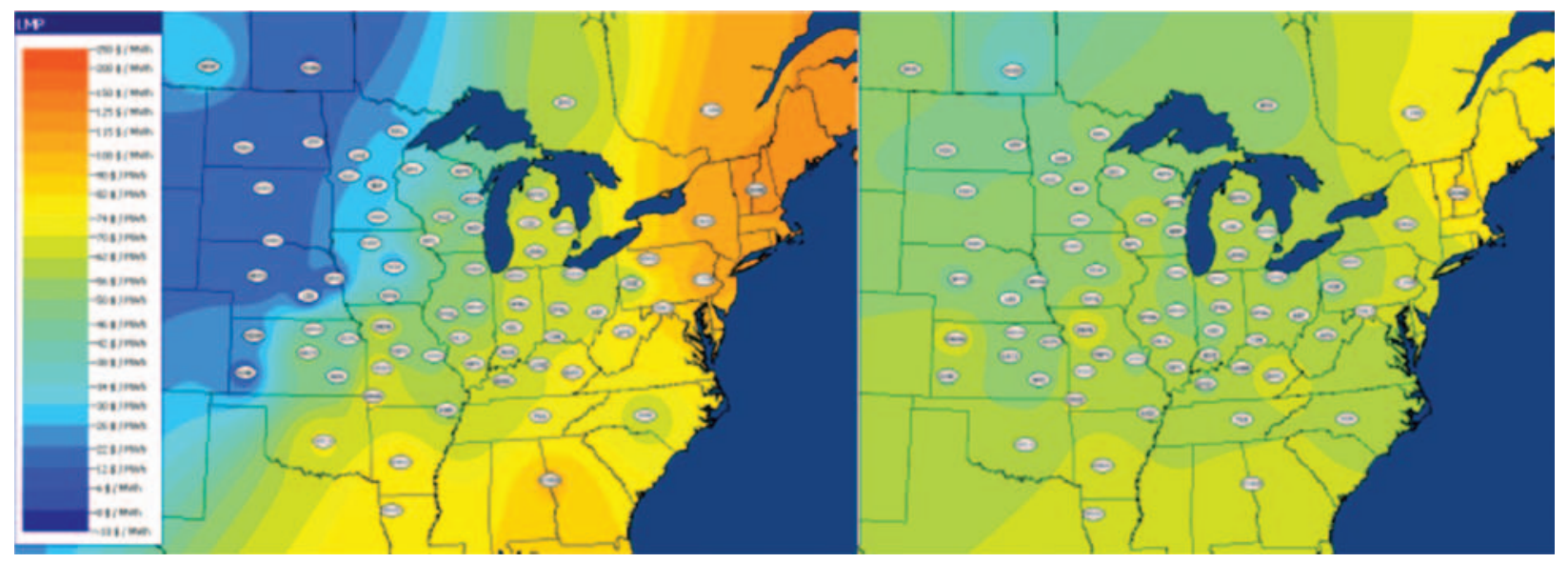

Figure 4-16. Scenario 1 annual generation-weighted LMP comparison

The LMP change demonstrates the ability of the conceptual transmission overlay to create a more competitive market in the Midwest ISO, thereby reducing costs to the East Coast. With the conceptual transmission overlay, more low-cost energy in the western regions is available to energy markets and is economically transferred to the high-priced East Coast regions. As the result of the economic energy transfer, LMPs increase in the western regions with the increased baseload generation output, but decrease in the eastern regions because the output of the high-priced generation is displaced by the imported low-cost energy.

With the increased LMPs in the western regions, significant amounts of the generation revenue benefits are achieved, which could potentially be reallocated back to end-use customers through regulatory mechanisms. Other mechanisms might have to be put in place to distribute the revenues back to load.

Figures 4-17 through 4-19 illustrate the comparison of the annual generationweighted LMPs across the study footprint for Scenarios 2, 3, and 4, respectively.

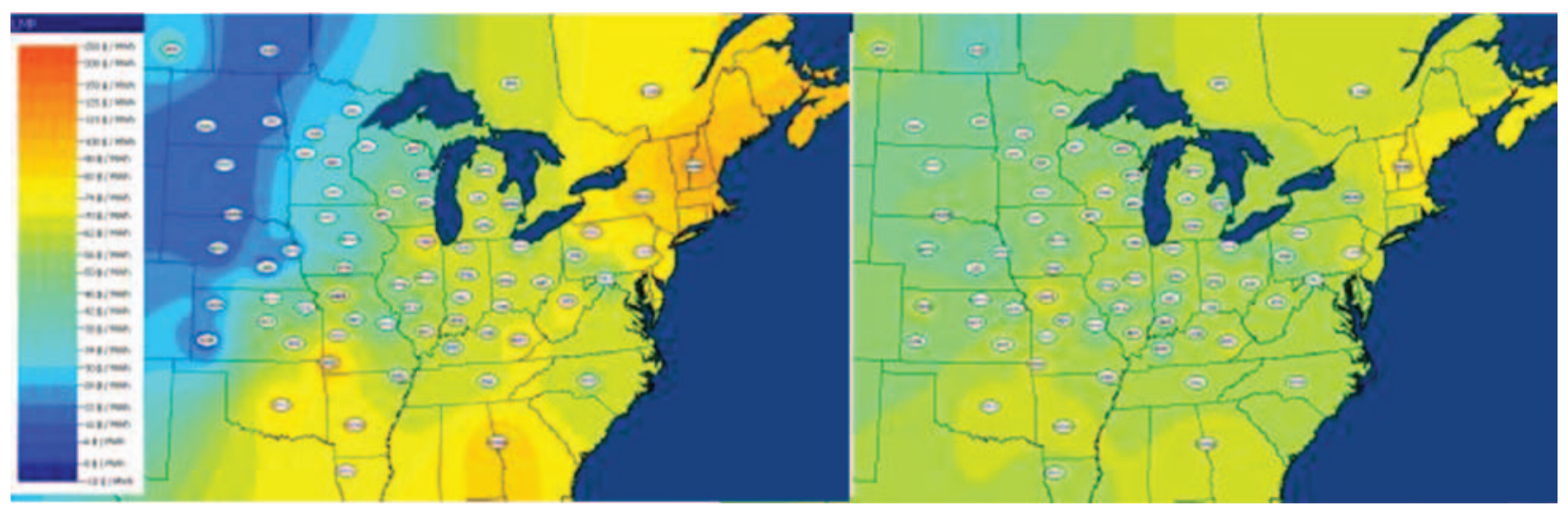

Figure 4-17. Scenario 2 annual generation-weighted LMP comparison 


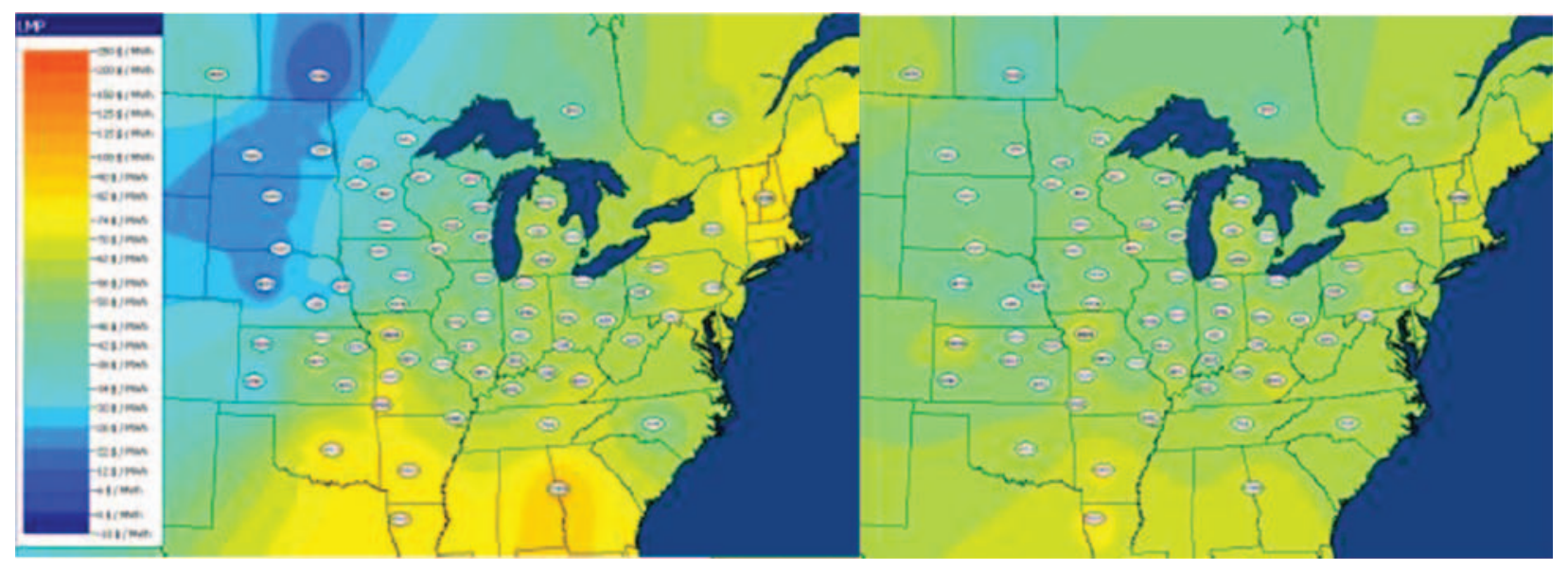

Figure 4-18. Scenario 3 annual generation-weighted LMP comparison

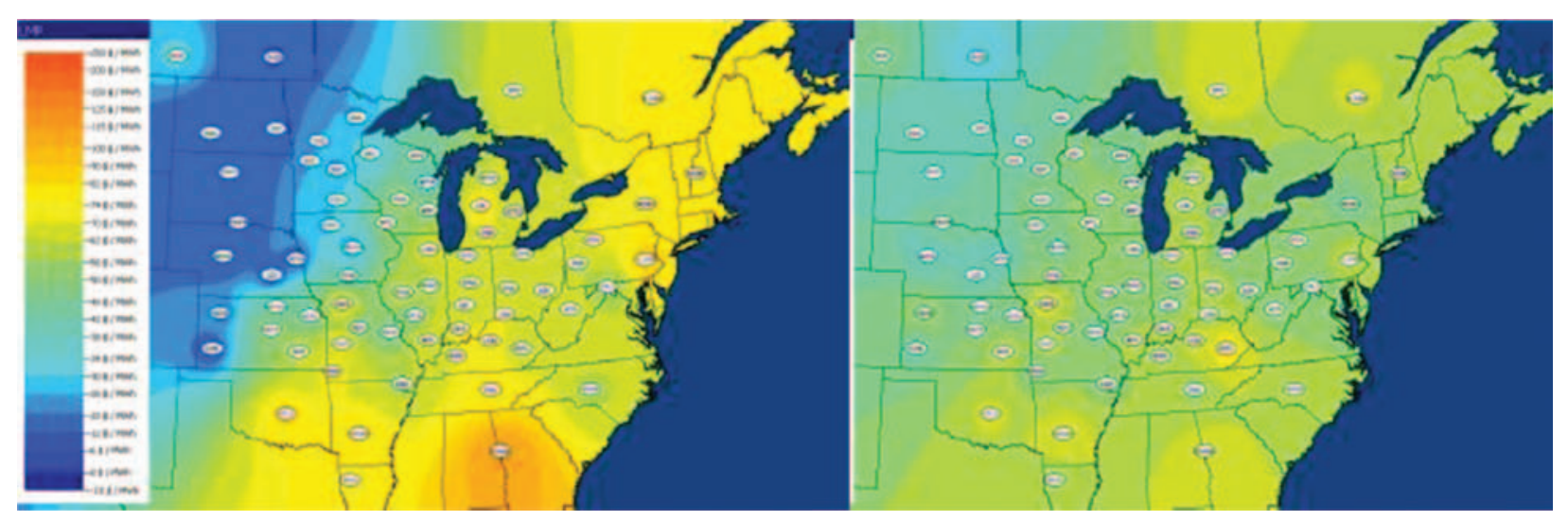

Figure 4-19. Scenario 3 annual generation-weighted LMP comparison

\section{WIND CURTAILMENT}

To accommodate increasingly high wind penetration levels, regional transmission infrastructure is needed to deliver substantial amounts of highquality wind energy to remote load centers. Without new transmission corridors to access the wind resources, large amounts of wind curtailment would occur. To minimize the wind curtailment levels seen in the transmission overlay cases, the study team performed a sensitivity analysis to include negative wind dispatch price in the production-cost model. The renewable energy production tax credit (PTC) is the primary federal incentive to encourage wind power development. For this sensitivity analysis, a negative $\$ 40$ / megawatt-hour (MWh) was assumed. This value includes the PTC along with renewable energy credits (RECs). 
Table 4-11 summarizes the wind curtailment for the base constrained case, the transmission overlay case, and the transmission overlay case modeling the negative $\$ 40 / \mathrm{MWh}$ wind dispatch price. With the transmission overlays to move the wind energy, the curtailment drops down, ranging from $3.61 \%$ to $10.04 \%$. And the curtailment is further reduced to the range between $1.05 \%$ and $3.83 \%$ with the negative $\$ 40$ / MWh wind dispatch price included. Section 6 discusses more detailed sensitivity analyses for this topic.

\begin{tabular}{|l|l|l|l|}
\hline TABLE 4-11. WIND CURTAILMENT SUMMARY \\
\hline SCENARIO & $\begin{array}{l}\text { CONSTRAINED } \\
\text { CASE (\%) }\end{array}$ & $\begin{array}{l}\text { TRASMISSION } \\
\text { OVERLAY CASE (\%) }\end{array}$ & $\begin{array}{l}\text { TRANSMISSION } \\
\text { OVERLAY WITH - } \\
\text { 40\$/MWh WIND } \\
\text { DISPATCH PRICE (\%) }\end{array}$ \\
\hline 1 & 47.55 & 7.11 & 3.53 \\
\hline 2 & 37.78 & 6.73 & 3.83 \\
\hline 3 & 18.94 & 3.61 & 1.05 \\
\hline 4 & 36.39 & 10.04 & 2.83 \\
\hline
\end{tabular}

\section{DESIGN OF HVDC OVERLAY TRANSMISSION}

The HVDC transmission lines and the $765-\mathrm{kV}$ and $500-\mathrm{kV}$ AC systems for the EWITS scenarios form a self-contingent system that is designed not to overload existing underlying transmission. HVDC lines perform the task of bulk energy transfer mostly from west to east and west to southeast for Scenarios 1 and 2. For Scenario 3, the HVDC system also delivers energy from the northern half of the eastern part of the interconnection to the southeast. The AC system is used to collect wind energy and deliver the energy to the source terminals of the HVDC lines, to distribute energy from the HVDC lines at the sink terminals to the loads, and to transfer energy from an area with an HVDC terminal influenced by a fault or outage to other areas that have HVDC terminals with capacity to increase schedules and their associated AC systems.

Figure 4-20 shows a five 800-kV HVDC line (black, west-to-east horizontal) example tied by $765-\mathrm{kV}$ lines (green, north-to-south vertical loops) and underlying 345-kV lines (red, north-to-south vertical loops). The HVDC $765-\mathrm{kV}$ lines are part of the overlay, and the $345-\mathrm{kV}$ lines are part of the underlying system. 
$\mathrm{AC}$

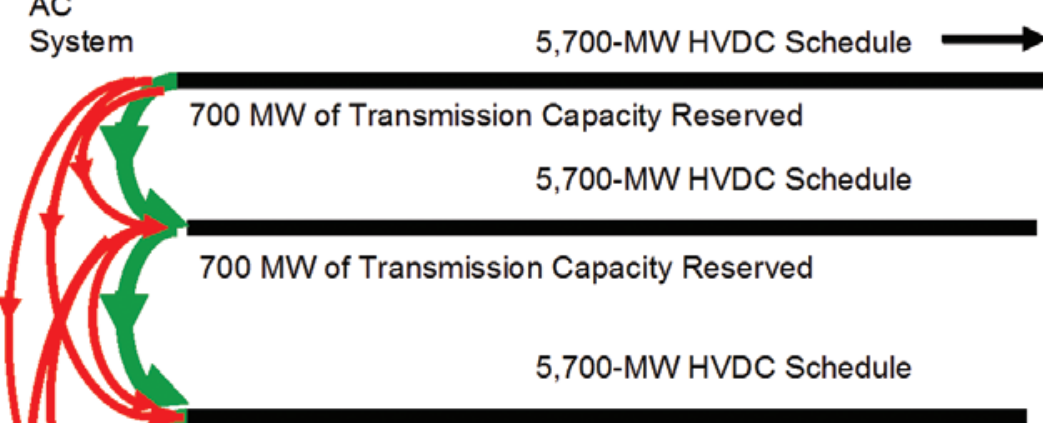

700 MW of Transmission Capacity Reserved

5,700-MW HVDC Schedule

700 MW of Transmission Capacity Reserved

5,700-MW HVDC Schedule

700 MW of Transmission Capacity Reserved

Total HVDC Schedule 28,500 MW

Figure 4-20. An example showing 800-kV HVDC lines (black) tied by 765-kV lines (green) and underlying 345-kV lines (red)

Postcontingency incremental flows are indicated in Figure 4-21. There is no change in generation. The postcontingent flows would be adjusted to a securityconstrained dispatch within 30 minutes. The HVDC schedules would be less than the initial 5,700 MW because there are fewer lines to distribute the contingency. Detailed power flows and dynamic simulations would have to be performed to fine-tune the transmission design.

The use of the underlying AC system during an outage of an HVDC line would be in return for the use of the HVDC transmission reserve capacity during AC disturbances or generator outages. The overlay has ample capacity to back up a 1,500-MW design limit used in this example. With the HVDC response to AC disturbances, the severity of the AC disturbances in the area of the contingency and elsewhere would be considerably reduced compared to the case with no HVDC and 765-kV overlays. The probability of an HVDC bipole outage is much lower than the probability of an AC outage on a 345-kV network or the loss of the largest generator.

The EWITS conceptual transmission design uses three terminal HVDC lines that would tap the lines in the middle of the line. Three terminal lines would reduce the area affected by a contingency and reduce the impact of a contingency as more HVDC terminals than the end terminals could respond to the HVDC 
contingency. The AC system would not have to deliver power over such long distances because some of the power could be rescheduled back on the HVDC lines at the third terminal. The conceptual design of the overlay would be more robust than that of the example (an example of an overlay with three terminal HVDC lines would be too complex to show here).

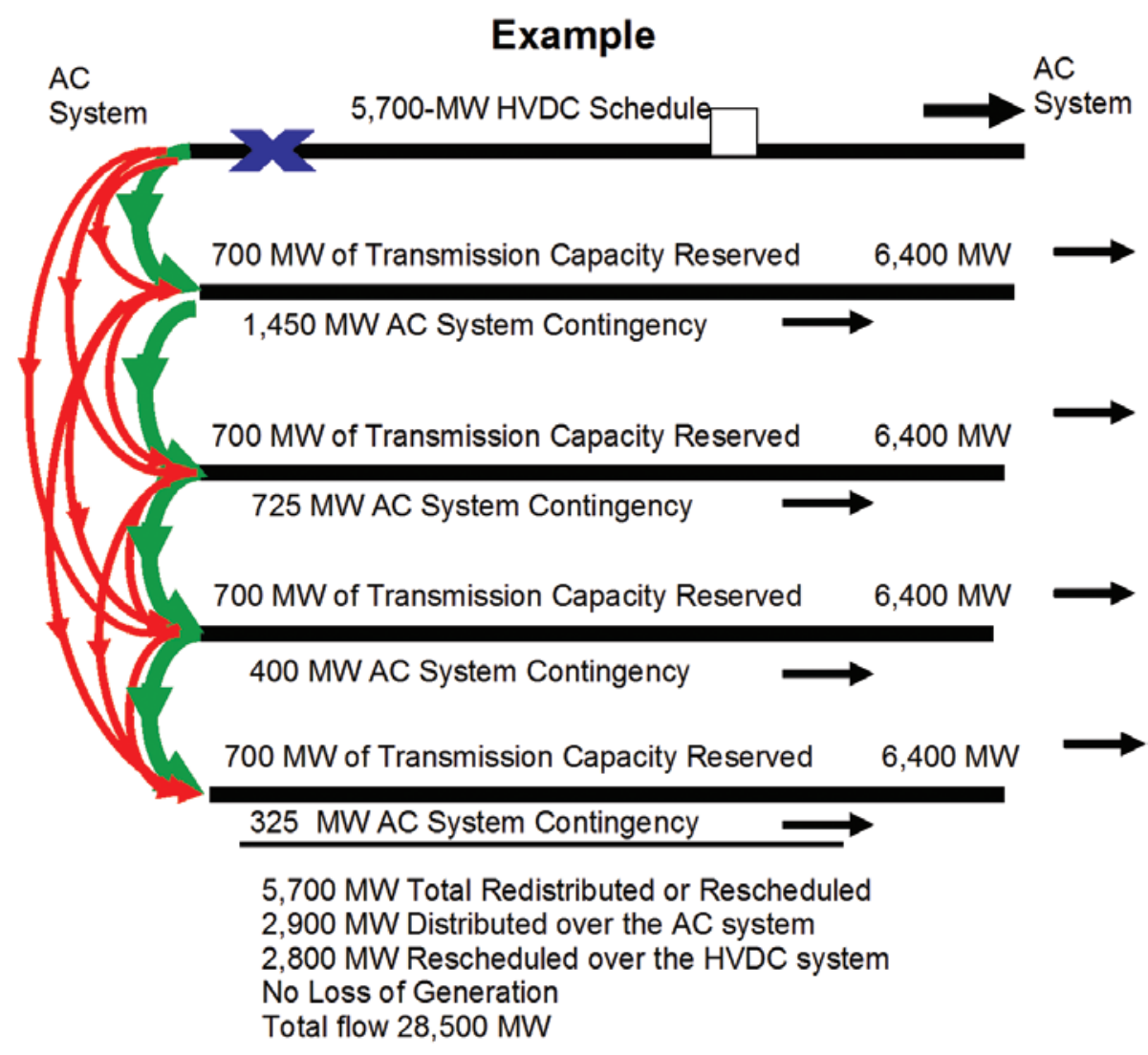

Figure 4-21. A postcontingency example showing five 800-kV HVDC lines (black) example tied by 765-kV lines (green) and underlying 345-kV lines (red)

Figure 4-22 details the assumed distribution of the flows on the underlying AC system for the example. The impact of a contingency is expected to reduce with distance from the area in which it occurs. 


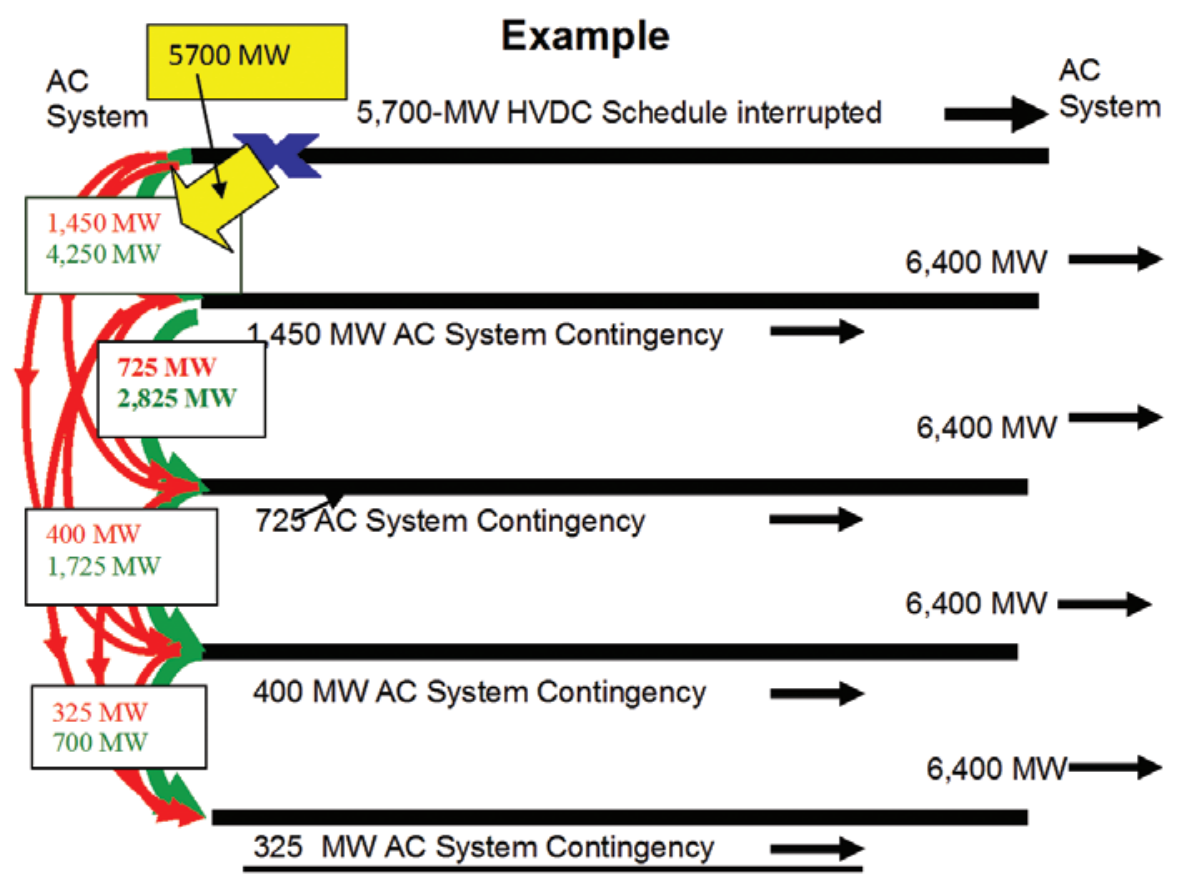

5,700 MW Total - 2,900 MW on AC and 2,800 MW on HVDC

A $10 \%$ Redistribution of Flow on the AC system

Figure 4-22. An example of the assumed distribution of the flows on the underlying $A C$ system

The overlay is designed not to have an impact greater than 1,500 MW on any part of the underlying (red, 345-kV) AC system. The amount of power that can be scheduled on an HVDC line depends on the following:

1. The number of HVDC lines

2. The power transfer capacity of the $765-\mathrm{kV}$ lines to move energy from an outage of the top HVDC line in these examples to the other HVDC lines and the other underlying 345-kV AC systems.

3. The rating of the underlying AC systems to be able to withstand a contingency in its area. A rating of 1,500 MW is assumed for these examples.

Again, a large number of detailed power flow and dynamic studies must be completed before the conceptual transmission plan in EWITS could be refined into a ready-for-construction transmission plan. 


\section{SECTION 5: POWER SYSTEM REGULATION AND BALANCING WITH SIGNIFICANT WIND GENERATION}

Matching the supply of electrical energy to the demand for electricity, over time frames ranging from seconds to decades, is a fundamental building block for maintaining resource adequacy in the bulk power system. Wind generation introduces additional variability and uncertainty that make the general task incrementally more challenging.

\section{POWER SYSTEM OPERATION AND CONTROL}

Power system operation is near the real-time end of the spectrum of the operating time horizon. To maintain system reliability in day-to-day operations, several functions are necessary. These functions have traditionally been performed by individual utility "control areas," and now can be performed by one or several entities in a balancing authority that have been approved by the North American Electric Reliability Corporation (NERC). These reliability functions can be categorized by different names and are sometimes broken down into more components depending on the context. These functions-or ancillary services-follow:

1. Scheduling (unit commitment), system control, and dispatch

2. Reactive supply and voltage control from generation

3. Energy imbalance

4. Regulation and frequency response

5. Operating reserve-spinning

6. Operating reserve-supplemental (e.g., nonspinning)

7. Generator imbalance

As a result of the Energy Policy Act of 2005, reliability standards are now mandatory in the United States, and NERC is the federally mandated Electric Reliability Organization (ERO). In the NERC Functional Model, the actions in the list are called reliability-related services. These include the range of services, other than supplying energy for load, that are physically supplied by generators, transmitters, and loads to maintain reliability.

\section{OPERATIONAL STRUCTURE}

A balancing authority operates within metered boundaries that define a balancing authority area (BAA). Every element of the bulk power system-generator, transmission facility, and end-use customer-is in one and only one BAA. 
The four synchronous interconnections in the United States and Canada each comprise one or more BAAs (the Electric Reliability Council of Texas [ERCOT] and Quebec are single BAAs). The original BAAs—except for the three "tight" power pools in the Northeast (the New England Independent System Operator [ISO-NE], the New York ISO [NYISO], and the PJM Interconnection [PJM])were previously individual electric utility control areas.

The restructuring of the electric power industry over the past two decades and the emergence of wholesale energy markets have reduced the number of both BAAs and balancing authorities (Figure 5-1). Further consolidation is expected over the coming years. The Midwest ISO and the Southwest Power Pool (SPP) regional transmission organizations (RTOs) are examples. Balancing authorities that are part of the Midwest ISO (shown as MISO RTO in Figure 5-2) energy market, located in the Midwest Reliability Organization (MRO), Mid-American Interconnected Network (MAIN), Southeastern Electric Reliability Council (SERC), and ReliabilityFirst Corporation (RFC) regional reliability organizations, were consolidated under a single BAA when the Midwest ISO ancillary services market started up. The SPP RTO began market operations with an Energy Imbalance Service and is transitioning to other offerings that could eventually supplant conventional individual balancing authority functions within its market footprint.

In this Eastern Wind Integration and Transmission Study (EWITS), the subset of reliability-related services that involve the control of generation to meet demand, facilitate the delivery of wind energy, and maintain the security of the bulk power system is of primary interest. All are covered in this section, which also focuses on the control of generation in real time in response to changes in wind generation and load. The generation capacity assigned to serve these roles is generally known as reserves, and specific categories of reserves are designated to fulfill specific functions.

The terminology for reserves is not rigidly defined, and varies by region and country. For example, common definitions for operating reserve categories used in the Union for the Co-ordination of Transmission of Electricity (UCTE) in Europe are different than those used in the United States. Even within the United States, variations in operational practice have led to reserve definitions that are not uniform across the country.

Table 5-1 lists relevant definitions from the NERC Glossary of Terms Used in Reliability Standards. ${ }^{4}$ The definitions are somewhat overlapping-operating reserve comprises regulating reserve and contingency reserve-and not completely consistent or precise; "operating reserve-spinning" does not seem to include regulating reserve, and the general category of operating reserve 
does. Mapping each of these terms to the reliability-related services in the NERC Functional Model is also not straightforward.

For purposes of this study, the categories of operating reserve to be specifically evaluated are as follows:

- Regulating reserve: Generation responsive to automatic generation control (AGC) that is adjusted to support the frequency of the interconnection and compensate for errors in short-term forecasts of balancing area demand.

- Contingency reserve: The unloaded capacity carried to guard against major system disruptions such as the sudden loss of a large generating unit or major transmission facility.

- Contingency reserve-spinning: That portion of the contingency reserves that is synchronized to the system and fully available to serve load within the time specified by the NERC Disturbance Control Standard (DCS).

- Contingency reserve-supplemental: That portion of the contingency reserve consisting of generation that is either synchronized to the system or capable of being synchronized to the system within a specified window of time that is fully available to serve load within the time specified by the NERC DCS. 

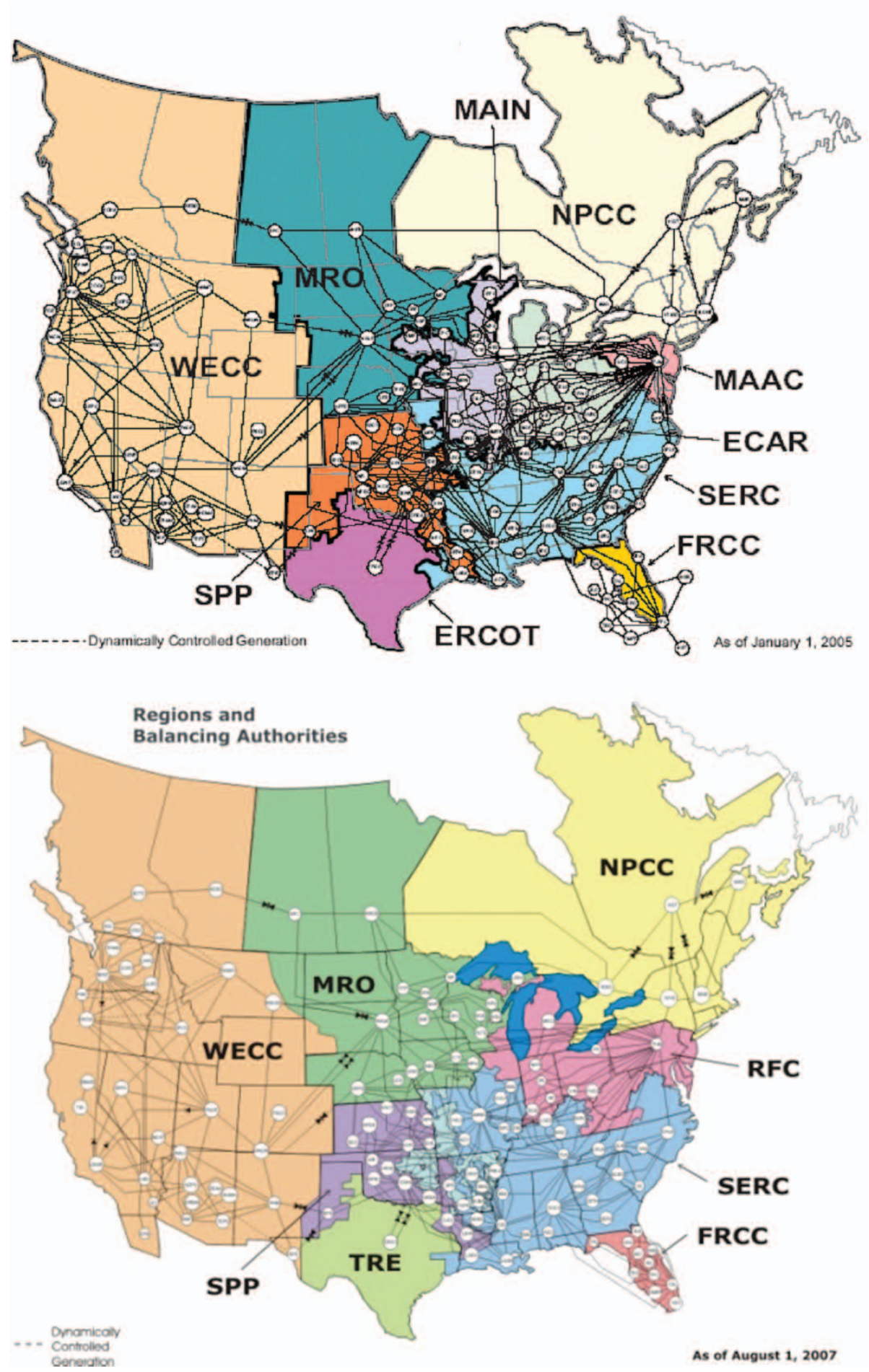

Notes: WECC $=$ Western Electricity Coordinating Council; FRCC $=$ Florida Reliability Coordinating Council; NPCC = Northeast Power Coordinating Council; TRE = Texas Regional Entity. The MidAtlantic Area Council (MACC) and the East Central Area Reliability Coordinating Agreement (ECAR) are NERC reliability regions that no longer exist.

Figure 5-1. NERC reliability regions and balancing authorities as of January 2005 (top) and August 2007 (bottom) 


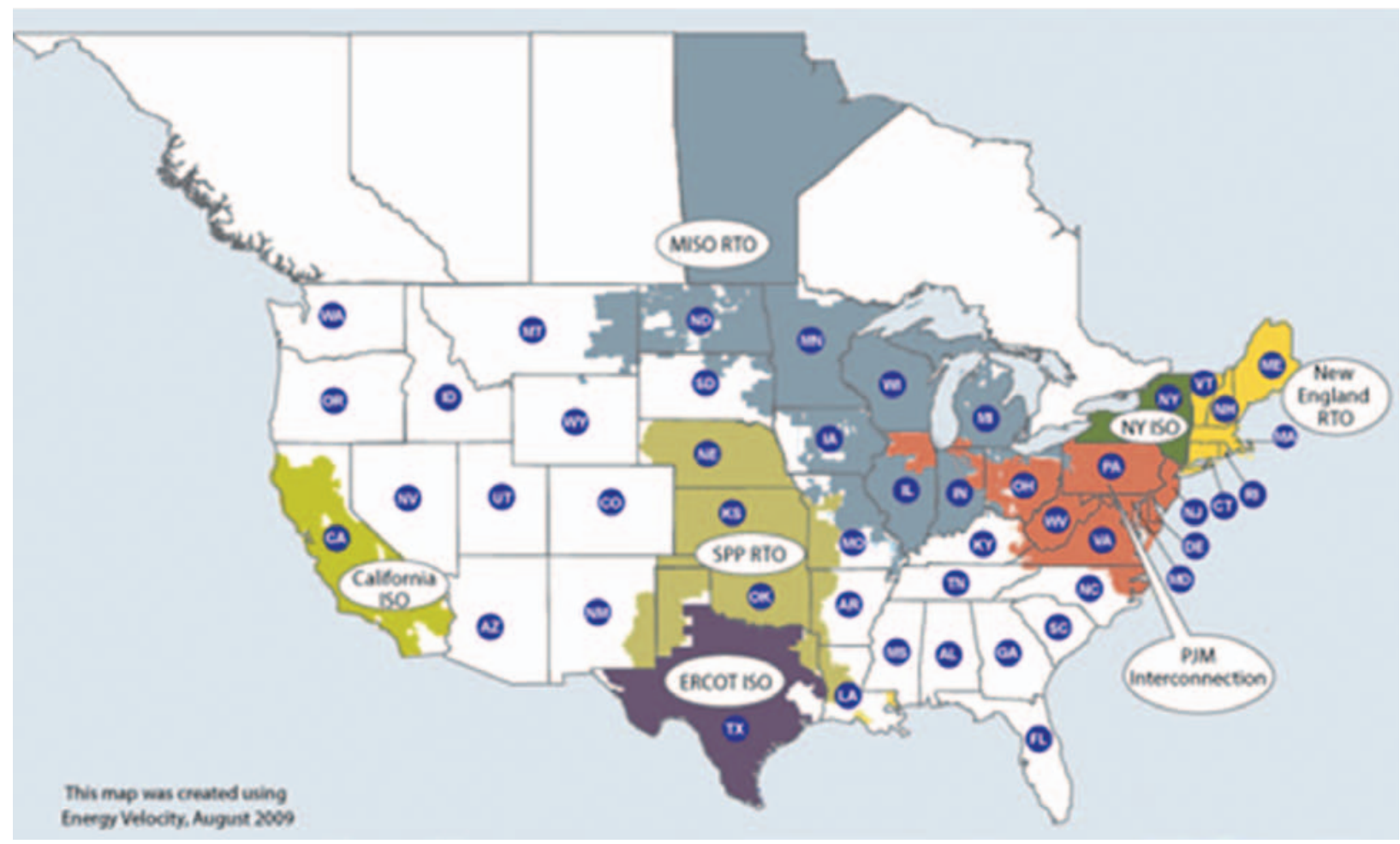

Figure 5-2. U.S. RTOs 


\begin{tabular}{|c|c|}
\hline TERM & DEFINITION \\
\hline ANCILLARY SERVICE & $\begin{array}{l}\text { Those services necessary to support the transmission of } \\
\text { capacity and energy from resources to loads while maintain- } \\
\text { ing reliable operation of the transmission service provider's } \\
\text { transmission system in accordance with good utility practice. }\end{array}$ \\
\hline CONTINGENCY RESERVE & $\begin{array}{l}\text { The provision of capacity deployed by the balancing author- } \\
\text { ity to meet the DCS and other NERC and regional reliability } \\
\text { organization contingency requirements. }\end{array}$ \\
\hline OPERATING RESERVE & $\begin{array}{l}\text { That capability above firm system demand required to pro- } \\
\text { vide for regulation, load forecasting error, forced and sched- } \\
\text { uled equipment outages, and local area protection. Consists } \\
\text { of spinning and nonspinning reserve. }\end{array}$ \\
\hline $\begin{array}{l}\text { OPERATING RESERVE- } \\
\text { SPINNING }\end{array}$ & $\begin{array}{l}\text { The portion of operating reserve that consists of } \\
\text { - Generation synchronized to the system and fully } \\
\text { available to serve load within the disturbance recovery } \\
\text { period that follows the contingency event } \\
\text { - Load that can be fully removed from the system within } \\
\text { the disturbance recovery period after the contingency } \\
\text { event. }\end{array}$ \\
\hline $\begin{array}{l}\text { OPERATING RESERVE- } \\
\text { SUPPLEMENTAL }\end{array}$ & $\begin{array}{l}\text { The portion of operating reserve that consists of } \\
\text { - Generation (synchronized or capable of being synchro- } \\
\text { nized to the system) that is fully available to serve load } \\
\text { within the disturbance recovery period that follows } \\
\text { the contingency event } \\
\text { - Load that can be fully removed from the system within } \\
\text { the disturbance recovery period after the contingency } \\
\text { event. }\end{array}$ \\
\hline REGULATING RESERVE & $\begin{array}{l}\text { An amount of reserve that is responsive to AGC, which is suf- } \\
\text { ficient to provide normal regulating margin. }\end{array}$ \\
\hline SPINNING RESERVE & $\begin{array}{l}\text { Synchronized unloaded generation that is ready to serve ad- } \\
\text { ditional demand. }\end{array}$ \\
\hline
\end{tabular}

${ }^{a}$ Adapted from http://www.nerc.com/files/Glossary_12Feb08.pdf. Accessed December 2009. ${ }^{b}$ From Federal Energy Regulatory Commission (FERC) Order 888-A. See http://www.ferc.gov/legal/ maj-ord-reg/land-docs/order888.asp. Accessed December 2009.

\section{MANAGING VARIABILITY}

Each BAA must assist the larger interconnection with maintaining frequency at the target level (usually 60 hertz [Hz]) and must maintain scheduled energy flows to the BAAs with which it is interconnected. Balancing real power supply with real power demand is the means by which frequency is maintained. Regulation and load following are mechanisms for achieving this control under normal operating conditions. Figure 5-3 illustrates the load characteristics that drive the demand for these services. Variations in the aggregate electric demand are continuous, and can be roughly separated into two components:

- Fast variations, nearly random in nature, that result from a great number (millions) of individual decisions or actions like flipping light switches 
- Slower trends that are relatively predictable, such as the rising load in the morning and the falling load through the evening into nighttime.

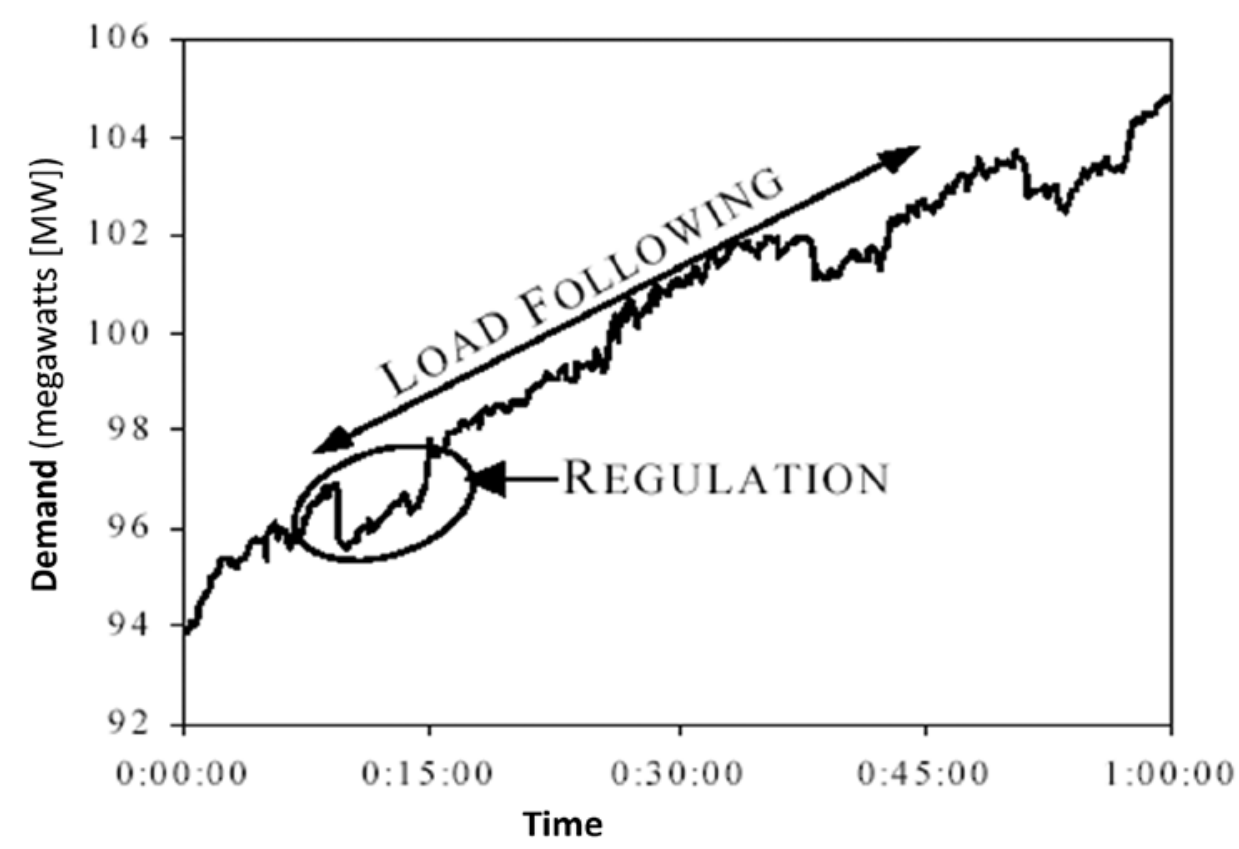

Figure 5-3. Depiction of regulation and load-following characteristics of demand

Generation units on regulation duty are adjusted to compensate for random or sudden changes in demand. These adjustments take place automatically through AGC and occur, depending on the characteristics of the balancing area, over tens of seconds to a minute. Regulation movements both up and down are required, and the amount of net energy over a period is small because the movements tend to cancel each other. To offer regulation, therefore, a generating unit must reserve capacity and operate below its maximum (to reserve room for upward movement) and above its minimum (for downward movement). In addition, only generating units that meet the balancing authority's requirements for providing regulation and frequency service can participate in the regulation market.

The term "load following" does not appear in NERC's glossary, but is generally taken to mean the adjustment of generation over periods of several minutes to hours to compensate for changes in demand. Generation movement is in response to economic-dispatch commands from the balancing area energy management system (EMS). In real-time or subhourly energy markets, clearing points are determined from short-term forecasts of demand, and generating units participating in that market are instructed to move to the forecast clearing point. Subhourly market intervals as short as 5 minutes are used today, with the clearing points established two or three intervals prior.

Subhourly markets are dispatched economically, meaning that the least costly units available (i.e., those participating in the subhourly market) that satisfy 
system security constraints are called on to follow the forecast change in demand. Regulation service requires a commitment on the part of generators to leave capacity both up and down and to allow their units to be moved automatically by the market operator. Consequently, analysis of current market operation reveals that regulation can be quite expensive (Kirby et al. 2009). Conversely, load following obtained in subhourly markets is not. Although prices within the hour can vary dramatically, on average prices in subhourly markets track day-ahead energy prices quite closely. This has important consequences for the method used to calculate incremental operating reserve requirements with large amounts of wind generation.

\section{MEASURING CONTROL PERFORMANCE}

A running evaluation of control performance is kept for each BAA. The primary measure of control performance is area control error (ACE). The equation for a $\mathrm{BAA}^{\prime}$ s ACE has interchange and frequency error terms:

$$
A C E=\left(N I_{A}-N I_{S}\right)-10 \beta\left(F_{A}-F_{S}\right)-I_{M E}
$$

where

$\mathrm{NI}_{\mathrm{A}}=$ the sum of the actual interchange with other balancing areas

$\mathrm{NI}_{\mathrm{S}}=$ the total scheduled interchange with other balancing areas

$\beta=\quad$ the balancing area frequency bias, reflecting the fact that load will change with frequency

$\mathrm{F}_{\mathrm{A}}=\quad$ the actual frequency of the interconnection

$\mathrm{F}_{\mathrm{S}}=\quad$ the scheduled frequency of the interconnection; usually $60 \mathrm{~Hz}$, although there are times when the scheduled frequency is slightly above or below the nominal value to effect what is known as "time error correction"

$\mathrm{I}_{\mathrm{ME}}=$ metering error, which is neglected for the purposes of this discussion.

ACE is computed automatically by the balancing area EMS every few seconds. The adequacy of generation adjustments by the balancing area operators and the EMS is gauged by two metrics that use ACE as an input. The first metric, Control Performance Standard 1 (CPS1), uses ACE values averaged over a 1-minute period. It is a measure of how the balancing area is helping to support and manage the frequency of the entire interconnection. If the interconnection frequency is low, it signifies that demand exceeds generation (the "machine" is slowing down). If a particular balancing area has a negative ACE, it is contributing to this frequency depression. Conversely, if the ACE were positive during that period, overgeneration in the balancing area would help restore the interconnect frequency. 
The CPS1 score for balancing authorities is based on performance over a rolling 12-month period. This score must be greater than $100 \%$, which is an artifact of the equations used to compute the compliance factor. Maintaining adequate capacity on AGC is a major factor in complying with CPS1.

The second metric is Control Performance Standard 2 (CPS2). It uses the average ACE over a 10-minute period. Over each period, the 10-minute average ACE for a balancing area must be within specific bounds, known as L10. These bounds, which are unique for each balancing area, are generally based on system size. Table 5-2 shows the 2009 CPS2 bounds for BAAs relevant to EWITS in the Eastern Interconnection.

\begin{tabular}{|c|c|c|c|c|c|}
\hline BAA & $\begin{array}{l}\text { ESTIMATED } \\
\text { PEAK } \\
\text { DEMAND } \\
(\mathrm{MW})\end{array}$ & $\begin{array}{l}\text { FREQUENCY } \\
\text { BIAS } \\
(\mathrm{MW} / 0.1 \mathrm{~Hz})\end{array}$ & $\begin{array}{l}\text { BIAS/LOAD } \\
\text { (\%) }\end{array}$ & $\begin{array}{l}\text { BIAS/TOTAL } \\
\text { BIAS } \\
(\%)\end{array}$ & $\begin{array}{l}\mathrm{L}_{10} \\
(\mathrm{MW})\end{array}$ \\
\hline NPCC & 93,851 & -975 & 1.04 & 14.98 & \\
\hline IESO & 25,657 & & 1.11 & 4.38 & 128.10 \\
\hline ISO-NE & 28,480 & -285 & 1.00 & 4.38 & 128.10 \\
\hline NBSO & 5,547 & -63 & 1.14 & 0.97 & 60.23 \\
\hline NYISO & 34,167 & -342 & 1.00 & 5.25 & 140.33 \\
\hline RFC & 245,175 & $-2,480$ & 1.01 & 38.10 & \\
\hline MISO & 110,625 & $-1,106$ & 1.00 & 16.99 & 252.36 \\
\hline PJM & 134,428 & $-1,344$ & 1.00 & 20.65 & 278.19 \\
\hline
\end{tabular}

Note: IESO - Independent Electricity System Operator; NBSO = New Brunswick Security Operator. Source: Adapted from http://www.nerc.com/docs/oc/rs/CPS2Bounds_2009.9b.pdf.

The CPS2 metric is tabulated monthly. To comply with CPS2 requirements, $90 \%$ or more of the 10-minute average ACE values must be within the designated L10 bounds for the balancing authority. Minimum performance allows 14.4 violations per day. Most balancing authorities maintain CPS2 scores in the mid-90\% range. The equations for average $\mathrm{ACE}$ and CPS2 follow:

$$
A V G_{10-\text { minute }}(A C E) \leq L_{10}
$$

$$
\text { CPS2 }=\left[1-\frac{\text { Violations month }}{\text { TotalPeriods month }- \text { UnavailablePeriods month }}\right] \cdot 100
$$

Balancing area compliance with NERC performance standards is defined as a combination of CPS1 and CPS2 scores:

- In compliance: CPS1 > 100\% and CPS2 >90\%

- Out of compliance: CPS1 $<100 \%$ or CPS $2<90 \%$.

Compliance is based solely on control performance relative to the required scores for the two metrics; required reserve amounts are not directly specified for each 
operating area. Each operating area must establish policies and practices to comply with the NERC standards.

Field trials of a new reliability-based control standard (NERC draft standard BAL-007-1) are under way. If adopted, two new performance metrics-CPM (control performance measure) and BAAL (balancing authority ACE limit)— would replace CPS1 and CPS2. The new metrics are designed to improve interconnection frequency support, reduce short-term frequency deviations caused by ramping associated with transaction schedules, and ensure timely transmission congestion relief. The effects of the new standards on the challenge of managing significant wind generation in a balancing area have not yet been studied quantitatively.

\section{MAINTAINING SYSTEM SECURITY}

To achieve high levels of reliability, the bulk power system must be operated so that it can withstand the loss of major elements without cascading failure or tripping of additional elements. It must also be able to resume normal operation within a specified period of time. The operating reserve elements of the reliability-related services listed previously are intended to preserve bulk power system security.

Contingency reserve is the conventional name for the spare generating capacity that can be called on in system emergencies. The spinning portion of the contingency reserve is synchronized with the grid and ready to respond immediately; off-line capacity that can be called on, started, and synchronized within a defined period of time (10 minutes or 30 minutes) makes up the nonspinning or supplemental contingency reserve.

Unlike reserves for regulation, which are for supporting normal system operations within applicable reliability criteria, contingency reserves that are spinning are not dispatched continuously by AGC in response to ACE and are held in reserves for system emergencies. They are also unidirectional, in that the ability to move upward-serve more load-is counted as contingency reserve.

Currently, the basis for the required contingency reserves varies across the interconnection. The need is usually defined by the magnitude of the top one or two largest loss-of-source events, which could result from a single contingency. For example, in an operating region where the largest plant is a 900-MW nuclear unit, enough additional generation must be available to cover the sudden loss of this large unit, assuming it normally operates at its rated output. In many reliability regions, a substantial portion of this additional generation must be synchronized with the grid (i.e., spinning). The required fraction of contingency reserves that must be spinning is often about $50 \%$ of total contingency reserves. 
Immediately on losing the large generator in the example, system frequency would begin to decline because the amount of load now exceeds the available supply. As frequency declines, however, governors on all generating units, whether they are regulating units, units participating in the energy market, or operating reserve units, would detect the abnormal low frequency. If the deviation is large enough or exceeds a defined deadband, the governors would increase the mechanical power inputs to the generators. The system operator would use the operating reserves to replace the loss of generation. The NERC DCS requires balancing authorities to rebalance their systems within 15 minutes of a major disturbance and to restore the deployed contingency reserves within 105 minutes.

\section{EFFECTS OF WIND GENERATION ON POWER SYSTEM CONTROL}

Actions to support frequency and maintain scheduled interchanges in a BAA are driven by the variety of errors in the generation and load balance. As a result, the effects of wind generation's variability and uncertainty on the net variability and uncertainty of the BAA's aggregate demand defines how a given amount of wind generation affects power system control. Measurable impacts would be manifested in increased requirements for regulation capacity and load-following capability. Wind plants typically do not affect contingency reserve requirements because the individual generators are relatively small.

Previous integration studies (see, for example, EnerNex Corporation and WindLogics 2004; GE Energy Consulting 2007; and AWS Truewind 2009;) have shown that the net variability concept is extremely important and the effects of aggregation and diversity are quite powerful. With load alone, in practice, the normalized variability of larger aggregations of load - that is, larger BAAs—is much less than for smaller areas. The same phenomenon is observed with wind generation because of spatial and geographic diversity effects. As the number of turbines grows and the area over which they are installed expands, the aggregate variability declines. When these aggregations increase to span multiple balancing authorities, realizing any potential benefit of these aggregations can require examining impacts on current operating protocols.

Figure 5-4 illustrates the effects of diversity on the variability of wind generation using actual scenario profile data. The curves represent the changes in wind generation over a 10-minute interval; the value plotted on the vertical axis is the standard deviation of all incremental changes over 3 years of data for hourly production levels (per unit) corresponding to the value on the horizontal axis. The curves illustrate that more variability can be expected when the wind generation is in the midrange of the aggregate nameplate production. Second, and also of great interest for EWITS, the per-unit variability declines greatly as more wind is aggregated. 


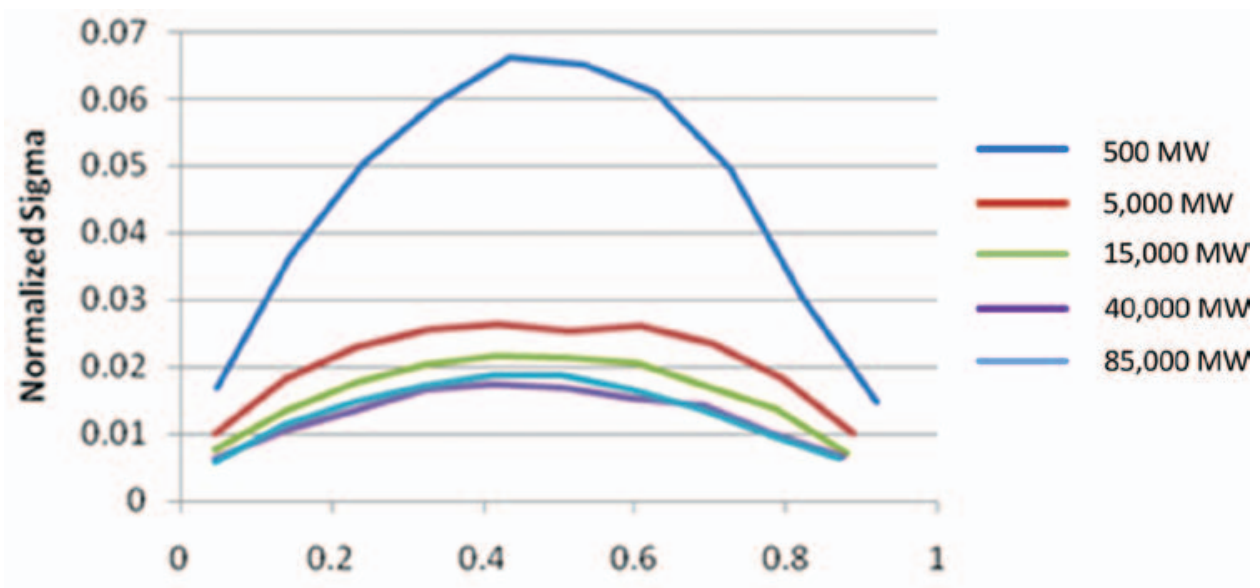

Production Level On Nameplate

Figure 5-4. Normalized 10-minute variability for five different groups of wind generation. The 500MW scenario is part of the 5,000-MW scenario, which is part of the 15,000-MW scenario, and so on.

The magnitude of the effects of diversity on the variability of the balancing authority net load will depend on the amount of wind generation relative to load, the variability of load alone, and the amount of diversity that characterizes the aggregate wind generation. Figure 5-5 uses actual load and wind data for Scenarios 1 and 3 to illustrate the effect on the Midwest ISO and PJM operating areas in EWITS. The charts show the variability of load by itself from one 10-minute interval to the next, along with the variability of load net of wind generation for the defined scenario.

In the Midwest ISO, wind generation in Scenario 1 has a greater effect on net variability because of the much higher amount of installed capacity. The converse is true for PJM-in Scenario 1 the variability is just slightly higher, and in Scenario 3, with much more installed wind generation capacity, the effect is much more pronounced. 

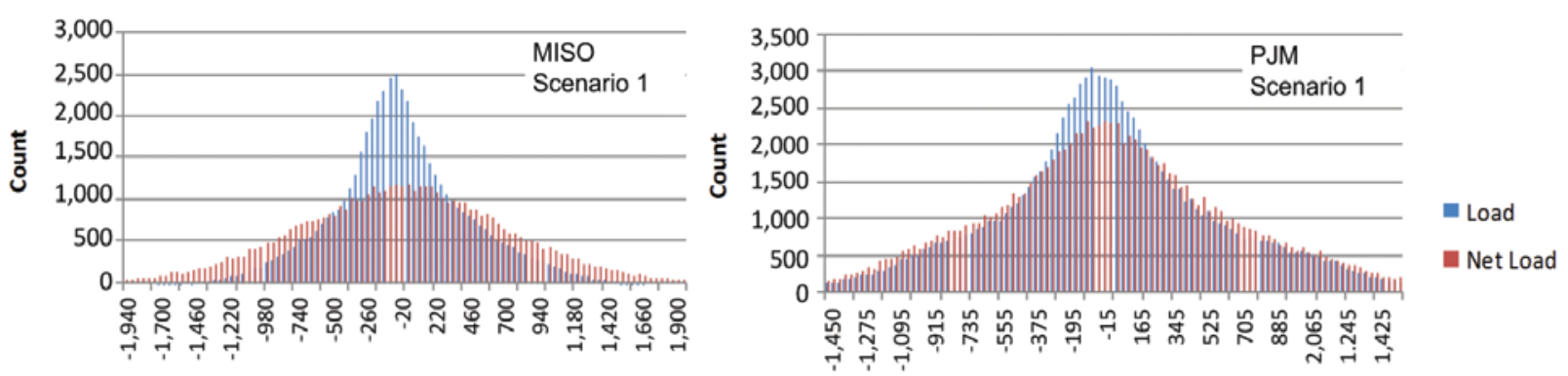

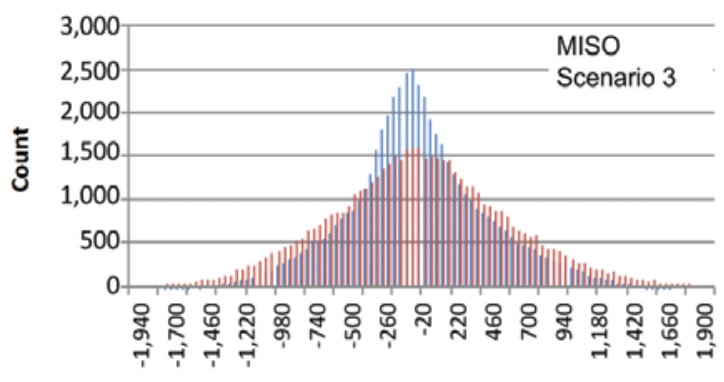

10-Minute Change in MW

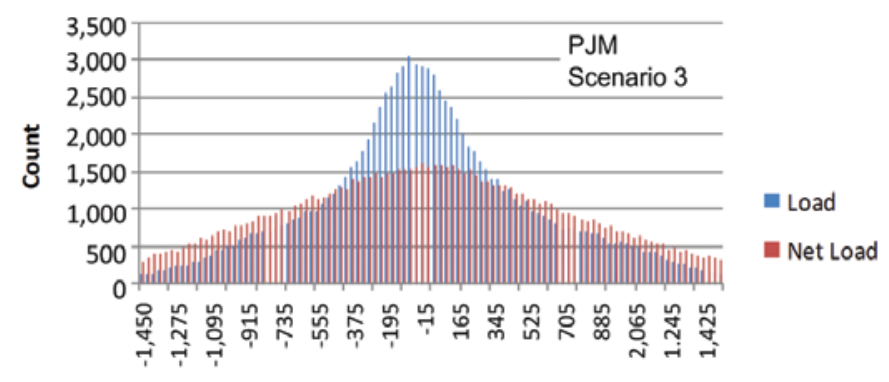

10-Minute Change in MW

Figure 5-5. Ten-minute variability of load and net load for MISO (left) and PJM (right). Scenario 1 is shown at the top and Scenario 3 is depicted on the bottom.

Changes in wind generation over other time frames must also be factored into operational practices. Large drops in wind energy production could be as large as the contingency for which operating reserves are carried, but there would be a significant difference in the event duration. The nuclear unit described earlier could be lost in an instant, producing 900 MW 1 minute and going off line the next. Large reductions in aggregate wind generation do not occur suddenlyinstead they can evolve over several hours. This is caused by the many individual turbines, the large geographic area over which they are installed, and the time it takes for major meteorological phenomena such as fronts to propagate.

Smaller, but more frequent, changes in wind generation over 1 to 4 hours are also operationally important. On these time scales, uncertainty about how much wind generation will be available becomes more important than variability. Because of the short lead time, replacement capacity for forecast wind generation that does not materialize in this time frame must be found. This replacement capacity can come from units already committed, regulating reserves (until economic replacement energy can be committed), units with quick-start capability if insufficient regulating reserves are available, or a neighboring balancing authority. Consequently, the expected error in wind generation forecasts over these horizons could play a role in the policy and practice for operating reserves. A centralized wind production forecast will assist balancing authorities in mitigating the impact of changes in wind generation; a level of operating reserves may, however, still be required to mitigate the remaining errors. 


\section{MODELING AND ANALYSIS FOR ASSESSING WIND INTEGRATION IMPACTS}

In the analysis of wind generation impacts on power system regulation and balancing, the EWITS team had two primary objectives:

- Starting with wind generation and load profile data, use engineering judgment and technical knowledge of power system operation and control to develop a methodology for estimating how wind generation in the study scenarios would be managed in real-time operations.

- Develop a process for mapping these requirements to the chronological production simulations that will be used to assess overall wind integration impacts.

The second bullet is very important to the overall analytical methodology employed in EWITS. The within-the-hour impacts of varying load and wind generation are accounted for, at least approximately, in the production simulations by setting constraints on the unit-commitment and economicdispatch algorithms. In each hour, specified amounts of reserves must be set aside and not used to serve load.

Impacts of changing load and wind generation are more explicitly considered in the production simulation at increments of 1 hour or more. Additional constraints are defined for each generating unit in terms of the amount of its output that can be changed over a single hour, maximum and minimum output, start-up and shutdown times, and minimum runtimes and downtimes. The unit-commitment and economic-dispatch steps must observe these constraints on each unit. Consequently, situations of specific interest for wind integration, such as minimum load and minimum generation periods, are evaluated in the production simulation program. Violations of constraints are reported, or appear as dump energy (see Glossary) or load that is not served.

\section{ASSUMPTIONS}

The U.S. electric power industry is trending toward larger effective operating pools, through either energy markets or interarea operating agreements. Previous wind integration studies (see Bibliography) concluded that larger operating areas are an effective means for managing wind integration because they take natural advantage of geographic diversity of load and wind and aggregate a larger set of discrete generating units to compensate for load variations; they also offer frequent economic dispatch of units with movement capability to follow slower variations in balancing area demand.

For the study horizon of 2024, the EWITS team assumed that the Eastern Interconnection will contain seven major operating areas corresponding to the current boundaries of the following entities, as shown in Figure 5-6: ISO-NE, NYISO, PJM, SPP, MISO, the Tennessee Valley Authority (TVA), and SERC. 
The first five correspond to current wholesale energy markets in the interconnection.

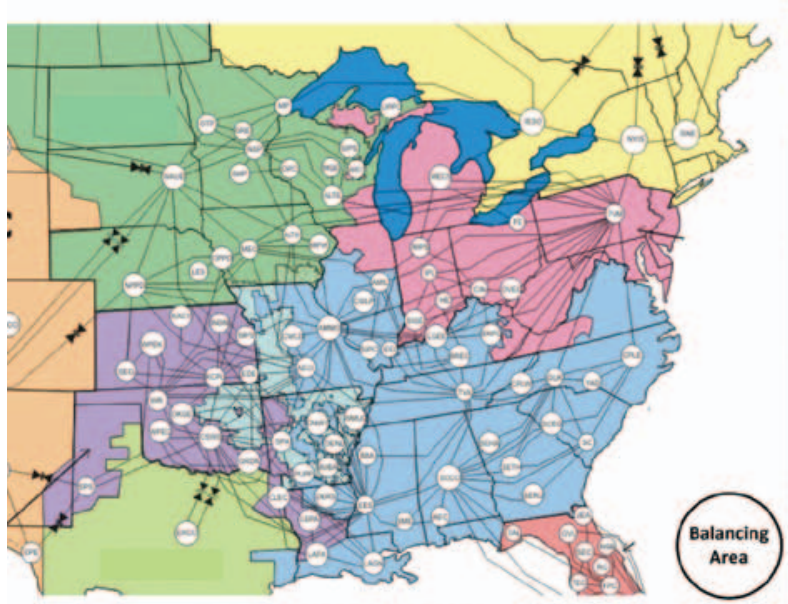

As of August 1, 2007

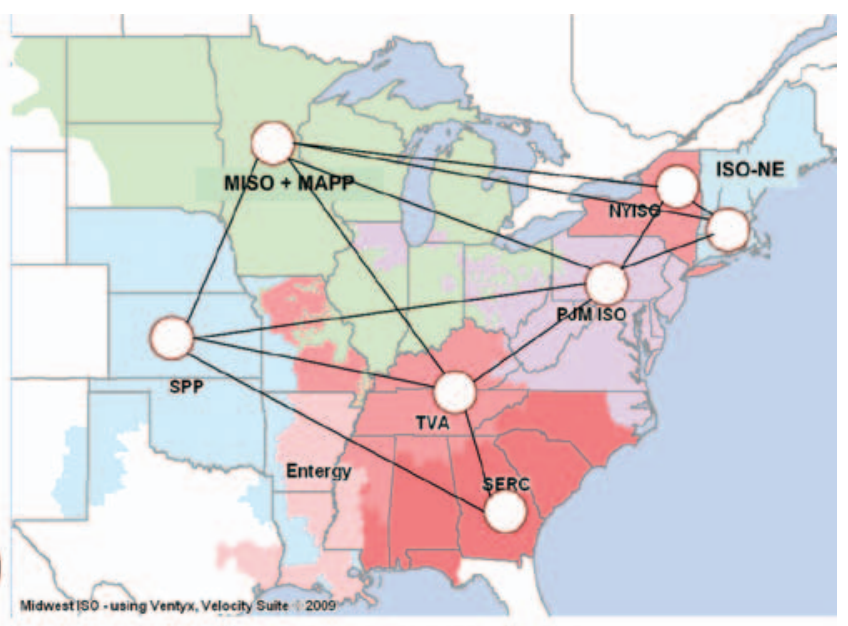

Assumption for 2024

Figure 5-6. Eastern Interconnection balancing authorities (existing on left; assumption for study on right)

The study team further assumed that by 2024 all operating areas will have a uniform structure in terms of market products, unit dispatch, and real-time operations and will fulfill the functions of a balancing authority. This structure consists of the following:

- A day-ahead energy market followed by a security-constrained unit commitment (SCUC) later on the day before the operating day.

- A real-time energy market, cleared at frequent intervals during the operating hour. Each real-time market clearing point is based on short-term forecasts of load and wind generation. To align with the data available for EWITS, the clearing interval was defined as 10 minutes, with the market clearing point based on information available at the previous 10-minute interval.

- An ancillary services market, where a large pool of resources competes to offer the defined regulating and operating reserves.

The areas modeled in this study currently operate according to these assumptions in varying degrees. Although the progress in consolidating and advancing markets in the direction of the study assumptions is significant, the operation of the entire study footprint under these assumptions by 2024 is not a foregone conclusion. Additionally, the project team assumed that reserves could be shared across the entire operating area footprint; transmission congestion internal to a region does not create subregions with reserve requirements that must be met locally.

There is a general recognition that wind generation, in the current operating and markets constructs, would face very real barriers to realizing these levels 
of wind energy penetration. This analysis, then, looks at wind impacts in a possible "future world" operating and market construct that might be able to accommodate high levels of wind. This study team also recognizes that considerable work remains to be done before this operating scenario could be realized.

The study analysts used existing practice as a starting point for estimating the amount of regulating reserve required for load alone. They assumed a value of $1 \%$ of the hourly load. Although that fraction of the forecast daily peak load for each hour of the day would have been somewhat more reflective of current practice and policies, $1 \%$ of hourly load is a reasonable working assumption.

\section{MAPPING RESERVE REQUIREMENTS FOR PRODUCTION SIMULATIONS}

The methodology used in this study for assessing the impacts and cost of integrating wind energy into a utility balancing area is based on chronological simulations of scheduling and real-time operations. The study team used production costing and other optimization tools to conduct these simulations. In most cases, the time step for these simulations is in 1-hour increments. As a result, many details of real-time operation cannot be simulated explicitly. Generation capacity that operators use to manage the system in real time-i.e., the units on AGC used by the EMS for fast response to ACE and the capacity that is frequently economically redispatched to follow changes in balancing area demand-is assigned to one or more reserve categories defined in the various tools.

At this level of granularity, the reserve requirements for the system are constraints on optimization and dispatch. Supply resources are designated by their ability to contribute to system requirements in one or more reserve categories. During optimization or dispatch, the solution algorithm must honor system reserve needs, meaning that some capacity cannot be used to meet load or fulfill transactions.

The reserve requirements with wind generation for the study operating areas were computed on a technical basis from the functional considerations for system reliability and security. To allow their use in the production simulations, the various reserve components had to be translated into the reserve categories considered by the simulation tools. For the large-scale production simulations in this study, only two types of reserves could be considered: spinning and nonspinning. Note that synchronized and nonsynchronized would be clearer terms here, as "spinning" is generally associated with a specific ancillary service. But because the simulation tools actually use the terms spinning and nonspinning, they are retained here. 
Table 5-3 shows the mapping for the reserve types discussed in this section. By definition, regulating reserve must be spinning, because it must continuously compensate for changes in balancing area demand to help control the frequency of the interconnection. In the mapping, the study team divided regulation into two components that were assumed to be additive. And, per the NERC glossary definition, regulation is also carried to cover errors in demand forecasts, so the team assigned forecast error as a regulation category as well. The rationale for this is explained in detail later in this section.

According to the reliability-related services definition, contingency reserve consists of both spinning and nonspinning portions. It was computed for the study scenarios as described in the next section.

\begin{tabular}{|c|c|c|}
\hline RESERVE COMPONENT & SPINNING (\%) & NONSPINNING (\%) \\
\hline $\begin{array}{l}\text { REGULATION } \\
\text { (VARIABILITY) }\end{array}$ & 100 & 0 \\
\hline $\begin{array}{l}\text { REGULATION } \\
\text { (FORECAST ERROR) }\end{array}$ & 100 & 0 \\
\hline CONTINGENCY & $\begin{array}{r}50 \\
\text { (or designated fraction) }\end{array}$ & (or designated fraction) \\
\hline
\end{tabular}

\section{CONTINGENCY RESERVES}

Because sufficient contingency reserves are maintained to respond to the largest generator within a balancing authority or as part of a reserve-sharing group, it is conceivable that the existing contingency reserves are sufficient to maintain the same level of reliability at varying levels of wind penetration. Contingency reserves would need to be increased if it were determined that the total output of a wind plant or multiple wind plants within a specific area is larger than the current contingency and has the potential to trip off line within a few minutes.

In this study, the team assumed that the spinning and nonspinning (supplemental) contingency reserves would not influenced by the amount of wind generation in the operating area, but would instead be a function of conventional equipment and the network, as is the current practice.

The operating regions defined for EWITS do not exactly conform to the existing reliability regions and reserve-sharing groups. Consequently, it was necessary to define requirements for contingency reserves on another basis. Where no information was available from current practice, the total contingency reserve requirement was defined as 1.5 times the single largest hazard (SLH) in the operating area. At least half of this requirement was required to be spinning. 
The transmission overlays developed in Section 4 result in large high-voltage DC (HVDC) terminals in most of the operating areas in EWITS. The rating of an individual terminal is 1,600 MW, which would mean that the total contingency reserve requirement-assuming that the terminal is the SLH-would be 2,400 MW. The 800-kilovolt (kV) extra-high voltage DC (EHV DC) overlays, however, assume a self-redundant design; the maximum transfer on any single DC element of the overlay is limited so that if it were to fail, the transfer could be picked up by other portions of the DC overlay. Individual terminals are limited to 1,500 MW. Consequently, the contingency reserve requirement is established by the existing $\mathrm{AC}$ equipment for each area, and does not vary between the Reference Scenario and the high-penetration scenarios.

Table 5-4 lists the assumed contingency reserve requirements for each operating region and scenario. The requirement is split 50/50 between spinning and nonspinning (supplemental) except in the Midwest ISO, the PJM, and the TVA.

\begin{tabular}{|l|l|l|}
\hline \multicolumn{4}{|l|}{ TABLE 5-4. CONTINGENCY RESERVE REQUIREMENTS BY OPERATION REGION FOR 2024 } \\
\hline REGION & $\begin{array}{l}\text { CONTINGENCY RESERVE } \\
\text { REQUIREMENT-ALL } \\
\text { SCENARIOS } \\
\text { (MW) }\end{array}$ & $\begin{array}{l}\text { SPINNING/SUPPLEMENTAL } \\
\text { SPLIT } \\
(\%)\end{array}$ \\
\hline ISO-NE & 1,158 & $50 / 50$ \\
\hline NYISO & 1,200 & $50 / 50$ \\
\hline PJM & 3,350 & $100 / 0$ \\
\hline SPP & 1,539 & $50 / 50$ \\
\hline MISO & 2,271 & $100 / 0$ \\
\hline TVA & 1,750 & $23 / 77$ \\
\hline SERC (partial) & 1,140 & $50 / 50$ \\
\hline
\end{tabular}

Note: The spinning contingency reserve assumed for PJM is high by about $50 \%$. Because of the size of the PJM market, effects of the error on the results were deemed to be minimal.

\section{REGULATION AND LOAD FOLLOWING}

The approach for calculating the incremental regulation and load-following capacity required to maintain control performance in each study BAA was based on observations from current market operations and experience from previous studies.

The minute-to-minute variability of wind generation, relative to that of the aggregate load, is very small. Because the National Renewable Energy Laboratory's (NREL) mesoscale data only goes down to a 10-minute resolution, actual wind data collected by NREL (Wan 2004) and others was used for the analysis in the quicker time frames.

Those measurement data show that the standard deviation of the minute-tominute variability - faster than that which can be dealt with by the subhourly 
energy market or subhourly scheduling — is about $1 \mathrm{MW}$ for a 100-MW wind plant, based on separating the fastest variations from longer term trends using a 20-minute rolling average window. (As the results show, the details of this process - i.e., resolution of the data, width of the averaging window-are not critical to the results and conclusions.)

Minute-to-minute variability is also uncorrelated between individual wind plants and between wind and load. Considering a BAA with 100 gigawatts (GW) of load and $60 \mathrm{GW}$ of wind generation, the impact of wind generation on the fast variations of the net BAA demand can be estimated:

- Assume that the $60 \mathrm{GW}$ of wind generation is made up of 100-MW plants (to use the variability characteristics given previously). If each of the 100MW plants exhibits a minute-to-minute variability of $1 \mathrm{MW}$ (as measured by the standard deviation of these variations), and they are uncorrelated with similar variations from other wind plants in the sample, the standard deviation of the variability for all $60 \mathrm{GW}$ would be as follows:

$$
\sigma_{(\text {aggregate wind })}=\sqrt{\left(\frac{60,000}{100}(1 \mathrm{MW})^{2}\right)}=24.5 \mathrm{MW}
$$

- Assume that the $1 \%$ regulation amount carried for load alone (100 GW of load in this example) is three times ${ }^{5}$ the standard deviation of the load variability on this same time scale:

$$
\sigma_{\text {load }}=\frac{100,000 \cdot 0.01}{3}=333.3 \mathrm{MW}
$$

- The standard deviation of the load net of wind generation, which is a basis for the regulating reserve, can be computed assuming that the fast variations from load are not correlated with those from the aggregate

$$
\sigma_{\text {Total }}=\sqrt{\left({\sigma_{\text {load }}}^{2}+\sigma_{(\text {aggregate wind })}^{2}\right)}=334.2 \mathrm{MW}
$$

As the calculations show, the effect of the fast variations in aggregate wind production is negligible.

Considering the uniform structure assumed for the operating areas in EWITS, it becomes apparent that wind variability would most likely have larger impacts on time scales associated with the subhourly markets and economic dispatch of generating resources.

5 A multiple of 3 times the standard deviation encapsulates almost $99.9 \%$ of all samples in a normal distribution. There is precedent in the U.S. electric utility industry for using a multiplier of 3, although instances of higher multiples can be found. The multiplier assumed here is thought to be more appropriate for the very large balancing areas defined for the 2024 scenario. In smaller balancing areas, multipliers of up to 5 are used. 
Subhourly market clearing points are based on short-term forecasts of demand. In an existing 5-minute energy market, for example, the clearing point is based on projections of demand made 15 to 20 minutes before the interval. Participating units are instructed to move to cover the projected change in load; any difference between the forecast load and the actual load for the interval (assuming that all generating units follow dispatch instructions precisely) will effectively "spill over" into the regulation bin.

Very-short-term aggregate forecasts of large amounts of load can be quite accurate. For wind generation, the variations over these same time periods are less so. Errors in the short-term forecast of wind generation will therefore increase the requirement for regulation.

The wind generation profile data at a 10-minute resolution for each scenario were used to estimate this impact on regulation. Using a persistence forecast, where the average production for the last several intervals (six intervals in this case) is the forecast for the next 10-minute interval, the expected error in this simple, short-term wind generation forecast can be easily calculated and characterized. Persistence performs reasonably well as a forecast technique for limited horizons, on average. Other techniques might be better for predicting significant ramps, but over all the intervals in a year, those techniques might not outperform simple persistence. The team's objective here was to employ a simple, yet reasonable, approximation to a more sophisticated approach that would be used in practice.

Figure 5-7 illustrates the short-term forecast errors for load and wind generation with data from one of the scenarios and operating regions. Here the study team assumed that the subhourly market operates on 10-minute intervals (to match the resolution of data available for this study), and the load forecast is generated one interval prior. A simple regression-extrapolation technique performs very well for forecasting load; this is most likely caused by the smoothness of the variations. In reality, more sophisticated techniques are used, and can account for the expected load shape and other factors that would further improve performance near peak intervals.

The persistence forecast for wind generation performs reasonably well, but the variations at 10-minute intervals for even this large amount of wind generation exhibit more volatility than is observed in the aggregate load. Consequently, the errors in wind generation forecasts dominate the net error, as Figure 5-8 shows. 


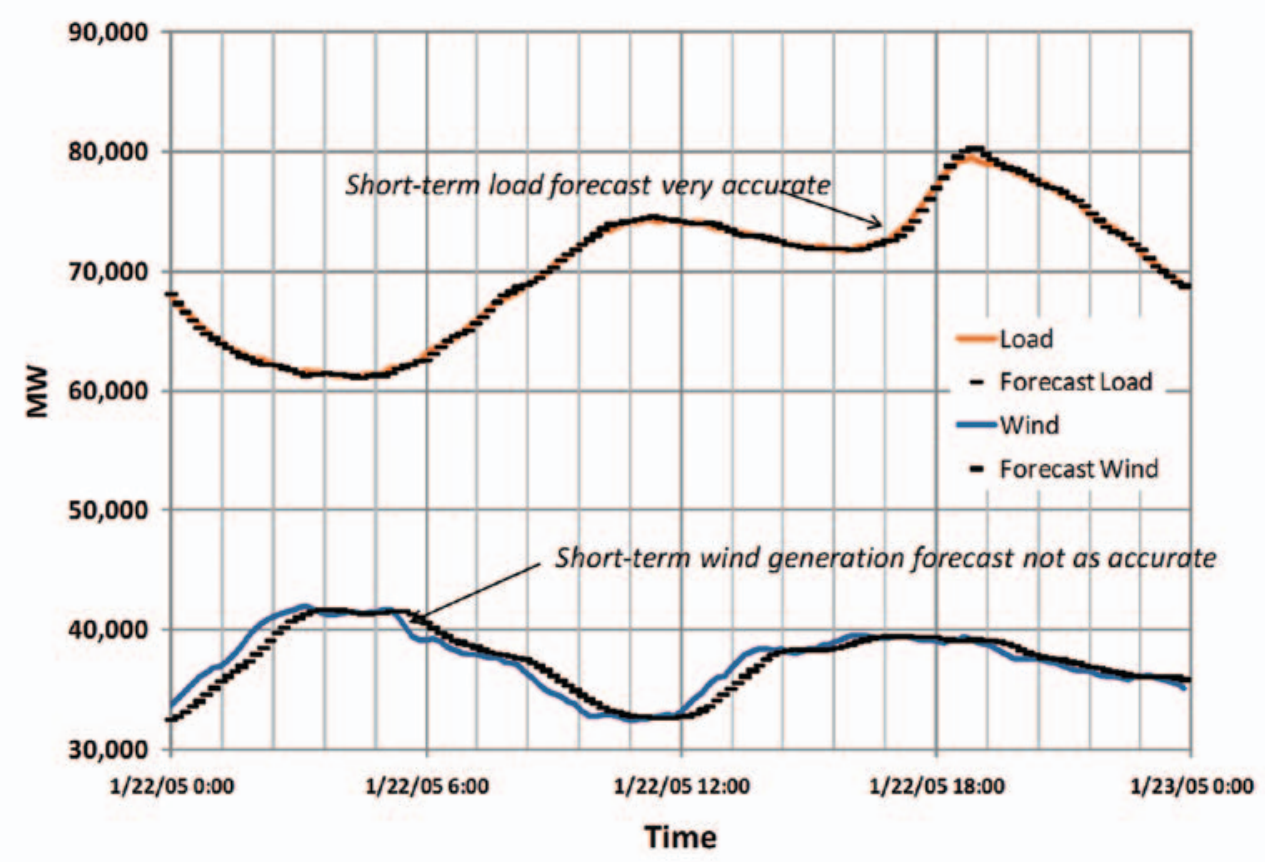

Figure 5-7. Illustration of short-term (next 10-minute interval) forecasts of load and wind generation

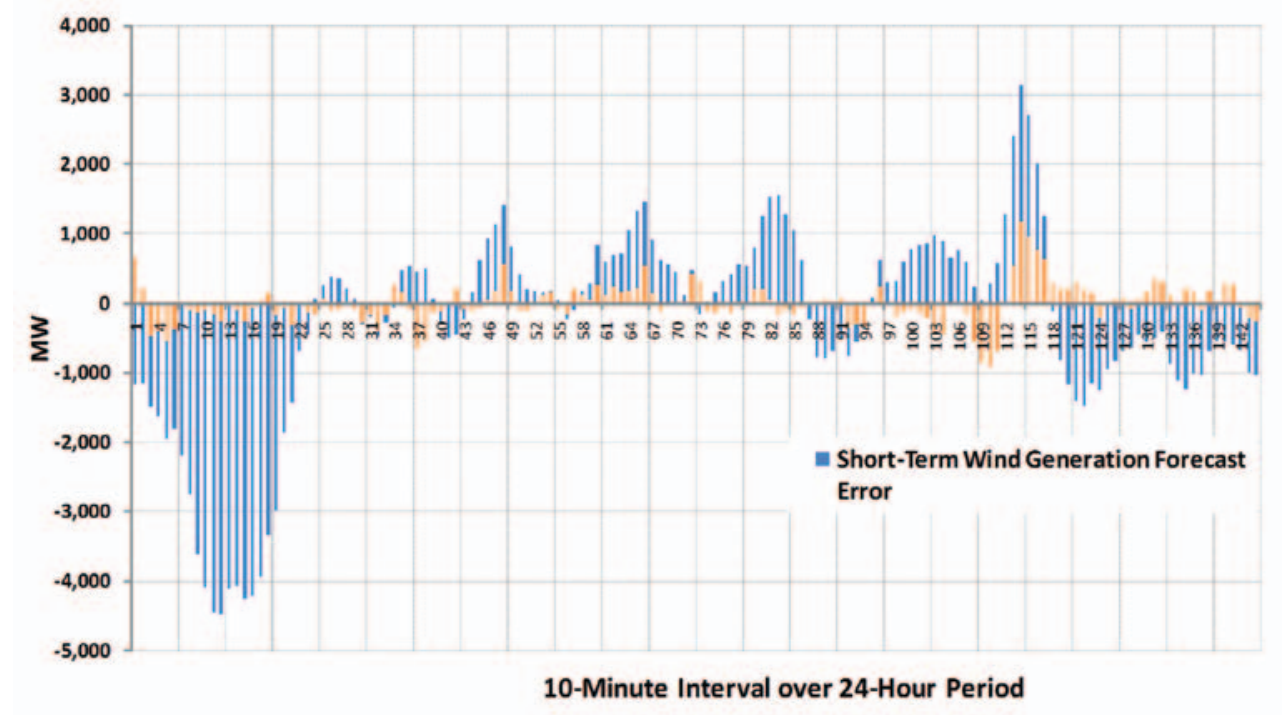

Figure 5-8. Errors in short-term forecasts of load and wind generation; load error is assumed to be zero in the mathematical procedure

The high-resolution data available for the study allowed the expected errors in short-term wind generation forecasts to be statistically characterized. The errors for each interval forecast were sorted into deciles based on the average hourly 
production at the time of the forecast. The errors in each of the deciles appear to be normally distributed, so the standard deviation was calculated and used as a measure of the expected forecast error.

Figure 5-9 shows the result for one scenario and operating region. The maximum expected error occurs in the midrange of the aggregate production, which is expected, because it would be where the largest number of turbines is operating on the steep part of their power curves. For low levels of production, the error is small because the output is small; at higher production levels, the error also declines, because in this region, many turbines are operating above rated wind speed, where fluctuating wind speed does not translate into varying energy production.

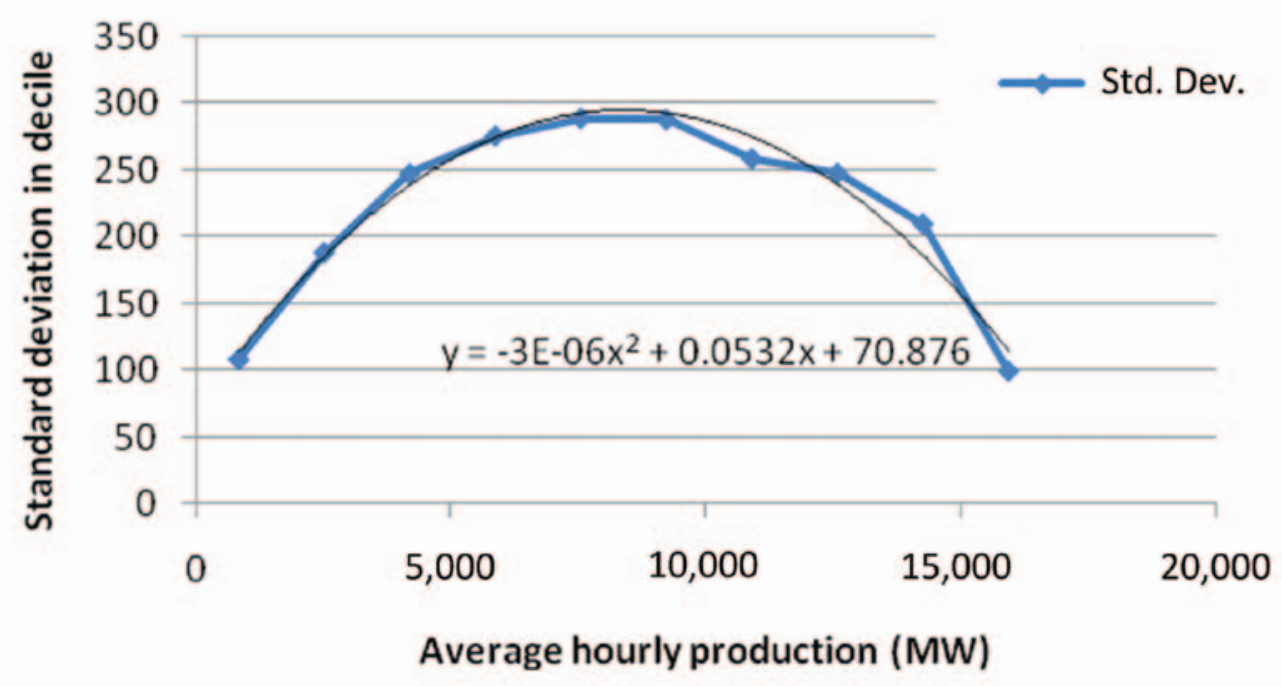

Figure 5-9. Illustration of short-term (10-minute ahead) wind generation forecast errors as a function of average hourly production

The empirical expected error characteristic can be approximated with a quadratic expression as shown in Figure 5-9. The input to this expression is the average hourly production, and the output is the standard deviation of the expected error in the short-term wind generation forecast for the current level of wind production.

Fast variations in load are almost certainly uncorrelated with the short-term forecast errors for wind generation. Therefore, the regulation requirements for load alone and short-term wind generation forecast errors do not add arithmetically. To account for this, the individual requirements are combined as a root of the sum of the squares.

In summary, for regulating reserves with no wind generation, the amount of regulation capacity carried is equal to $1 \%$ of the hourly load. The total spinning 
reserve carried forward to the production simulations is the regulation amount plus the spinning part of the contingency reserve defined earlier:

Spinning Reserve $($ Load Only $)=1 \% \cdot($ Hourly Load $)+$ Spinning Contingency Reserve

With wind generation, the regulation reserve is augmented to account for the short-term wind generation forecast errors using statistical characterizations like the one shown in Figure 5-10. The resulting regulation reserve requirement, using this characterization, follows:

Regulation Requirement $($ with Wind $)=3 \cdot \sqrt{\left(\frac{1 \% \cdot \text { HourlyLoad }}{3}\right)^{2}+\left(\sigma_{S T}(\text { HourlyWind })^{2}\right.}$

where

$\sigma_{\mathrm{ST}}($ Hourly Wind $)=\quad$ the function described in Figure 5-9 for the specific operating area and wind generation scenario.

The amount of regulation capacity is taken to be three times the standard deviation of the combined variability of load and wind, which accounts for the division of load regulation by three and the multiple of three on the radical in the previous equation. Again, a multiplier of 3 was selected because of the large size of the operating areas in EWITS.

As described previously, movements of generators to follow trends in load were assumed to come from the subhourly energy market. Economic dispatch in the production simulation honors individual unit ramp rates on an hourly basis, and, to reiterate, the average price for energy in the subhourly market was assumed not to diverge from the day-ahead price. As a result, the movements of generation to follow trends in the aggregate load are reasonably captured in the production simulations. This is, of course, based on an additional assumption that a significant increase in demand for such capabilities would not increase the price.

Uncertainty in the amount of wind generation to be delivered in the next hour also has an effect on the reserve picture. A procedure similar to that the team employed to characterize the very-short-term forecast errors can characterize the expected hour-ahead error for wind generation in each operating area and scenario (Figure 5-10). The expected next-hour forecast errors exhibit characteristics similar to those of the very-short-term forecasts; the highest errors occur when the aggregate wind production is in the midrange of capability, and the errors decline for both lower and higher production levels.

Reductions in next-hour wind generation output-which, given the persistence forecast assumption, is equivalent to the forecast being more than what actually is delivered-could possibly be covered by quick-start (nonspinning) generation. 
For EWITS, the study team assumed that some additional spinning reserve would be held to cover next-hour forecast errors, which are expected to be frequent (once or more per day). The amount of additional spinning reserve was set at one standard deviation of the expected error. Additional supplemental or nonspinning reserve was also allocated to cover the larger but less frequent forecast errors. An amount equivalent to twice the standard deviation of the expected next-hour wind generation forecast error was used here.

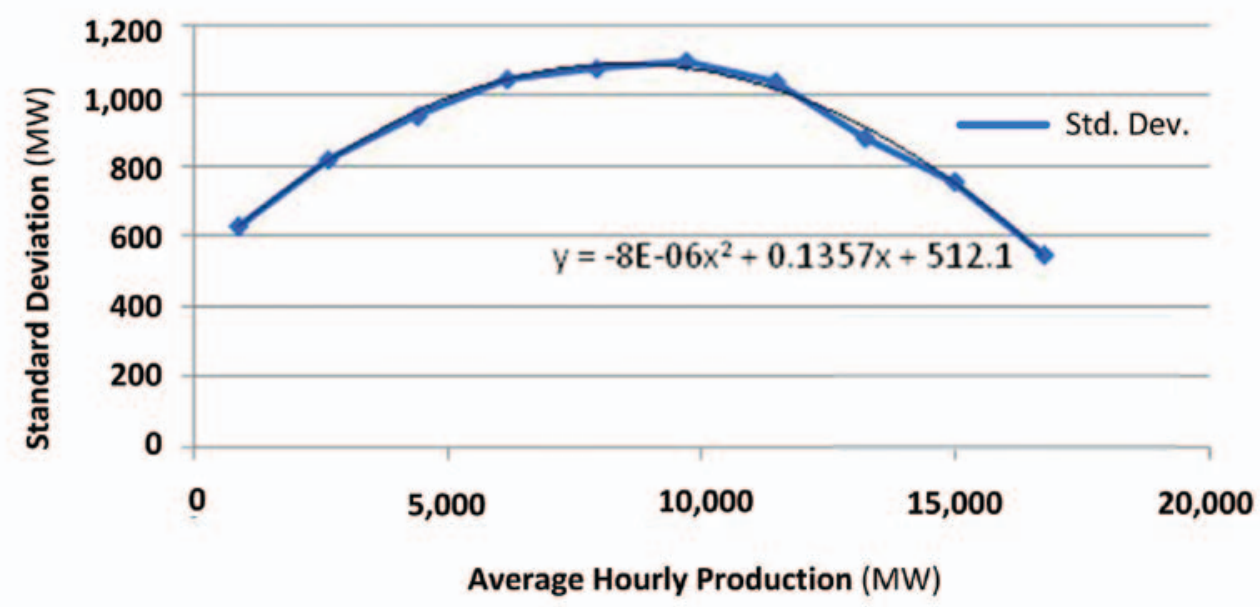

Figure 5-10. Standard deviation of 1-hour persistence forecast error for PJM in Reference Case

Table 5-5 summarizes the elements of the spinning and nonspinning reserves used in the production simulations. Because hourly wind and load are inputs to certain components, the result is an hourly profile instead of a single number. Using the statistical characterizations of short-term and next-hour wind generation forecast error embeds aspects of the specific wind generation scenarios within the reserve determination.

\begin{tabular}{|c|c|c|}
\hline RESERVE COMPONENT & SPINNING (MW) & NONSPINNING (MW) \\
\hline $\begin{array}{l}\text { REGULATION (VARIABILITY } \\
\text { AND SHORT-TERM WIND } \\
\text { FORECAST ERROR) }\end{array}$ & $3 \times \sqrt{\left(\frac{1 \% \cdot \text { HourlyLoad }}{3}\right)^{2}+\sigma_{S T}(\text { HourlyWind })^{2}}$ & 0 \\
\hline $\begin{array}{l}\text { REGULATION (NEXT-HOUR } \\
\text { WIND FORECAST ERROR) }\end{array}$ & & 0 \\
\hline ADDITIONAL RESERVE & $1 \times \sigma_{\text {NextHourError }}$ (PreviousHourWind) & $\begin{array}{l}2 \times \text { (Regulation for } \\
\text { next hour wind } \\
\text { forecast error) }\end{array}$ \\
\hline CONTINGENCY & $\begin{array}{c}50 \% \text { of } 1.5 \times \mathrm{SLH} \\
\text { (or designated fraction) }\end{array}$ & $\begin{array}{l}50 \% \text { of } 1.5 \times \mathrm{SLH} \\
\text { (or designated } \\
\text { fraction) }\end{array}$ \\
\hline $\begin{array}{l}\text { TOTAL (USED IN } \\
\text { PRODUCTION } \\
\text { SIMULATIONS) }\end{array}$ & SUM OF ABOVE & SUM OF ABOVE \\
\hline
\end{tabular}


Load forecast errors, both in the very short term and for the next hour or hours, have similar effects on the regulating and load following reserves. Some of these errors were considered in the assumption of $1 \%$ regulation for load. With sufficient data and information on load behavior and forecast accuracy, the study analysts used the process to assess whether requirements with wind generation could be applied to determine the regulation and load-following requirements for load.

Table 5-6 gives an example of the calculations used to determine the hourly regulating and spinning reserve requirement for each operating area. Hourly load (column 1) and wind generation (column 2) are the key inputs, along with the equations from Figures 5-9 and 5-10. These equations were developed for each operating area for each scenario from the high-resolution and hourly production data.

The regulation amount for load alone was assumed to be $1 \%$ of the hourly load (column 3). The standard deviation of the short-term wind generation forecast error was calculated using the appropriate equation and the hourly average wind production (column 4). The regulation for load net of wind generation was then computed by statistically combining the load regulation (assuming that it represents three times the standard deviation of load) with the standard deviation of the short-term wind generation forecast error (column 5).

The spinning portion of the contingency reserve (column 6) is constant for each hour. In column 7 , the expected error of the forecast wind generation for the hour was computed using the appropriate equation and the previous hour's wind generation. The total spinning reserve requirement for the hour (column 8), then, is the sum of total regulation (column 5), the spinning portion of the contingency reserve (column 6), and the additional regulating reserve that was set aside during the previous hour to cover expected reductions in wind generation (column 7). 


\begin{tabular}{|c|c|c|c|c|c|c|c|c|}
\hline $\begin{array}{l}\text { COLUMN } \\
\text { NUMBER }\end{array}$ & 1 & 2 & 3 & 4 & 5 & 6 & 7 & 8 \\
\hline HOUR & $\begin{array}{l}\text { ACTUAL } \\
\text { LOAD } \\
\text { (MW) }\end{array}$ & $\begin{array}{l}\text { ACTUAL } \\
\text { WIND } \\
\text { (MW) }\end{array}$ & $\begin{array}{l}\text { REGULA- } \\
\text { TION FOR } \\
\text { LOAD } \\
\text { (MW) }\end{array}$ & $\sigma_{S T}(M W)$ & $\begin{array}{l}\text { TOTAL } \\
\text { REGULA- } \\
\text { TION (MW) }\end{array}$ & $\begin{array}{l}\text { CONTIN- } \\
\text { GENCY } \\
\text { RESERVE- } \\
\text { SPINNING } \\
\text { (MW) }\end{array}$ & $\begin{array}{l}\sigma_{\text {Next Hour Error }} \\
\text { (MW) }\end{array}$ & $\begin{array}{l}\text { TOTAL } \\
\text { SPINNING } \\
\text { RESERVE } \\
\text { (MW) }\end{array}$ \\
\hline 1 & 56,341 & 11,860 & 563 & 280 & 1,011 & 2,271 & 1,037 & 4,319 \\
\hline 2 & 54,788 & 15,174 & 548 & 187 & 785 & 2,271 & 996 & 3,056 \\
\hline 3 & 53,993 & 14,261 & 540 & 219 & 851 & 2,271 & 729 & 3,122 \\
\hline 4 & 53,786 & 11,926 & 538 & 279 & 994 & 2,271 & 820 & 3,265 \\
\hline 5 & 54,922 & 10,843 & 549 & 295 & 1,042 & 2,271 & 993 & 3,313 \\
\hline 6 & 58,120 & 10,283 & 581 & 301 & 1,073 & 2,271 & 1,043 & 3,344 \\
\hline 7 & 63,929 & 9,193 & 639 & 306 & 1,120 & 2,271 & 1,062 & 3,391 \\
\hline 8 & 69,969 & 7,942 & 700 & 304 & 1,150 & 2,271 & 1,083 & 3,421 \\
\hline 9 & 72,432 & 8,077 & 724 & 305 & 1,167 & 2,271 & 1,085 & 3,438 \\
\hline 10 & 72,992 & 8,726 & 730 & 307 & 1,174 & 2,271 & 1,086 & 3,445 \\
\hline 11 & 73,475 & 9,736 & 735 & 304 & 1,172 & 2,271 & 1,087 & 3,433 \\
\hline 12 & 73,502 & 9,838 & 735 & 304 & 1,171 & 2,271 & 1,075 & 3,442 \\
\hline 13 & 73,316 & 9,201 & 733 & 306 & 1,176 & 2,271 & 1,073 & 3,447 \\
\hline 14 & 72,894 & 8,801 & 729 & 307 & 1,174 & 2,271 & 1,083 & 3,445 \\
\hline 15 & 72,704 & 10,146 & 727 & 302 & 1,161 & 2,271 & 1,087 & 3,432 \\
\hline 16 & 72,201 & 12,733 & 722 & 262 & 1,067 & 2,271 & 1,065 & 3,338 \\
\hline 17 & 73,160 & 13,937 & 732 & 230 & 1,005 & 2,271 & 943 & 3,276 \\
\hline
\end{tabular}

Notes: The equation for column 3 is from Figure 5-9 and uses current hour wind generation from column 2:

$$
\sigma_{S T}(\text { HourlyWind })=-3 \cdot 10^{-6} \cdot(\text { HourlyWind })^{2}+0.0532 \cdot(\text { HourlyWind })+70.876
$$

The column 5 value is computed from column 3 and column 4 using:

$$
3 \cdot \sqrt{\left(\frac{1 \% \cdot \text { HourlyLoad }}{3}\right)^{2}+\sigma_{S T}(\text { HourlyWind })^{2}}
$$

The equation for column 7 is from Figure 5-10 and uses wind generation from the previous hour:

$$
\sigma_{\text {NextHourError }}\left(\text { Wind }_{H-1}\right)=-8 \cdot 10^{-6} \cdot\left(\text { Wind }_{H-1}\right)^{2}+0.1357 \cdot\left(\text { Wind }_{H-1}\right)+512.1
$$

The total spinning reserve contains a component that is allocated specifically to be used if wind generation is less than was forecast in the previous hour. To avoid double counting of these reserves, the profile is adjusted to deploy this capacity in the production simulation. This is accomplished by reducing the hourly spinning reserve constraint by the amount of the reduction in wind generation from the previous hour, up to the amount that was held. This is illustrated in Table 5-7. In hour 3, 729 MW of extra spinning reserve was 
being carried to cover hourly wind generation forecast error (column 3). Wind generation declined by $913 \mathrm{MW}$ from the previous hour (column 5). All of the $729 \mathrm{MW}$ was deployed to cover this drop, so the total spinning reserve constraint for that hour in the production simulation is reduced by that amount, from 3,122 MW to 2,392 MW.

As can be seen in hour 2, if wind generation increases from the previous hour, there is no adjustment.

If covering a larger number of the reductions in wind generation output with regulation versus nonspinning (quick-start) generation was desired, the amount of regulating reserve would increase. In this example, an amount equivalent to one standard deviation of the next-hour persistence forecast error was held; increasing the amount to two standard deviations, which would be adequate to cover about $90 \%$ of the reductions in next-hour wind generation output, would double this component of the overall spinning reserve. It would also result in more spinning reserve that is not actually dispatched to cover forecast errors, thus increasing the cost.

The "cost" of releasing the spinning reserves is tabulated by the production simulation program; generation capacity that would have otherwise been unloaded is dispatched to cover the loss in wind, and associated production costs are accumulated. 


\begin{tabular}{|c|c|c|c|c|c|c|c|}
\hline $\begin{array}{l}\text { COLUMN } \\
\text { NUMBER }\end{array}$ & 1 & 2 & 3 & 4 & 5 & 6 & 7 \\
\hline HOUR & $\begin{array}{l}\text { ACTUAL } \\
\text { LOAD (MW) }\end{array}$ & $\begin{array}{l}\text { ACTUAL } \\
\text { WIND (MW) }\end{array}$ & $\begin{array}{l}\sigma_{\text {Wind_1Hour }} \\
(\mathrm{MW})^{-1}\end{array}$ & $\begin{array}{l}\text { TOTAL } \\
\text { SPINNING } \\
\text { RESERVE } \\
\text { (MW) }\end{array}$ & $\begin{array}{l}\text { CHANGE IN } \\
\text { WIND } \\
\text { GENERATION } \\
\text { (MW) }\end{array}$ & $\begin{array}{l}\text { ADJUSTMENT } \\
\text { (MW) }\end{array}$ & $\begin{array}{l}\text { ADJUSTED } \\
\text { SPINNING } \\
\text { RESERVE } \\
\text { (MW) }\end{array}$ \\
\hline 1 & 56,341 & 11,860 & 1,037 & 4,319 & 50 & 0 & 4,319 \\
\hline 2 & 54,788 & 15,174 & 996 & 3,056 & 3,314 & 0 & 3,056 \\
\hline 3 & 53,993 & 14,261 & 729 & 3,122 & (913) & 729 & 2,393 \\
\hline 4 & 53,786 & 11,926 & 820 & 3,265 & $(2,335)$ & 820 & 2,445 \\
\hline 5 & 54,922 & 10,843 & 993 & 3,313 & $(1,084)$ & 993 & 2,320 \\
\hline 6 & 58,120 & 10,283 & 1,043 & 3,344 & (559) & 559 & 2,785 \\
\hline 7 & 63,929 & 9,193 & 1,062 & 3,391 & $(1,090)$ & 1,062 & 2,329 \\
\hline 8 & 69,969 & 7,942 & 1,083 & 3,421 & $(1,252)$ & 1,083 & 2,337 \\
\hline 9 & 72,432 & 8,077 & 1,085 & 3,438 & 135 & 0 & 3,438 \\
\hline 10 & 72,992 & 8,726 & 1,086 & 3,445 & 649 & 0 & 3,445 \\
\hline 11 & 73,475 & 9,736 & 1,087 & 3,443 & 1,010 & 0 & 3,443 \\
\hline 12 & 73,502 & 9,838 & 1,075 & 3,442 & 101 & 0 & 3,442 \\
\hline 13 & 73,316 & 9,201 & 1,073 & 3,447 & (636) & 636 & 2,810 \\
\hline 14 & 72,894 & 8,801 & 1,083 & 3,445 & $(400)$ & 400 & 3,045 \\
\hline 15 & 72,704 & 10,146 & 1,087 & 3,432 & 1,346 & 0 & 3,432 \\
\hline 16 & 72,201 & 12,733 & 1,065 & 3,338 & 2,586 & 0 & 3,338 \\
\hline 17 & 73,160 & 13,937 & 943 & 3,276 & 1,204 & 0 & 3,276 \\
\hline
\end{tabular}

The resulting 8,760-hour profiles for each year and scenario are input to the production simulation program as operating area requirements, which constrain the algorithms for optimization and economic dispatch.

\section{REGULATING RESERVE RESULTS FOR STUDY SCENARIOS}

Tables 5-8 through 5-12 document the statistics of the regulation portion of the spinning reserves for each operating region and wind generation scenario. These amounts include the additional amount of spinning operating reserve for covering next-hour wind generation deficits from the hour-ahead forecast. The tables list the maximum and average values of an 8,760-hour profile.

Figure 5-11 shows a more detailed view of the PJM requirements, showing distributions of the regulating requirement for load only and load net wind for Scenario 3. 


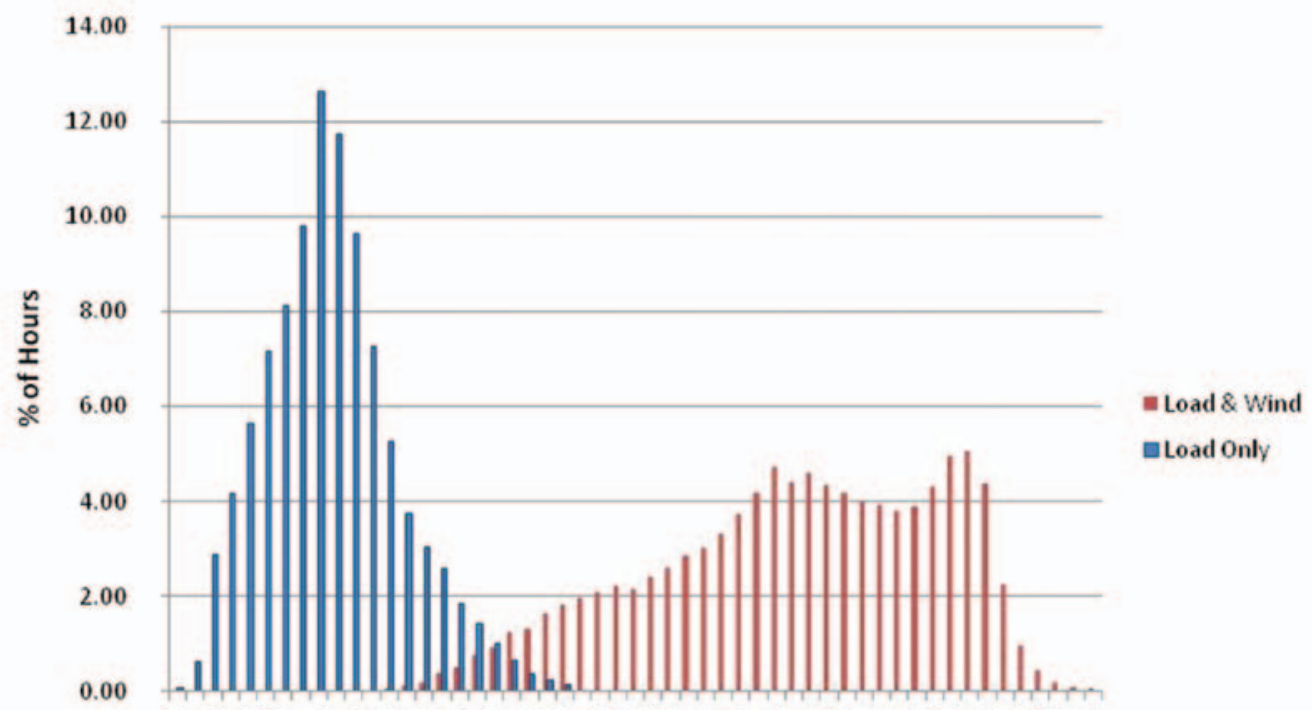

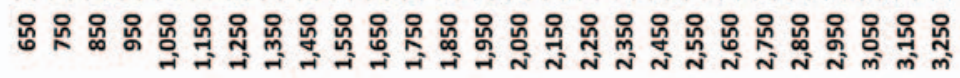

Regulating Reserve Requirement (MW)

Figure 5-11. Distributions of hourly regulating reserve requirements for PJM Scenario 3, for load only (ideal wind generation) and load net of wind generation

\begin{tabular}{|c|c|c|c|c|c|}
\hline \multirow[b]{2}{*}{ REGION } & \multicolumn{2}{|l|}{ LOAD ONLY } & \multicolumn{2}{|c|}{ LOAD AND WIND } & \multirow{2}{*}{$\begin{array}{l}\text { CONTINGENCY- } \\
\text { SPINNING (MW) }\end{array}$} \\
\hline & $\begin{array}{l}\text { MAXIMUM } \\
\text { (MW) }\end{array}$ & $\begin{array}{l}\text { AVERAGE } \\
(\mathrm{MW})\end{array}$ & $\begin{array}{l}\text { MAXIMUM } \\
(\mathrm{MW})\end{array}$ & $\begin{array}{l}\text { AVERAGE } \\
(\mathrm{MW})\end{array}$ & \\
\hline MISO & 1,480 & 924 & 2,235 & 1,635 & 2,271 \\
\hline ISO-NE & 399 & 202 & 1,040 & 762 & 579 \\
\hline NYISO & 390 & 219 & 738 & 531 & 600 \\
\hline PJM & 1,741 & 1,060 & 2,545 & 1,817 & 3,350 \\
\hline SERC & 1,343 & 744 & 1,549 & 886 & 570 \\
\hline SPP & 870 & 514 & 1,135 & 800 & 770 \\
\hline TVA & 721 & 365 & 769 & 419 & 403 \\
\hline
\end{tabular}

\begin{tabular}{|c|c|c|c|c|c|}
\hline \multirow[b]{2}{*}{ REGION } & \multicolumn{2}{|l|}{ LOAD ONLY } & \multicolumn{2}{|c|}{ LOAD AND WIND } & \multirow{2}{*}{$\begin{array}{l}\text { CONTINGENCY- } \\
\text { SPINNING (MW) }\end{array}$} \\
\hline & $\begin{array}{l}\text { MAXIMUM } \\
\text { (MW) }\end{array}$ & $\begin{array}{l}\text { AVERAGE } \\
\text { (MW) }\end{array}$ & $\begin{array}{l}\text { MAXIMUM } \\
\text { (MW) }\end{array}$ & $\begin{array}{l}\text { AVERAGE } \\
(\mathrm{MW})\end{array}$ & \\
\hline MISO & 1,480 & 924 & 6,806 & 5,460 & 2,271 \\
\hline ISO-NE & 399 & 202 & 600 & 395 & 579 \\
\hline NYISO & 390 & 219 & 921 & 623 & 600 \\
\hline PJM & 1,741 & 1,060 & 2,966 & 2,006 & 3,350 \\
\hline SERC & 1,343 & 744 & 1,348 & 753 & 570 \\
\hline SPP & 870 & 514 & 8,154 & 6,245 & 770 \\
\hline TVA & 721 & 365 & 769 & 419 & 403 \\
\hline
\end{tabular}




\begin{tabular}{|c|c|c|c|c|c|}
\hline \multirow[b]{2}{*}{ REGION } & \multicolumn{2}{|l|}{ LOAD ONLY } & \multicolumn{2}{|c|}{ LOAD AND WIND } & \multirow{2}{*}{$\begin{array}{l}\text { CONTINGENCY- } \\
\text { SPINNING (MW) }\end{array}$} \\
\hline & $\begin{array}{l}\text { MAXIMUM } \\
\text { (MW) }\end{array}$ & $\begin{array}{l}\text { AVERAGE } \\
(\mathrm{MW})\end{array}$ & $\begin{array}{l}\text { MAXIMUM } \\
\text { (MW) }\end{array}$ & $\begin{array}{l}\text { AVERAGE } \\
(\mathrm{MW})\end{array}$ & \\
\hline MISO & 1,480 & 924 & 5,131 & 4,094 & 2,271 \\
\hline ISO-NE & 399 & 202 & 1,392 & 1,041 & 579 \\
\hline NYISO & 390 & 219 & 1,565 & 1,124 & 600 \\
\hline PJM & 1,741 & 1,060 & 3,247 & 2,377 & 3,350 \\
\hline SERC & 1,343 & 744 & 1,665 & 954 & 570 \\
\hline SPP & 870 & 514 & 8,179 & 6,110 & 770 \\
\hline TVA & 721 & 365 & 769 & 419 & 403 \\
\hline
\end{tabular}

\begin{tabular}{|c|c|c|c|c|c|}
\hline \multirow[b]{2}{*}{ REGION } & \multicolumn{2}{|l|}{ LOAD ONLY } & \multicolumn{2}{|c|}{ LOAD AND WIND } & \multirow{2}{*}{$\begin{array}{l}\text { CONTINGENCY } \\
\text { RESERVE- } \\
\text { SPINNING (MW) }\end{array}$} \\
\hline & $\begin{array}{l}\text { MAXIMUM } \\
\text { (MW) }\end{array}$ & $\begin{array}{l}\text { AVERAGE } \\
(\mathrm{MW})\end{array}$ & $\begin{array}{l}\text { MAXIMUM } \\
\text { (MW) }\end{array}$ & $\begin{array}{l}\text { AVERAGE } \\
(\mathrm{MW})\end{array}$ & \\
\hline MISO & 1,480 & 924 & 3,759 & 2,934 & 2,271 \\
\hline ISO-NE & 399 & 202 & 2,401 & 1,780 & 579 \\
\hline NYISO & 390 & 219 & 2,161 & 1,616 & 600 \\
\hline PJM & 1,741 & 1,060 & 5,690 & 4,467 & 3,350 \\
\hline SERC & 1,343 & 744 & 1,665 & 954 & 570 \\
\hline SPP & 870 & 514 & 4,837 & 3,658 & 770 \\
\hline TVA & 721 & 365 & 769 & 419 & 403 \\
\hline
\end{tabular}

\begin{tabular}{|c|c|c|c|c|c|}
\hline \multirow[b]{2}{*}{ REGION } & \multicolumn{2}{|l|}{ LOAD ONLY } & \multicolumn{2}{|c|}{ LOAD AND WIND } & \multirow{2}{*}{$\begin{array}{l}\text { CONTINGENCY } \\
\text { RESERVE- } \\
\text { SPINNING (MW) }\end{array}$} \\
\hline & $\begin{array}{l}\text { MAXIMUM } \\
\text { (MW) }\end{array}$ & $\begin{array}{l}\text { AVERAGE } \\
(\mathrm{MW})\end{array}$ & $\begin{array}{l}\text { MAXIMUM } \\
(\text { MW) }\end{array}$ & $\begin{array}{l}\text { AVERAGE } \\
(\mathrm{MW})\end{array}$ & \\
\hline MISO & 1,480 & 924 & 6,832 & 5,478 & 2,271 \\
\hline ISO-NE & 399 & 202 & 2,401 & 1,780 & 579 \\
\hline NYISO & 390 & 219 & 2,161 & 1,616 & 600 \\
\hline PJM & 1,741 & 1,060 & 7,006 & 5,413 & 3,350 \\
\hline SERC & 1,343 & 744 & 1,665 & 954 & 570 \\
\hline SPP & 870 & 514 & 8,412 & 6,423 & 770 \\
\hline TVA & 721 & 365 & 769 & 419 & 403 \\
\hline
\end{tabular}

\section{SUMMARY}

As mentioned previously, the algorithms in the production simulation program treat the spinning reserves profiles for each operating region as constraints. Generation must be committed and dispatched to meet load at minimum costs while honoring all constraints, including the hourly spinning reserve requirement.

The reserve constraints have an impact only when they are binding on either the unit commitment or economic dispatch. In Tables 5-8 through 5-12, the 
regulating reserve requirements appear to be very large (e.g., SPP). Note that these requirements are highest when wind generation is moderate to high. If the generation mix does not change except for the introduction of wind, heavy penetration of wind generation frees up nonwind generation to supply the required regulating reserves that support frequency and balance generation with demand. The decreased revenues of the fleet of intermediate generation and market structures, however, could affect the availability of these services in the market, as discussed further in this summary.

Costs are associated with carrying significant spinning reserve for wind generation. If additional conventional generation must be committed simply to meet the spinning reserve requirement, the reserve constraint is binding and additional operating costs will be incurred. Even without a change in commitment, units might not be loaded to their maximums, and as a result, will not operate as efficiently.

The reserve costs that can be extracted from production simulations reflect the less efficient dispatch and opportunity costs. Some additional operational costs associated with regulation duty, however, are not captured. In current markets, regulation is a relatively expensive service compared to the provision of spinning operating reserve.

The assumptions defined earlier are critical to the results presented here, and merit some additional discussion. First, although the philosophy behind the view of short-term forecast errors in wind generation as a contributor to needs for incremental regulation is sound, the persistence forecast technique is rudimentary and would not be implemented in practice. Improvements in short-term forecasts would reduce the impact on regulation requirements. The persistence assumption employed here has most likely led to conservative estimates of regulation requirements.

Second, high penetrations of wind generation and the increased requirements for regulation and flexibility mean that providing those services would have more value. Moving up the supply curve for those services might reach into units that are much less efficient, further increasing the cost. In addition, questions arise about the depth of the resource "stack" for flexibility, which could potentially be another limitation. Alternatively, loads and storage are beginning to supply regulation in at least three ISOs. Responsive load and storage could significantly increase the supply of regulation by 2024 .

Third, if large amounts of wind energy displace conventional units and significantly reduce capacity factors, additional questions are raised about compensation in lieu of energy sales for those units and keeping them economically feasible to ensure the flexibility that the system requires. 
Finally, the importance of the assumptions about the structure for operations in this 2024 scenario must be reiterated. Functional subhourly markets are the most economic means to compensate for short-term changes in load and wind generation that can be forecast. Very large balancing areas with adequate transmission take maximum advantage of diversity in both load and wind generation. By contrast, the Western Interconnection, with the exception of California, comprises smaller, less tightly interconnected balancing areas. Even modest penetrations of wind generation, much smaller than those considered here, can have very significant operational and cost impacts because of the additional requirements they bring for regulation and balancing.

The penetrations of wind generation considered in EWITS are well beyond what experience can speak to definitively; further analysis is certainly warranted. The knowledge gained from operating experience around the country and the world as wind generation penetrations continue to grow will build an increasingly better foundation for technical insights into this important challenge. 


\section{SECTION 6: ASSESSING IMPACTS ON POWER SYSTEM OPERATION}

For this Eastern Wind Integration and Transmission Study (EWITS), analysts assessed wind generation impacts on the operation of the Eastern Interconnection through chronological production simulations. They used a nodal model, in which all transmission is represented explicitly along with all generating units and loads at bulk delivery points. In the simulation, units are committed and dispatched to serve load at each bus while honoring transmission constraints and recognizing the security needs of the system.

Annual hourly profiles of wind generation and load, described in Section 2, are primary inputs to the process. The power system model is built on the data and assumptions described in Section 3. Transmission overlays and new conventional generation defined by the process in Section 4 are added to the model for each of four high-penetration wind generation scenarios.

The intent of these simulations is to mimic as closely as possible the assumed operational structure for the Eastern Interconnection in the 2024 study year. The simulations also quantify the specific impacts of the increased variability and uncertainty introduced by wind generation in each scenario.

\section{WIND INTEGRATION IMPACTS AND COST}

There is no formal or rigorous definition of wind integration costs. Many previous studies (see Bibliography) have used the following working definition: wind integration costs include those incremental costs incurred in the operational time frames that can be attributed to the variability and uncertainty introduced by wind generation. Calculating costs using this definition involves running chronological production simulations for an extended period of time-usually one or more years-with correlated wind generation and load data. Operating policies and practices are mapped as closely as possible to the production simulations. This is accomplished by mimicking the established (or desired) practices for unit commitment, transaction scheduling, and the maintenance of adequate reserves for system control and security.

The increased uncertainty of wind generation is considered in the unitcommitment step, where forecasts of both load and wind generation are the basis for optimizing generating unit deployment. The economic-dispatch step of the production simulation represents how the power system operates in real time. In 
EWITS, the increased variability and short-term uncertainty of wind generation require that additional operating reserves be carried.

The basic process for assessing the impacts of wind generation on power system operations involves running a production simulation that uses forecasts of load and wind generation in the unit-commitment step and honors operating reserve constraints in the economic-dispatch step that are adequate for managing the increased variability. The production costs incurred over the simulation, then, reflect the effects of both factors.

Extracting or isolating that increased cost requires an additional step. With significant wind generation, the conventional generation stack will change as marginal units are displaced by what is usually considered to be a "must take" resource. Because of this displacement, the costs related to uncertainty in the optimization process and the requirements for carrying additional reserves will differ from those in a case with no wind. In recognition of this factor, previous studies (see Bibliography) used the concept of a "proxy resource" to represent the energy provided by wind generation, but in a way that affects scheduling and real-time operations as little as possible (i.e., it neither helps nor hurts the scheduling and dispatch of other conventional resources and is therefore close to operational cost-neutrality. One conceptual energy resource that meets this definition is a daily flat block of energy equivalent to the energy produced in the actual wind profile for that same day. Despite much discussion and debate-but little consensus-about alternatives, many of the previous integration studies used this type of proxy resource. The amounts of wind in several of the scenarios and operating areas in EWITS, however, far exceed those considered previously. A cursory examination of the wind generation data for the $20 \%$ penetration scenarios revealed that using a flat daily block of energy as a proxy resource was not workable; very large ramps between days would have artificially affected the commitment and dispatch process. Instead, study analysts used the actual hourly delivery of the wind energy per the scenario profile data.

Integration costs are estimated by comparing the case where wind generation introduces additional uncertainty into the commitment process and requires additional reserves in the economic-dispatch steps to the case with the proxy resource, where only load carries uncertainty and exhibits variability.

Although previous studies focused on the costs of integrating wind generation, it must be noted that those costs are only one piece of the larger set of wind generation costs and benefits.

\section{ANALYTICAL APPROACH}

The general analytical approach for assessing operational impacts attributable to wind generation is quite straightforward, and was the basic method used in 
many previous integration studies. The size and extent of the model for this study, though - the entire Eastern Interconnection with a nodal representation-posed some new challenges.

The Reference Scenario (defined in Section 2), which includes about 6\% wind energy penetration in the Eastern Interconnection, was the basis for exploring some issues related to using an extremely large production model to assess wind integration impacts. The EWITS team explored two major issues in early iterations of the Reference Scenario:

1. The effect of various approaches for calculating reserve requirements with wind generation variability and short-term uncertainty

2. The approach for extracting the incremental production costs caused by wind generation variability and uncertainty (integration costs)

The costs of carrying additional spinning reserves were also explored through several iterations of the Reference Scenario. The results revealed a strong correlation between cost and the amount of spinning reserve. Consequently, the study analysts carefully evaluated the calculation of the spinning reserve requirements, and the approach described in Section 5 was the result.

Calculating the cost of wind generation variability and uncertainty involves running at least two annual production simulations for each scenario:

1. An ideal wind case, where the energy initially delivered on a daily basis was shaped into a flat block. Because the wind is ideal, there is no day-ahead forecast error and no requirement for incremental reserves. Load is uncertain in the day-ahead commitment and requires a baseline of operating reserves.

2. An actual wind case, where wind is delivered in the hourly shapes from the National Renewable Energy Laboratory's (NREL) mesoscale database, is uncertain in the day-ahead commitment (per the day-ahead forecasts in the data) and requires additional spinning reserves for regulation and load following. The difference between production costs for this case and the ideal wind case is the total integration cost.

To estimate the effects of either the day-ahead forecast error or incremental regulating reserves individually, two additional cases can be run:

1. A case where wind is known perfectly 1 day ahead, but more spinning reserve is carried because of the variability and short-term uncertainty of wind generation. Comparing this case to the actual wind case produces an estimate of the cost of the wind generation forecast error.

2. A case where wind imposes no additional burden in real time (i.e., additional spinning reserves), but the day-ahead forecast for unit 
commitment is imperfect. The uncertainty costs can then be computed as the difference between production costs for this case and for the actual wind case.

Applying this approach to the Reference Scenario produced some results that were initially in contrast to conclusions from previous integration studies. After some intensive analysis, the EWITS team determined that the costs of integrating wind generation had meaning only across the entire model; integration cost calculations on an individual operating footprint basis were subject to some difficulties associated with valuation of the hourly energy exchanges with other operating areas.

In earlier studies, the subject area was usually "isolated" - transactions with outside areas were of a defined hourly shape. The result was that the additional variability of wind generation had to be managed with internal resources only. In this study, transactions between operating areas are determined by the program algorithms and made on an economic basis (i.e., if surplus energy in one operating area is less expensive than native generation in that area, and transmission capacity is available, the energy will be sold). Consequently, incremental variability from wind generation can be exchanged with other areas if the appropriate economic signals are present. For this reason, the effects of wind generation variability and uncertainty in this study are for the entire Eastern Interconnection and are not allocated to individual operating areas.

\section{RESULTS}

\section{HIGH-PENETRATION WIND SCENARIOS 1-4}

The primary inputs for evaluating the operational impacts of wind generation variability and uncertainty are simulated wind generation data sets synchronized with historical load over an extended time series. The study team used NREL mesoscale wind data for 2004 through 2006 for this analysis. This section gives the production-cost simulation results using 2004 hourly wind and load profiles. Further analysis results with 3-year wind and load profiles are presented later in this section.

\section{SCENARIO CHARACTERISTICS}

After considering various locations of wind resources and different wind penetration levels, four wind scenarios were developed: three $20 \%$ wind energy scenarios and one 30\% wind energy scenario. Figure 6-1 summarizes the wind penetration levels by region and scenario. Among the three $20 \%$ wind scenarios, Scenario 1 has the highest penetration levels in the western regions because it uses the most high-quality wind resources in the Great Plains. Because wind is moved eastward and more offshore wind is used in Scenarios 2 and 3, the penetration levels increase in the PJM Interconnection, the New York ISO (NYISO), and the New England ISO (ISO-NE) as the levels drop in the western regions. To meet the $30 \%$ wind mandate, Scenario 4 uses a significant amount of good-quality wind 
across the footprint and offshore wind along the East Coast with the highest wind penetration levels in almost all the regions. Based on wind quality and availability, the Tennessee Valley Authority (TVA) and Southeastern Electric Reliability Council (SERC) have very little installed wind capacity and are the primary wind import regions. Conversely, the Southwest Power Pool (SPP) has very high wind penetration levels for all four scenarios.

Because of the unique characteristics of the wind resource, additional reserve requirements are required to regulate the wind and maintain system reliability. The incremental reserve for each region is an hourly profile and varies hourly with the amount of wind generation at that particular hour. Figure 6-2 shows the annual, average, variable spinning reserves by region and scenario. As the figure shows, the level of required operating reserves increases with wind penetration levels, as expected.

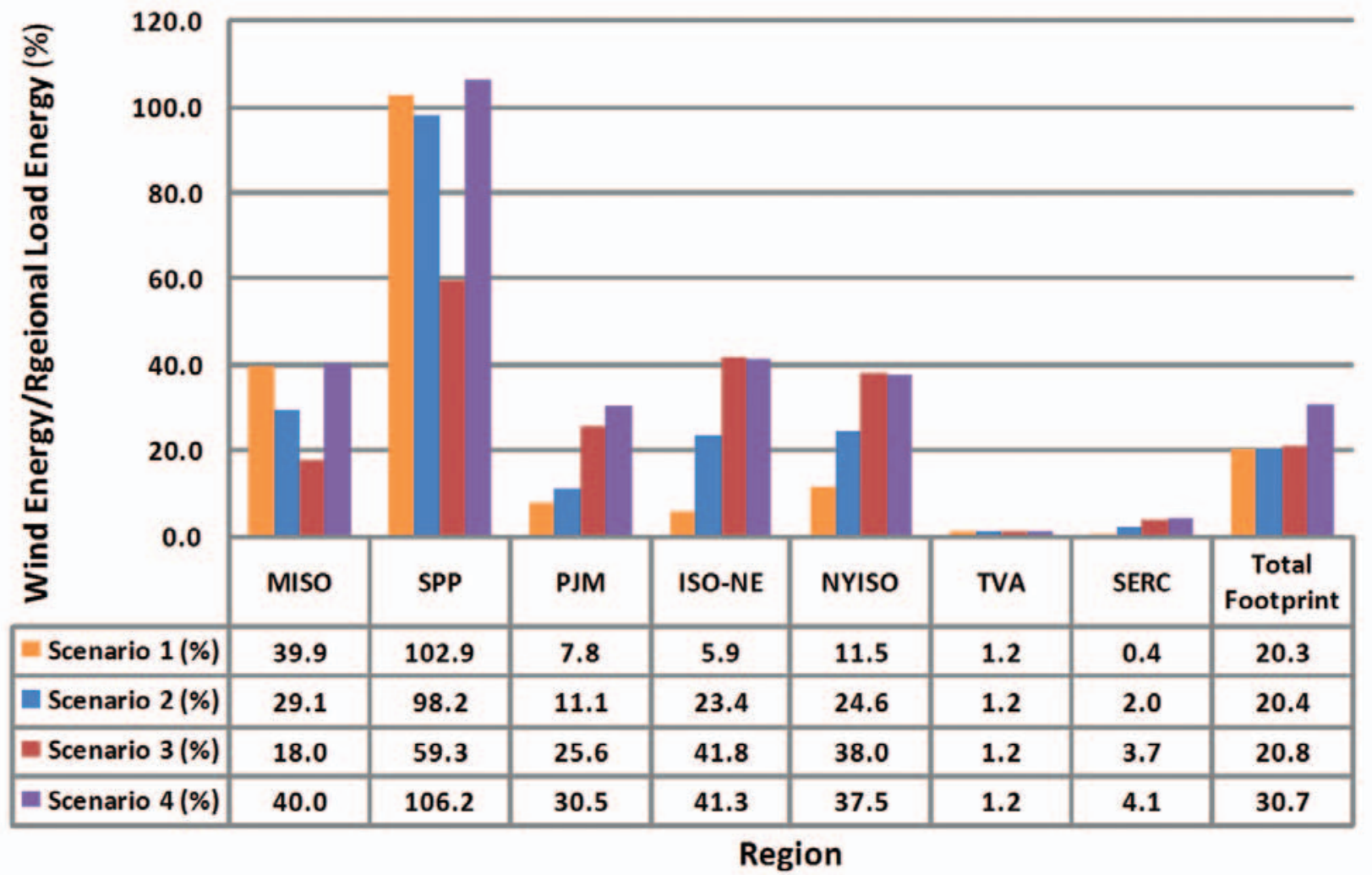

Figure 6-1. Wind energy penetration levels by region using 2004 hourly profiles 


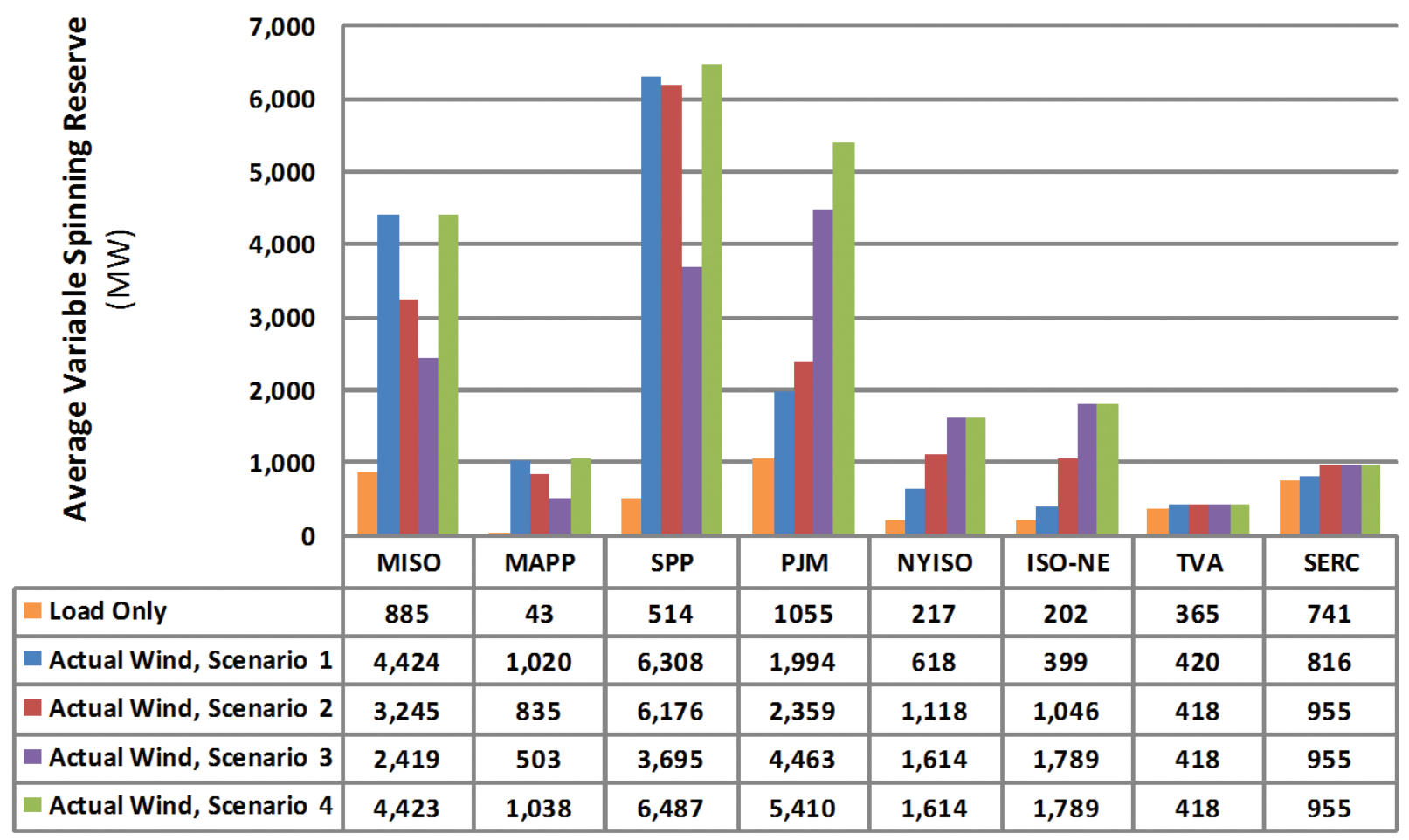

Region

Figure 6-2. Annual average variable spinning reserve using 2004 hourly profiles

\section{OPERATIONAL IMPACT}

To calculate the costs of operational impact associated with wind variability and uncertainty, the analysts initially defined two cases, the ideal wind case and the actual wind case. Given the assumption that the day-ahead wind forecast is perfect, no wind forecast error and incremental variable reserves for wind were modeled in the ideal wind case. Considering wind uncertainty and variability, the actual wind case modeled both the day-ahead wind forecast error and additional variable reserves driven by wind. Load uncertainty was accounted for in both cases by including hourly load forecast error and that portion of the additional reserves that resulted from the load uncertainty.

The cost difference between the actual and ideal wind cases is the total integration cost. To separate the individual operational effects of the day-ahead wind forecast error and the variable reserve requirement, an intermediate case was defined. That case included only the day-ahead wind forecast error and ignored the incremental reserve requirements driven by wind. Comparing this case to the ideal wind case gives the day-ahead wind forecast error cost; comparing this case to the actual wind case gives the cost of carrying the incremental reserves associated with wind. Adjusted production cost (APC) was used to calculate the integration cost with regional interchanges and associated costs captured as described in Section 4.2. 
Figure 6-3 shows APCs of the ideal, intermediate, and actual cases for each scenario. With the increased 30\% wind energy penetration offsetting base-load steam generation, Scenario 4 has the lowest APCs of the four wind scenarios.

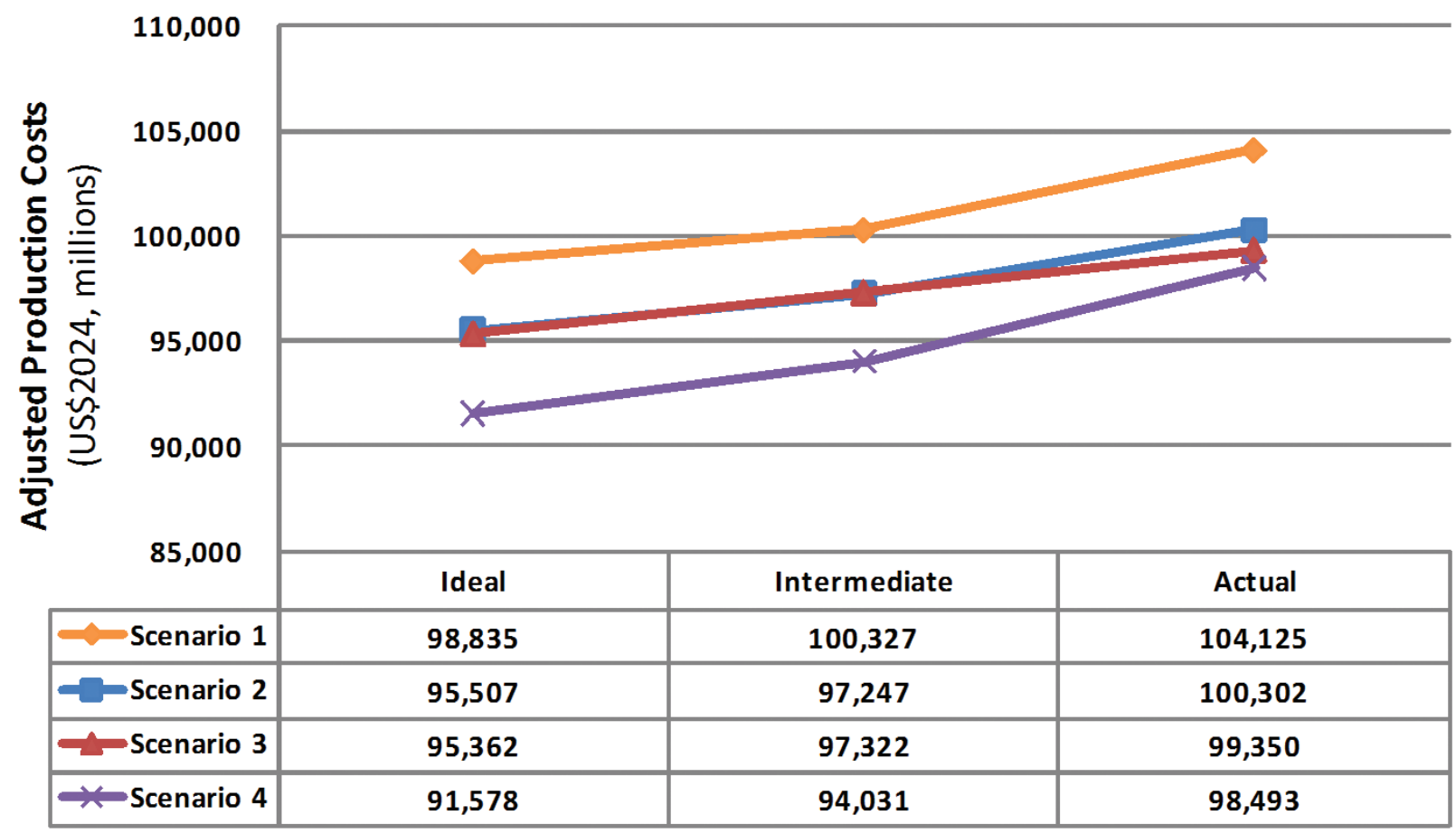

Case

Figure 6-3. Annual APCs using 2004 hourly profiles

Table 6-1 summarizes the integration costs for each scenario in US\$2024 per megawatt-hour (MWh) of wind energy. Carrying additional reserves has a much larger effect on total integration costs than the day-ahead wind forecast error, which could be caused by the resulting total forecast error reduction of aggregating many individual wind plants over a very large geographical area.

\begin{tabular}{|c|c|c|c|}
\hline SCENARIO & $\begin{array}{l}\text { DAY-AHEAD } \\
\text { FORECAST ERROR (\$/ } \\
\text { MWh) }\end{array}$ & $\begin{array}{l}\text { VARIABLE RESERVE } \\
\text { (\$/MWh) }\end{array}$ & $\begin{array}{l}\text { TOTAL INTEGRATION } \\
\text { COST } \\
\text { (\$/MWh) }\end{array}$ \\
\hline 1 & 2.26 & 5.74 & 8.00 \\
\hline 2 & 2.61 & 4.59 & 7.21 \\
\hline 3 & 2.84 & 2.93 & 5.77 \\
\hline 4 & 2.51 & 4.56 & 7.07 \\
\hline
\end{tabular}

Table 6-2 lists the integration costs for each scenario from different perspectives, in dollars per megawatt-hour $(\$ / M W h)$ normalized over total wind energy $(\$ /$ $\mathrm{MWh}$ ), as a percentage of total APCs, and in dollars normalized over the total load amount (\$/MWh). With 20\% to 30\% wind energy penetration levels for the Eastern Interconnection footprint, the total system operational costs caused by 
wind variability and uncertainty range from $\$ 5.77$ / MWh to $\$ 8.00 / \mathrm{MWh}$ of wind energy (in US\$2024).

\begin{tabular}{|c|c|c|c|c|}
\hline SCENARIO & 1 & 2 & 3 & 4 \\
\hline $\begin{array}{l}\text { INTEGRATION } \\
\text { COST (\$) }\end{array}$ & $5,290,351,725$ & $4,795,114,783$ & $3,988,497,258$ & $6,915,311,563$ \\
\hline APCs (\$) & $104,125,330,202$ & $100,302,223,283$ & $99,350,363,256$ & $98,493,233,640$ \\
\hline $\begin{array}{l}\text { INTEGRATION } \\
\text { COST (\$/MWh } \\
\text { of WIND) }\end{array}$ & 8.00 & 7.21 & 5.77 & 7.07 \\
\hline $\begin{array}{l}\text { INTEGRATION } \\
\text { COST ( } \% \text { of } \\
\text { APC) }\end{array}$ & 5.08 & 4.78 & 4.01 & 7.02 \\
\hline $\begin{array}{l}\text { INTEGRATION } \\
\text { COST (\$/MWh } \\
\text { of LOAD) }\end{array}$ & 1.52 & 1.37 & 1.14 & 1.98 \\
\hline
\end{tabular}

Figures 6-4 and 6-5 show the detailed annual generation production for the ideal, intermediate, and actual cases by fuel type and scenario. With day-ahead wind forecast error modeled in the intermediate case, the base-load coal units are displaced to some degree. And as a result of carrying additional reserves to accommodate wind variability and uncertainty in the actual wind case, the coal units are even further displaced in favor of more flexible gas-fired combined cycle (CC) and combustion turbine (CT) units.

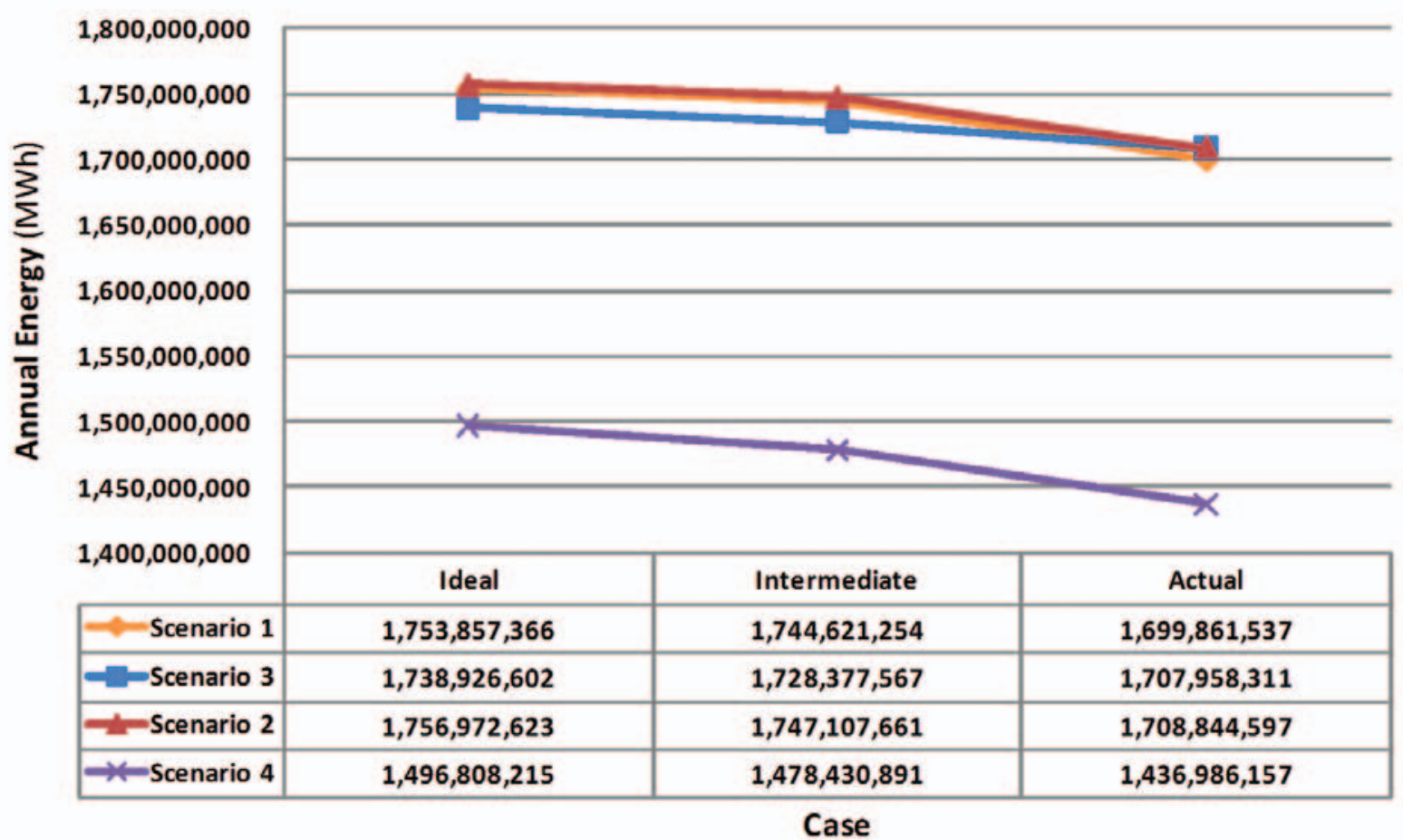

Figure 6-4. Annual steam turbine coal generation summary with 2004 hourly profiles 

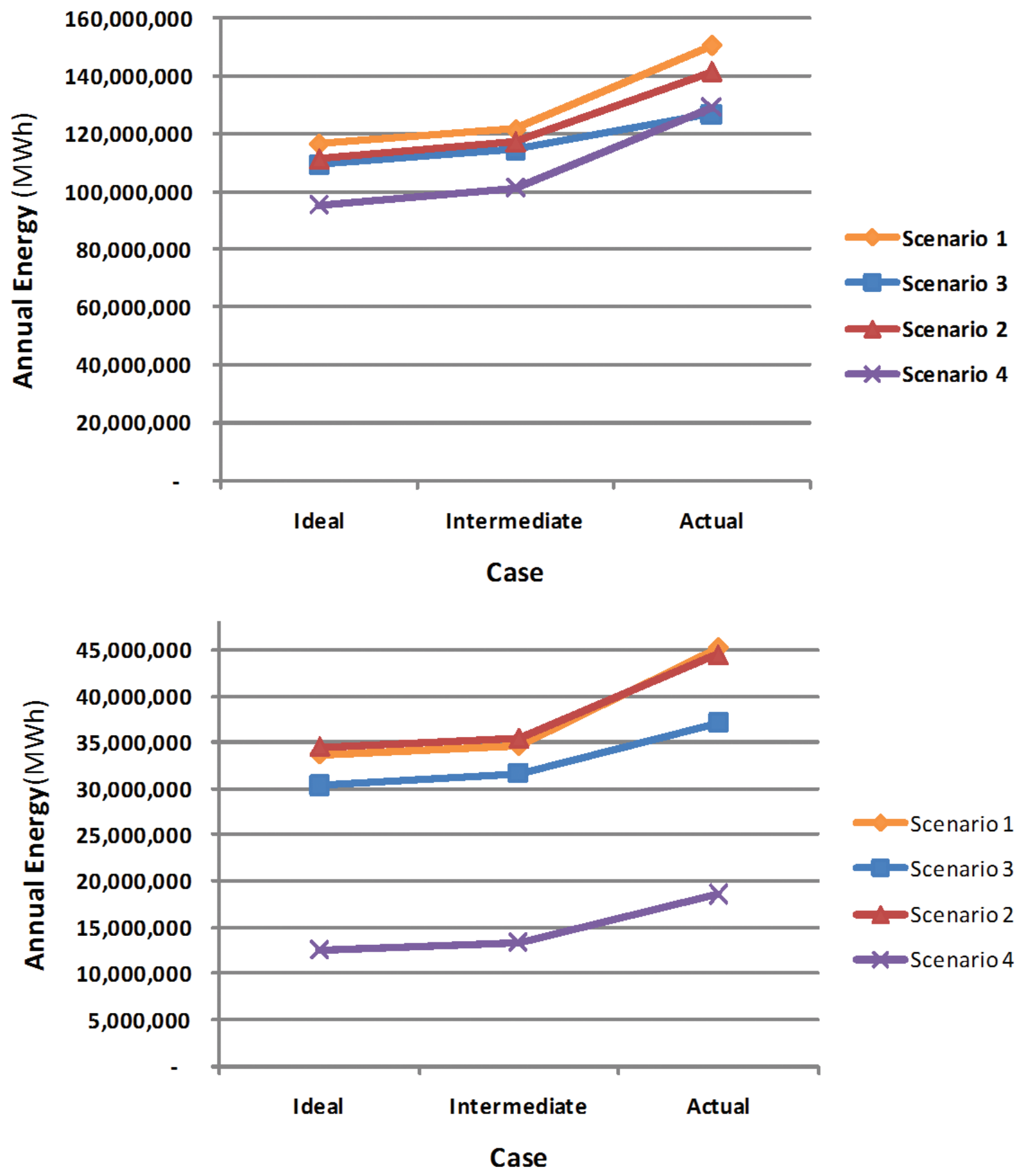

Figure 6-5. Annual combined cycle and combustion turbine gas generation with 2004 hourly profiles

\section{SCENARIO ANALYSIS}

The production-cost simulations using 2004 hourly wind and load profiles produced a substantial amount of information on what could be expected in terms of operational impacts and the associated costs of wind variability and uncertainty. Study analysts completed the production-cost simulations with 
2005 and 2006 wind and load patterns as a follow-up. The 3-year results for all scenarios, summarized here, offer more detailed analysis on integration cost, wind curtailment, generation production by fuel type, locational marginal prices (LMPs), and regional interchanges. All costs in this section are in US\$2024.

Wind penetration levels, geographical locations of wind, and additional variable reserve amounts for wind are a few of the key elements driving the total APC and integration cost for each scenario. As Figure 6-6 illustrates, Scenario 4 has the lowest APC because the least amount of conventional generation resources are committed to accommodate the aggressive $30 \%$ wind penetration. Among the three $20 \%$ wind scenarios, Scenario 1 has the highest APC, with wind resources concentrated in the western regions and the largest variable reserve amount carried because of wind on the whole study footprint. The Reference Scenario, with the least amount of wind energy and thus the most amount of conventional generation, has the highest APCs.

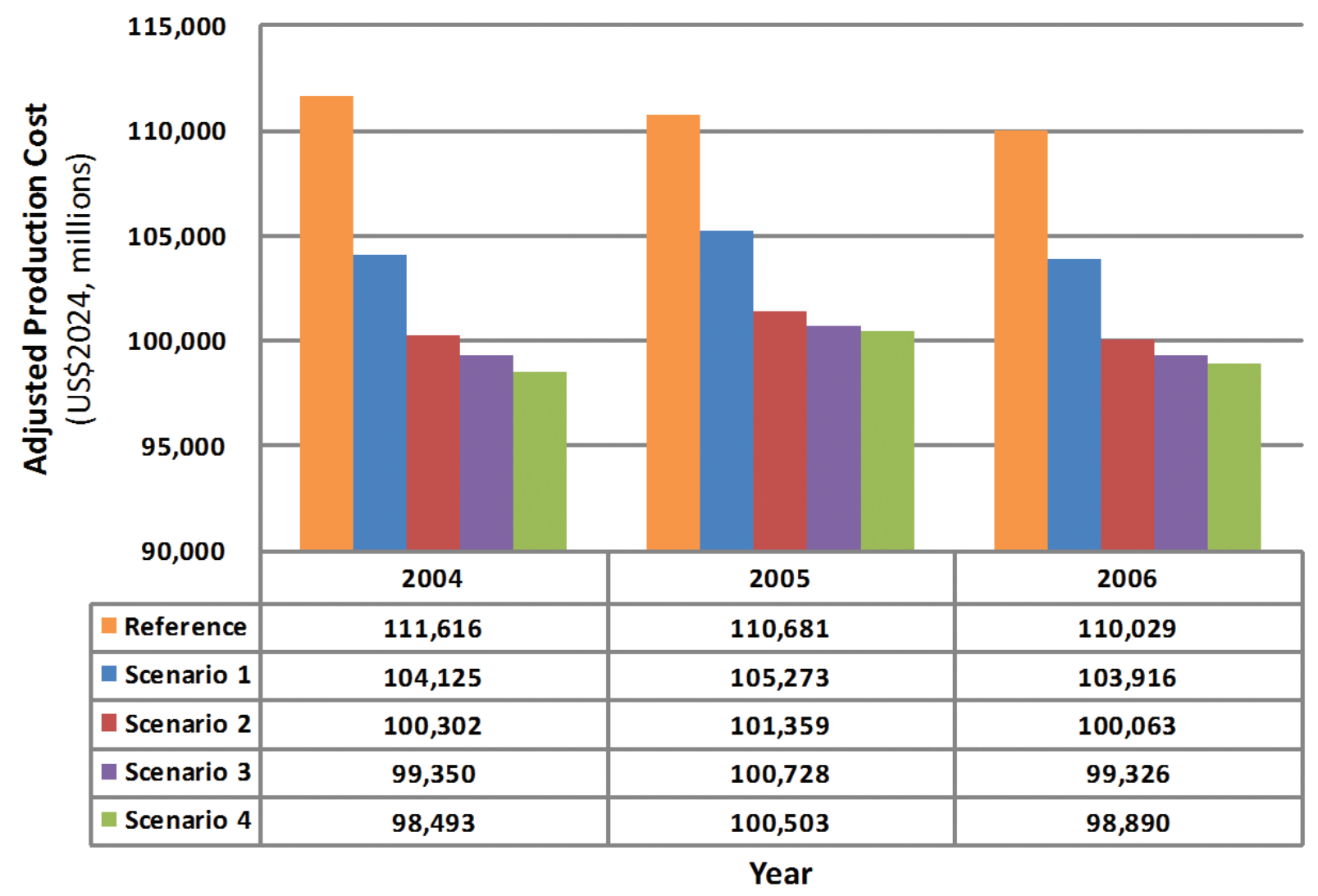

Figure 6-6. Annual APC comparison for actual cases

\section{INTEGRATION COSTS}

Figures 6-7 and 6-8 summarize 3-year wind integration costs by scenario in millions of dollars and dollars per megawatt-hour of wind, respectively. The costs for integrating wind across the Eastern Interconnection vary by scenario. 
As expected, the total integration cost of Scenario 4 is the highest among all the scenarios because it has the highest wind penetration level. The integration costs are reduced as wind moves toward load centers from Scenario 1 to 3 . By normalizing over wind generation for each scenario, the integration cost for Scenario 1 is the highest, up to $\$ 8 /$ MWh of wind energy. For Scenario 3, a low of approximately $\$ 5 / \mathrm{MWh}$ integration cost is obtained. These costs show very good consistency between the study results with 3-year wind and load patterns. As with production costs, the Reference Scenario integration costs are much lower because of the lower wind penetrations and associated reserves and forecast errors.

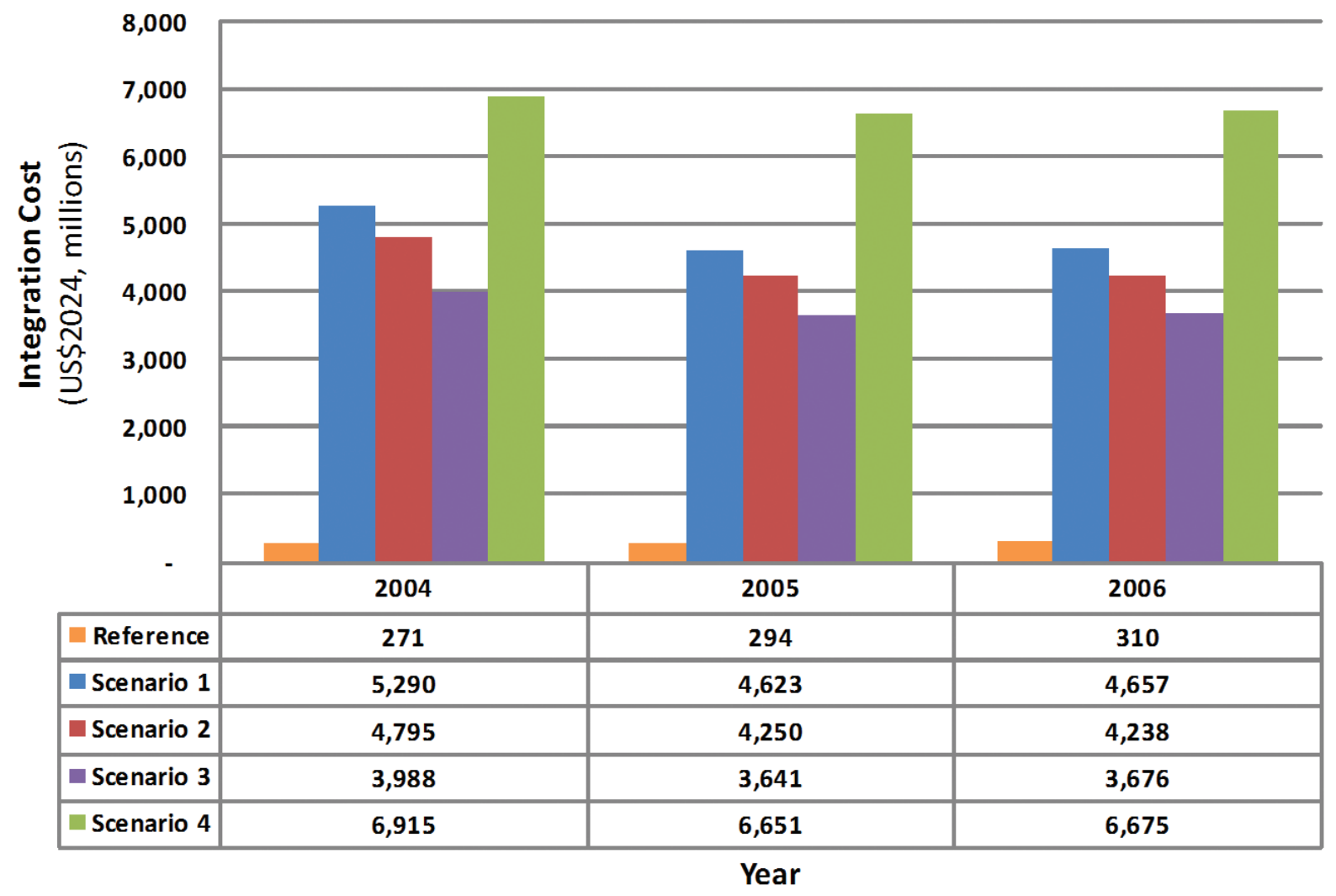

Figure 6-7. Wind integration costs (US\$2024, millions) 


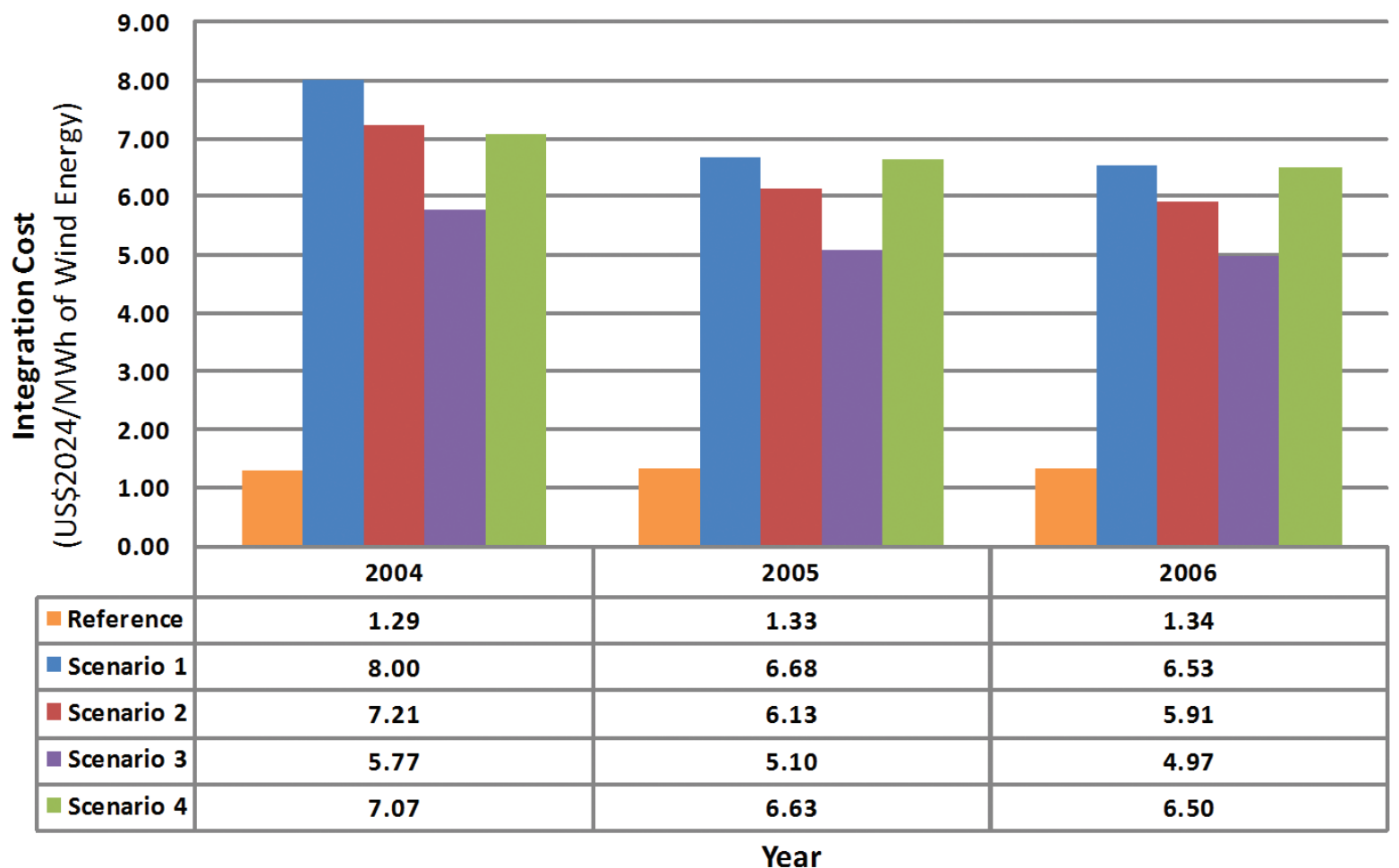

Figure 6-8. Wind integration costs (\$/MWh of annual wind energy in 2024)

\section{WIND ENERGY AND CURTAILMENT}

Each year offers a unique wind data hourly profile driven by a particular weather pattern corresponding to the historical hourly load shape of that year. Using realistic wind patterns is critical to ensure that an assessment of the operational impacts of wind variability and uncertainty on the system is credible. To account for wind uncertainty in production-cost simulations, forecast wind profiles are treated as firm transactions in the day-ahead unit commitment, and in the real-time dispatch wind, forecast errors are included to adjust the amount of wind energy to be essentially the actual wind data. Figure 6-9 shows the annual energy inputs for forecast wind and actual wind using 2004, 2005, and 2006 wind and load hourly profiles for Scenario 1 . Year 2005 shows a more balanced wind pattern compared to the other 2 years and is applied in some of the further sensitivity analyses in Section 6.5 . 


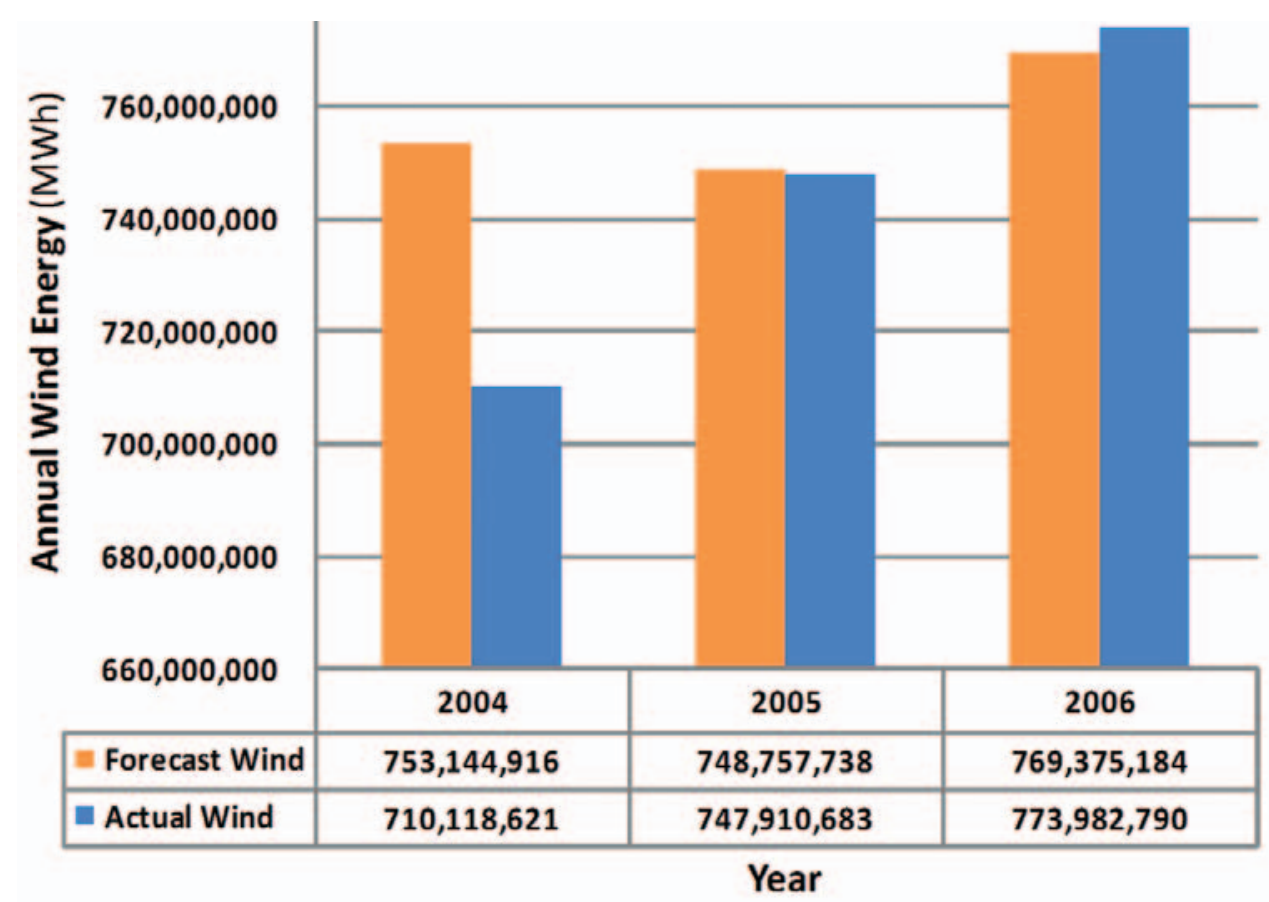

Figure 6-9. Annual wind energy input summary for Scenario 1

Figures 6-10 through 6-12 summarize the wind curtailment levels by region and scenario with 2004, 2005, and 2006 wind and load patterns, respectively. Roughly $2 \%$ to $10 \%$ wind curtailment occurs across the study footprint. SPP has the highest wind curtailment levels in all scenarios except Scenario 3. The lowest wind curtailment level occurs in Scenario 3, with wind spreading more evenly over the footprint. With their intertwined nature, transmission constraints and minimum generation events are clearly the main drivers for wind curtailment. To further investigate wind curtailment, the study team conducted detailed sensitivity analyses, and the results are discussed in Section 6.5.1. 


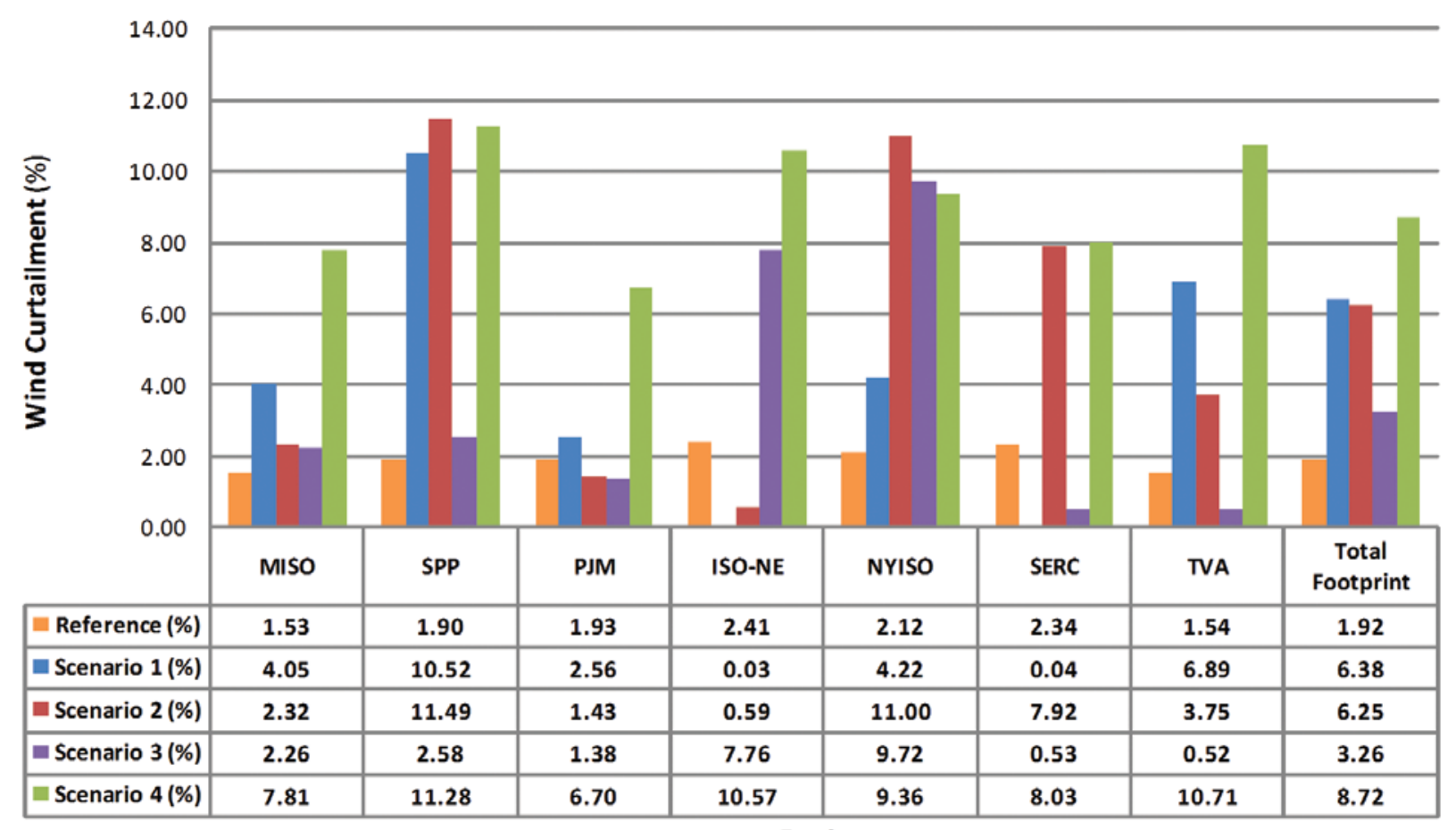

Region

Figure 6-10. Annual wind curtailment summary using 2004 hourly load and wind profiles

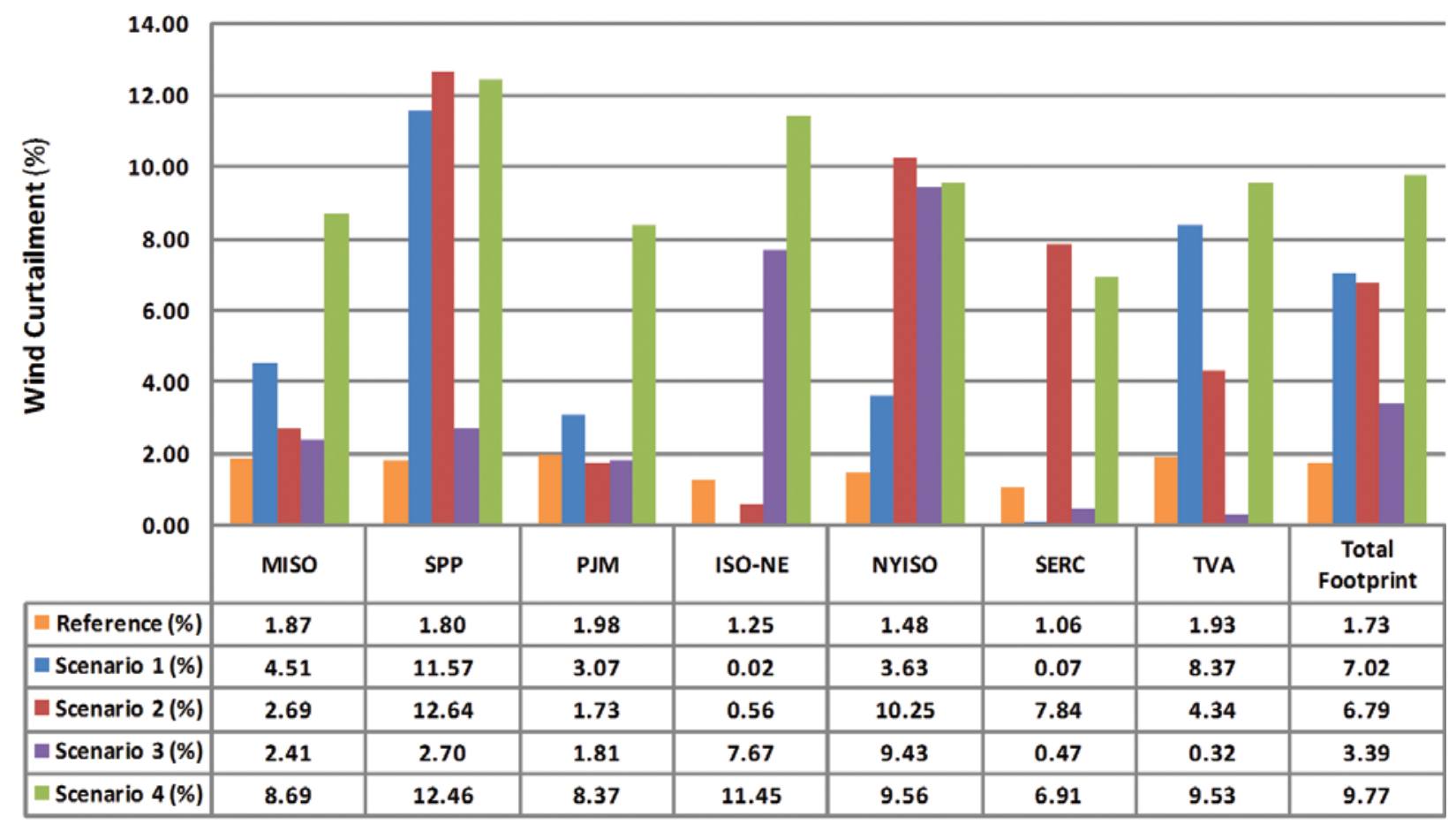

Region

Figure 6-11. Annual wind curtailment summary using 2005 hourly load and wind profiles 


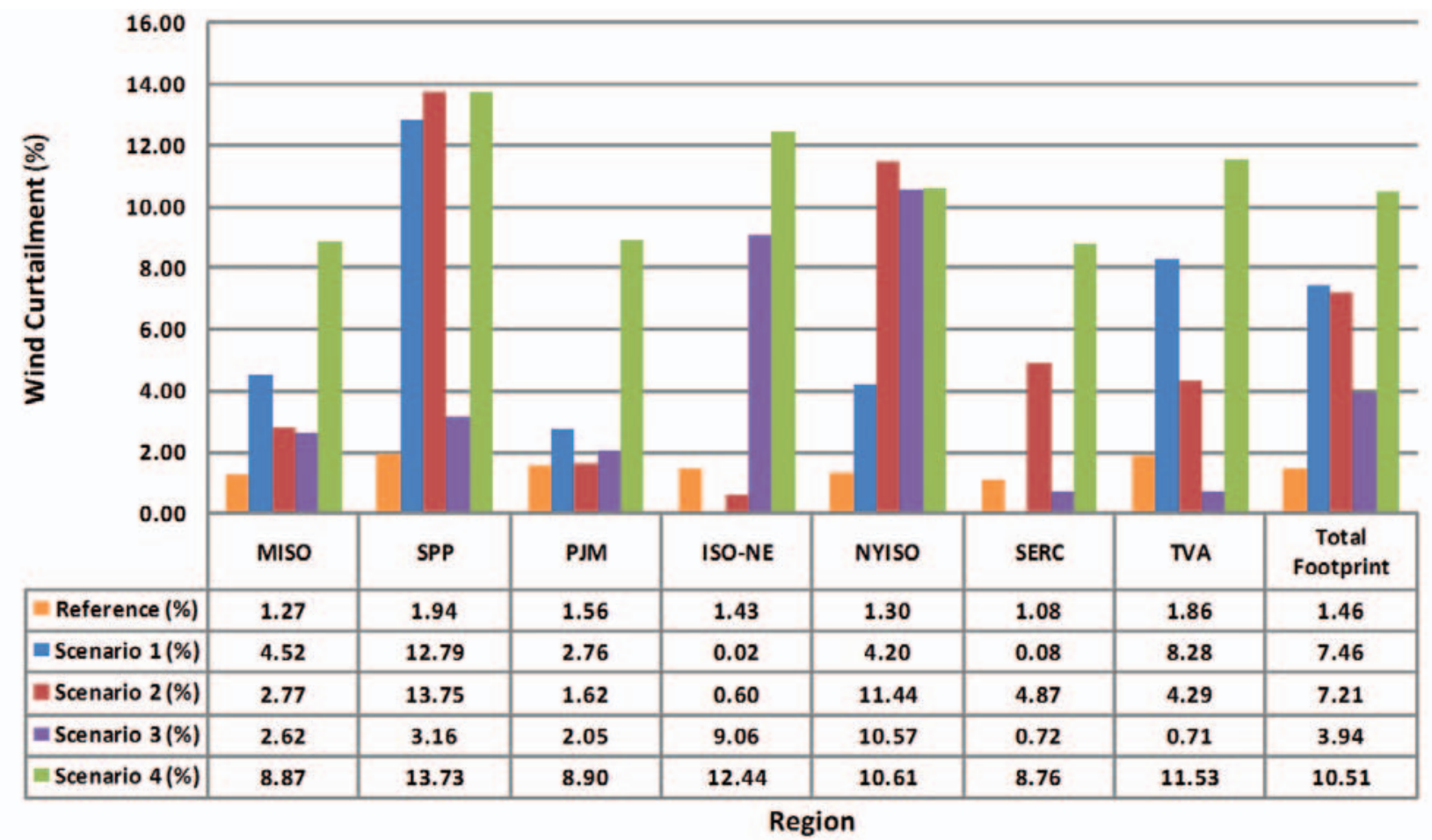

Figure 6-12. Annual wind curtailment summary using 2006 hourly load and wind profiles

\section{GENERATION BY FUEL TYPE}

The operating costs associated with wind variability and uncertainty depend on the nature of the generation mix developed for each scenario. For example, fuel prices, carbon emission regulations, variable operations and maintenance (O\&M) costs, and renewable energy mandates all feed into operating costs. Examining the generation dispatch pattern can offer valuable insights into understanding the effect of wind on system operations.

Generation by fuel type for each scenario with 3-year wind and load profiles is illustrated in Figures 6-13 through 6-15, and with the same information, Figures 6-16 through 6-18 show a different way to look at the dispatchable generation resources. Among the three 20\% wind scenarios, more gas-fired combined cycle (CC) units are dispatched in Scenario 1 to manage the largest variable reserves because the majority of wind units are located in the western regions. In Scenario 4 , the increased off-peak energy contribution of the $30 \%$ wind mandate results in an approximately $16 \%$ reduction of steam turbine (ST) coal generation compared to the three $20 \%$ wind scenarios, whereas a fairly comparable level of combined cycle production remains in Scenarios 3 and 4. In Scenario 4 (30\% wind penetration), wind becomes the second largest energy producer, behind only coal-fired steam turbines in terms of energy output. 


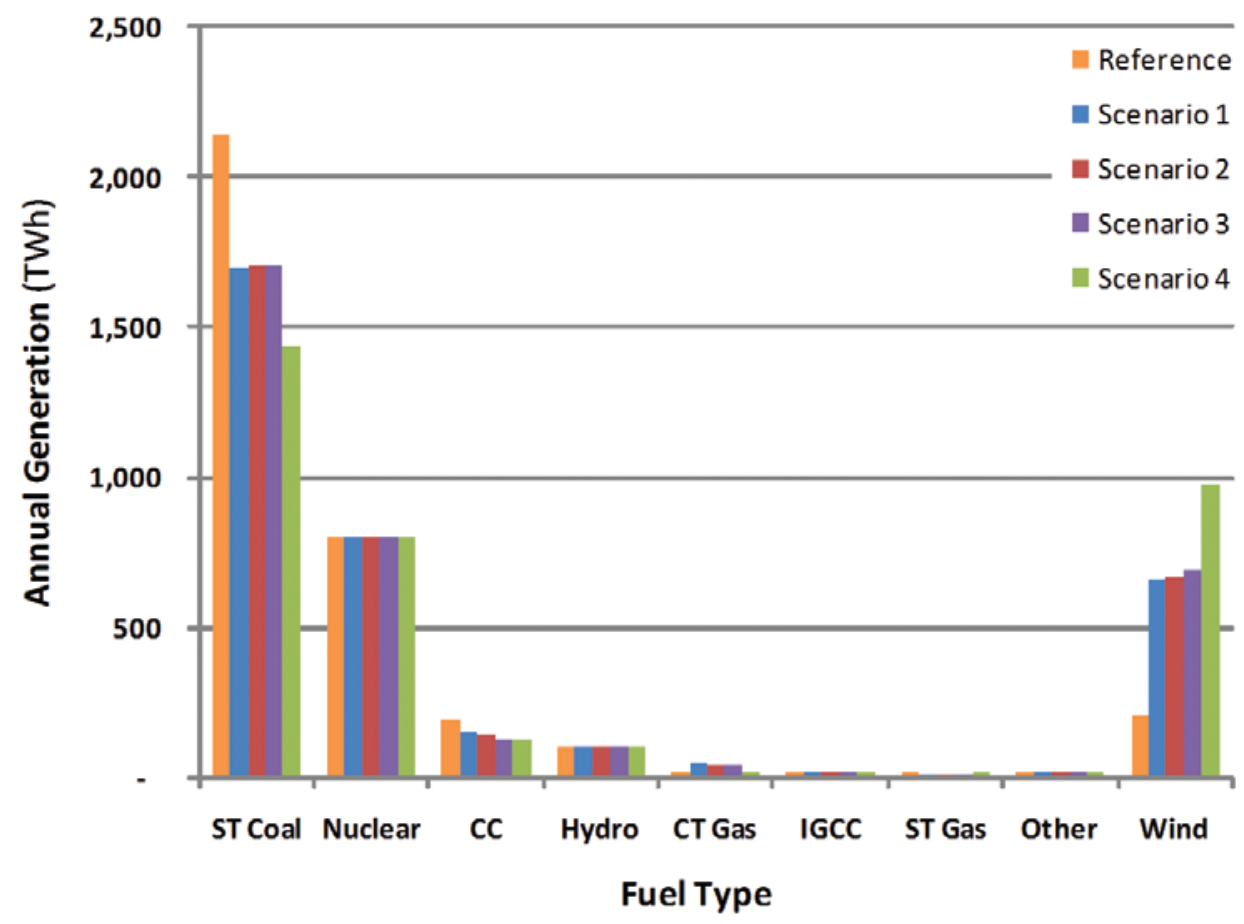

Note: IGCC = integrated gas combined cycle

Figure 6-13. Annual generation energy by fuel type using 2004 hourly load and wind profiles

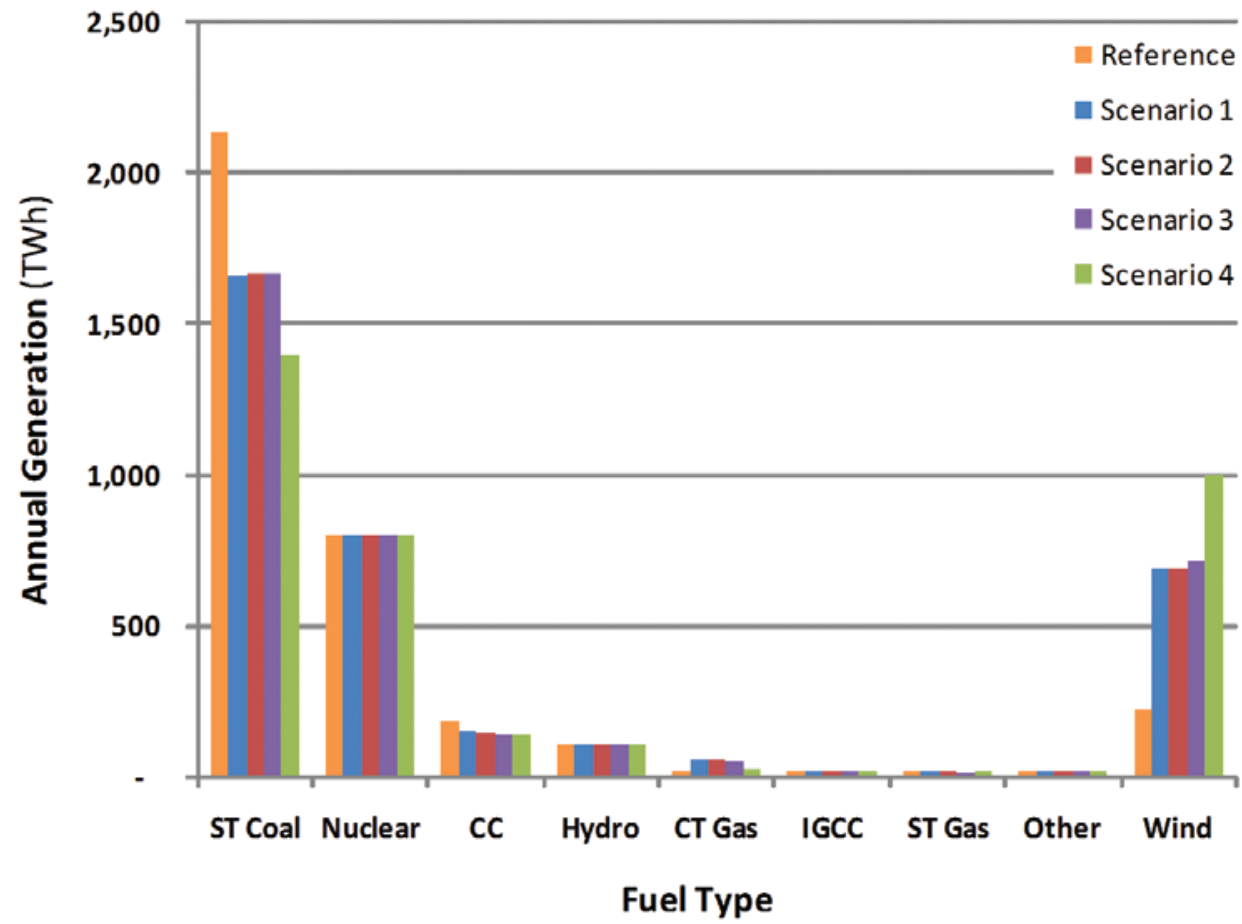

Figure 6-14. Annual generation energy by fuel type using 2005 hourly load and wind profiles 


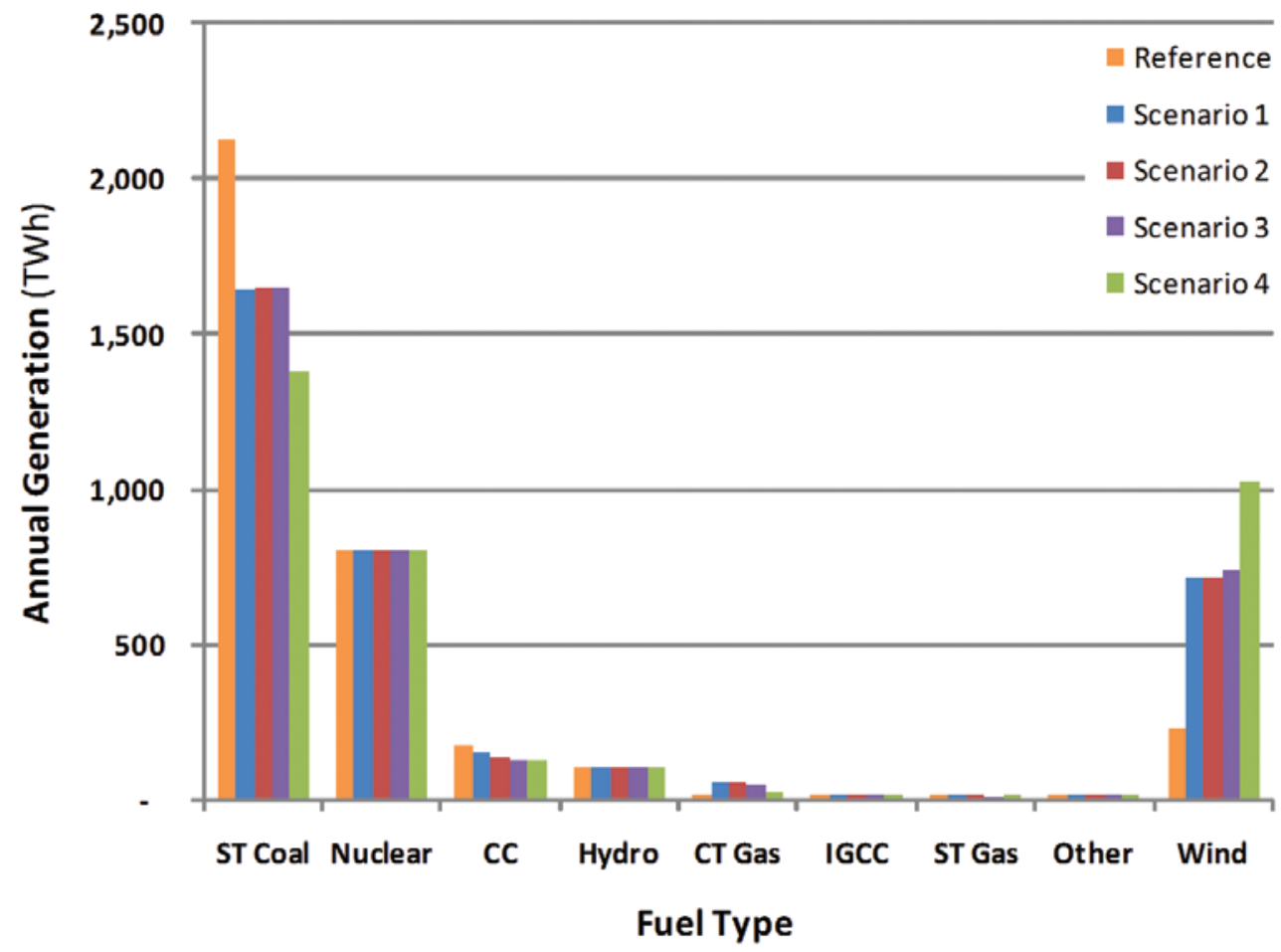

Figure 6-15. Annual generation energy by fuel type using 2006 hourly load and wind profiles

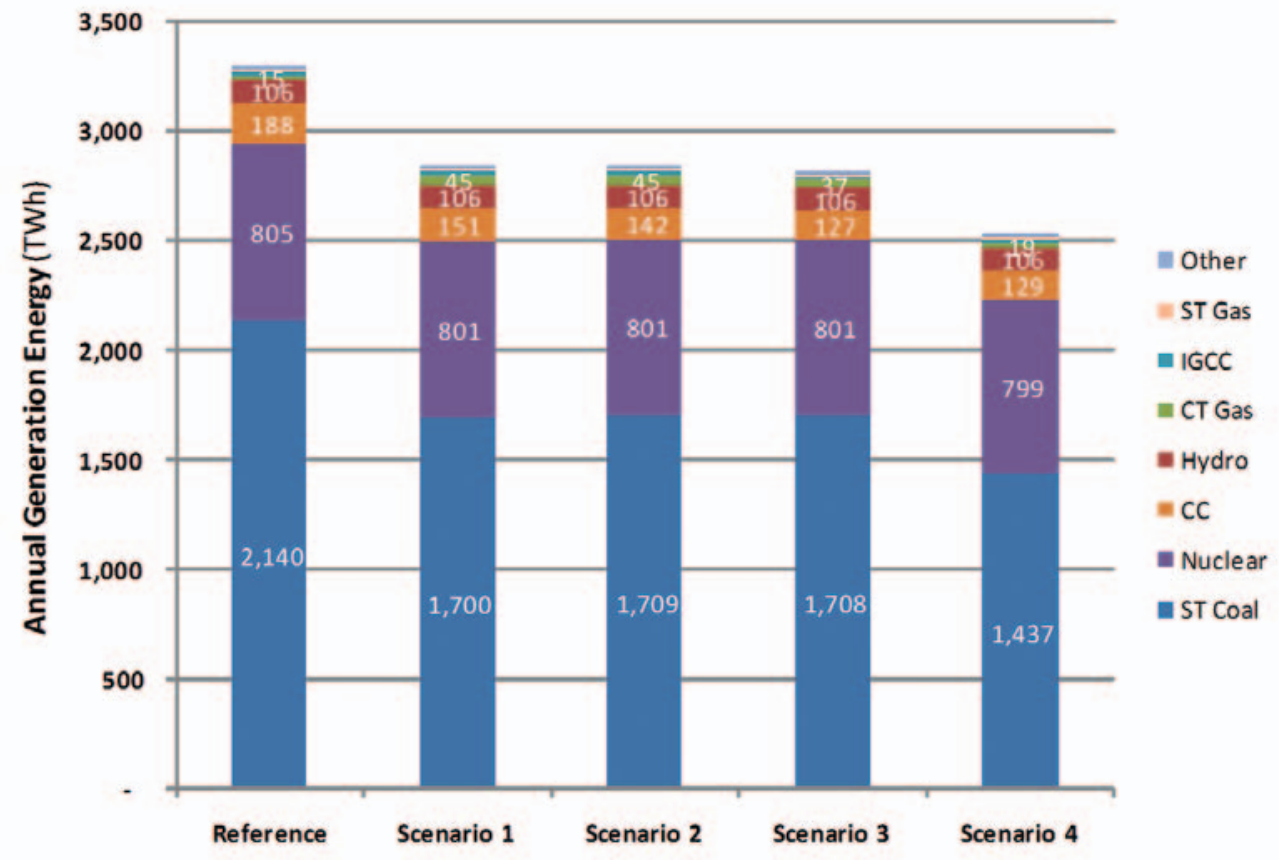

Figure 6-16. Annual generation energy by fuel type using 2004 hourly profiles 


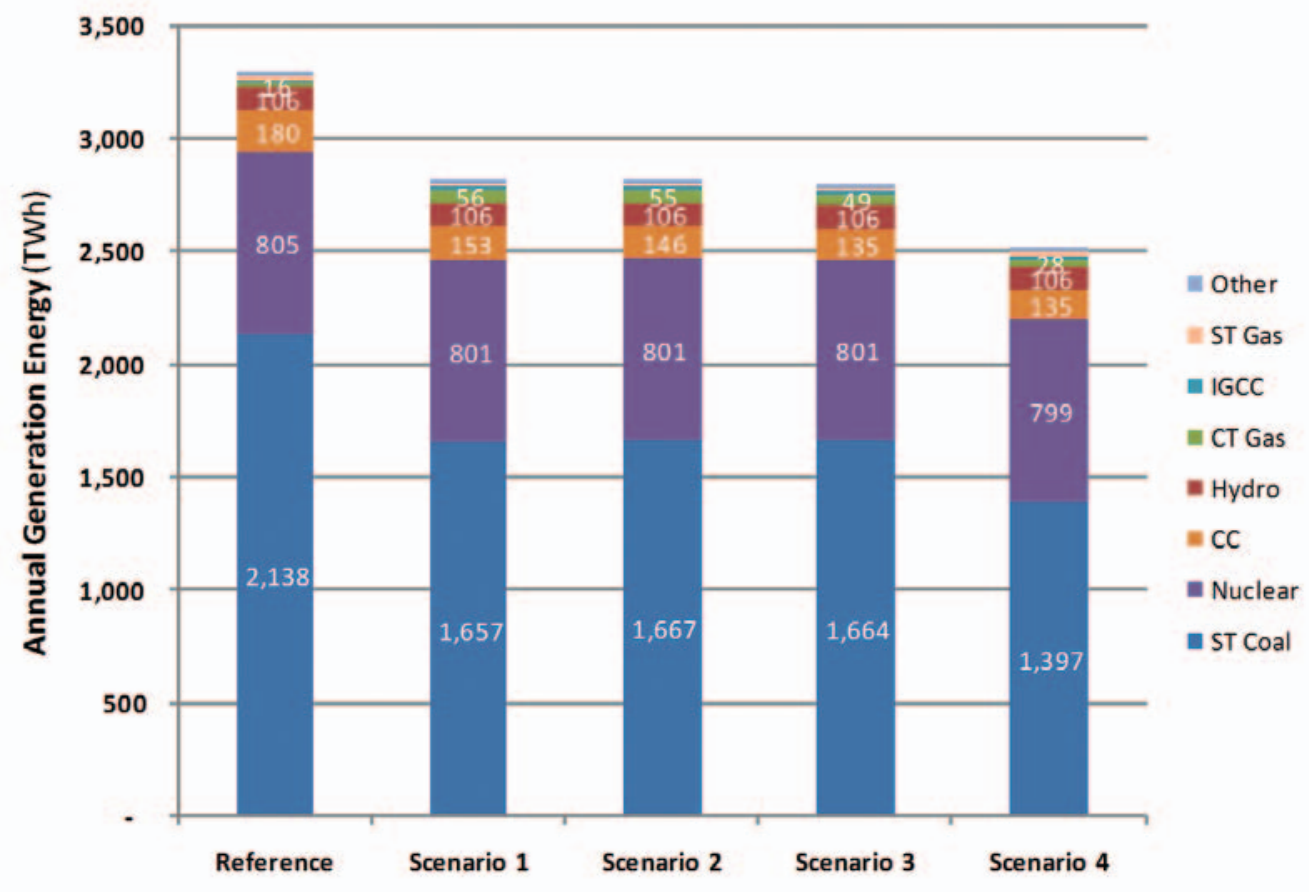

Figure 6-17. Annual generation energy by fuel type using 2005 hourly profiles

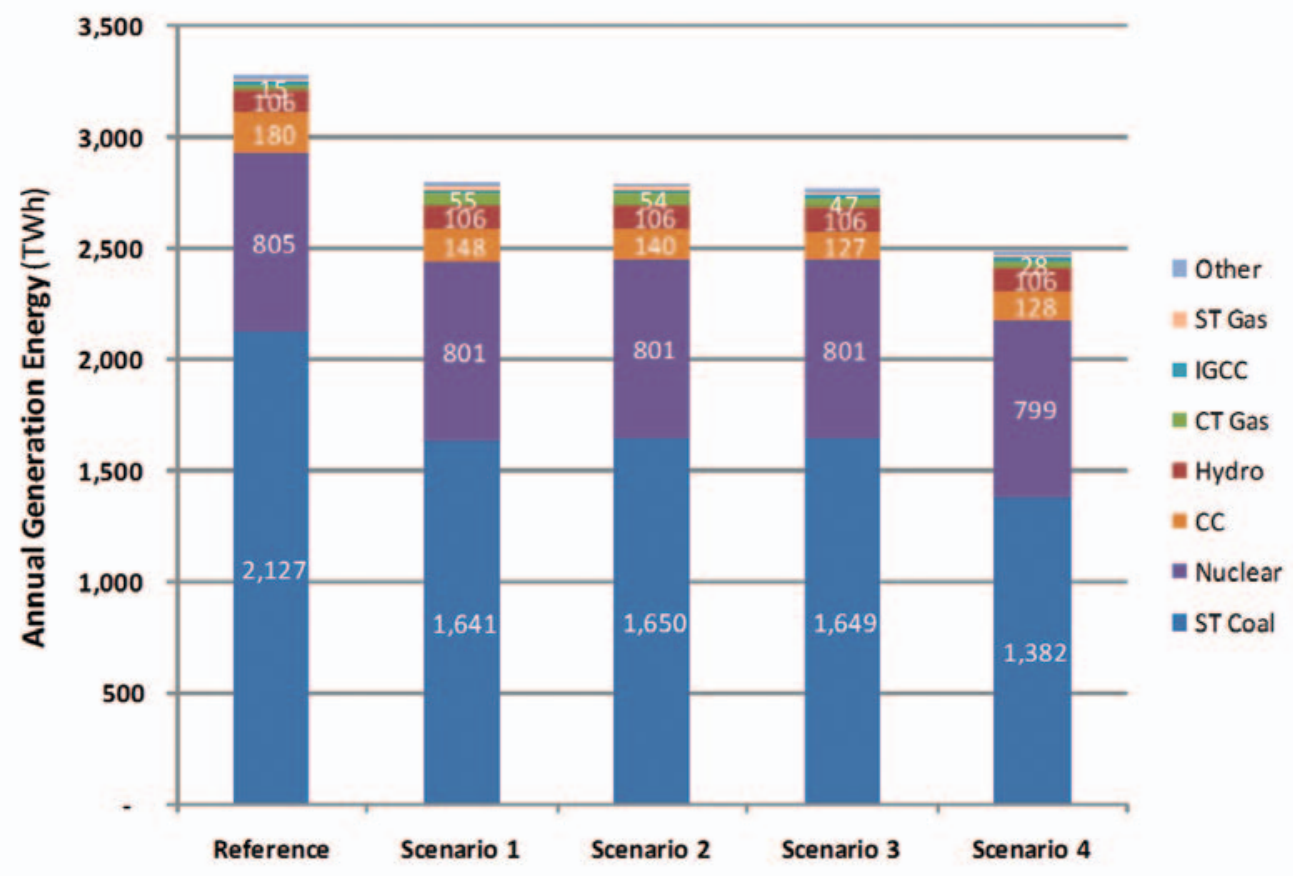

Figure 6-18. Annual generation energy by fuel type using 2006 hourly profiles 
Figures 6-19 through 6-21 summarize the annual generation changes between the ideal and actual wind cases by fuel type and scenario for the 3-year wind and load patterns. As described in Section 6.2, the day-ahead wind forecast error and additional reserve carried because of wind are used to differentiate the actual wind case from the ideal wind case and are the significant drivers for generation changes between these two cases. All the scenarios follow the same trend, with coal-fired steam turbines displaced primarily by gas-fired combined cycle and combustion turbines. To deal with the highest wind penetration and associated incremental reserve requirement, the most significant generation shifting is observed in Scenario 4. The generation shift in Scenario 3 is the most modest of the high-penetration wind scenarios because it has the least additional reserve requirement (as a result of moving wind close to load centers). Consistent with low wind penetration and integration costs, the Reference Scenario shows the least generation shift from the ideal to actual wind cases.

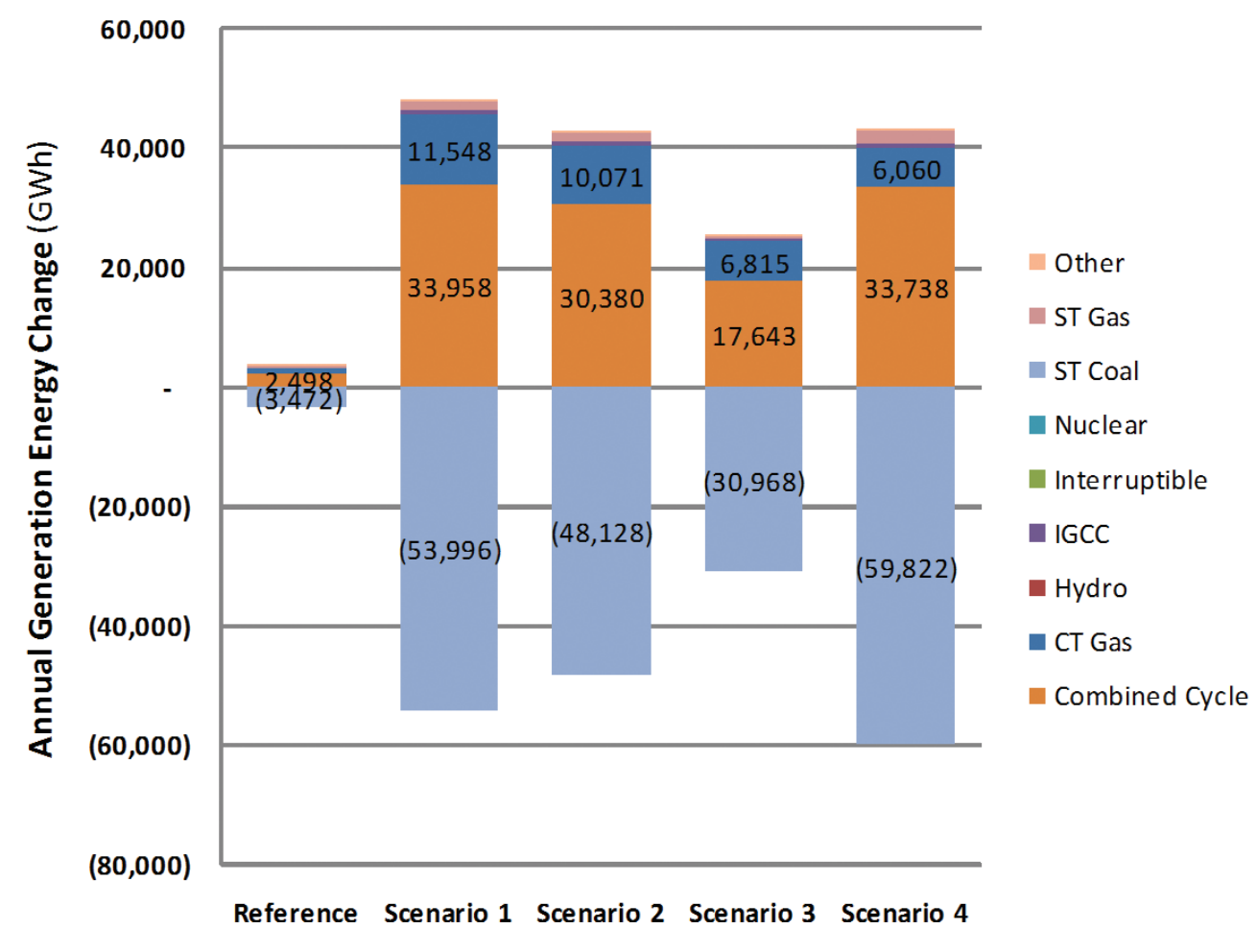

Figure 6-19. Change in annual generation from ideal to actual cases using 2004 hourly profiles 


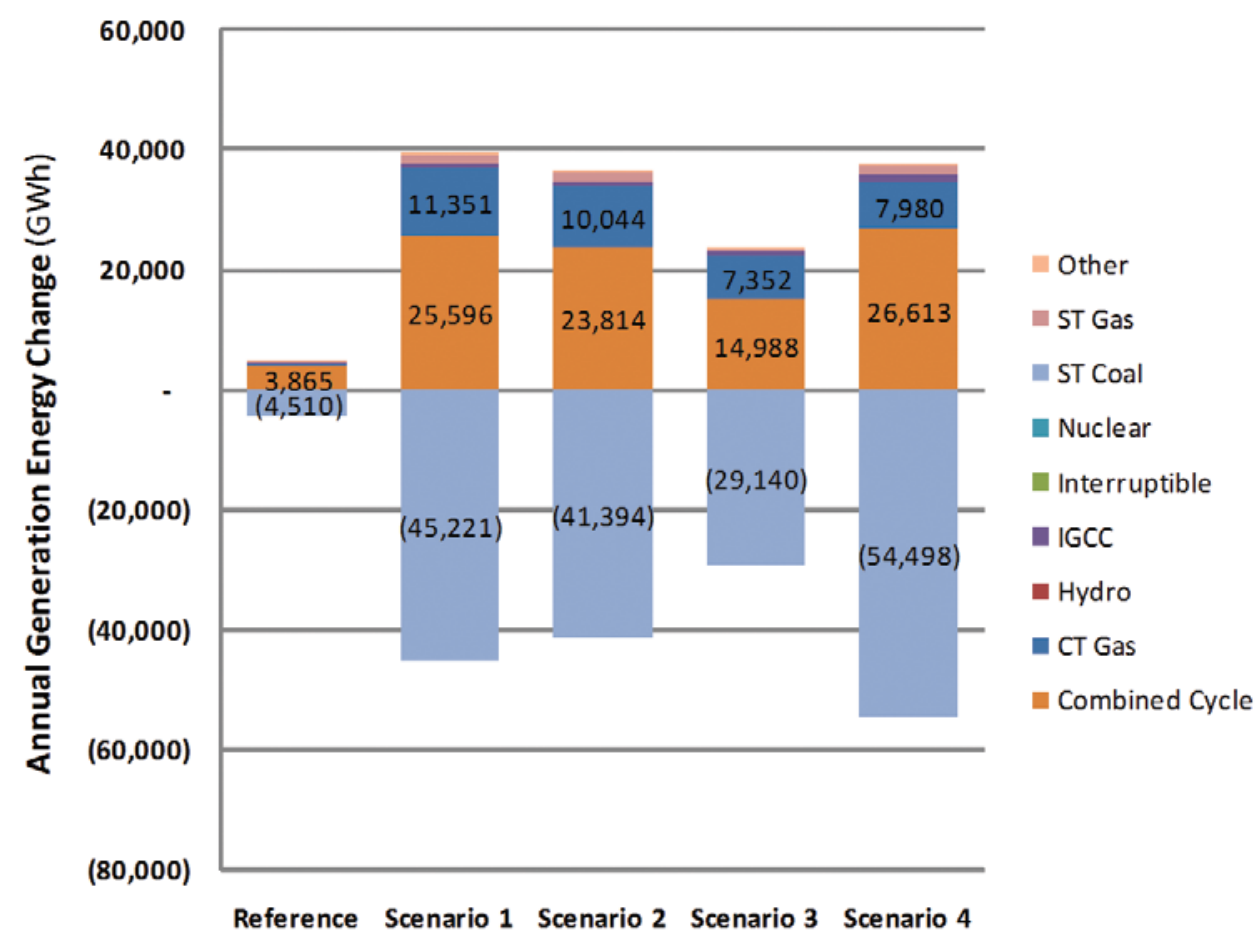

Figure 6-20. Change in annual generation from ideal to actual cases using 2005 hourly profiles

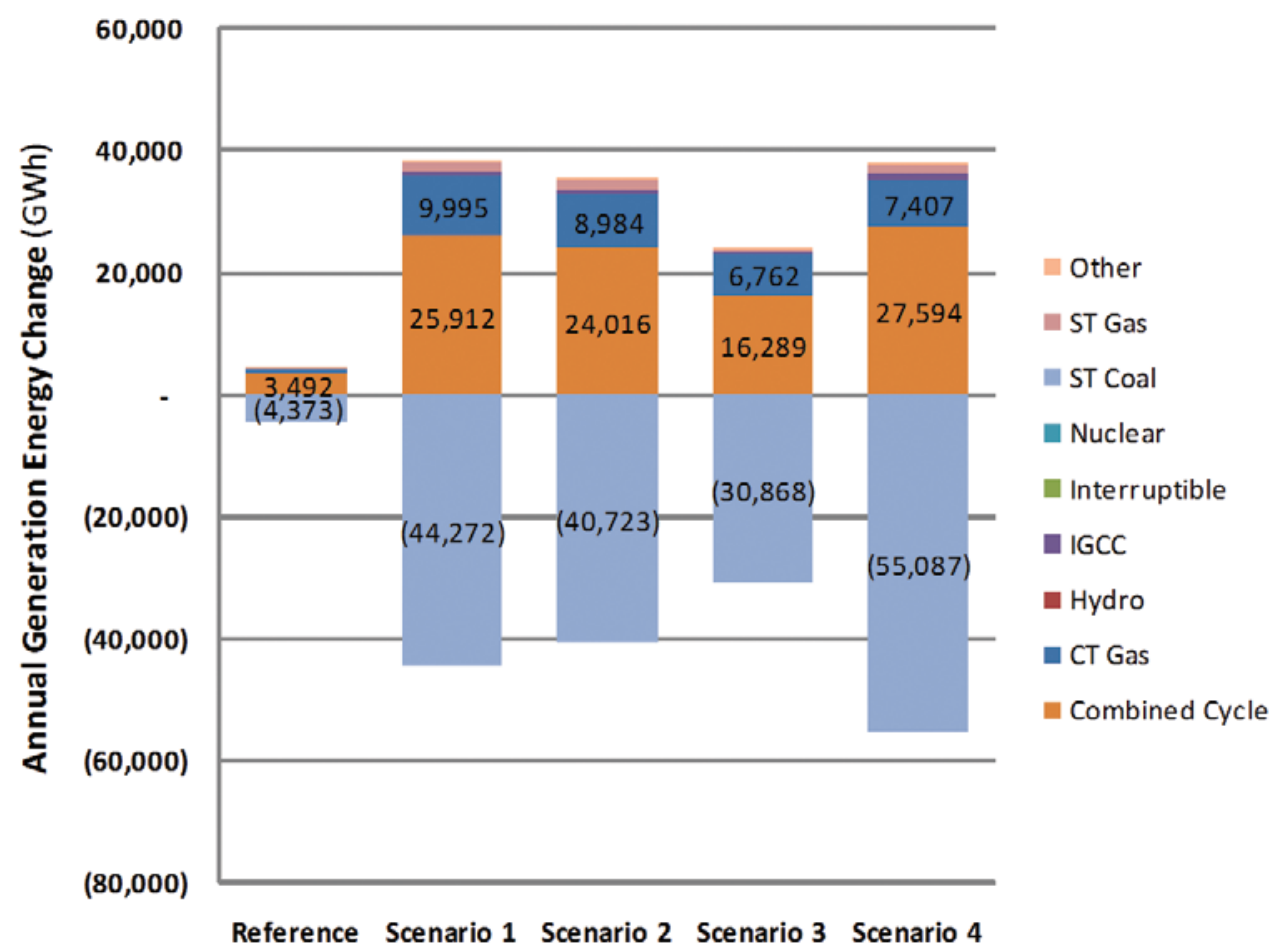

Figure 6-21. Change in annual generation from ideal to actual cases using 2006 hourly profiles 


\section{LOCATIONAL MARGINAL PRICES}

Figures 6-22 through 6-24 illustrate the effect of wind on annual generation-

weighted LMPs by region and scenario for the 3-year wind and load patterns.

The LMP is the marginal cost of serving the next megawatt of demand

and depends on the system transmission constraints and the performance

characteristics of generation resources. Because there is less congestion with wind moving toward load centers, it is intuitive to expect that the regional generationweighted LMPs decrease from Scenario 1 to 3.

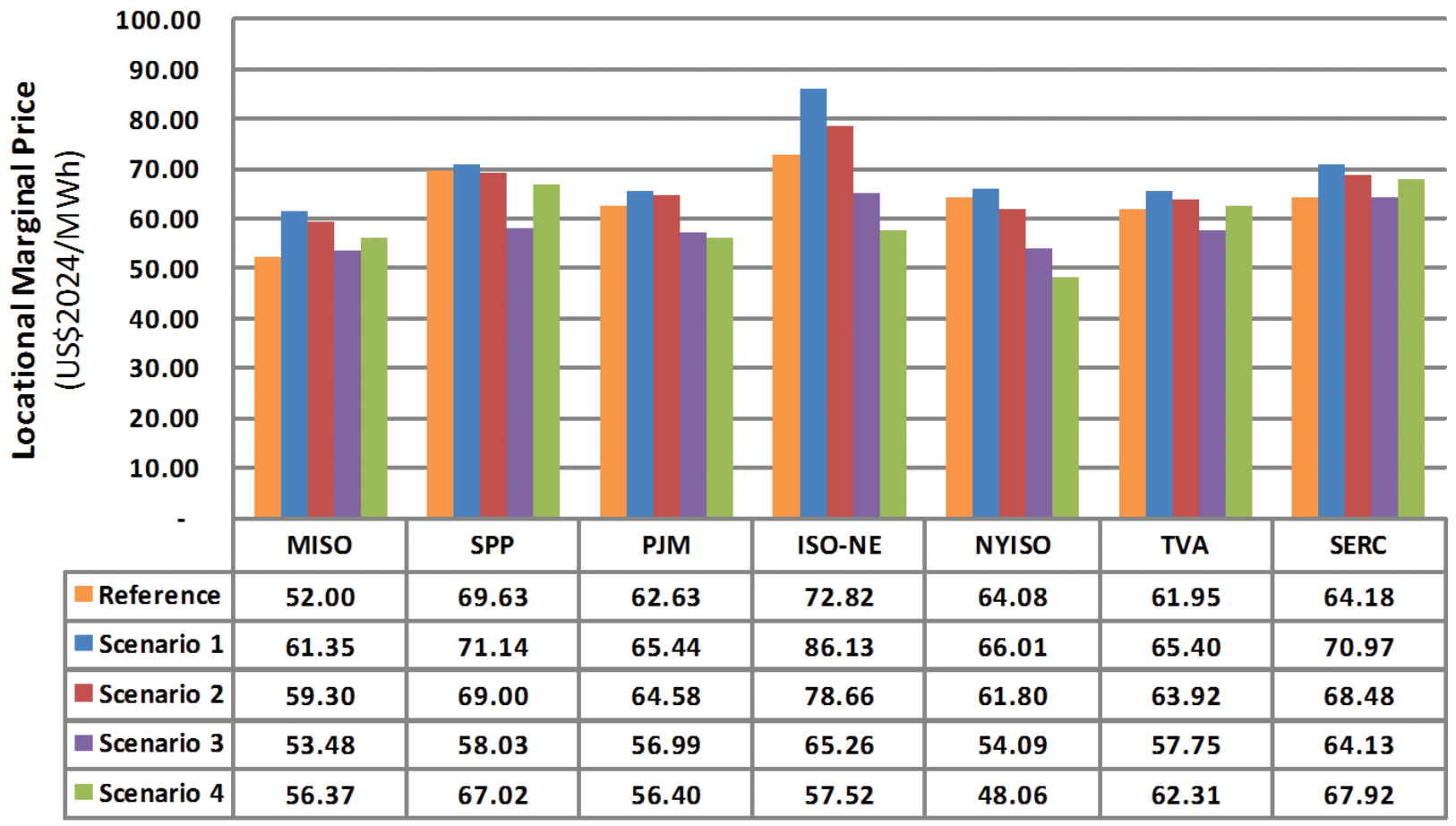

Region

Figure 6-22. Annual generation-weighted LMPs using 2004 hourly profiles 


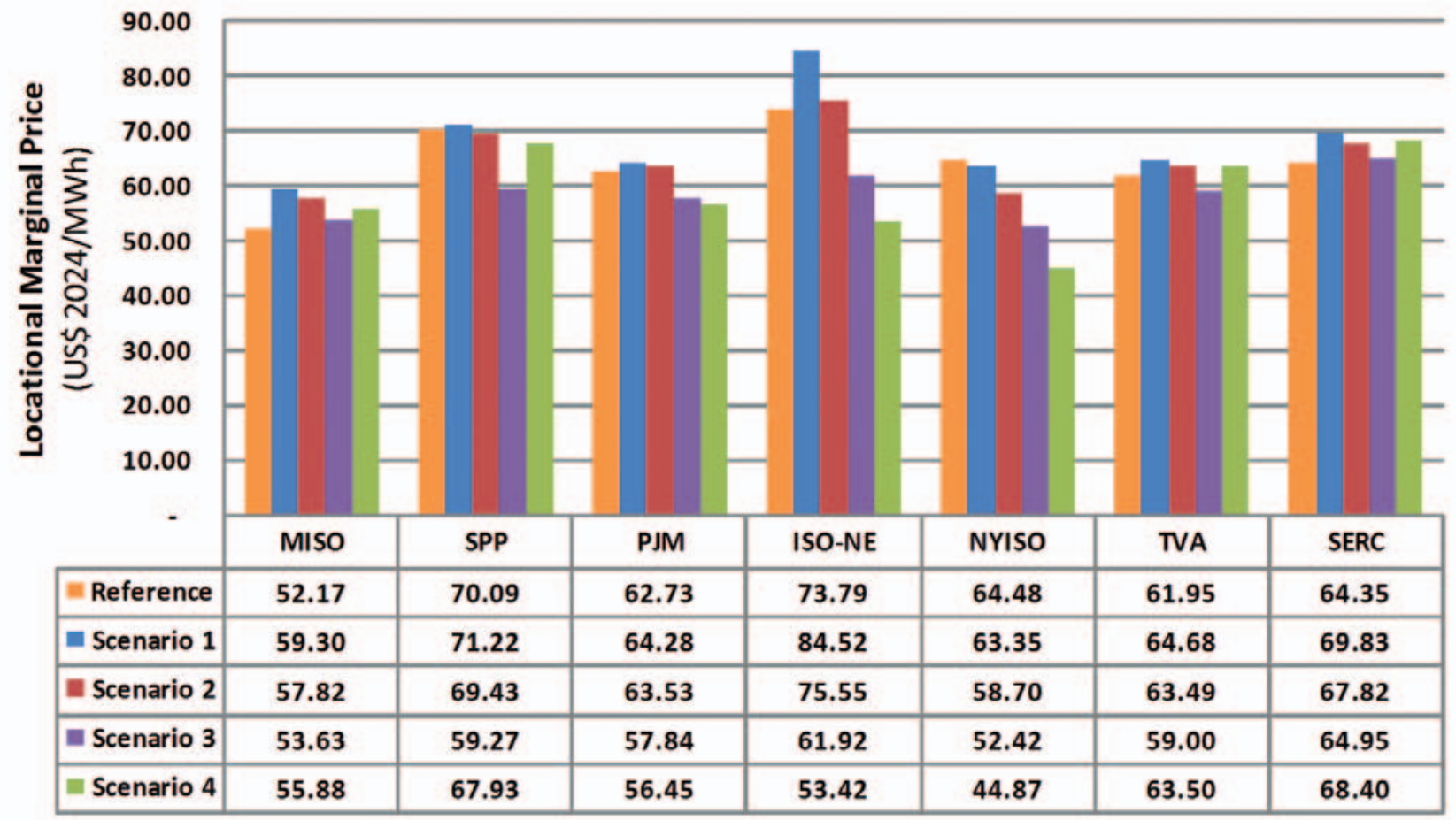

Region

Figure 6-23. Annual generation-weighted LMPs using 2005 hourly profiles

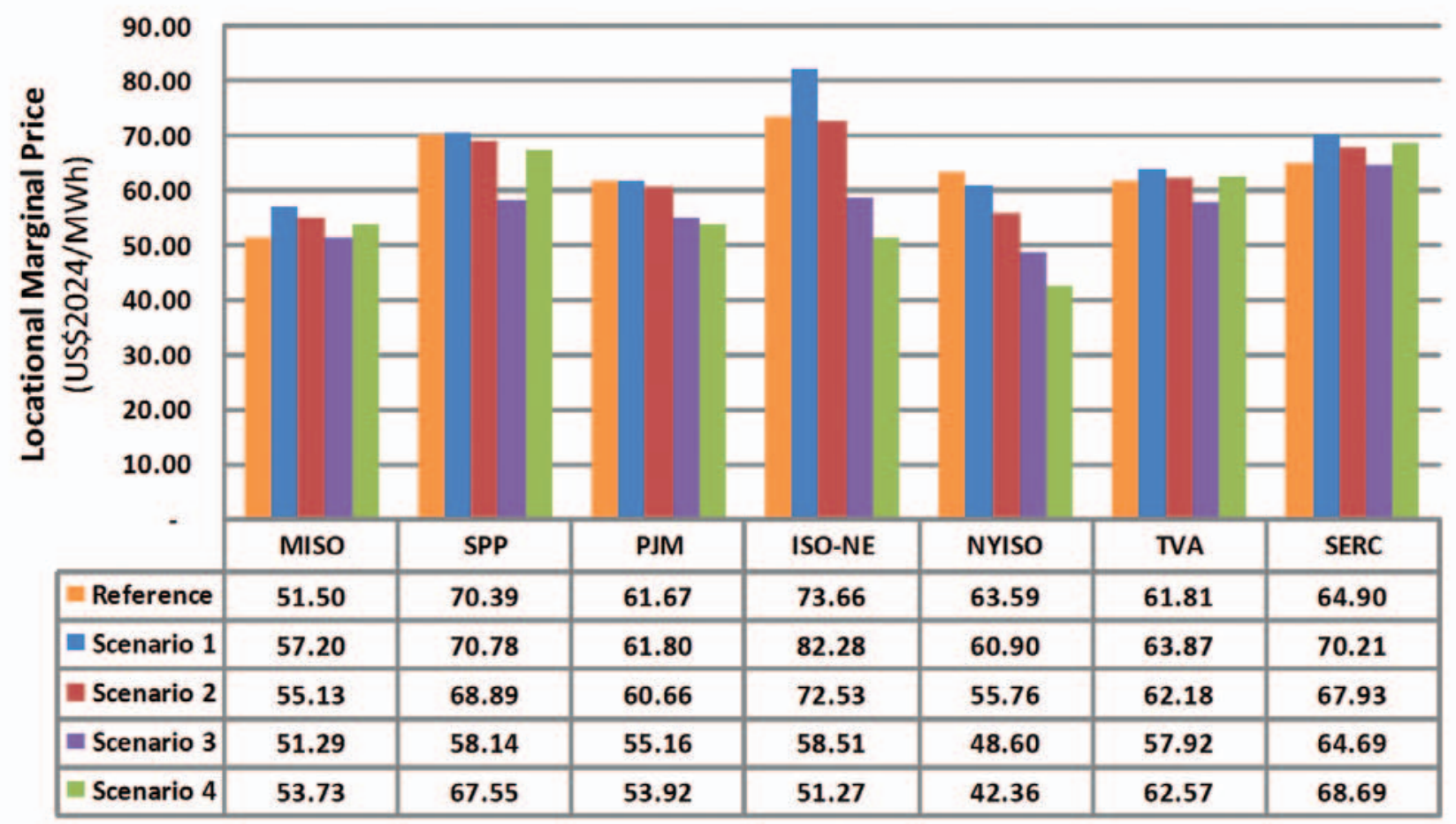

Region

Figure 6-24. Annual generation-weighted LMPs using 2006 hourly profiles 
Scenario 4 elevates the effect on energy market prices because it has the most aggressive wind penetration level. Regionally, the results are as follows:

- Even though both Scenarios 3 and 4 use a substantial amount of offshore wind along the East Coast with approximately the same installed wind capacity in ISO-NE and NYISO, the LMPs in East Coast regions are lower in Scenario 4 because more wind resources are accessible in the western regions for importing with the extra-high voltage (EHV) transmission overlay.

- For western regions SPP, Midwest ISO, and Mid-Continent Area Power Pool (MAPP), however, the LMPs in Scenario 4 are actually higher than those in Scenario 3. This is in recognition of the significant difference of the installed wind capacity and the resulting variable reserve requirement driven by wind between these two scenarios.

- As a consequence of the increased energy import in TVA and SERC because of little installed wind capacity, more flexible gas-fired units must be committed or available to accommodate the larger amount of imported variability and uncertainty in Scenario 4 . As a result, Scenario 4 has higher LMPs than Scenario 3.

\section{REGIONAL TRANSACTIONS}

The conceptual transmission overlay enables wind and base-load steam energy in the western regions to reach a wider footprint and results in a different unit commitment and dispatch across the entire study footprint. The associated regional transaction costs have a great impact on the APC calculation for each region. Figures 6-25 through 6-27 show the annual transaction energy by region with the 3-year wind and load profiles.

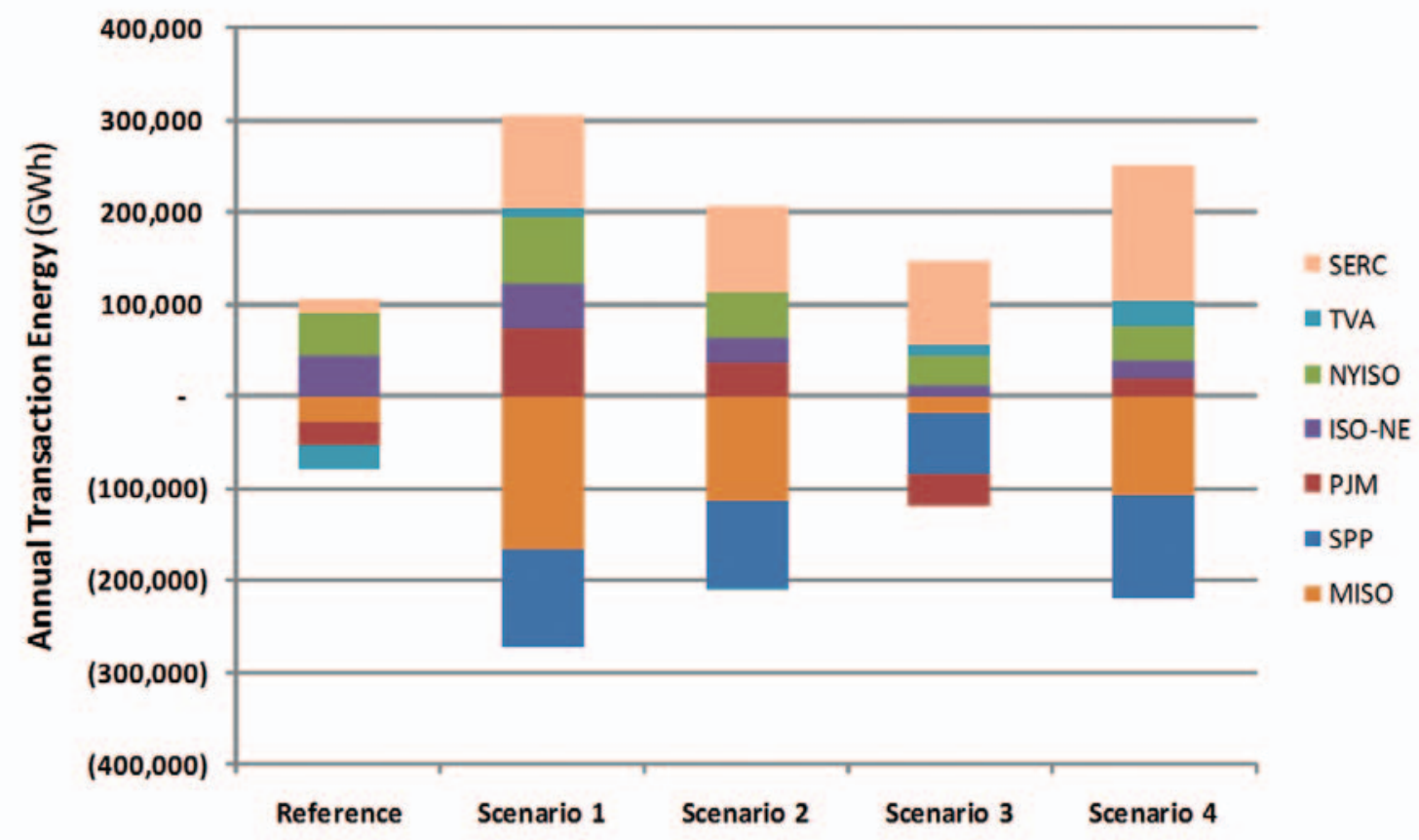

Figure 6-25. Annual regional transaction energy using 2004 hourly profiles 


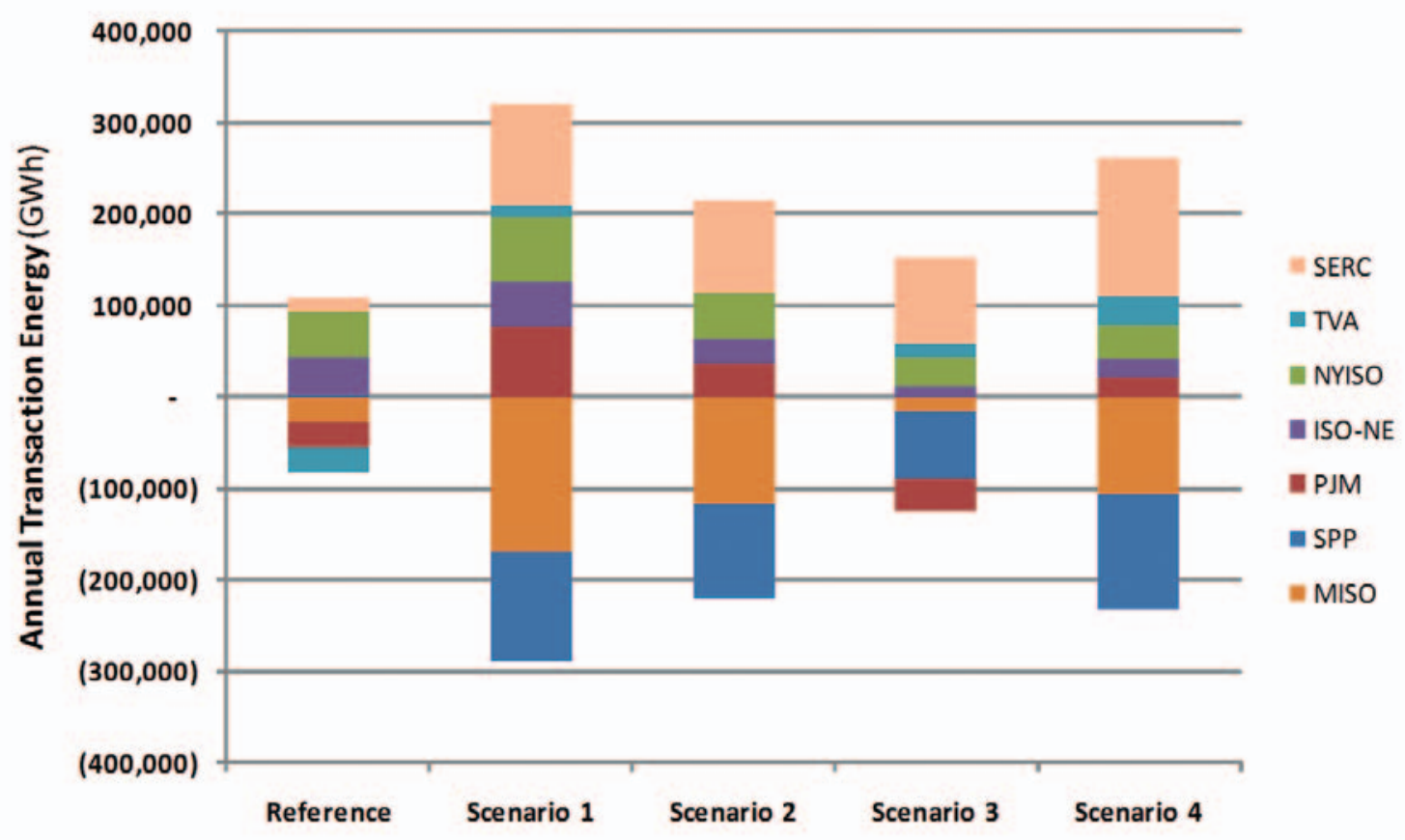

Figure 6-26. Annual regional transaction energy using 2005 hourly profiles

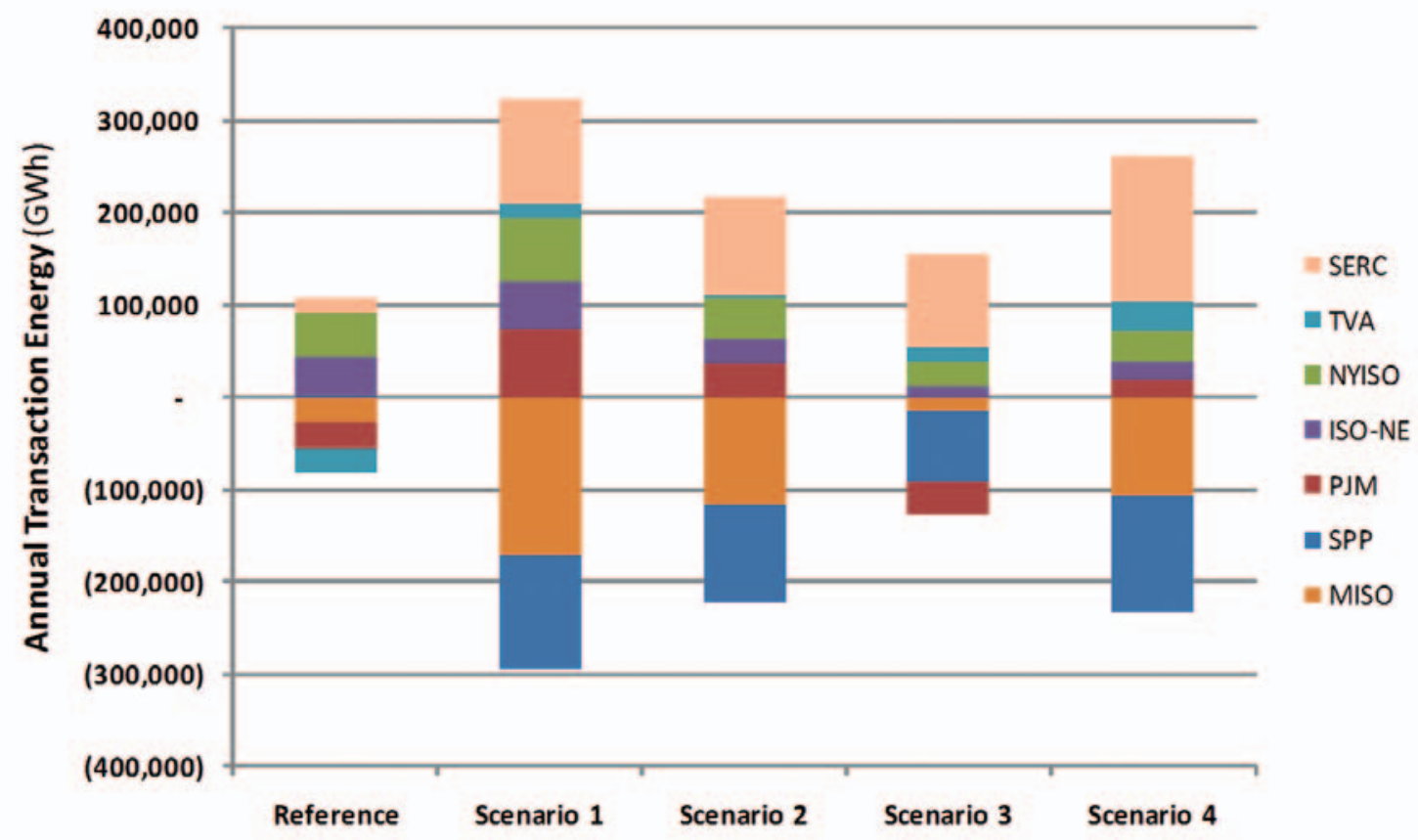

Figure 6-27. Annual regional transaction energy using 2006 hourly profiles 
The effects of wind generation on regional transactions can be summarized as follows:

- SPP, MISO, and MAPP are the primary export regions and SERC is the predominant import region because of low wind availability in all the scenarios. The total transaction amount decreases from Scenario 1 to 3 as wind resources move toward the East Coast. Scenario 3 has the least regional transaction energy among the high-penetration wind scenarios.

- As a result of using aggressive amounts of offshore wind capacity in eastern regions, Scenario 4 has smaller amounts of transactions on the total study footprint compared to Scenario 1 .

- The import amounts are roughly the same in SERC for the three $20 \%$ wind penetration scenarios, and there is an approximate $40 \%$ increase in Scenario 4 because the eastern regions need to import less.

- PJM, NYISO, and ISO-NE are exporters in Scenario 3 as more wind moves toward load centers. This results in a large increase of installed wind capacity in the eastern regions for export.

- With a different transmission overlay, different thermal expansion plan, and lower wind penetration with different siting, the Reference Scenario shows much lower total energy interchange and some different net positions for regions.

\section{SENSITIVITY ANALYSIS WIND CURTAILMENT}

Continuing the study effort described in Section 4.4.2, more detailed sensitivity analyses were performed to further investigate wind curtailment in the highpenetration wind scenarios. Wind curtailment ranges from approximately $3 \%$ to $10 \%$ with the conceptual transmission overlays developed for EWITS.

Using the Scenario 1 actual wind case with 2004 hourly wind and load profiles, the study team conducted three sensitivity analyses:

- Sensitivity Case 1, Non Must-Run: The must-run constraint is removed from coal units (i.e., the program is allowed to actually shut them down).

- Sensitivity Case 2, Copper Sheet: There are no transmission constraints in the system.

- Sensitivity Case 3, Wind Energy Credit: The wind curtailment price is set at negative $\$ 40 / \mathrm{MWh}$, twice as much as the current production tax credit (PTC).

Figure 6-28 shows the duration curve of the hourly flows across the sample interface. As described in Section 4, the transmission line across the interface is sized to deliver $80 \%$ of desired energy flow as an initial estimate of the preliminary economic transmission requirement. For very short periods of time, some wind energy curtailment would be expected for the four high-penetration wind scenarios. 


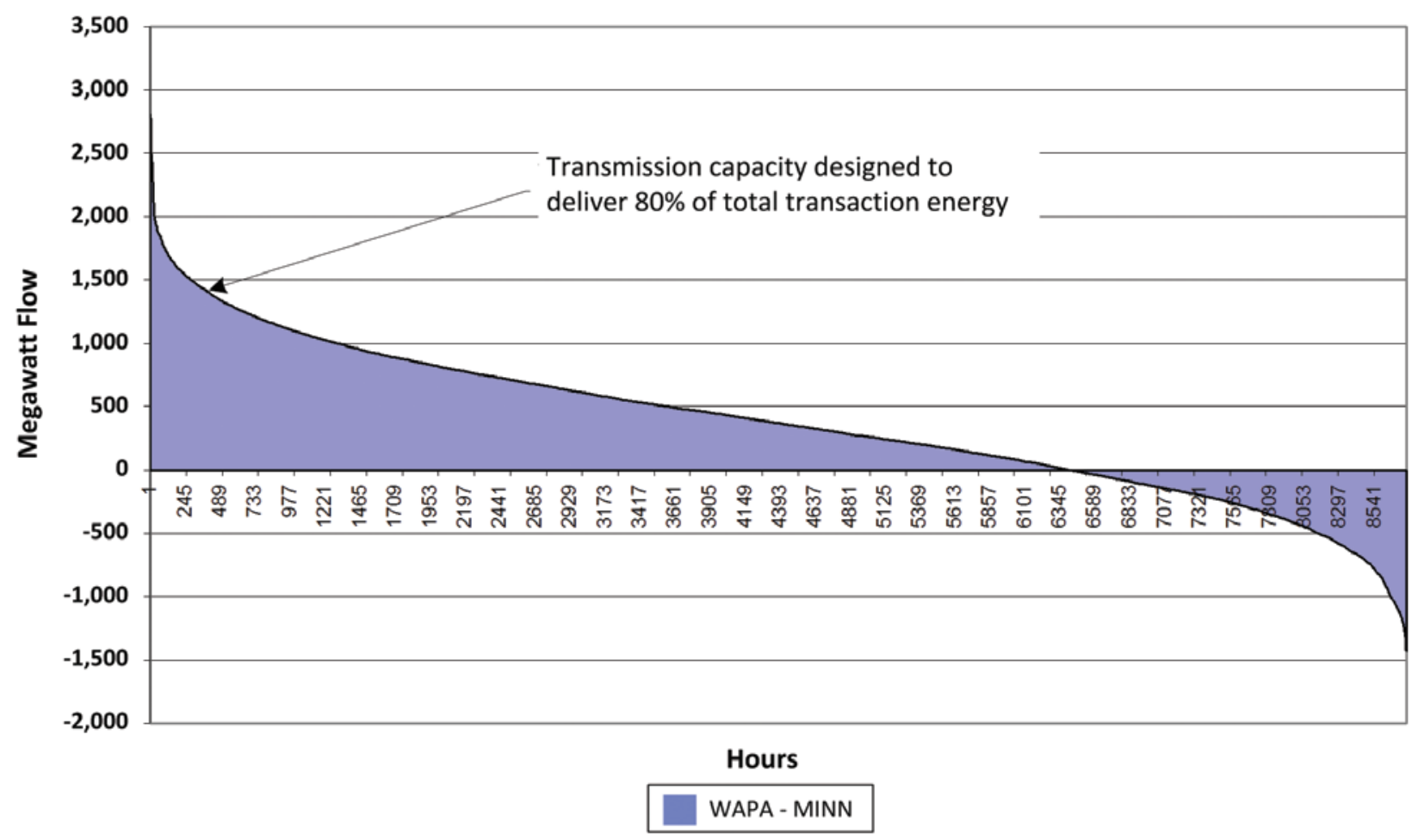

Figure 6-28. Interface flow duration curve sample

Tables 6-3 through 6-5 summarize the annual wind curtailment results by region for the three defined sensitivity cases, respectively. Removing the must-run status from coal units has the least effect on wind curtailment, with only $0.27 \%$ curtailment reduction compared to the original actual wind case. With a wind curtailment price at negative $\$ 40$ / MWh, approximately $3.51 \%$ wind curtailment is achieved for the whole study footprint as opposed to the original $6.38 \%$. The majority of wind curtailment is caused by transmission constraints because wind curtailment is significantly reduced with no transmission constraints in the system. Only $0.12 \%$ wind curtailment is left, which is most likely caused by the minimum generation events. 


\begin{tabular}{|c|c|c|c|c|c|}
\hline \multirow{2}{*}{ REGION } & \multicolumn{2}{|c|}{$\begin{array}{l}\text { SENSITIVITY NON } \\
\text { MUST-RUN }\end{array}$} & \multicolumn{2}{|c|}{ ORIGINAL ACTUAL CASE } & \multirow{2}{*}{$\begin{array}{l}\text { WIND INPUT } \\
\text { DATA } \\
\text { TOTAL }\end{array}$} \\
\hline & TOTAL & $\begin{array}{c}\text { CURTAILMENT } \\
(\%)\end{array}$ & TOTAL & $\begin{array}{c}\text { CURTAILMENT } \\
(\%)\end{array}$ & \\
\hline E_CAN & 648,088 & 0.03 & 648,088 & 0.03 & 648,283 \\
\hline ISO-NE & $10,514,801$ & 0.03 & $10,514,801$ & 0.03 & $10,517,477$ \\
\hline MAPP & $173,422,697$ & 4.33 & $172,292,204$ & 4.95 & $181,271,613$ \\
\hline MHEB & $2,598,952$ & 1.01 & $2,600,815$ & 0.93 & $2,625,348$ \\
\hline MISO & $129,742,596$ & 2.90 & $129,844,931$ & 2.83 & $133,622,952$ \\
\hline NYISO & $21,326,536$ & 3.72 & $21,216,681$ & 4.22 & $22,151,455$ \\
\hline PJM & $70,241,841$ & 2.52 & $70,206,710$ & 2.56 & $72,054,440$ \\
\hline SERCNI & $3,171,641$ & 0.03 & $3,171,218$ & 0.04 & $3,172,523$ \\
\hline SPP & $251,687,576$ & 10.28 & $251,004,870$ & 10.52 & $280,512,355$ \\
\hline TVASUB & $3,369,879$ & 4.86 & $3,297,972$ & 6.89 & $3,542,176$ \\
\hline TOTAL & $666,724,607$ & 6.11 & $664,798,290$ & 6.38 & $710,118,621$ \\
\hline
\end{tabular}

Notes: SERCNI, E-CAN, and TVASUB are monikers used in EWITS for subregions in the PROMOD IV model. MHEB = Manitoba Hydro Electric Board.

\begin{tabular}{|c|c|c|c|c|c|}
\hline \multirow{2}{*}{ REGION } & \multicolumn{2}{|c|}{ SENSITIVITY COPPER SHEET } & \multicolumn{2}{|c|}{ ORIGINAL ACTUAL CASE } & \multirow{2}{*}{$\begin{array}{l}\text { WIND } \\
\text { INPUT DATA } \\
\text { TOTAL }\end{array}$} \\
\hline & TOTAL & $\begin{array}{c}\text { CURTAILMENT } \\
(\%)\end{array}$ & TOTAL & $\begin{array}{c}\text { CURTAILMENT } \\
(\%)\end{array}$ & \\
\hline E_CAN & 648,024 & 0.04 & 648,088 & 0.03 & 648,283 \\
\hline ISO-NE & $10,514,801$ & 0.03 & $10,514,801$ & 0.03 & $10,517,477$ \\
\hline MAPPCOR & $180,775,920$ & 0.27 & $172,292,204$ & 4.95 & $181,271,613$ \\
\hline MHEB & $2,625,200$ & 0.01 & $2,600,815$ & 0.93 & $2,625,348$ \\
\hline MISO & $133,617,070$ & 0.00 & $129,844,931$ & 2.83 & $133,622,952$ \\
\hline NYISO & $22,147,645$ & 0.02 & $21,216,681$ & 4.22 & $22,151,455$ \\
\hline PJM & $72,047,686$ & 0.01 & $70,206,710$ & 2.56 & $72,054,440$ \\
\hline SERCNI & $3,172,046$ & 0.02 & $3,171,218$ & 0.04 & $3,172,523$ \\
\hline SPP & $280,148,134$ & 0.13 & $251,004,870$ & 10.52 & $280,512,355$ \\
\hline TVASUB & $3,541,986$ & 0.01 & $3,297,972$ & 6.89 & $3,542,176$ \\
\hline TOTAL & $709,238,512$ & 0.12 & $664,798,290$ & 6.38 & $710,118,621$ \\
\hline
\end{tabular}

Note: MAPPCOR is the service provider to MAPP. 


\begin{tabular}{|c|c|c|c|c|c|}
\hline \multirow{2}{*}{ REGION } & \multicolumn{2}{|c|}{$\begin{array}{l}\text { SENSITIVITY NON } \\
\text { MUST-RUN }\end{array}$} & \multicolumn{2}{|c|}{ ORIGINAL ACTUAL CASE } & \multirow{2}{*}{$\begin{array}{l}\text { WIND INPUT } \\
\text { DATA } \\
\text { TOTAL }\end{array}$} \\
\hline & TOTAL & $\begin{array}{c}\text { CURTAILMENT } \\
(\%)\end{array}$ & TOTAL & $\begin{array}{c}\text { CURTAILMENT } \\
(\%)\end{array}$ & \\
\hline E_CAN & 648,088 & 0.03 & 648,088 & 0.03 & 648,283 \\
\hline ISO-NE & $10,514,801$ & 0.03 & $10,514,801$ & 0.03 & $10,517,477$ \\
\hline MAPPCOR & $179,024,767$ & 1.24 & $172,292,204$ & 4.95 & $181,271,613$ \\
\hline MHEB & $2,625,069$ & 0.01 & $2,600,815$ & 0.93 & $2,625,348$ \\
\hline MISO & $130,820,220$ & 2.10 & $129,844,931$ & 2.83 & $133,622,952$ \\
\hline NYISO & $22,014,540$ & 0.62 & $21,216,681$ & 4.22 & $22,151,455$ \\
\hline PJM & $71,400,322$ & 0.91 & $70,206,710$ & 2.56 & $72,054,440$ \\
\hline SERCNI & $3,171,925$ & 0.02 & $3,171,218$ & 0.04 & $3,172,523$ \\
\hline SPP & $261,480,631$ & 6.78 & $251,004,870$ & 10.52 & $280,512,355$ \\
\hline TVASUB & $3,463,917$ & 2.21 & $3,297,972$ & 6.89 & $3,542,176$ \\
\hline TOTAL & $685,164,280$ & 3.51 & $664,798,290$ & 6.38 & $710,118,621$ \\
\hline
\end{tabular}

\section{TABLE 6-6. ANNUAL GENERATION ENERGY SUMMARY BY FUEL TYPE (MWh)}

\begin{tabular}{|l|r|r|r|r|r|r|r|r|}
\hline CASE & \multicolumn{1}{|c|}{ CC } & CT, GAS & CT, OIL & \multicolumn{1}{c|}{ IGCC } & ST, COAL & ST, GAS & ST, OIL & $\begin{array}{r}\text { DUMP } \\
\text { ENERGY }\end{array}$ \\
\hline ORIGINAL & $150,745,894$ & $45,260,490$ & 125,404 & $16,311,970$ & $1,699,861,537$ & $11,635,944$ & 201,453 & $2,663,506$ \\
\hline CASE 1 & $135,636,423$ & $42,194,976$ & 132,876 & $16,360,553$ & $1,711,360,316$ & $15,275,894$ & 517,574 & $2,236,014$ \\
\hline CASE 2 & $143,133,853$ & $38,051,768$ & 75,377 & $16,372,149$ & $1,673,395,676$ & $1,808,557$ & 126,010 & 39,851 \\
\hline CASE 3 & $150,896,689$ & $45,658,954$ & 125,974 & $16,189,417$ & $1,698,071,417$ & $11,820,054$ & 197,049 & $13,660,546$ \\
\hline
\end{tabular}

As illustrated in Table 6-6, by setting coal units as non must-run in Sensitivity Case 1, the coal units become more flexible and displace the higher cost combined cycle units. Coal prices vary across the Eastern Interconnection, with an average of $\$ 1.7 /$ million British thermal units (MBtu) in the SPP, an average of $\$ 2.91$ / MBtu in the SERC, and up to $\$ 3.50 /$ MBtu on the East Coast. Because of this, without enforcing the must-run constraints, coal and combined cycle resources in the high-cost regions are decommitted by importing the available low-cost, off-peak energy from the western regions. Because there are no penalties or additional costs associated with carbon emissions, energy from fossil resources in the Midwest can be exported when wind is not available. Adding restrictions or additional costs on carbon emissions would decrease the amount of exports from coal-fired units.

With the negative $\$ 40 / \mathrm{MWh}$ wind curtailment price, increased wind energy is forced into the production-cost model and results in substantial amounts of dump energy from conventional generation resources. Dump energy represents the unavoidable surplus minimum segment generation that cannot be used to serve the load because of either unit operating constraints or transmission constraints, and it occurs once the bus LMPs are negative. It is conceptual and is used only for the purpose of this report. Because the wind can be curtailed only 
when the bus LMPs go below negative $\$ 40 / \mathrm{MWh}$, before the price can reach that point, dumping energy from conventional generation is used to produce counter congestion and increase bus LMPs to greater than zero.

\section{BID-UP COMMITMENT LOGIC}

A multistep security constrained unit-commitment and dispatch process is used in the production-cost model (refer to details in Section 3). It includes a preliminary unitcommitment step (ignoring unit operating constraints and start-up costs), the bid-up commitment step with all unit constraints and commitment bid adders applied, and the final dispatch step to complete the linear optimization solution. Because the bidup commitment logic increases runtime significantly, the study team bypassed the second step in all the production-cost simulations performed for EWITS.

Additional production-cost simulations were run to determine the integration costs for all four EWITS wind scenarios with the bid-up commitment step included. The Technical Review Committee decided to use 2005 hourly wind and load profiles.

Figures 6-29 through 6-31 illustrate the effect of bid-up commitment logic on APC, integration costs, and regional LMPs. Enforcing unit minimum run- and downtimes, ramp rates, and unit bids, the bid-up commitment step allows more gas-fired fastresponse units to be committed to meet all the unit operating constraints, and results in higher APCs and LMPs relative to the original cases with this logic bypassed. The overall effect on the integration costs is minimal for the high-penetration wind scenarios, with an increased cost range from a low of $\$ 0.03 /$ MWh of wind energy in Scenario 3 to $\$ 0.52$ / MWh of wind energy in Scenario 1.

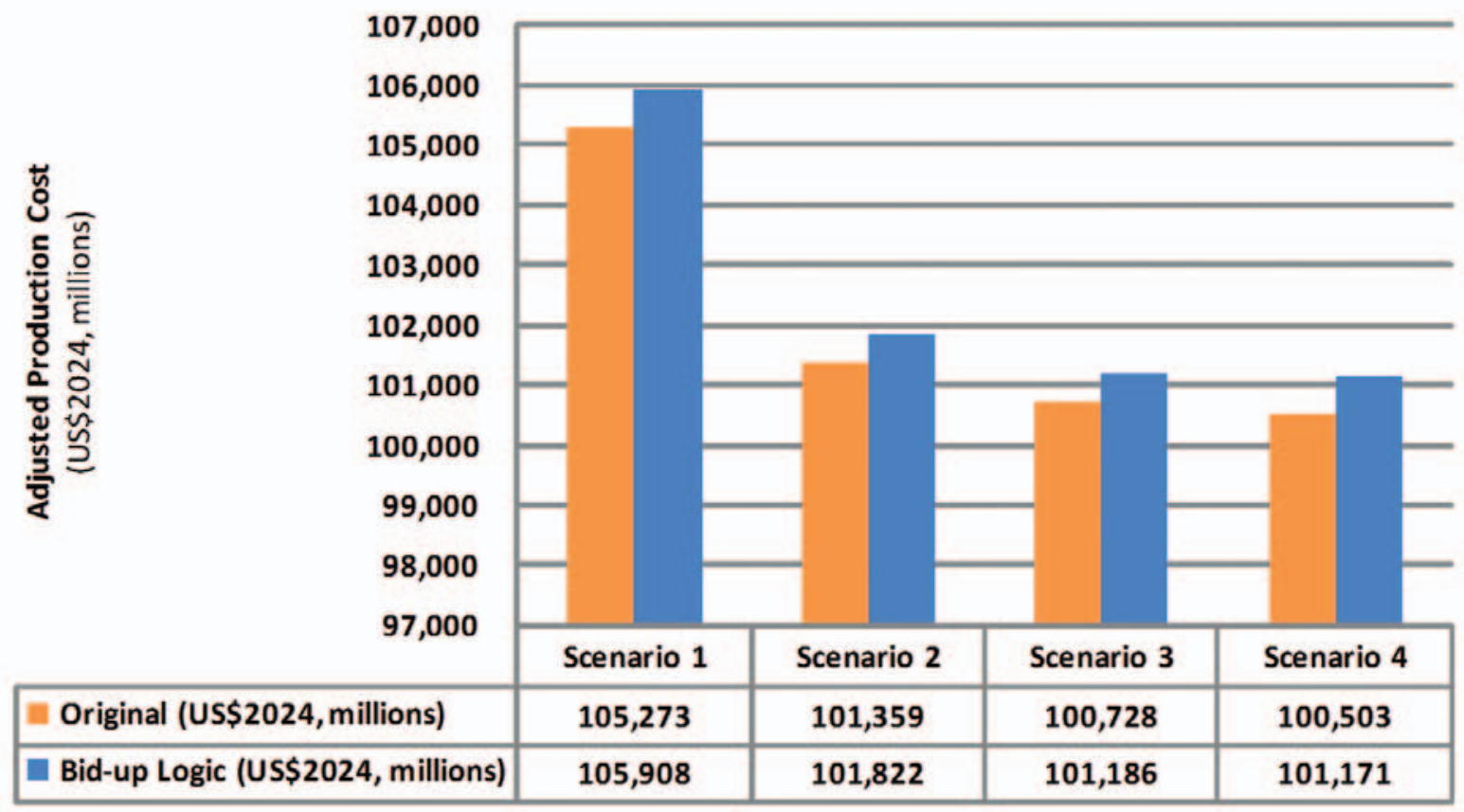

Figure 6-29. APCs with 2005 hourly wind and load patterns 


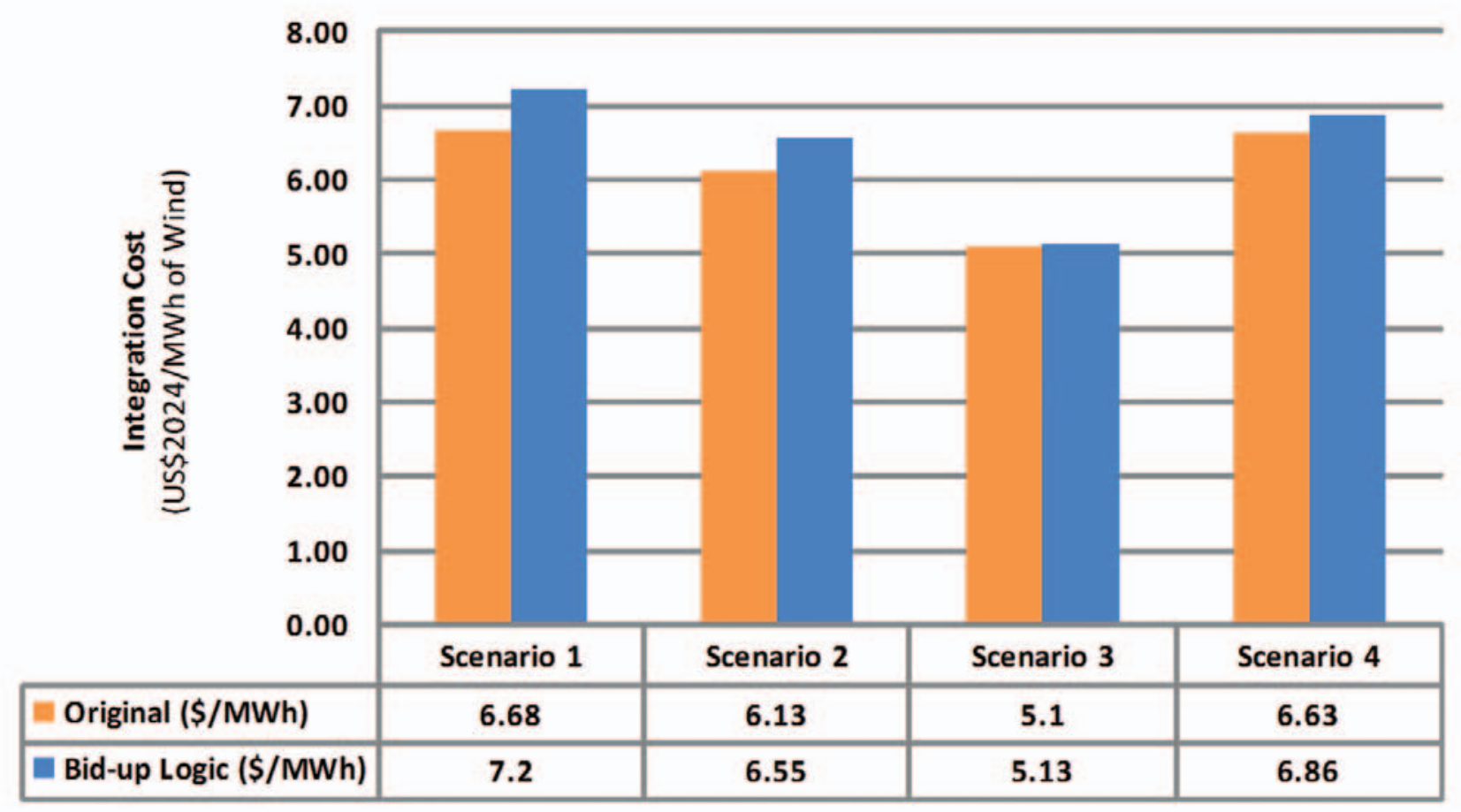

Figure 6-30. Integration cost summary with 2005 hourly wind and load patterns
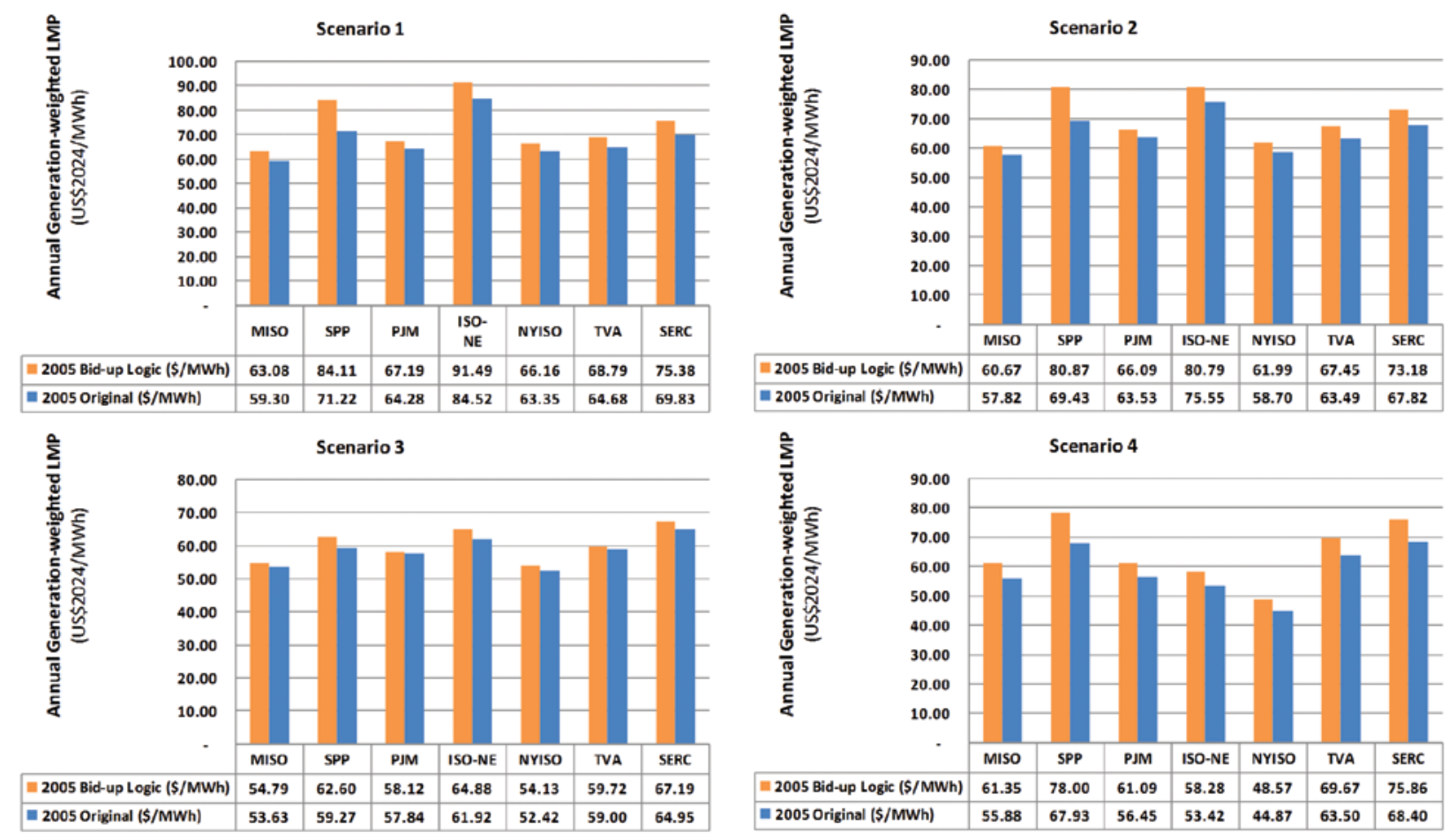

Figure 6-31. Annual generation-weighted LMPs with 2005 hourly wind and load patterns 


\section{HURDLE RATES}

Hurdle rates are used in the production-cost model to allow regional transactions during the security-constrained unit commitment (SCUC) and dispatch process. Two separate hurdle rates were defined for unit commitment and dispatch. The dispatch hurdle rates are the economic adders between applicable price zones to reflect either regulatory tariffs or market efficiency impacts. Within a regional transmission organization (RTO), there are no hurdle rates; the hurdle rates are between RTOs. The commitment hurdle rate is a mechanism to commit pool generation for pool load and then, based on price differentials, to commit additional units to serve load outside the pool.

The project team performed sensitivity analyses on Scenarios 1 and 3 to evaluate the effect of the system-wide integrated energy market on the operational impact of wind variability and uncertainty. The regional reserve requirements remain the same as in the original cases and the hurdle rates between regions are set at zero.

Table 6-7, Table 6-8, and Figure 6-32 demonstrate how the hurdle rates affect the integration costs for Scenarios 1 and 3. The results show that allowing more economic energy interchanges under the integrated energy markets across the study footprint results in less wind curtailment, lower APCs, and regional LMPs. And there is a very modest reduction in the integration costs because of the zero hurdle rates.

\begin{tabular}{|l|r|r|r|}
\hline \multicolumn{1}{|c|}{ TABLE 6-7. SCENARIO 1, HURDLE RATE SENSITIVITY RESULTS } \\
\hline SCENIO 1 & ORIGINAL & $\begin{array}{c}\text { ZERO HURDLE } \\
\text { RATE } \\
\text { SENSITIVITY }\end{array}$ & DIFFERENCE \\
\hline ANNUAL WIND ENERGY (MWh) & $664,798,102$ & $665,611,102$ & 812,812 \\
\hline WIND CURTAILMENT (\%) & 6.38 & 6.27 & -0.11 \\
\hline APCS (\$) & $104,125,330,202$ & $102,203,930,939$ & $-1,921,399,263$ \\
\hline INTEGRATION COST (\$) & $5,290,351,725$ & $4,879,216,581$ & -7.77 \\
\hline $\begin{array}{l}\text { INTEGRATION COST (\$/MWh } \\
\text { of wind) }\end{array}$ & 8.00 & 7.37 & -0.63 \\
\hline INTEGRATION COST (\% OF APC) & 5.08 & 4.77 & -0.31 \\
\hline
\end{tabular}

\begin{tabular}{|l|r|r|r|}
\hline \multicolumn{1}{|c|}{ TABLE 6-8. SCENARIO 3, HURDLE RATE SENSITIVITY RESULTS } \\
\hline SCENARIO 3 & \multicolumn{1}{|c|}{ ORIGINAL } & $\begin{array}{c}\text { ZERO HURDLE } \\
\text { RATE } \\
\text { SENSITIVITY }\end{array}$ & DIFFERENCE \\
\hline ANNUAL WIND ENERGY (MWh) & $696,093,674$ & $698,339,429$ & $2,245,755$ \\
\hline WIND CURTAILMENT (\%) & 3.26 & 2.95 & -0.31 \\
\hline APCS (\$) & $99,350,363,256$ & $98,712,905,090$ & $-637,458,167$ \\
\hline INTEGRATION COST (\$) & $3,988,497,258$ & $3,993,564,039$ & 0.13 \\
\hline $\begin{array}{l}\text { INTEGRATION COST (\$\$MWh } \\
\text { of Wind) }\end{array}$ & 5.77 & 5.76 & -0.01 \\
\hline INTEGRATION COST (\% OF APC) & 4.01 & 4.05 & 0.03 \\
\hline
\end{tabular}




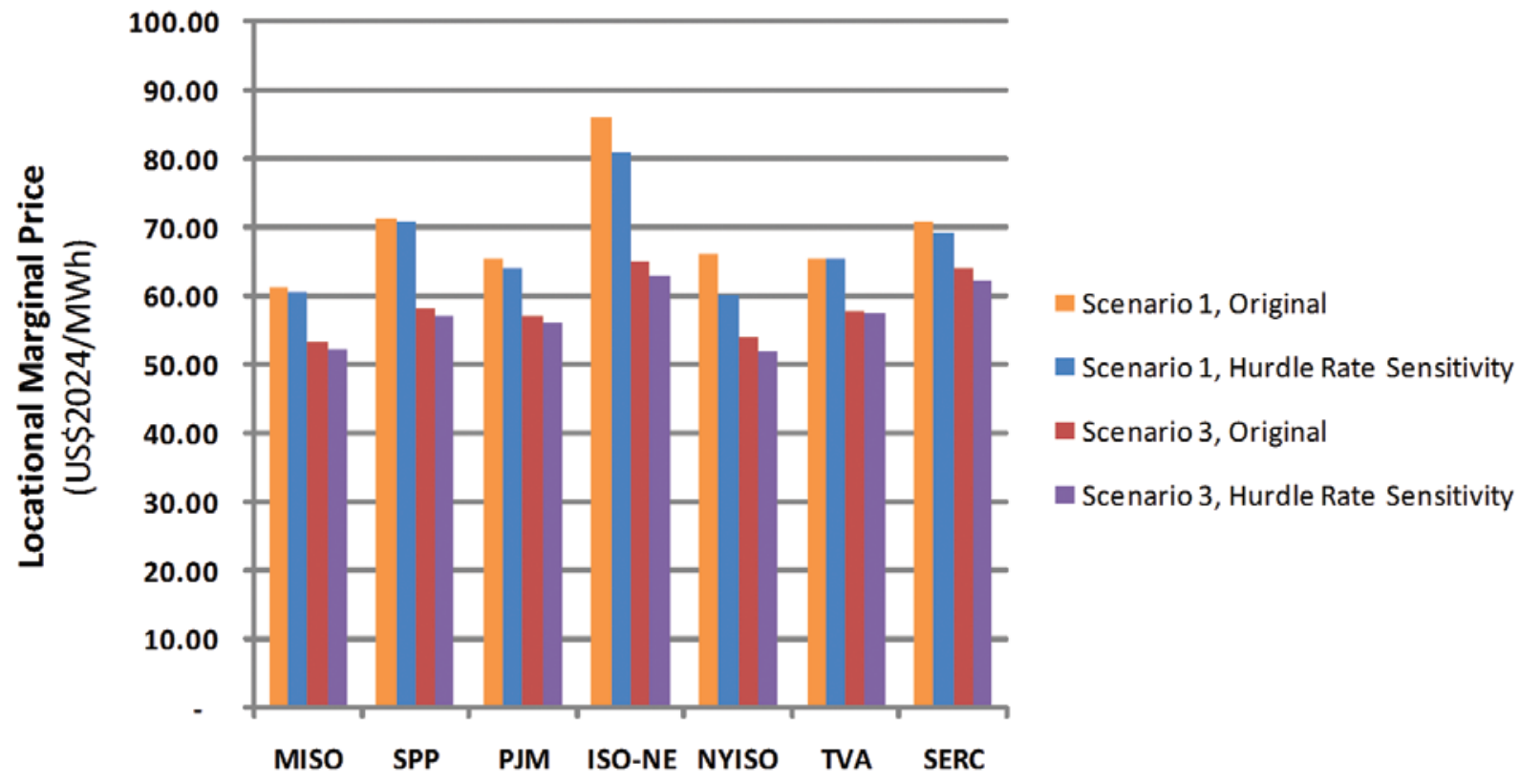

Figure 6-32. Annual generation-weighted LMP comparison

\section{CARBON SENSITIVITY}

\section{EGEAS REGIONAL RESOURCE FORECASTING EXPANSION}

The EWITS team ran a sensitivity analysis based on carbon production cost on Scenario 2. It holds all assumptions in the Electric Generation Expansion Analysis System (EGEAS) economic model the same except for the price to produce a ton of carbon. This sensitivity analysis places a cost on carbon of $\$ 100$ per ton of $\mathrm{CO}_{2}$ starting in 2008 and escalated by inflation thereafter.

Figure 6-33 shows the nameplate capacity expansion comparison when the carbon sensitivity is applied to Scenario 2 . The primary difference in the new output is that the economic benefit of base-load expansion moves from coal-fired capacity to nuclear power because of the penalty applied to the production of carbon from the coal-fired plant. Because nuclear capacity has minimum mustrun requirements greater than the coal capacity, however, off-peak minimum generation events became a problem and limitations had to be set on the amount of base-load nuclear capacity that could be placed within the model.

Finally, a limited option of existing fleet retirements was offered as an alternative in the model. The retired existing coal capacity would be replaced with new combined cycle capacity. The model recognized the benefit of removing the higher carbon-producing coal facilities from the fleet and replacing them with the more moderate carbon-producing combined cycle facilities. 


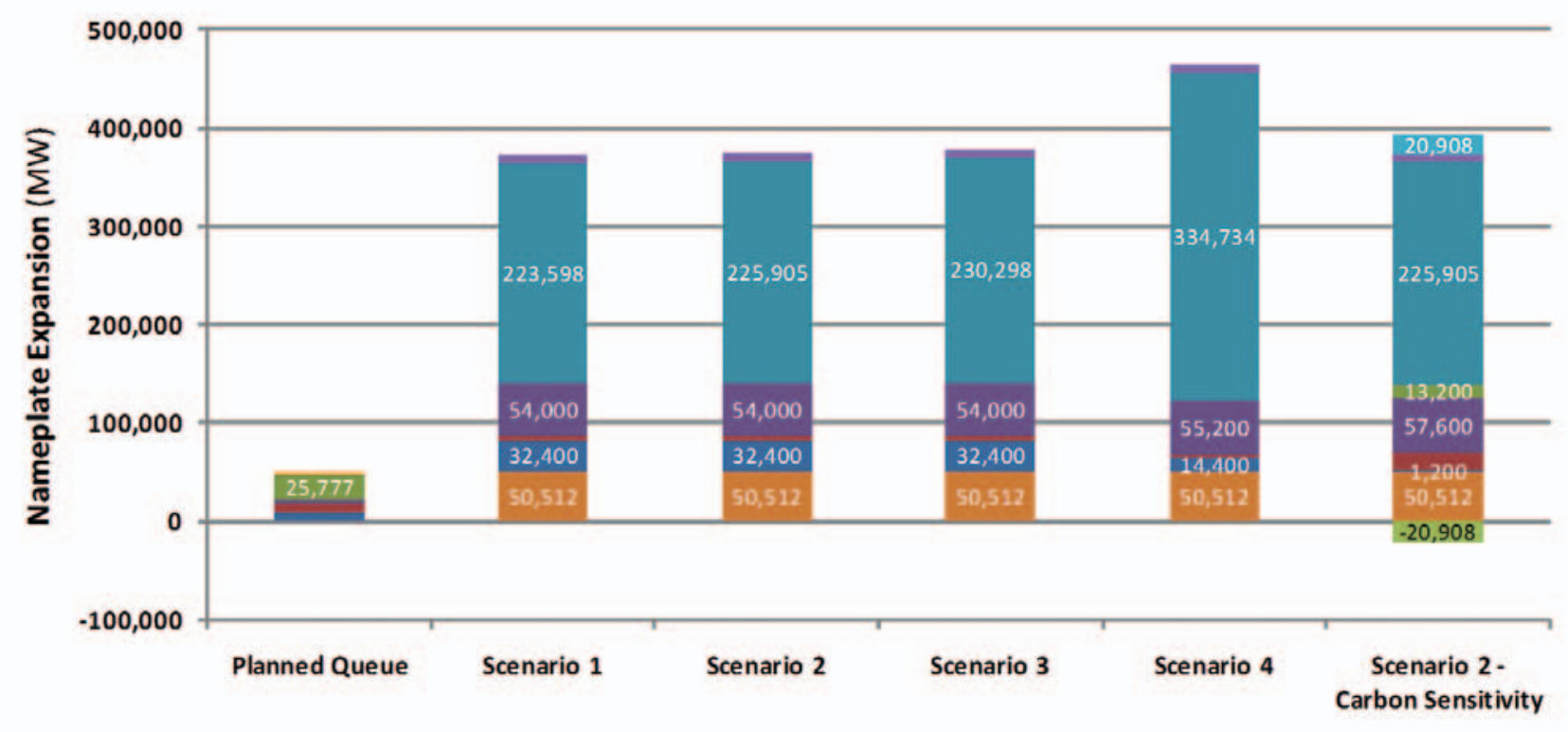

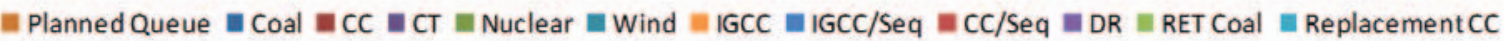

Notes: IGCC/Seq = IGCC with sequestration; $D R=$ demand response; $R E T$ Coal = coal plant retirements; Replacement $C C=$ replacement combined cycle

\section{Figure 6-33. Capacity expansion by scenario including carbon sensitivity,} 2008-2024

Energy growth will inherently increase carbon production on the system if the new energy demand is met primarily with carbon-producing resources. Within the modeling performed, however, increasing wind energy penetration to $20 \%$ of Eastern Interconnection energy requirements by 2024 (Scenarios 1 through 3) would reduce actual annual carbon production compared to 2008 modeled production by about 5\% (see Figure 6-34). Increasing the wind energy penetration to $30 \%$ of the Eastern Interconnection energy requirements for 2024 (Scenario 4) reduces annual modeled carbon production nearly 19\% from the 2008 production. Finally, adding the $\$ 100$ / ton cost to carbon for Scenario 2 produces significant carbon reduction benefits of about 33\%. This, however, has significant effects on the cost of energy to the system; see Figure 6-35. 


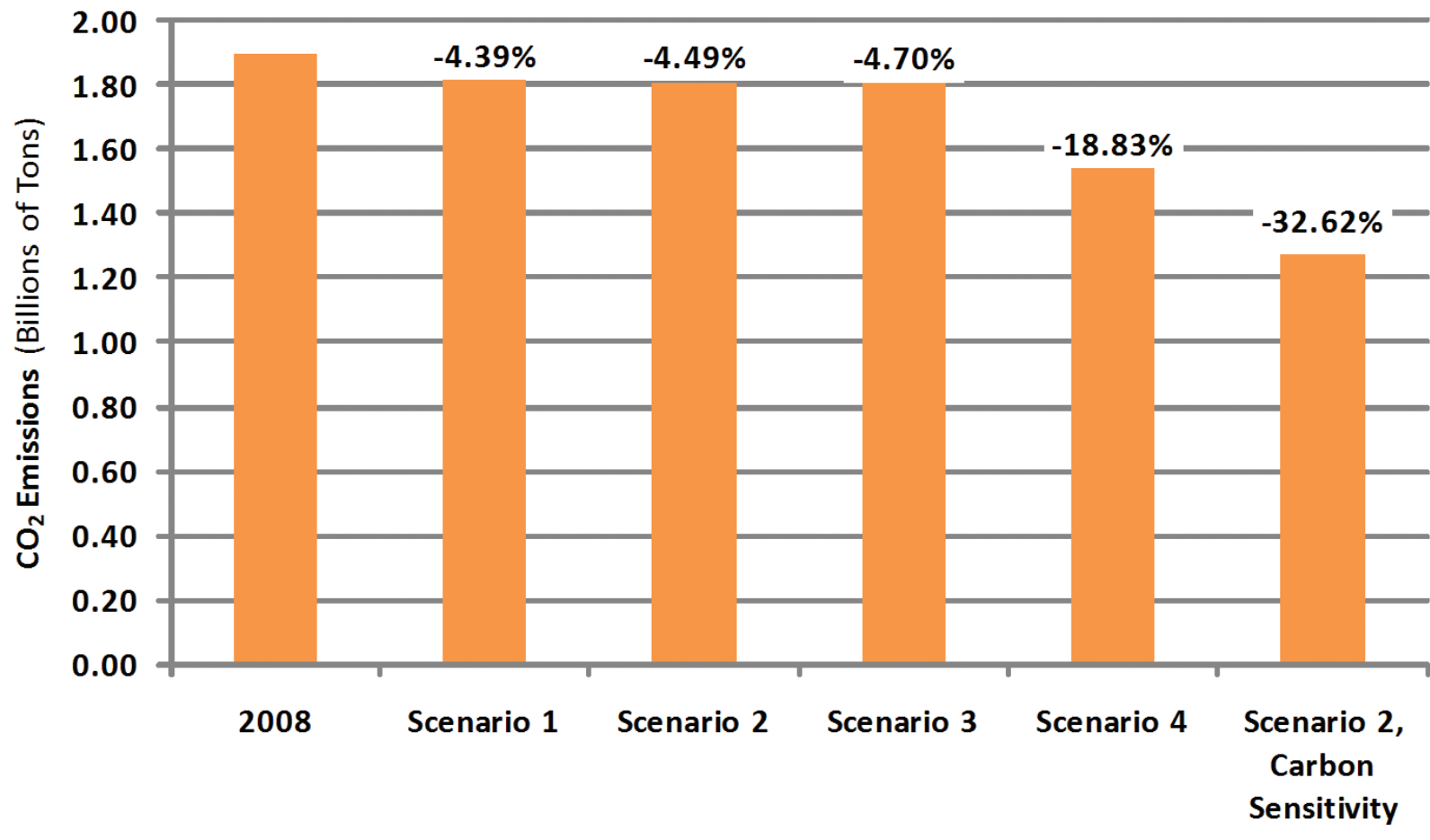

Figure 6-34. Carbon impact of modeled scenarios

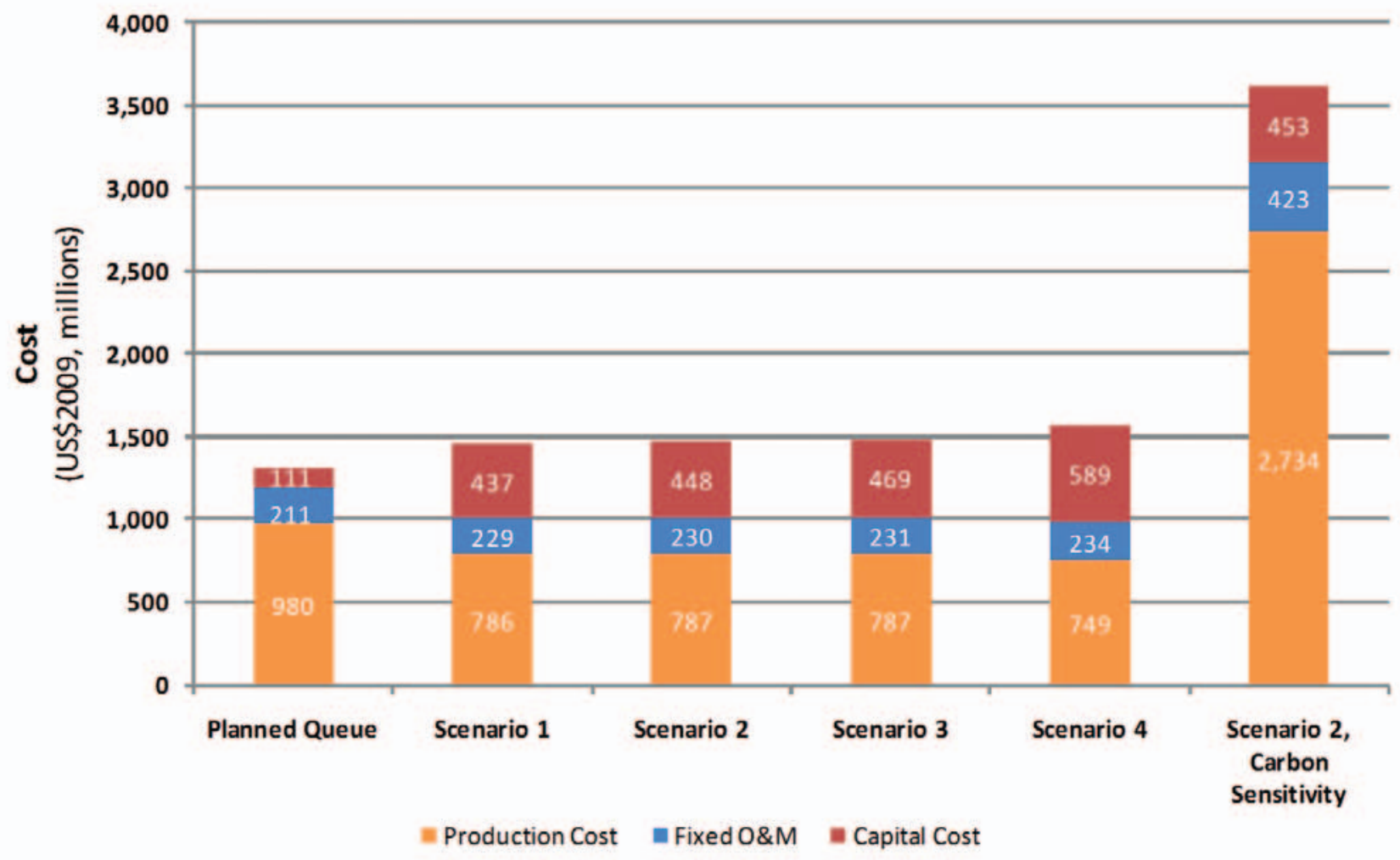

Figure 6-35. Cost impact of modeled scenarios 


\section{CAPACITY SITING FOR SENSITIVITY}

Again, the EGEAS model gives only a type and a timing result of what capacity would be needed to meet resource adequacy requirements. Using the same wind locations as Scenario 2, the study team sited thermal units locally using brownfield and queue facilities. Figure 6-36 shows the locations of new generation for the carbon sensitivity scenario, along with the locations of the wind generation facilities for Scenario 2.

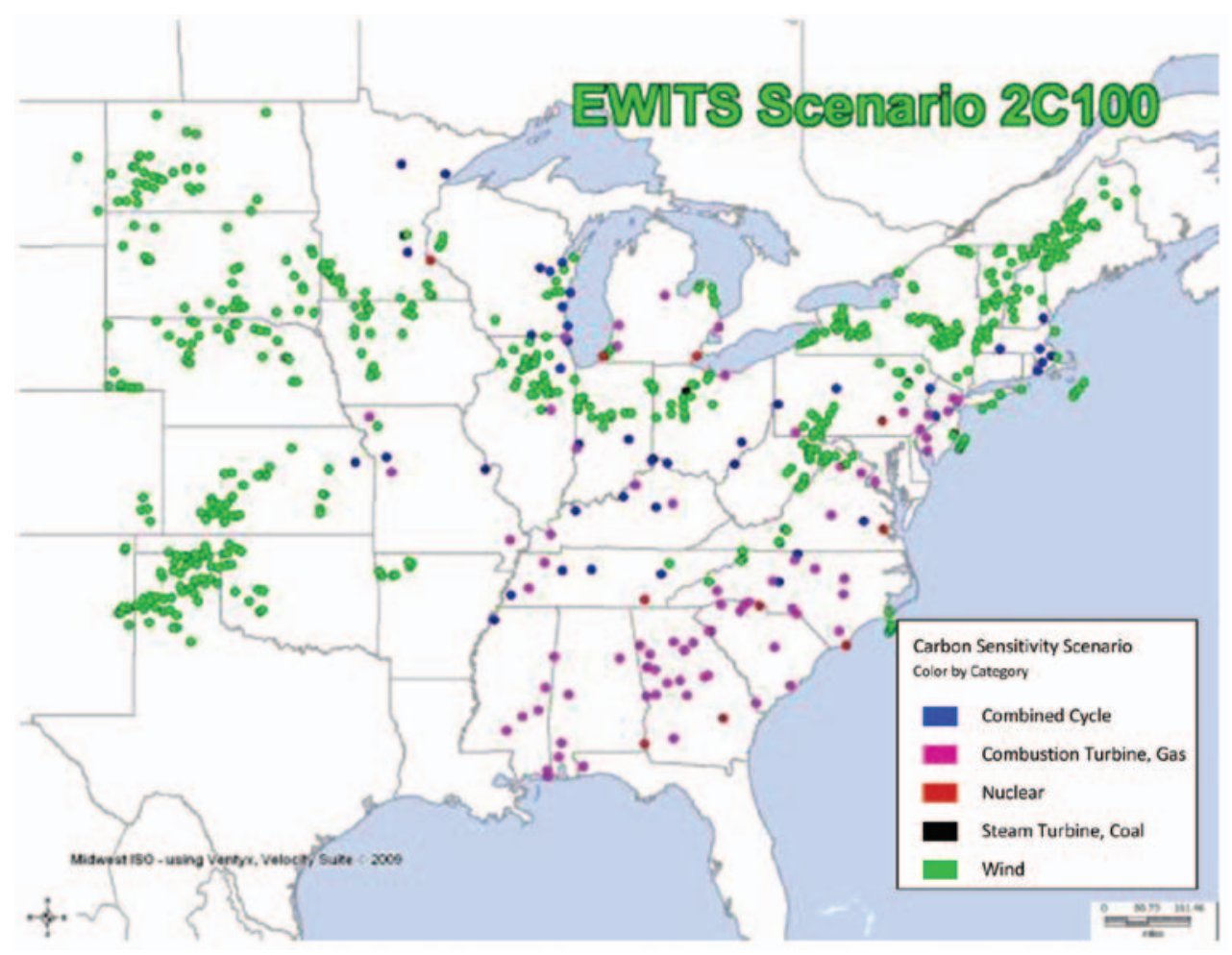

Figure 6-36. Forecast generation locations for sensitivity to Scenario 2

\section{OPERATIONAL IMPACT ANALYSIS}

The potential effects of carbon cost on the system operational cost caused by wind variability and uncertainty were evaluated with the capacity expansion results. This sensitivity analysis used the same day-ahead wind forecasts and additional reserve requirements as in Scenario 2 with 2005 hourly wind and load patterns.

Figure 6-37 shows the annual production of conventional generation resources by fuel type. With a carbon cost penalty in capacity expansion, the base-load expansion shifts from coal-fired resources to nuclear and less carbon-intensive gas-fired combined cycle resources. This results in higher nuclear production and lower coal generation than in Scenario 2. Coal, however, is still required to meet the majority of demand compared to other types of resources.

Figure 6-38 shows the annual generation changes between the ideal and actual wind cases by fuel type and scenario with 2005 wind and load patterns. ${ }^{5}$ As in 
Scenarios 1 to 4 , the carbon sensitivity scenario follows the same trend of coalfired units displaced by primarily gas-fired combined cycle and combustion turbines. There is a significant increase in the installed combined cycle capacity in the carbon sensitivity. Because of this, the coal and combined cycle generation changes from the ideal to actual wind cases are much higher in carbon sensitivity, as seen in Figure 6-38.

Figure 6-39 shows a major increase in the average generation-weighted LMPs caused by a $\$ 100 /$ ton carbon cost. As summarized in Table 6-9, the carbon cost penalty has a significant effect on the APC, about a $25 \%$ increase, but has little wind curtailment improvement and only a minimal integration cost reduction.

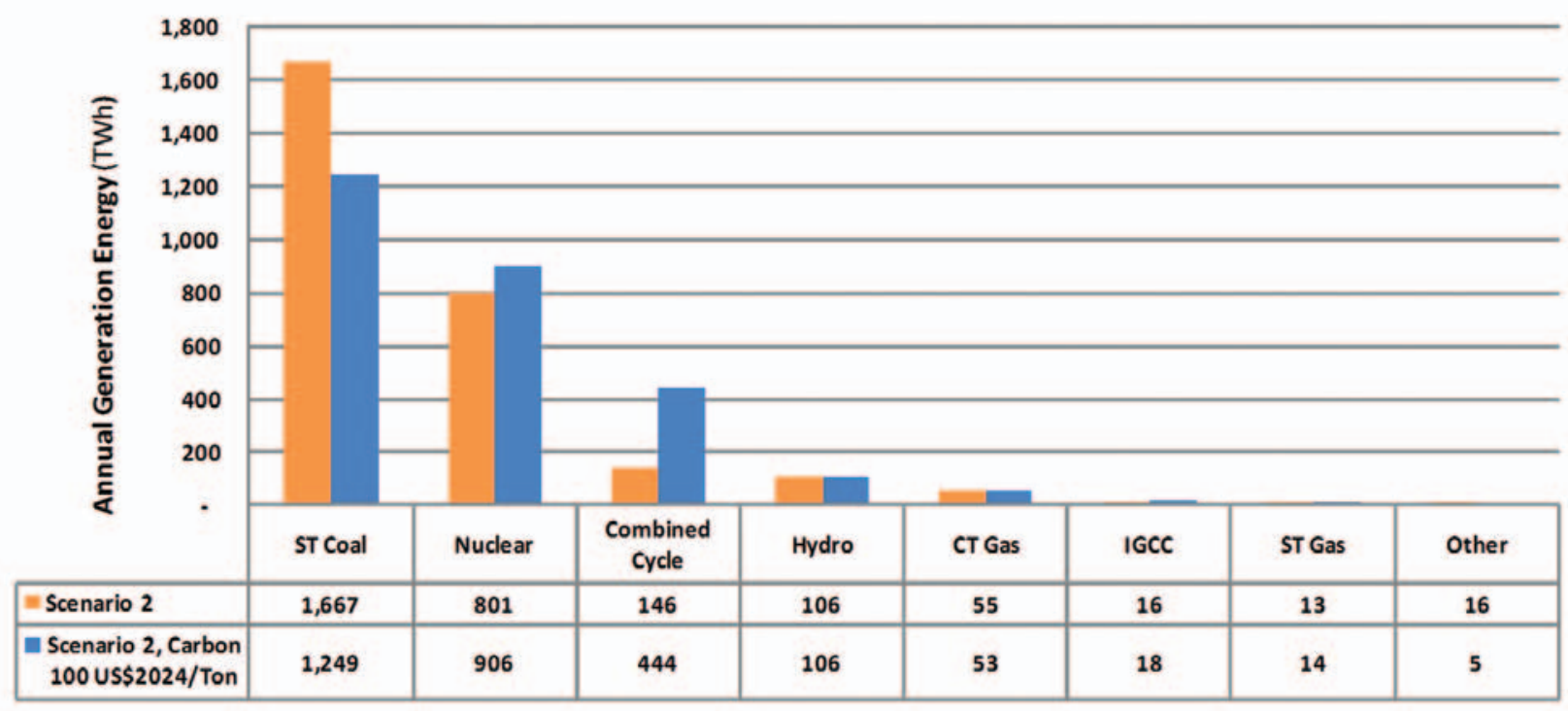

Figure 6-37. Annual generation production by fuel type with 2005 hourly wind and load patterns

${ }_{5}^{5}$ Note that in the ideal case, wind generation is known perfectly and does not add within-the-hour variability. In the actual case, day-ahead forecasts of wind generation will contain some error, and more regulating reserves must be carried to deal with increased variability. The combination of additional forecast error and additional variability will favor units that are more flexible. 


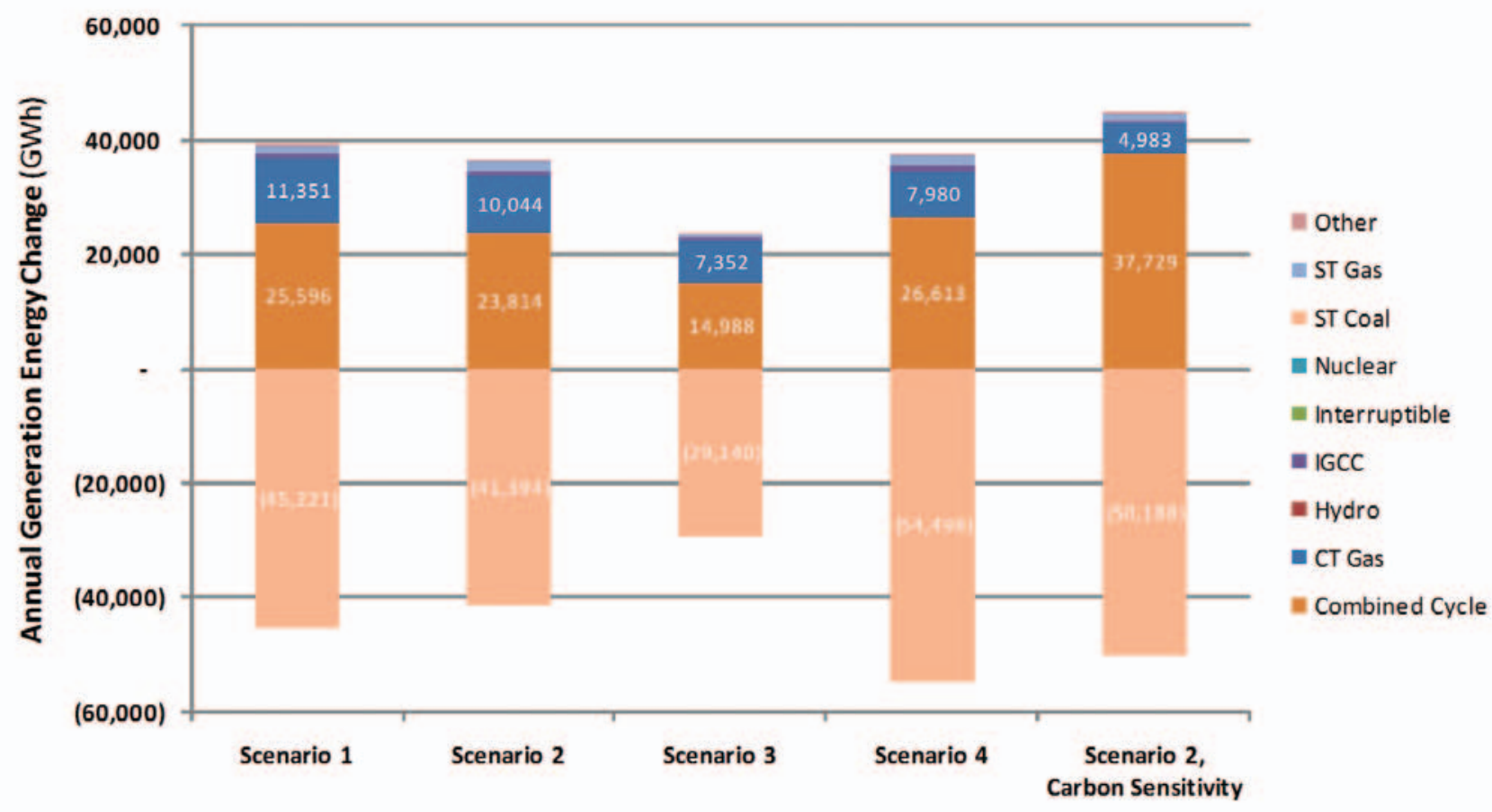

Figure 6-38. Annual generation energy changes from ideal case to actual case

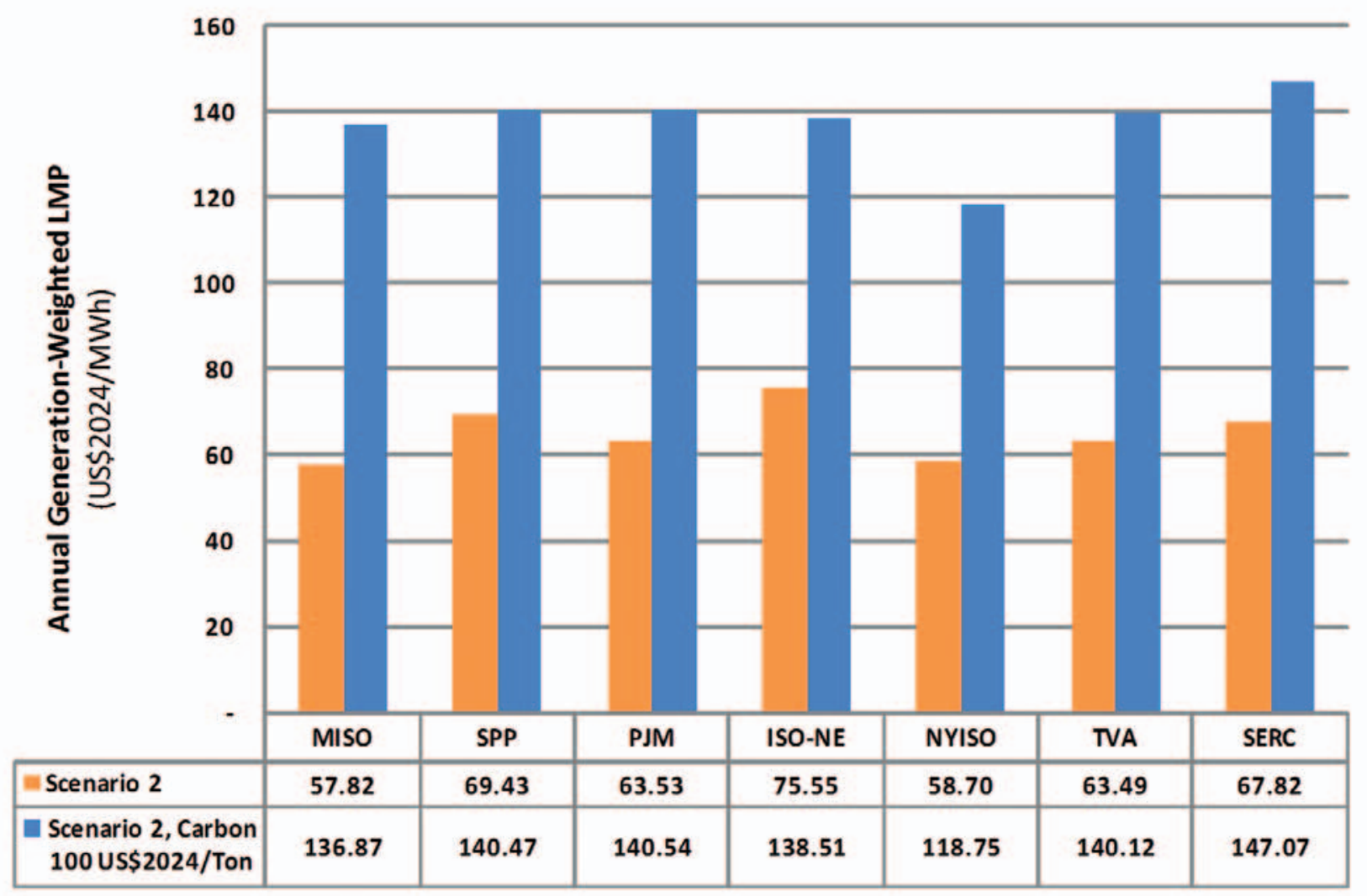

Figure 6-39. Annual generation-weighted LMP comparison 


\begin{tabular}{|l|r|r|r|}
\hline \multicolumn{1}{|c|}{ TABLE 6-9. SCENARIO 2, CARBON SENSITIVITY OPERATIONAL IMPACT RESULTS } \\
\hline & ORIGINAL & $\begin{array}{c}\text { CARBON } \\
\text { SENSITIITY }\end{array}$ & DIFFERENCE \\
\hline ANNUAL WIND ENERGY (MWh) & $696,317,330$ & $706,155,399$ & $9,838,069$ \\
\hline WIND CURTAILMENT (\%) & 6.79 & 5.47 & -1.32 \\
\hline APCS (\$) & $101,359,089,490$ & $127,228,010,909$ & $25,868,921,419$ \\
\hline INTEGRATION COST (\$) & $4,249,967,969$ & $4,652,597,813$ & $402,629,844$ \\
\hline $\begin{array}{l}\text { INTEGRATION COST (\$MWh } \\
\text { of wind) }\end{array}$ & 6.13 & 6.70 & 0.57 \\
\hline
\end{tabular}




\section{SECTION 7: WIND GENERATION CONTRIBUTIONS TO RESOURCE ADEQUACY AND PLANNING MARGIN}

\section{BACKGROUND}

The Eastern Interconnection reliability analysis in the Eastern Wind Integration and Transmission Study (EWITS) has two goals. The first is to estimate the possible future capacity value of wind generation based on projected penetration levels and potential wind location scenarios. The second is to isolate and quantify the reliability benefits of the prospective transmission system overlay. Note that the reliability-focused analysis described in this section is an independent piece of work done separately from the economic and operation effects analysis covered in the other report sections.

\section{ANALYTICAL APPROACH}

To estimate a 2024 capacity value for wind, analysts used the 2004, 2005, and 2006 simulated wind output and historical load profiles for the same 3 years to calculate the effective load-carrying capability (ELCC) of wind at the future penetration level. This analysis was also conducted using the same four wind penetration scenarios examined in Section 2.

The four scenarios are as follows:

- Scenario 1, 20\% penetration-High Capacity Factor, Onshore

- Scenario 2, 20\% penetration-Hybrid with Offshore

- Scenario 3, 20\% penetration-Local with Aggressive Offshore

- Scenario 4, 30\% penetration-Aggressive On- and Offshore.

The team also performed three different transmission level sensitivity analyses in this study. The level of transmission being modeled varied from no ties between areas to the different transmission levels of each existing and conceptual overlay scenario. The three transmission sensitivities are as follows:

- Isolated system-stand-alone zone (no zone-to-zone interfaces modeled)

- Existing transmission system-constrained case and interface limits

- Conceptual transmission overlay-increased zone-to-zone interface limits and new ties.

\section{ELCC CALCULATION METHODOLOGY}

ELCC is defined as the amount of incremental load a resource like wind can dependably and reliably contribute to serve load, considering the probabilistic 
nature of generation shortfalls and random forced outages that result in load not being served. The probabilistic measure of load not being served is known as loss of load probability (LOLP), and when this probability is summed over a time frame (e.g., 1 year), it is referred to as loss of load expectation (LOLE). The accepted industry standard for what has been considered a reliable system has been the "less than 1 day in 10 years" criterion for LOLE. This measure is often expressed as $0.1 \mathrm{~d} / \mathrm{yr}(0.1 \mathrm{~d} / \mathrm{yr}=1$ day per 10 years), because that is often the time period (1 year) over which the LOLE index is calculated.

To measure the ELCC of a particular resource, the reliability effects of all the other sources must be isolated from the resource in question. This is accomplished by calculating the LOLE of two different cases: one with and one without the resource (Figure 7-1). Inherently, the case with the resource should be more reliable and consequently have fewer days per year of expected loss of load (smaller LOLE).

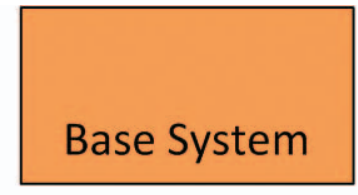

LOLE $=0.15$ day/year

(or 1.5 days in 10 years)

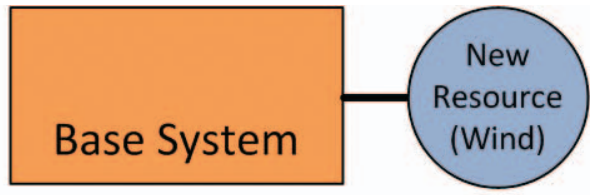

LOLE $=0.08$ day/year

(or 0.8 days in 10 years)

Figure 7-1. ELCC example system with and without resource

\section{ELCC EXAMPLE SYSTEM WITH AND WITHOUT RESOURCE}

The new resource in the ELCC example made the system $0.07 \mathrm{~d} / \mathrm{yr}$ more reliable, but there is another way to express the reliability contribution of the new resource besides the change in LOLE. The other option requires establishing a common baseline reliability level and then adjusting the load in each case with and without the new resource to a common LOLE level (Figure 7-2). The common baseline is the industry-accepted reliability standard of the 1 day in 10 years $(0.1 \mathrm{~d} / \mathrm{yr})$ LOLE criterion.

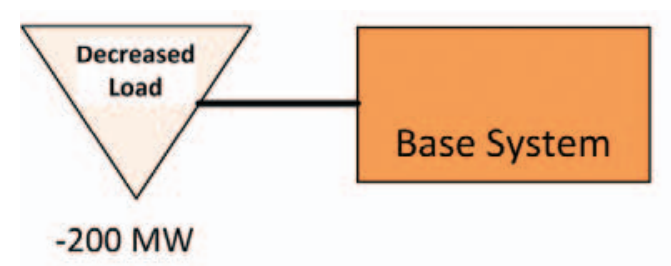

LOLE $=0.10$ day/year (or 1.0 days in 10 years)

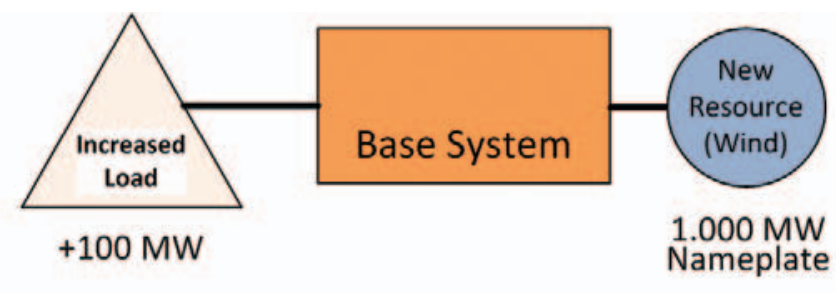

LOLE $=0.1$ day/year

(or 1 day in 10 years)

Figure 7-2. ELCC example system at the same LOLE 


\section{ELCC EXAMPLE SYSTEM AT THE SAME LOLE}

With each case at the same reliability level, the only difference between them is the amount by which the load was adjusted in each case. This difference is the amount of ELCC expressed in load or megawatts (MW). Sometimes this number is divided by the nameplate rating of the new resource and then expressed as a percentage. The new resource in the ELCC example has an ELCC of $300 \mathrm{MW}$, or $30 \%$ of the resource nameplate.

The same analytical approach used in this simple single-zone example was employed to calculate ELCC in the much more complex Eastern Interconnection system, with one very slight simplification. EWITS analysts used the LOLE model in GE Energy's Multi-Area Reliability Simulation (GE-MARS) program, and in that model, a load-modifying resource is adjusted in each interconnected zone to make the LOLE equal to $0.1 \mathrm{~d} / \mathrm{yr}$. In EWITS, this was performed instead of adjusting the 8,760 hourly load values of each of the multiple zones for each of the different hourly profiles and scenarios being studied. This modeling technique is implemented in the software program by means of the LOLE calculation and does not result in any difference from the indirect load adjustment method.

\section{LOLE MODEL INPUT ASSUMPTIONS}

The source for all LOLE model input data was the same database and source used to develop PROMOD IV. The data were conditioned into the correct format for use in the LOLE model. Because the GE-MARS LOLE model uses a transportation style of modeling, which consists of a system of interconnected zones (sometimes referred to as areas), those zones must be defined. This requires data to be aggregated and organized up to the level of the defined zones and interface limits between these zones must be calculated. Analysts used predefined regional and subregional planning areas as the modeling zones for this study; they are listed in Table 7-1 with their total nameplate amount of wind for each study scenario. 


\begin{tabular}{|c|c|c|c|c|}
\hline ZONE & SCENARIO 1 & SCENARIO 2 & SCENARIO 3 & SCENARIO 4 \\
\hline MISO West & 59,260 & 39,953 & 23,656 & 59,260 \\
\hline MISO Central & 12,193 & 11,380 & 11,380 & 12,193 \\
\hline MISO East & 9,091 & 6,456 & 4,284 & 9,091 \\
\hline MAPP USA & 13,809 & 11,655 & 6,935 & 14,047 \\
\hline SPP North & 48,243 & 40,394 & 24,961 & 50,326 \\
\hline SPP Central & 44,055 & 46,272 & 25,997 & 44,705 \\
\hline PJM & 22,669 & 33,192 & 78,736 & 93,736 \\
\hline TVA & 1,247 & 1,247 & 1,247 & 1,247 \\
\hline SERC & 1,009 & 5,009 & 5,009 & 5,009 \\
\hline NYISO & 7,742 & 16,507 & 23,167 & 23,167 \\
\hline ISO-NE & 4,291 & 13,837 & 24,927 & 24,927 \\
\hline Entergy & 0 & 0 & 0 & 0 \\
\hline IESO & 0 & 0 & 0 & 0 \\
\hline MAPP Canada & 0 & 0 & 0 & 0 \\
\hline $\begin{array}{l}\text { FULL STUDY } \\
\text { SYSTEM }\end{array}$ & 223,609 & 225,902 & 230,299 & 337,708 \\
\hline
\end{tabular}

Notes: Midwest ISO is shortened to MISO here because of space considerations. Other definitions follow: MAPP = Mid-Continent Area Power Pool; SPP = Southwest Power Pool; PJM = PJM Interconnection; TVA = Tennessee Valley Authority; SERC = Southeastern Electric Reliability Council (Entergy is operated as part of SERC); NYISO = New York ISO; ISO-NE = New England ISO; IESO = Independent Electricity System Operator.

The last step in developing the LOLE model and the input parameters was to calculate the interface limits between the study zones. Because of its ability to realistically model unit operating characteristics and produce detailed hourly output, the study team used PROMOD IV to calculate these interface limits. PROMOD IV runs were conducted for each zone on an import basis, meaning that dispatchable generators within the zone are given a penalty factor to induce flow from outside the zone to inside the zone. Interfaces were defined and import flows were monitored and recorded. The hourly interface flow values (8,760 values) were filtered down to only those values that occur at the time of the each zone's daily peak load (365 values). The logic behind using only those interface flow values is derived from the use of the daily LOLE index, which is also calculated over the same daily peak load hours. These values were then averaged into monthly interface numbers, which is what the LOLE model program uses. This calculation was performed for every zone and every scenario twice, once with only the existing transmission system and once with the new additional transmission system of the scenario overlays included. Figures 7-3 through 7-10 show the results of these calculations. The diagrams also illustrate the interconnectivity of the zones for each scenario and transmission sensitivity. Note that for simplicity, only the values for August are shown in the diagrams (August is the study system's peak load month). 


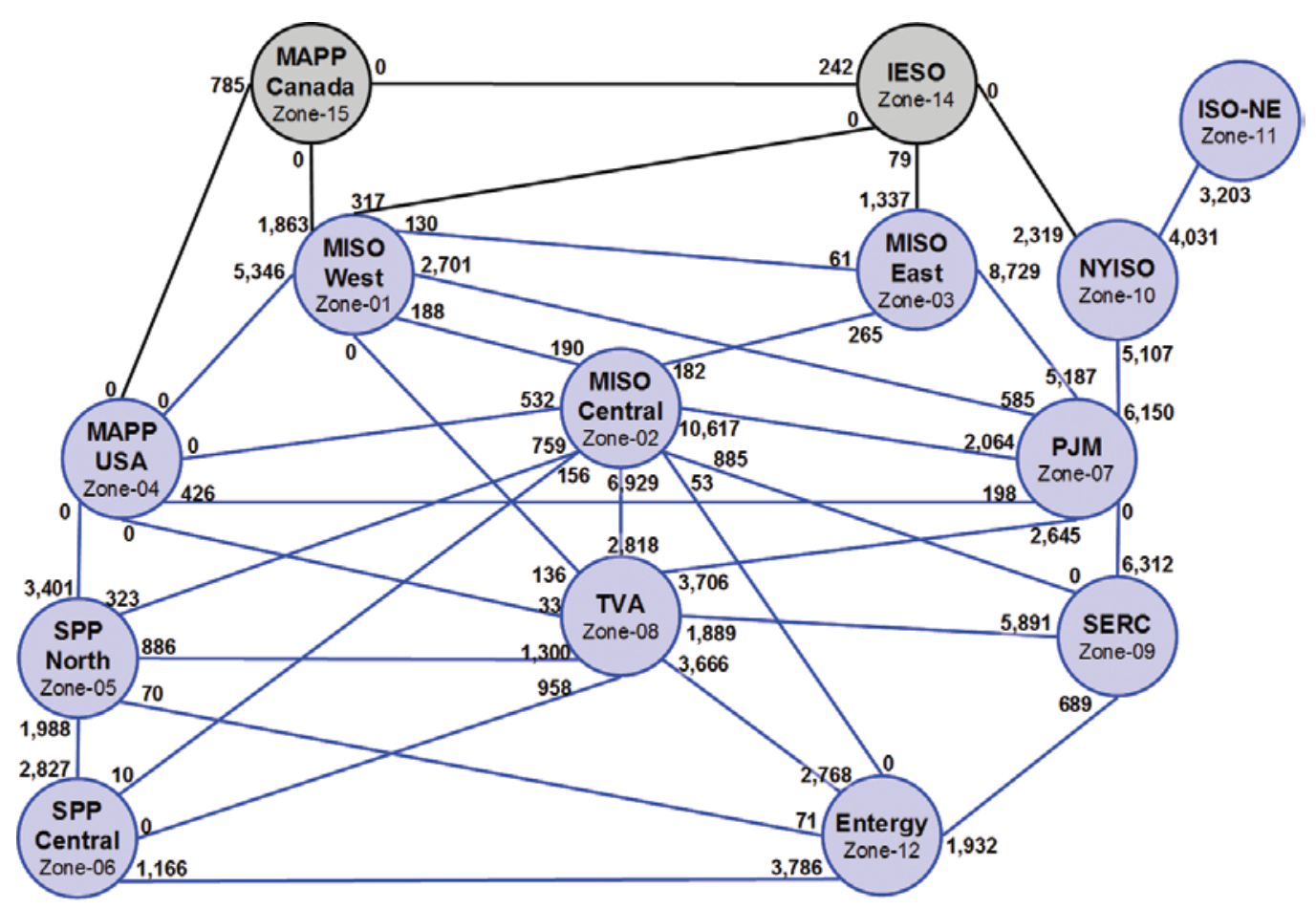

Figure 7-3. Scenario 1, existing transmission system August interface limits (MW)

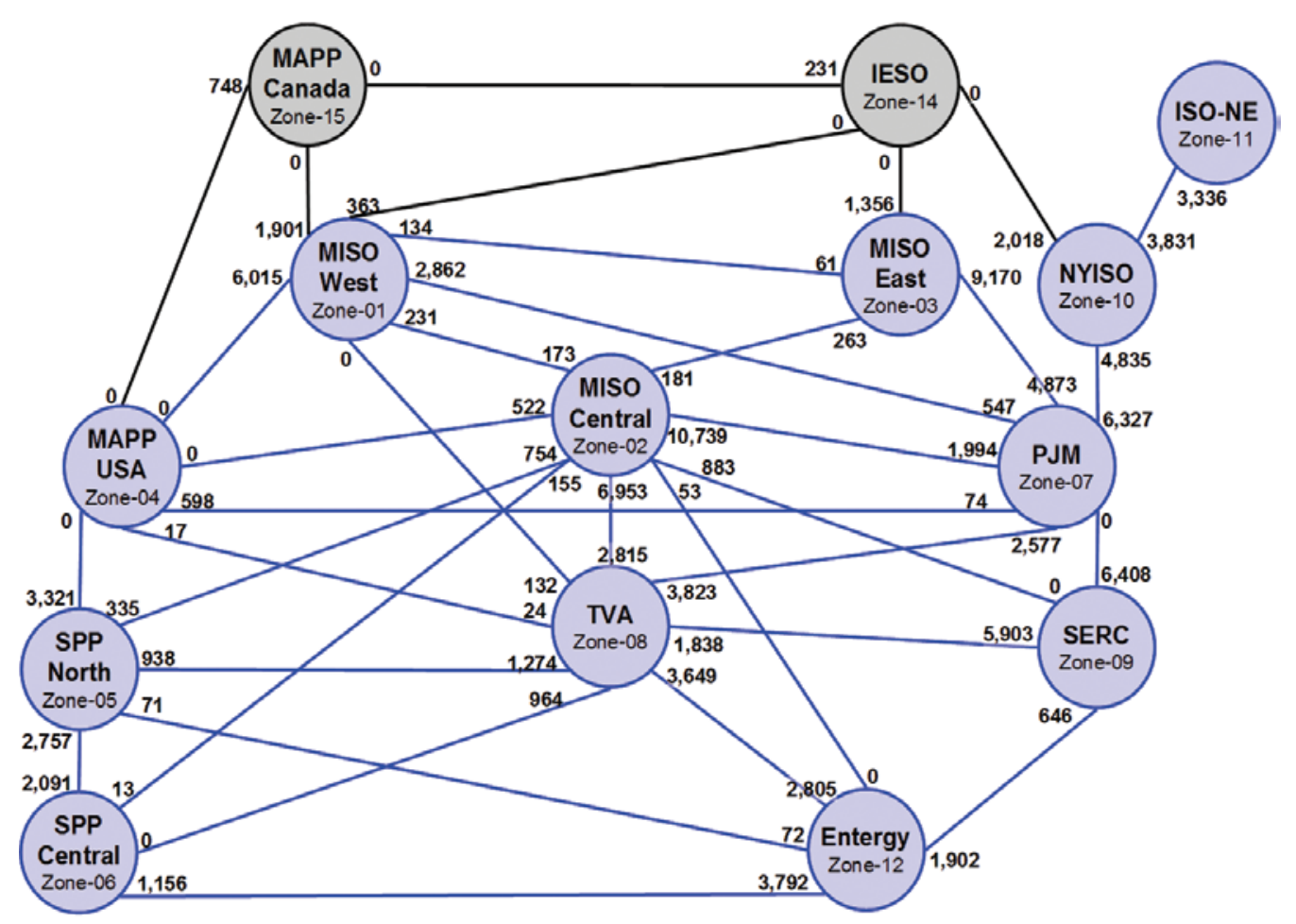

Figure 7-4. Scenario 2, existing transmission system August interface limits (MW) 


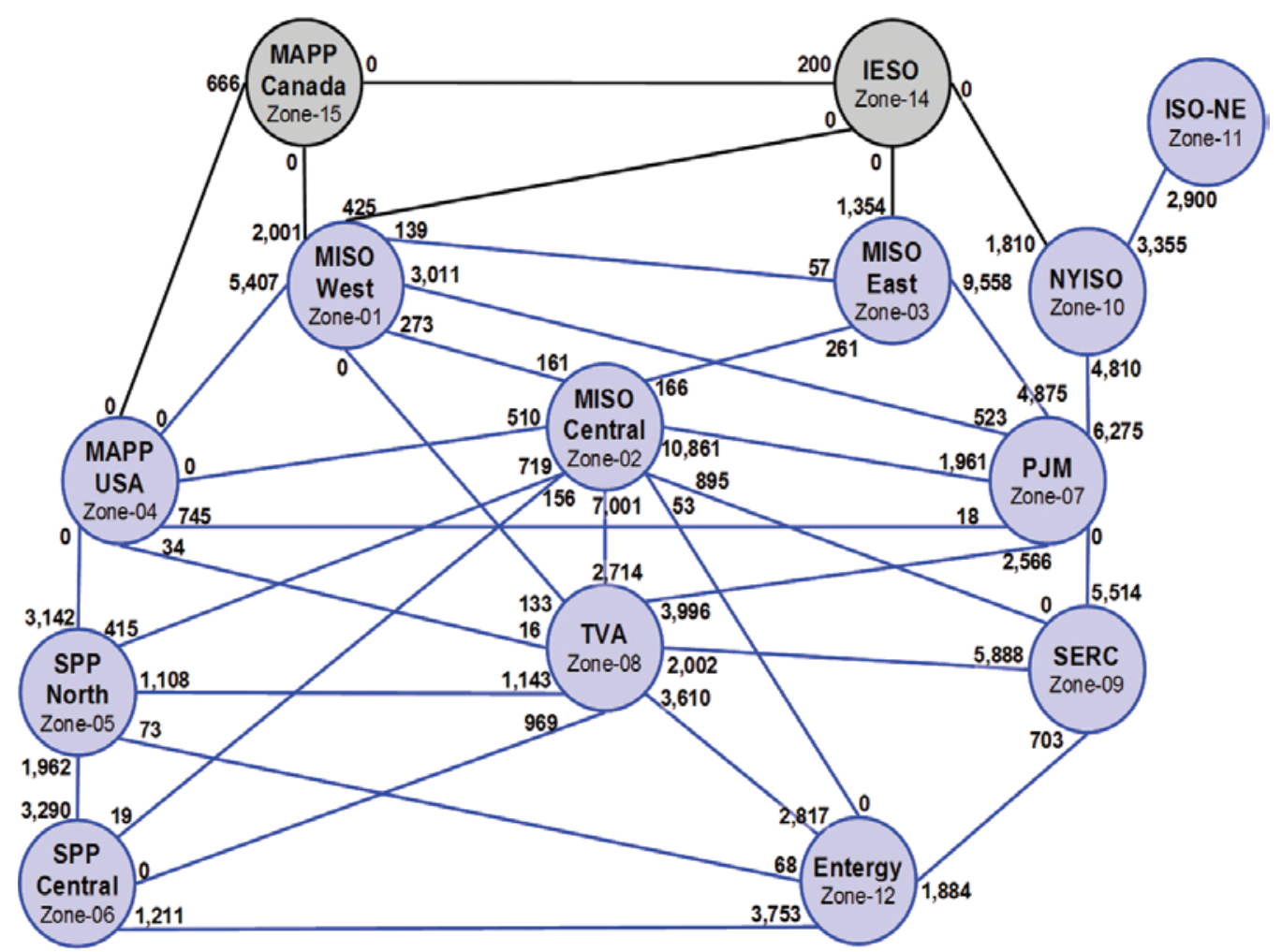

Figure 7-5. Scenario 3, existing transmission system August interface limits (MW)

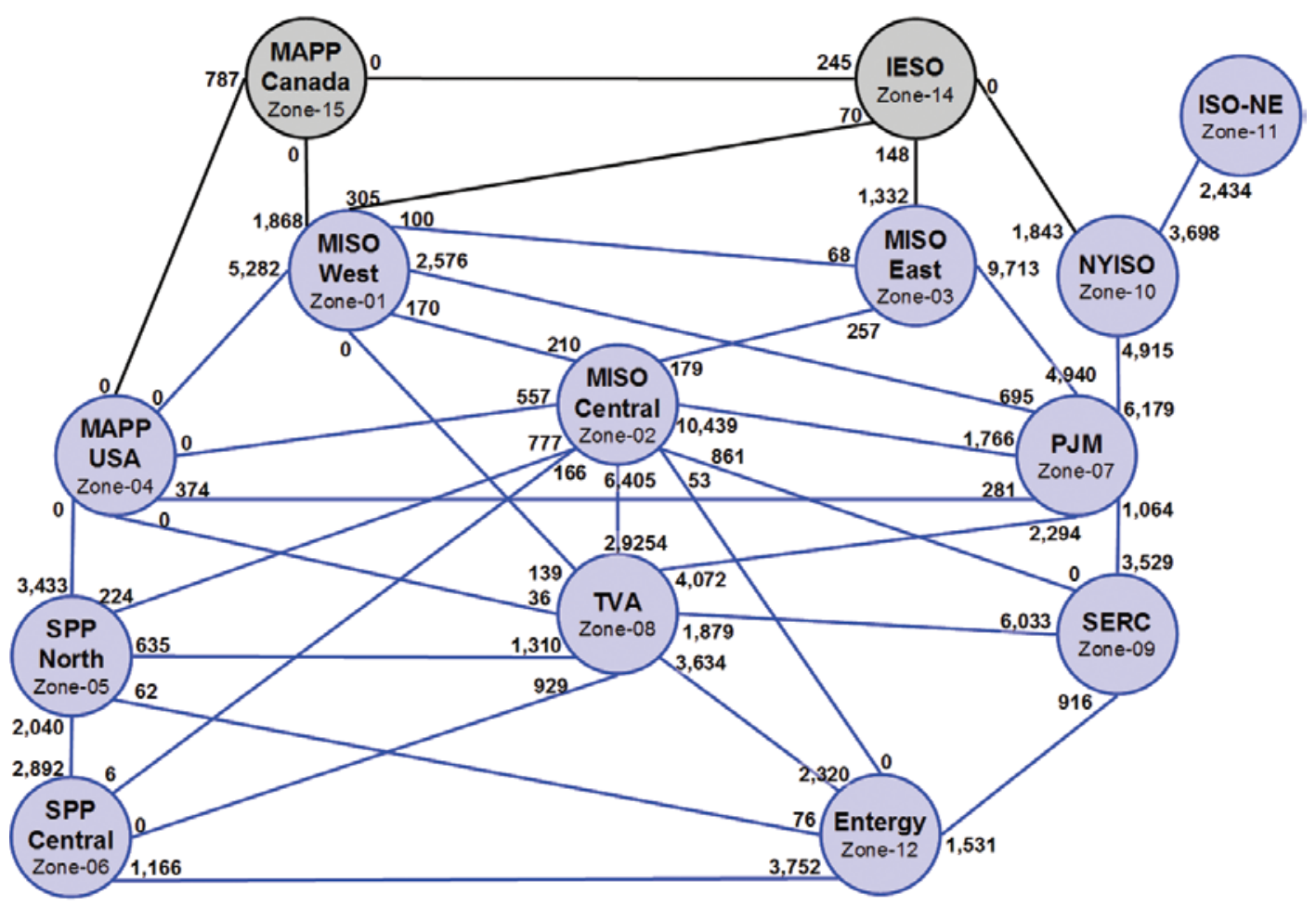

Figure 7-6. Scenario 4, existing transmission system August interface limits (MW) 


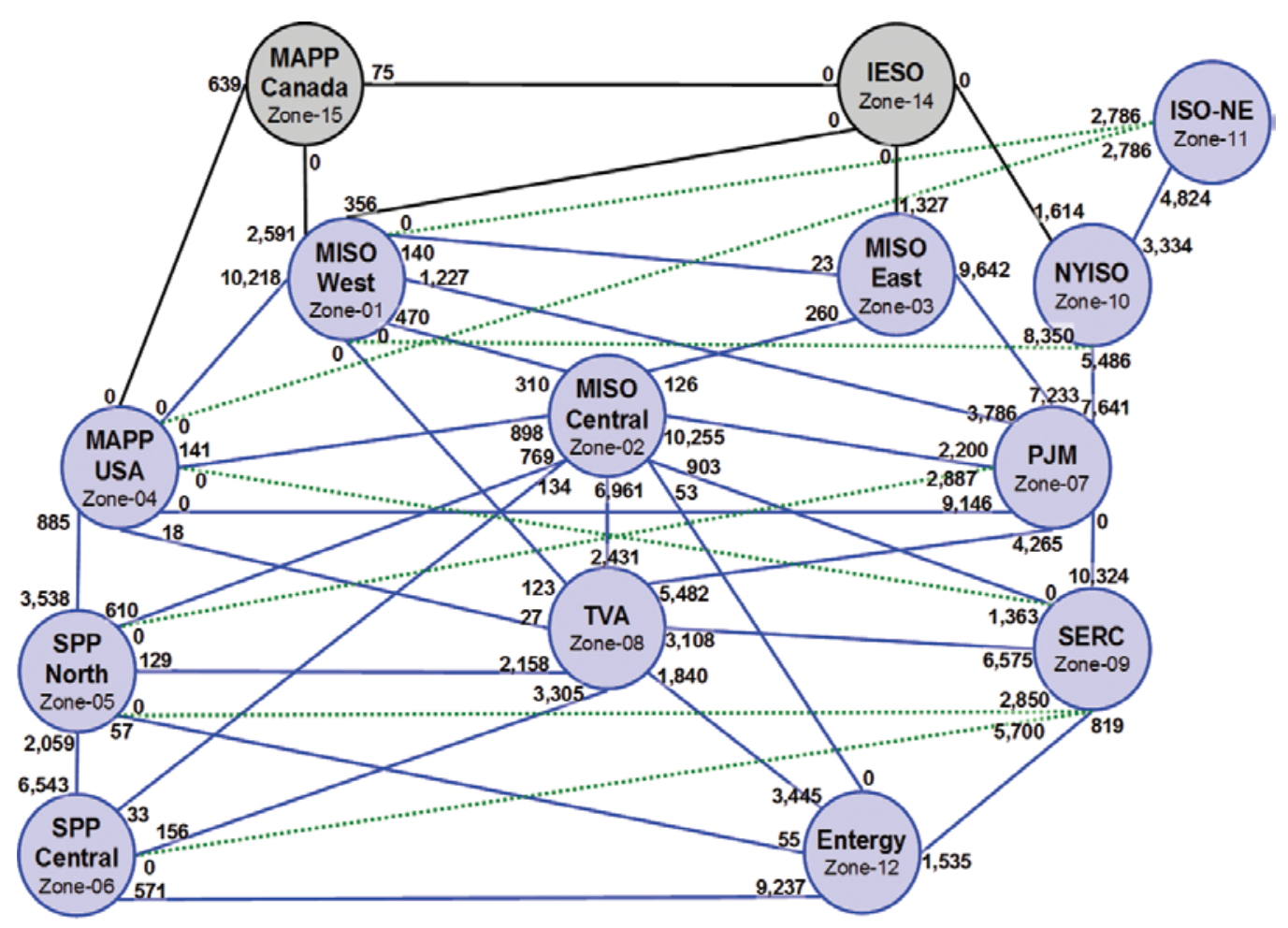

Figure 7-7. Scenario 1, conceptual transmission overlay August interface limits (MW)

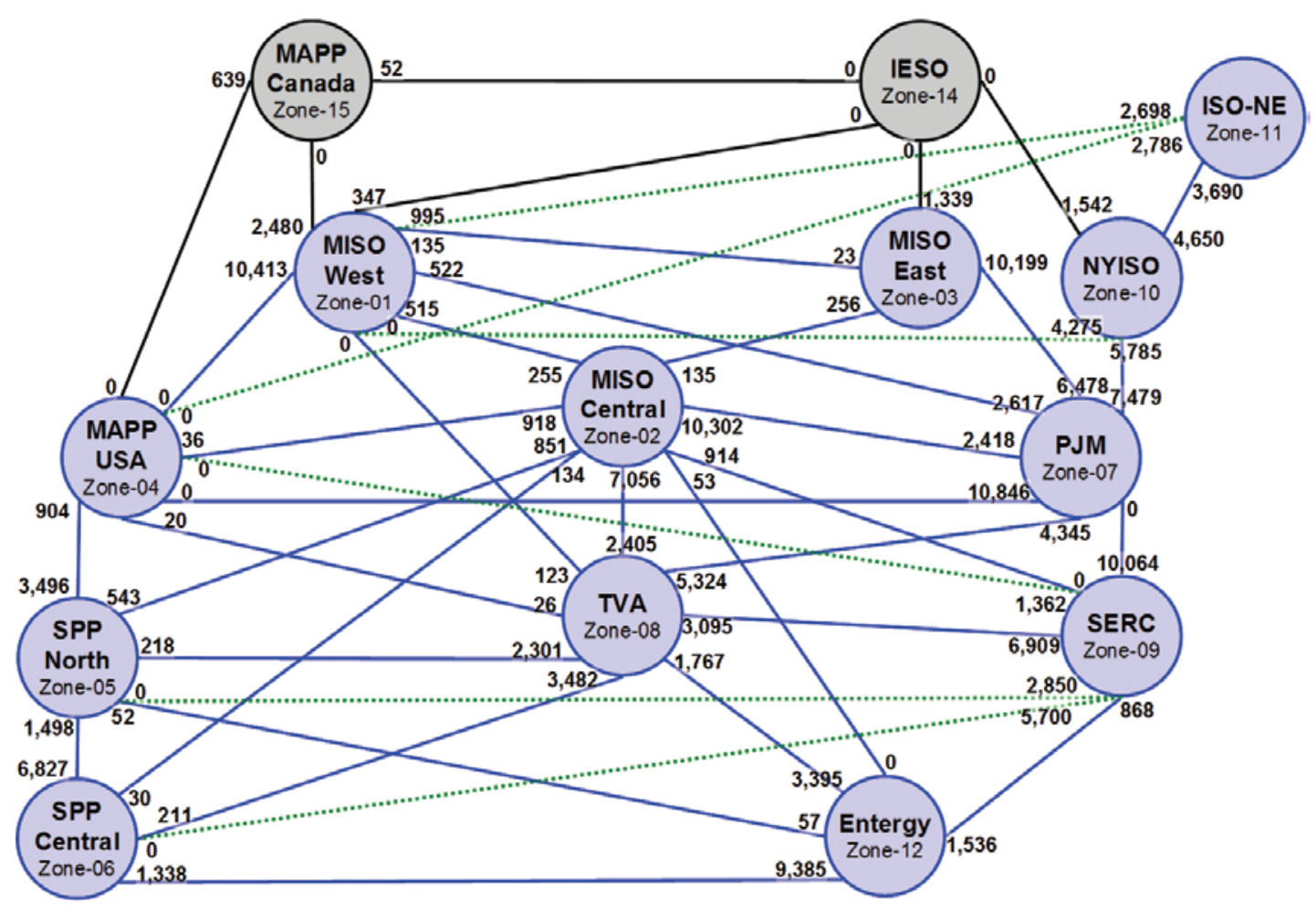

Figure 7-8. Scenario 2, conceptual transmission overlay August interface limits (MW) 


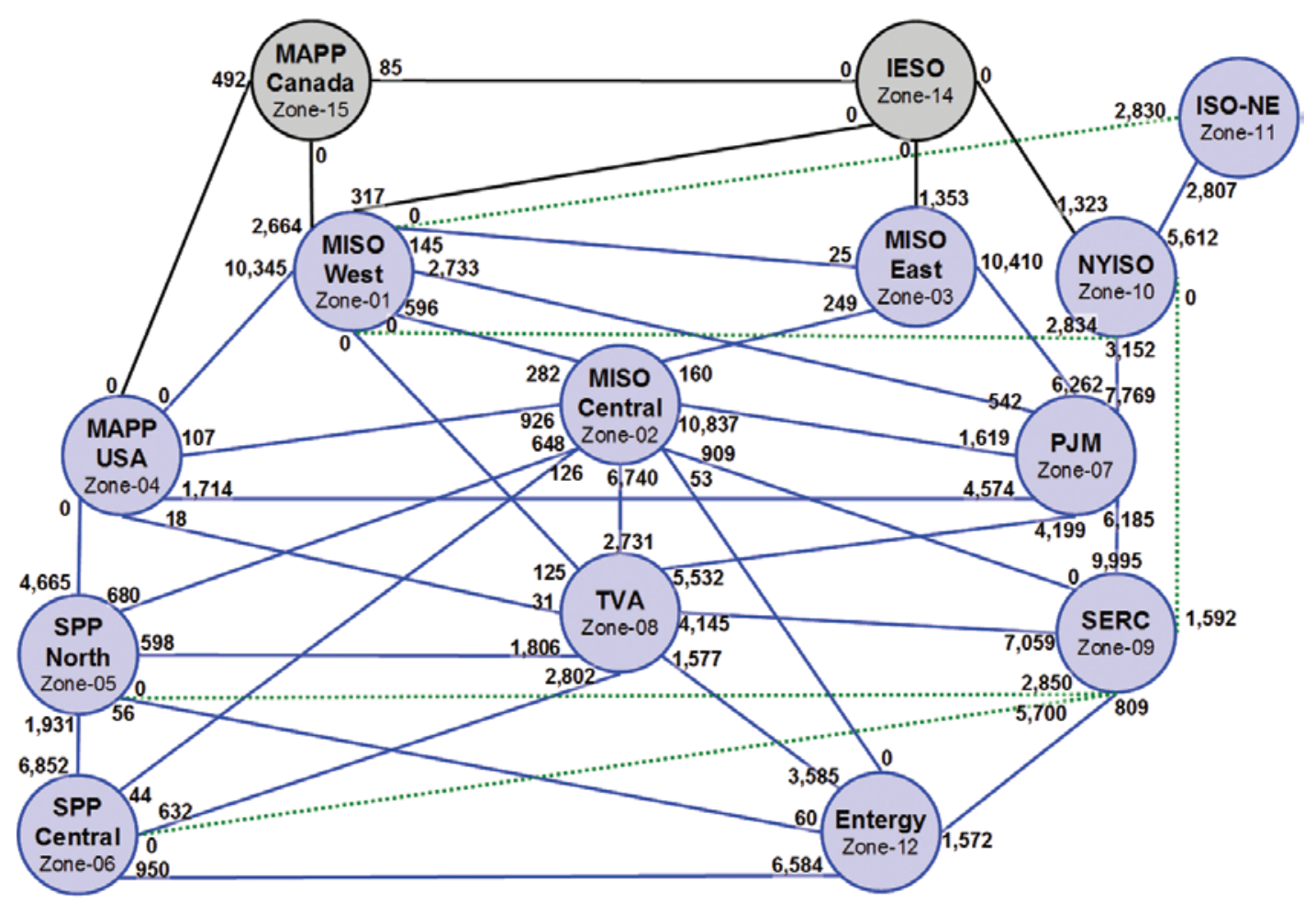

Figure 7-9. Scenario 3, conceptual transmission overlay August interface limits (MW)

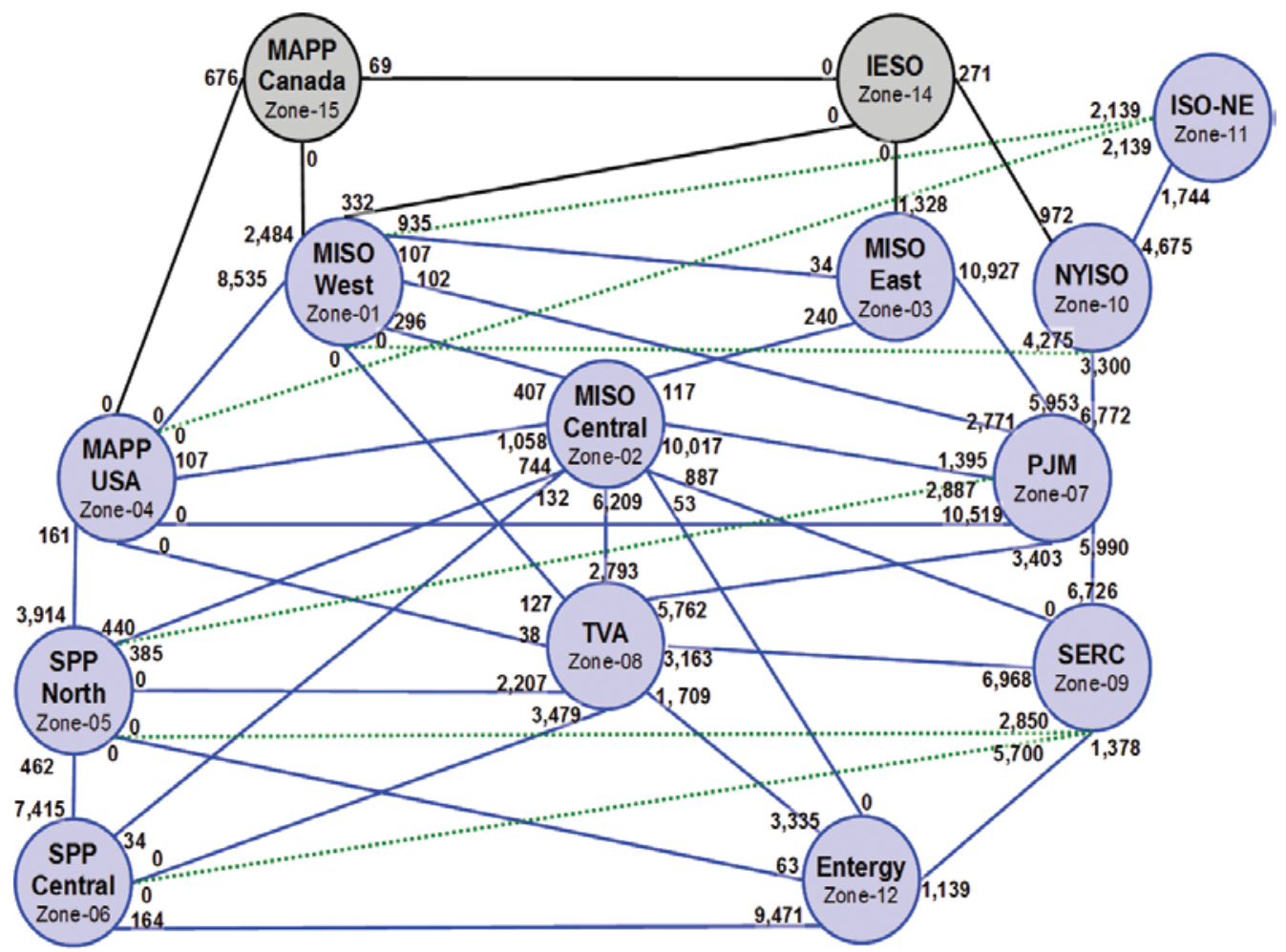

Figure 7-10. Scenario 4, conceptual transmission overlay August interface limits (MW) 


\section{RESULTS}

\section{ISOLATED SYSTEM}

Table 7-2 shows the ELCC results summed over the entire Eastern

Interconnection study system on an isolated system basis for the four wind penetration scenarios and three different profiles studied. "On an isolated system basis" means that there is no transfer capability or ties between any of the zones and thus no ability to share the wind resource with the rest of the system. This transmission sensitivity limits the wind capacity to serving load only in the zone where the wind resource is actually located.

\begin{tabular}{|l|r|r|r|r|}
\hline \multicolumn{1}{|c|}{ TABLE 7-2. ELCC RESULTS FOR ISOLATED SYSTEM (NO TIES) } \\
\hline \multicolumn{1}{|c|}{ RESULTS } & \multicolumn{1}{c|}{$\begin{array}{c}\text { SCENARIO } \\
\end{array}$} & $\begin{array}{c}\text { SCENARIO } \\
\mathbf{2}\end{array}$ & $\begin{array}{c}\text { SCENARIO } \\
\mathbf{3}\end{array}$ & $\begin{array}{c}\text { SCENARIO } \\
\mathbf{4}\end{array}$ \\
\hline Nameplate Wind (MW) & 32,144 & 35,868 & 41,264 & 54,408 \\
\hline 2004 Profile-ELCC (MW) & 14.4 & 15.9 & 17.9 & 16.1 \\
\hline 2004 Profile-ELCC (\%) & 31,433 & 40,322 & 46,484 & 54,218 \\
\hline 2005 Profile-ELCC (MW) & 14.1 & 17.8 & 20.2 & 16.1 \\
\hline 2005 Profile-ELCC (\%) & 36,126 & 43,986 & 53,375 & 63,586 \\
\hline 2006 Profile-ELCC (MW) & 16.2 & 19.5 & 23.2 & 18.8 \\
\hline 2006 Profile-ELCC (\%) & & & & 337,708 \\
\hline
\end{tabular}

\section{EXISTING TRANSMISSION}

Table 7-3 shows the ELCC results under the transmission sensitivity of using only the existing transmission system. This allows for transfer capability and ties between zones at levels of today's existing infrastructure. Figures 7-3 through 7-6 show these tie configurations and interface limits for all four scenarios.

\begin{tabular}{|l|r|r|r|r|}
\hline \multicolumn{1}{|c|}{ TABLE 7-3. ELCC RESULTS FOR EXISTING TRANSMISSION SYSTEM } \\
\hline \multicolumn{1}{|c|}{ RESULTS } & \multicolumn{1}{c|}{$\begin{array}{c}\text { SCENARIO } \\
\text { SCENARIO }\end{array}$} & $\begin{array}{c}\text { SCENARIO } \\
\mathbf{2}\end{array}$ & $\begin{array}{c}\text { SCENARIO } \\
\mathbf{4}\end{array}$ \\
\hline Nameplate Wind (MW) & 223,609 & 225,902 & 230,299 & 337,708 \\
\hline 2004 Profile-ELCC (MW) & 35,708 & 42,468 & 52,286 & 68,932 \\
2004 Profile-ELCC (\%) & 16.0 & 18.8 & 22.7 & 20.4 \\
\hline 2005 Profile-ELCC (MW) & 45,216 & 54,764 & 60,765 & 69,655 \\
2005 Profile-ELCC (\%) & 20.2 & 24.2 & 26.4 & 20.6 \\
\hline 2006 Profile-ELCC (MW) & 44,560 & 53,864 & 70,155 & 83,007 \\
2006 Profile-ELCC (\%) & 19.9 & 23.8 & 30.5 & 24.6 \\
\hline
\end{tabular}

\section{OVERLAY TRANSMISSION}

Table 7-4 shows the ELCC values calculated for the transmission sensitivity case of the conceptual transmission overlay system. The overlay transmission system increases the transfer capability between zones and allows more of the wind capacity to serve load outside the zone where it is physically located. The transmission overlay consists of multiple new DC and AC lines in various different configurations in each of the four scenarios; these lines both increase 
the transfer limits and add new interfaces between the zones. These changes in interface limits and new ties can be seen in Figures 7-7 through 7-10.

\begin{tabular}{|c|c|c|c|c|}
\hline RESULTS & $\begin{array}{c}\text { SCENARIO } \\
1\end{array}$ & $\begin{array}{c}\text { SCENARIO } \\
2\end{array}$ & $\begin{array}{c}\text { SCENARIO } \\
3\end{array}$ & $\begin{array}{c}\text { SCENARIO } \\
4\end{array}$ \\
\hline Nameplate Wind (MW) & 223,609 & 225,902 & 230,299 & 337,708 \\
\hline 2004 Profile-ELCC (MW) & 61,884 & 61,655 & 65,205 & 89,763 \\
\hline 2004 Profile-ELCC (\%) & 27.7 & 27.3 & 28.3 & 26.6 \\
\hline 2005 Profile-ELCC (MW) & 56,737 & 63,248 & 64,711 & 83,807 \\
\hline 2005 Profile-ELCC (\%) & 25.4 & 28.0 & 28.1 & 24.8 \\
\hline 2006 Profile-ELCC (MW) & 53,956 & 60,913 & 75,552 & 100,680 \\
\hline 2006 Profile-ELCC (\%) & 24.1 & 27.0 & 32.8 & 29.8 \\
\hline
\end{tabular}

Figure 7-11 shows the ELCC results for both the existing and the overlay transmission systems. The figure also illustrates how the ELCC increased in the overlay system because the conceptual overlay increased the transfer capability between zones. These results are depicted for the four scenarios, and the different colors represent the three yearly profiles studied.

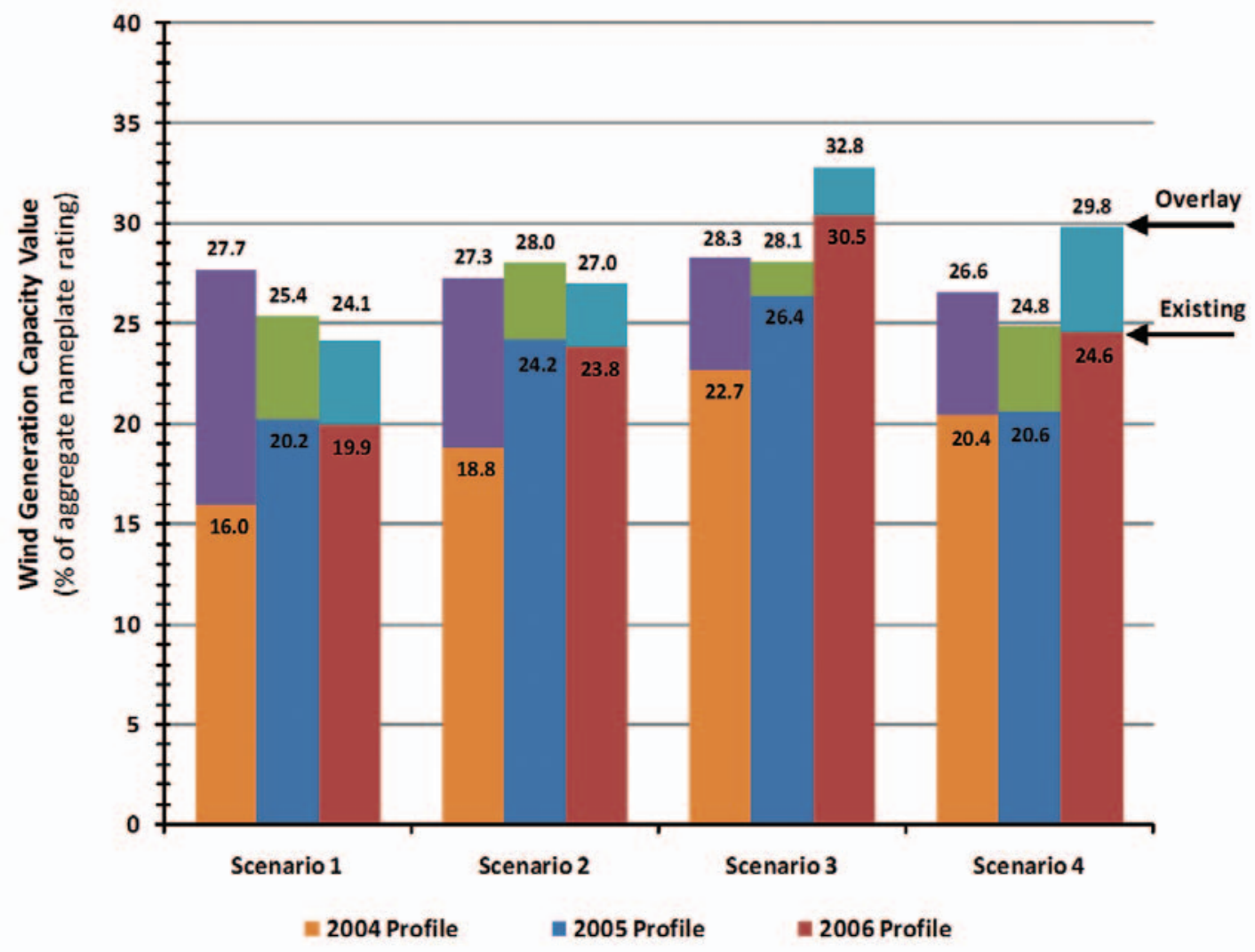

Figure 7-11. ELCC results for existing and overlay transmission 


\section{TIE-ONLY BENEFITS}

Figure 7-12 and Table 7-5 show the total and incremental benefits gained from including ties in the system, without including any of the benefits from wind. These tie-only LOLE benefits are calculated by looking only at the cases without any wind resources modeled and then comparing the isolated system results with those of an interconnected system such as the existing and overlay transmission systems. Clearly, significant benefits are gained from an interconnected system. These results show that roughly 50,000 MW of benefits in the Eastern Interconnection system are gained from the existing transmission system because it operates as an interconnected system. These benefits would not be realized if each of the zones were not part of an interconnected system, meaning that they would function like an isolated system.

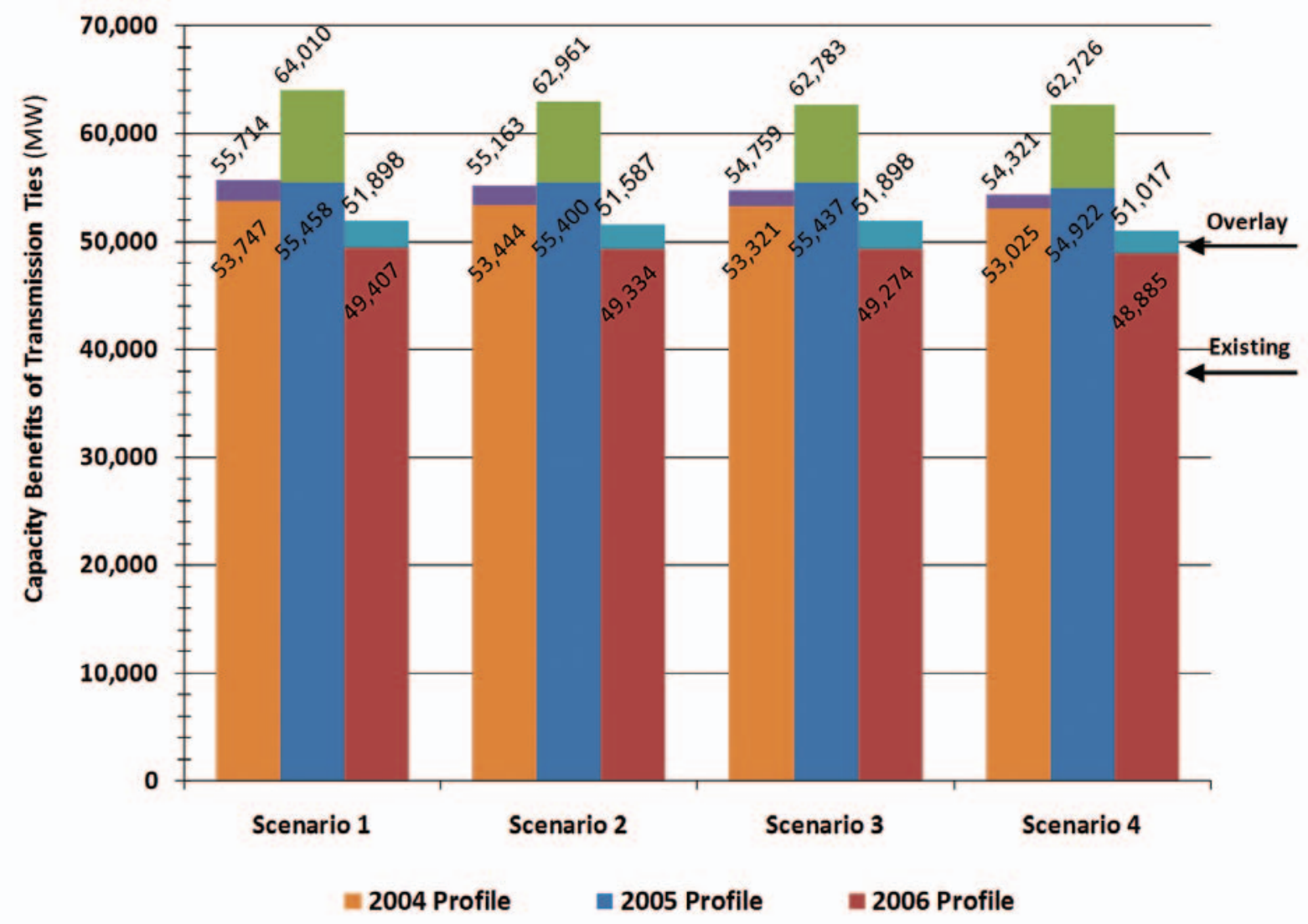

Figure 7-12. Tie benefit results for existing and overlay transmission 


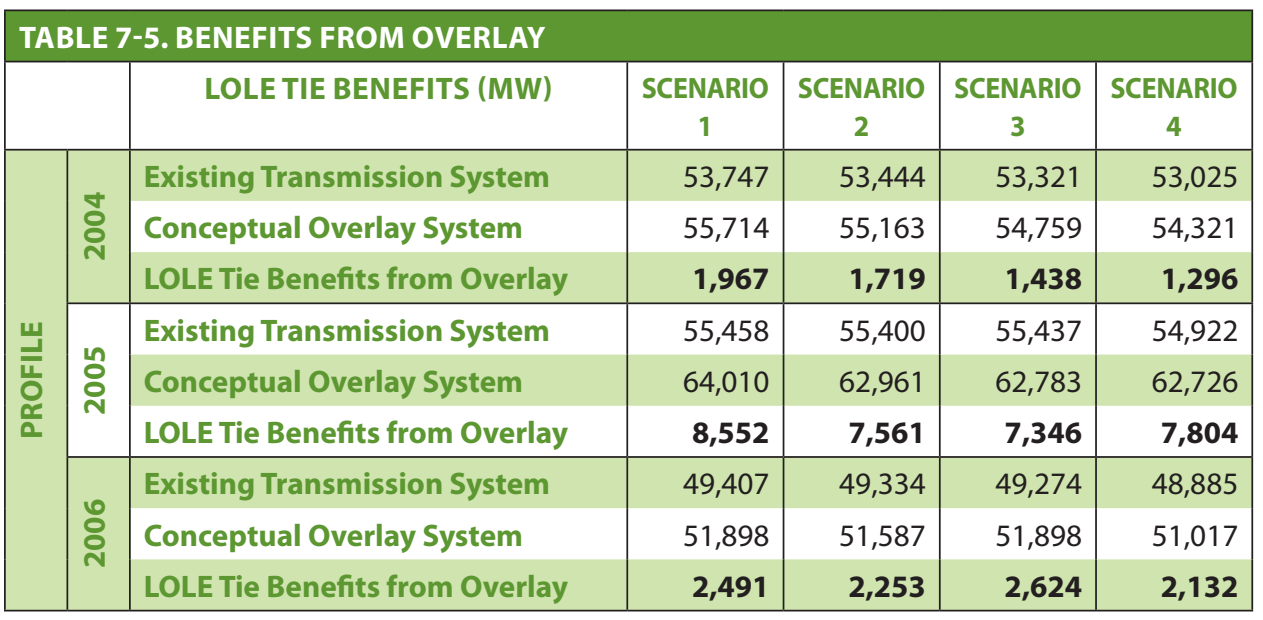

\section{ANALYSIS \\ WIND CONTRIBUTION}

The ELCC results from this analysis based on the four wind penetration scenarios and three simulated wind output and historical load profiles (2004, 2005 , and 2006) show that the wind resource can achieve $>24 \%$ capacity contribution to serving load with the conceptual transmission overlay added. The existing transmission system without the transmission overlay could expect to achieve $16 \%$ or greater capacity contribution. The findings discussed here are the conservative lower bounds of the overall study results because of the risk associated with overestimating the capacity contribution of wind.

Discretion and prudence must be practiced when considering these results. This analysis looked at only three different yearly profiles, and the results vary year by year. Many more profiles would need to be simulated and studied to begin to form statistically based confidence levels around these results. Another thing to consider is the limitation of using a transportation-style model. Although there are interface limits and ties between study zones, it is still assumed that there are no internal constraints or deliverability issues within the study zones. When splitting and dividing a system of this size and magnitude into a configuration of study zones, some liberties must be exercised when defining large zones.

\section{OVERLAY CONTRIBUTION}

The LOLE-based tie benefits illustrate that the conceptual transmission overlay incrementally adds to the tie benefits of the existing transmission system. The overlay adds from 1,200 to 8,500 MW of tie benefits to the Eastern Interconnection system. These benefits indicate that the conceptual transmission overlay would help move capacity needed for resource adequacy out of one area where it is not particularly needed into another area where it is needed. With the conceptual transmission overlay in place, there is less need for new power plants. 
As with the ELCC results, discretion must be practiced when looking at these results. These values can vary greatly among the historical profiles studied. The LOLE tie benefits depend greatly on the amount of capacity a particular area needs at a specific time and simultaneously on how much reserve is available in the rest of the system. The tie benefits, then, depend on the overall diversity of a system, which can vary greatly and yearly throughout the entire Eastern Interconnection. 


\section{SECTION 8: SYNTHESIS AND IMPLICATIONS}

\section{NOTES ON THE ANALYTICAL METHODOLOGY}

The analytical methodology used in the Eastern Wind Integration and Transmission Study (EWITS) conforms to the economic transmission expansion procedure illustrated in Figure 8-1. The National Renewable Energy Laboratory's (NREL) mesoscale data set for the eastern United States was the starting point for EWITS. After doing some initial characterization, the study team defined four wind generation scenarios by selecting specific wind plants from the database. Wind plant locations in each scenario were mapped into a generation expansion model that estimated the amount of new conventional generation that would be required across the Eastern Interconnection in 2024 to serve load and ensure a sufficient level of resource adequacy.

To begin the transmission overlay development process, the EWITS team incorporated new generation from the expansion process and wind from the defined scenarios into a chronological production simulation model. Comparing a case with transmission constraints enforced to one with no transmission constraints allowed calculation of annual congestion charges over constrained interfaces in the production model. The congestion charges then served as the basis for the design of overlay transmission and regional transmission upgrades to move energy from sources to sinks.

Hourly and subhourly profile data corresponding to the selected wind plants and 2024 load data were also used in various statistical analyses. These analyses were designed to determine the requirements for regulation and operating reserves that would be needed in each of the operating areas to manage the incremental variability and uncertainty introduced by wind generation.

Wind generation, new nonwind generation, transmission overlay designs, and results of the statistical analysis were merged into a new set of annual production simulations. The objective here was to simulate as closely as possible the operation of individual operating pools or markets in the Eastern Interconnection, along with their economic interactions. The same approach was used to estimate the operating cost of the incremental variability and uncertainty introduced by wind generation.

The production model was also the basis for analyzing resource adequacy. The comprehensive loss of load expectation (LOLE) analysis looked at the contribution of wind generation to resource adequacy for individual regions in isolation, with existing transmission ties, and with the transmission overlays 
developed in the earlier step. Running cases with and without wind generation allowed the project team to calculate the effective load-carrying capability (ELCC) of wind generation in each scenario. Figure 8-1 clearly shows that the procedure was intended to be iterative. In other words, more than one pass through the analyses that make up the process would allow for reconciliation of inconsistencies among interim results and for improvement of subsequent outcomes. In EWITS, only a single pass was possible because of the very large study scope and schedule limitations.

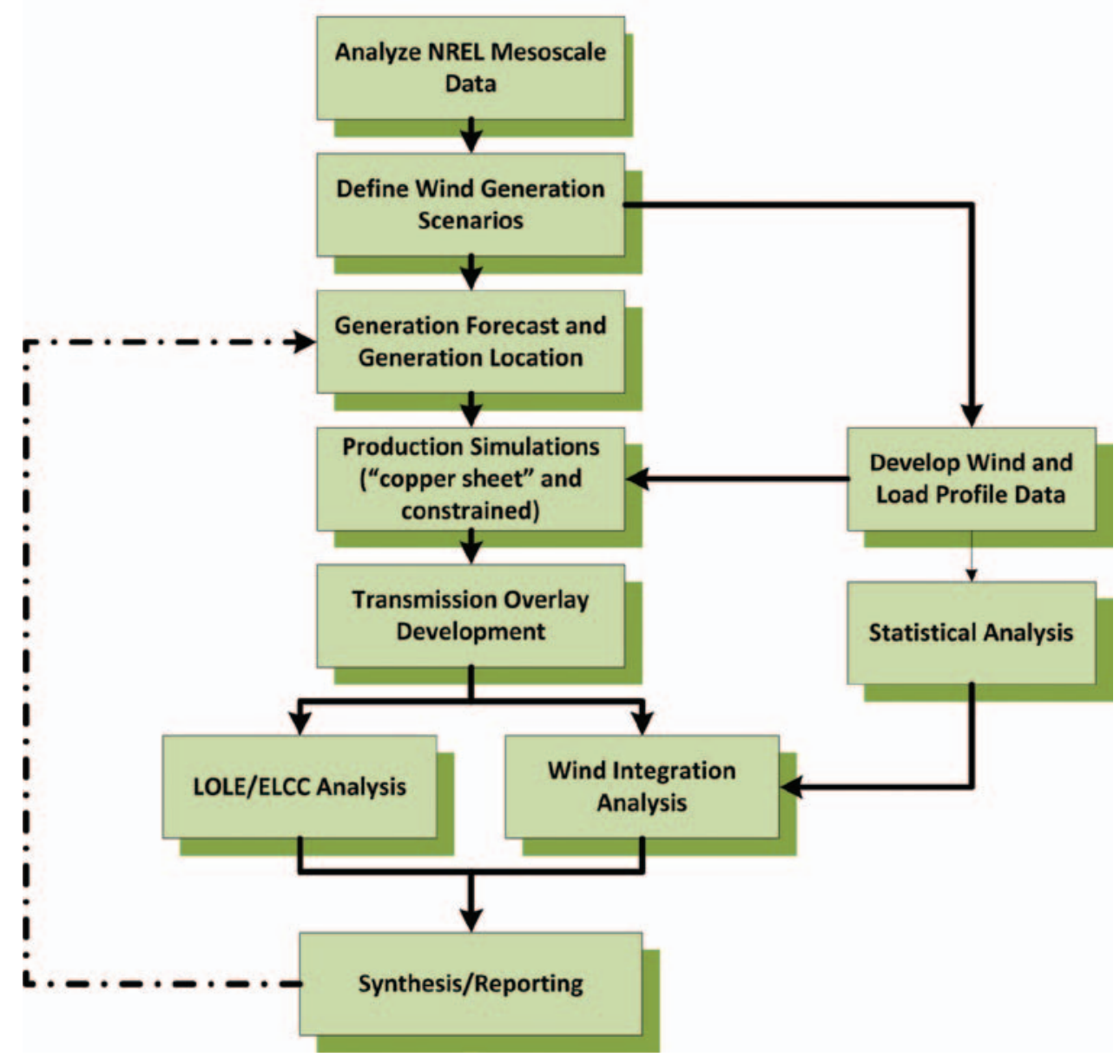

Figure 8-1. Flow diagram for study analytical methodology

Bottom-up processes make decisions from the present to the future based on annual incremental expansions. Most previous transmission expansions used bottom-up processes; most states, for example, use such a process for approval of projects from a list of alternatives. Each transmission line is decided one at a time to meet near-term resource adequacy or delivery requirements. Bottom-up processes are usually based on resolving line-loading or voltage-level problems associated with reliability criteria. 
The EWITS study team used top-down economic methods to design the conceptual transmission expansion. These methods tend to create transmission designs with more transmission than bottom-up transmission methods, primarily because the total economic potential of increasing the economic efficiency of the generation fleet, including wind generation in the Eastern Interconnection, is used to justify transmission. The combination of capturing the economic potential of nonwind and wind generation loads transmission lines to high load factors, resulting in more efficient use of the transmission. The transmission requirements are mainly off peak for the wind generation and on peak for the nonwind generation.

Previous sections of this report focused on results from the individual analytical steps of the process. This section brings together the various results of the analyses for an overall perspective.

\section{TOTAL COSTS}

Each EWITS scenario created for 2024 results in a picture of the Eastern Interconnection that is substantially different from what is in place today. The changes made include adding very large amounts of wind, regional and overlay transmission, and conventional generation. As described earlier, the top-down method leads to a snapshot of 2024; it does not consider the evolution of today's power system through time to get to 2024. After refining each scenario through additional iterations of the study process, more conventional planning methods would be employed to fill in the details of the evolution over time, along with even further refinement.

Components of cost and the approaches for tabulating them are described next.

\section{ASSUMPTIONS}

Costs for each scenario comprise both capital investment and production-related costs. To better compare between scenarios, the team annualized capital costs. Table 8-1 gives the assumptions used for capital costs.

\begin{tabular}{|l|r|r|}
\hline \multicolumn{1}{|c|}{ TYPE } & $\begin{array}{r}\text { LEVELIZED FIXED } \\
\text { CHARGE RATE (\%) }\end{array}$ & $\begin{array}{r}\text { CAPITAL COST, } \\
\text { US\$2008 }(\mathbf{\$} / \mathbf{k W} \text { ) }\end{array}$ \\
\hline COAL & 12.50 & 1,833 \\
\hline COMBUSTION TURBINE (CT) & 12.43 & 597 \\
\hline COMBINED CYCLE (CC) & 12.50 & 857 \\
\hline NUCLEAR & 12.53 & 2,928 \\
\hline ONSHORE WIND & 11.92 & 1,875 \\
\hline OFFSHORE WIND & 11.92 & 3,700 \\
\hline TRANSMISSION & 15 & NOT APPLICABLE \\
\hline ESCALATION & 3 & NOT APPLICABLE \\
\hline
\end{tabular}

${ }^{a} k W=$ kilowatt 


\section{CAPITAL COSTS-NEW GENERATION}

The economic transmission development process began with a conventional generation expansion exercise. Its purpose was to ensure that there is adequate generation in the case to meet the load reliably in the future year being studied. For this study, the expansion was performed by first siting the wind generation for each scenario, then determining what new generation would be required to maintain regional resource adequacy.

Wind generation was assigned a capacity value of $20 \%$ of nameplate for the generation expansion runs. The LOLE analysis described in Section 7 revealed that the actual capacity value with the overlay transmission was higher than $20 \%$ for all scenarios. To compensate, the original conventional generation expansion could be adjusted downward to reflect the fact that, with wind generation and transmission, a certain amount of that capacity would not be needed for resource adequacy. Given that capital costs for conventional generation technologies vary widely, the adjustment cannot be done without further iterations of the generation expansion model. Consequently, the conventional generation capital costs in EWITS are based on a wind generation capacity value of $20 \%$.

\section{CAPITAL COSTS-NEW TRANSMISSION}

Section 4 covered the cost of regional and overlay transmission for each scenario. Here, the amounts are capitalized using a fixed charge rate of $15 \%$. The transmission capital costs include estimates for the extra-high voltage (EHV) overlays, the identified regional upgrades, and the associated terminal/ substation equipment.

Some regional or local upgrades would be necessary for moving energy to or from the transmission backbone, and cost estimates for these upgrades are not included in EWITS. Because of related internal work in operating areas covered by the Midwest Independent System Operator (Midwest ISO) and the Southwest Power Pool (SPP), some detail was available for regional upgrades in these areas. Much less information was available for the other operating areas, and the transmission capital costs may be understated as a result. The overlay transmission makes up the majority of the transmission capital cost, however, and the results are from a single iteration of the top-down economics-based analysis. Refinements from further iterations would presumably work to reduce capital costs.

\section{PRODUCTION COSTS}

Production costs for each scenario were extracted from the annual PROMOD IV simulations. Fuel and operating costs, along with variable operations and maintenance $(\mathrm{O} \& \mathrm{M})$ costs, make up production costs. 


\section{TOTAL COSTS}

Figure 8-2 shows the total costs for each scenario.

Costs for each scenario are calculated as the sum of production-related costs plus annualized amounts for capital investments in new conventional generation, wind plants, and transmission. The results for the Reference Scenario and the four EWITS high-penetration scenarios (Figure 8-2) show that Scenario 1 is the least costly of the $20 \%$ scenarios and that the increased cost of offshore wind is a major cost element of Scenarios 3 and 4.

Transmission costs are a relatively small fraction for all scenarios, with only a small absolute difference in this component in the $20 \%$ cases.

None of the scenarios includes any costs associated with carbon.

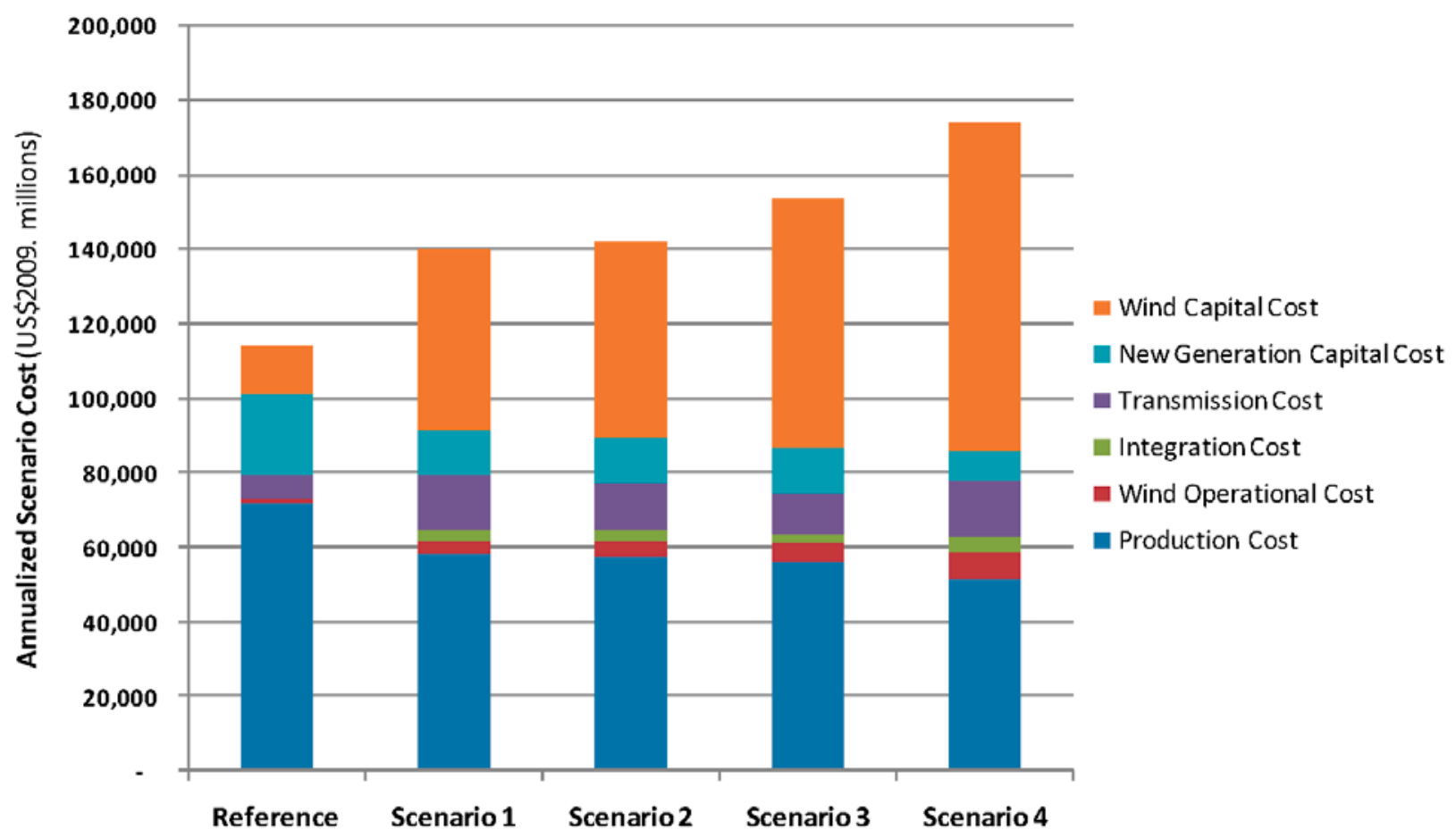

Figure 8-2. Costs by scenario

\section{IMPLICATIONS OF THIS STUDY}

EWITS is the first study that considered three geographic generation scenarios for the 20\% wind energy level for the Eastern Interconnection. All costs for integrating wind-costs for generation expansion, transmission expansion, production, and operations - were calculated based on defined assumptions for the study. 


\section{GENERAL OBSERVATIONS}

Based on the work done in this study, the EWITS team can make a number of general observations. The wind generation does not need 100\% transmission for the rated wind generation connected to the transmission system. The geographic diversity of wind generation produces a coincident peak capacity of $80 \%-90 \%$ of the total rated wind generation. Transmission does not need to be sized to handle all the wind generation at its maximum coincident output. Some wind can be curtailed for some hours more economically than building transmission that would be loaded only for those few hours. Adding more generation with small curtailments to meet the renewable energy standards can be more costeffective than designing a transmission system for the peak coincident output of the generation. The top-down economic process used for EWITS determines the curtailment energy for wind and also the potential benefit of adding transmission compared to the cost.

The combination of large pools of low-cost energy delivered to higher priced areas and the abundance of generation capacity off peak creates a large market price signal that drives the justification of economic transmission expansion at the $20 \%$ wind energy level. The price signal is quite sensitive to the price of natural gas. Natural gas-fired generation sets the marginal price on the energy market. The difference in marginal prices across the Eastern Interconnection drives the need for transmission. The assumed price of $\$ 8 / \mathrm{MBtu}$ (millions of British thermal units) translates to a significant differential in marginal prices across the interconnection.

At the US\$2009 price of natural gas in the \$3-\$4/ MBtu range, the energy market prices are already level and the difference in energy price across the Eastern Interconnection is reduced. Less transmission can be justified at lower gas prices that reduce the differential pricing across the Eastern Interconnection.

At 30\% wind energy, energy market prices are practically level across the Eastern Interconnection. The energy market no longer gives a signal to justify additional transmission expansion based on marginal prices.

Wind generation generally does not appear on peak and contributes less to serving load on peak than off peak. Wind generation on the peak hour in the Midwest ISO for the last 5 years has been $1.2 \%, 11.4 \%, 1.2 \%, 11.8 \%$, and $56 \%$, respectively. Currently, wind generation in the Midwest ISO area is concentrated in a small geographic area in southwestern Minnesota and northern Iowa. Wind generation potential exists in much of the Midwest ISO's footprint. Geographic diversity is expected to increase the capacity contribution of wind on the peak period. 
The EWITS LOLE studies show that when the geographic diversity of the Eastern Interconnection is considered, the capacity credit could increase to $25 \%$. The capacity credit given to wind reduces the amount of other generation that must be constructed. The incremental economic value of the diversity factor (the capacity factor owing to diversity) can be estimated by running a case with an assumed wind capacity credit such as the $20 \%$ used in EWITS, then running the EWITS process again using the ELCC wind energy capacity credit. In this example, an $8 \%$ reduction in other generation would apply to about $30 \%$ of the total cost of the wholesale price energy.

\section{POLICY IMPLICATIONS}

Although EWITS is a technical study that examines future wind scenarios, the results of this study pose some interesting policy and technology development questions:

- Could the levels of transmission, including the Reference Case, ever be permitted and built, and if so, what is a realistic time frame?

- Could the level of offshore wind energy infrastructure be ramped up fast enough to meet the aggressive offshore wind assumption in the EWITS scenarios?

- Would a different renewable profile or transmission overlay arise from a bottom-up process with more stakeholders involved?

- How can states and the federal government best work together on regional transmission expansion and the massive development of onshore and offshore wind infrastructure?

- What is the best way for regional entities to collaborate to make sure wind is optimally and reliably integrated into the bulk electrical grid?

- What is the difference between applying a carbon price instead of mandating and giving incentives for additional wind? 


\section{SECTION 9: FINDINGS, CONCLUSIONS, AND RECOMMENDATIONS}

The analytical modeling of the operational impacts of wind generation in the Eastern Wind Integration and Transmission Study (EWITS) was conducted on a scale and at a level of detail not previously attempted for this type of analysis. The volume of raw results is immense-hourly data for any generator or monitored interface in the Eastern Interconnection for four scenarios of wind generation over three annual periods.

This section describes the key findings and conclusions of the project, and recommends follow-up actions or further investigation.

\section{KEY FINDINGS AND CONCLUSIONS}

A number of conclusions can be drawn from the process and results of the analytical work in this study. These are summarized by topical category in the following subsections.

\section{CONCEPTUAL TRANSMISSION OVERLAY}

In contrast to previous wind integration studies, adding significant new transmission across an interconnection was a principal element of this study.

- The conceptual transmission overlays consist of multiple 800-kilovolt (kV) high-voltage DC (HVDC) and extra-high voltage (EHV) AC lines. HVDC is preferred if not required because of the volumes of energy that must be transported across and around the interconnection and the distances involved.

- Similar levels of new transmission are needed across the four scenarios, and certain major facilities appear in all of the scenarios. The study focused on a snapshot of four possible 2024 futures; how to get to any one of those futures was outside the scope of the study. The commonality of transmission elements across the four scenarios reveals important information should that effort be undertaken.

- The modeling indicates that a substantial amount of wind can be accommodated if adequate transmission is available.

- Transmission produces capacity benefits in its own right, and enhances the capacity credit contribution of wind generation by a measurable and significant amount.

- The EHV DC transmission that constitutes a major portion of the overlays designed for the EWITS scenarios has benefits beyond those evaluated here. For example, it would be possible to schedule reserves from one area 
to another, effectively transporting variability caused by wind and load to areas that might be better equipped to handle it. And the transfer capability of the underlying AC network could be enhanced by using the DC terminals to mitigate limitations related to transient stability issues.

\section{WIND GENERATION IMPACT ON RESERVES}

Current operating experience gives little guidance on how to manage the incremental variability and uncertainty associated with large amounts of wind generation in the operating footprints defined for this study. The statistical analysis conducted on the time-series data from the scenarios, however, produced a very reasonable analytical foundation for the assumptions and reserve requirement results that were carried forward to the production simulations.

Study findings and conclusions relative to reserve requirements and impacts include the following:

- The assumptions made about how the Eastern Interconnection will be operated in 2024 played an important role in minimizing the additional amounts of spinning reserve that would be required to manage the variability of large amounts of wind generation.

- The geographic size of the market areas assumed in EWITS allows substantial benefits of geographic diversity to be realized.

- The pooling of larger amounts of load and discrete generating resources via regional markets also realizes the benefits of diversity. The per-unit variability of load declines as the amount of load increases; larger markets also have more discrete generating units of diverse fuel types and capabilities to use for meeting load and managing variability.

- With real-time energy markets, changes in load and wind that can be forecast over a short interval-10 minutes in this study, 15 to 20 minutes in current practice-are compensated for in a very economic manner.

- Incremental spinning reserve requirements are driven by errors in shortterm forecasts of wind generation.

- Both variability and uncertainty of aggregate wind decrease percentagewise with more wind and larger geographic areas.

- Both variability and uncertainty can be characterized for a defined scenario using National Renewable Energy Laboratory (NREL) mesoscale data.

- Characterizations are useful for estimating incremental reserve requirements.

- Variations on a second-by-second basis are still dominated by load.

- Load changes over 10-minute intervals can be forecast well, and are therefore cleared in the regional transactions market.

- Current energy market performance shows that subhourly market prices, on average, do not command a premium over day-ahead prices. As a consequence, the hourly production simulation will capture most of the costs associated with units moving in subhourly markets, and the spinning 
reserve requirements for regulation and contingency will appropriately constrain the unit commitment and dispatch.

\section{OPERATIONAL IMPACTS}

The detailed production modeling of a system of such size and scope reduces the number of assumptions and approximations required to obtain a solution. The extremely large volume of results is a disadvantage, but they do contain information that can be used to draw conclusions of relatively high confidence with respect to wind generation impacts on other system resources:

- Generation displacement depends on location and amount of wind generation.

- Fossil units are displaced because of the requirements for additional reserves and influences of day-ahead forecast error (ideal to actual cases).

- Wind generation reduces locational marginal price (LMP) in all operating regions.

- The effect appears to be greatest with local wind resources.

- Offshore wind has more effect on LMP in eastern load centers.

\section{WIND GENERATION CURTAILMENT}

In the production simulations, the EWITS team assigned a very low dispatch price to wind generation, so that other sources would first be redispatched to relieve congestion. Even so, a modest amount of curtailment was observed in some operating areas. Local or subregional transmission congestion is the probable cause because the production simulation results gave no clear evidence that the other likely causes-minimum generation levels, reserve requirements, or ramp limitations-were responsible.

A certain amount of wind generation curtailment was to be expected, based on the process by which the overlay transmission concepts were developed. Transmission was sized to accommodate a large fraction—but not $100 \%$ - of the transaction energy from the unconstrained production simulation case.

\section{WIND GENERATION CONTRIBUTION TO RESOURCE ADEQUACY}

Assessing the capacity value of wind generation has been a staple of most of the integration studies conducted over the past several years (see Bibliography). The approach taken in this project represents the most thorough and detailed investigation to date because of the size and scope of the model, the process by which areas transfer limits were determined, and the sensitivity analyses performed. The study team recognizes that the results represent a macro view and do not consider some important intraregional transmission constraints. Because of the project focus on transmission, however, the results represent a target resource adequacy contribution that could be achieved for the wind generation scenarios. 
Specific findings and conclusions are as follows:

- The loss of load expectation (LOLE) analysis performed for this study shows that the existing transmission network in the Eastern Interconnection contributes roughly 50,000 megawatts (MW) of capacity benefits. With the transmission overlays developed for the wind scenarios, the benefit increases by up to 8,500 MW.

- LOLE analysis of the Eastern Interconnection with wind generation and the transmission overlays developed in this study estimates that the ELCC of the wind generation ranges from $24.1 \%$ to $32.8 \%$ of the rated installed capacity.

- The transmission overlays increase the ELCC of wind generation anywhere from a few to almost 10 percentage points (e.g., $18 \%$ to $28 \%$ ).

- The ELCC of wind can vary greatly geographically depending on which historical load and wind profiles are being studied. The EWITS team observed interannual variations; these variations, however, were much smaller than had been observed in previous studies (e.g., EnerNex 2006).

- Characteristics of the zonal ELCC differences between profiles tended to be the same between all four scenarios.

\section{WIND INTEGRATION COSTS AND IMPACTS}

Assessing the costs and impacts of integrating large amounts of wind generation was another key aspect of this study. Methods and analytical approaches used in earlier integration studies were the starting point, but as interim results became available, nuances and challenges in those methods when they are applied to a large, multiarea production model became apparent. As a result of this project, then, the team learned a great deal of useful information about the total costs associated with managing the delivery of wind energy.

Despite the challenges, the study team has confidence in the results as applied over the entire model footprint. Salient points include the following:

- The conventional proxy resource assumption is not usable with very large amounts of wind generation.

- Because the production simulation model contains multiple operating areas, and transactions between these areas are determined on an economic basis, variability from wind in a given area will be carried through economic transactions to other areas.

- Earlier integration studies isolated the subject area by restricting transactions to predefined shapes based on historical contracts.

- The integration costs over the entire model are accurate because all transactions sum to (nearly) zero.

- Costs for integrating wind across the interconnection vary by scenario. For the $20 \%$ cases, Scenario 1 showed the highest cost at $\$ 8.00 / \mathrm{MWh}$ (megawatt-hour) of wind energy; Scenario 2 follows at \$7.21/ MWh. Scenario 3 shows the lowest integration costs at $\$ 5.77 / \mathrm{MWh}$. These costs 
are in US\$2024; using the 3\% escalation factor, the integration costs in US $\$ 2009$ would be $\$ 5.13$ / MWh for Scenario 1, $\$ 4.63$ / MWh for Scenario 2, and $\$ 3.10 / \mathrm{MWh}$ for Scenario 3.

- The integration cost results for the $20 \%$ scenarios show that spreading the wind more evenly over the footprint reduces the cost of integration. Integration costs increase to $\$ 7.07$ / MWh for the $30 \%$ scenario, or $\$ 4.54$ / MWh in US\$2009. This scenario is roughly a combination of Scenarios 1 and 3.

- Using the actual shape as the proxy resource (with no intrahour variability or uncertainty over any forward time frame) eliminates any issues related to the "value" of wind energy between the actual and ideal wind cases.

- The actual shape proxy, however, does potentially mask or leave out some true operational costs, for example, backing down or possibly even decommitting fossil-fuel units to accommodate wind generation.

- Wind generation reduces LMP in all operating regions.

- The reduction appears to be greatest with local wind resources.

- Offshore wind has more effects on LMP in eastern load centers.

\section{SENSITIVITIES}

\section{PRODUCTION MODEL ASSUMPTIONS AND CURTAILMENT}

The study team investigated the cause of wind generation curtailment by running additional production simulation cases. The results produced quantitative information about the causes, revealing the following:

- Removing must-run flags from coal units had very little effect on wind generation curtailment (decrease of $0.27 \%$ ).

- Setting the dispatch price of wind generation to negative $\$ 40 / \mathrm{MWh}$ reduced curtailment by just under 50\% (6.38\% to $3.51 \%$ ).

- The copper sheet case shows a curtailment level of $0.12 \%$, which is most likely because of minimum generation constraints.

- Increasing minimum generation levels to $50 \%$ on coal plants increased curtailment by only $2 \%$.

This information led the team to conclude that transmission congestion is the primary cause of wind generation curtailment in Scenarios 1 through 4 .

\section{UNIT COMMITMENT WITH PROMOD IV BID LOGIC}

PROMOD IV offers a more sophisticated security-constrained unit-commitment algorithm that was not used for the base production simulations in the study because it increases simulation time. A sensitivity case using wind and load profiles based on 2005 data was run to assess the performance of this alternative approach and the effect on production and integration costs. 
Figure 9-1 presents a comparison of the two approaches and shows that although the bid-logic approach does increase production and integration costs, the effects are relatively minor.

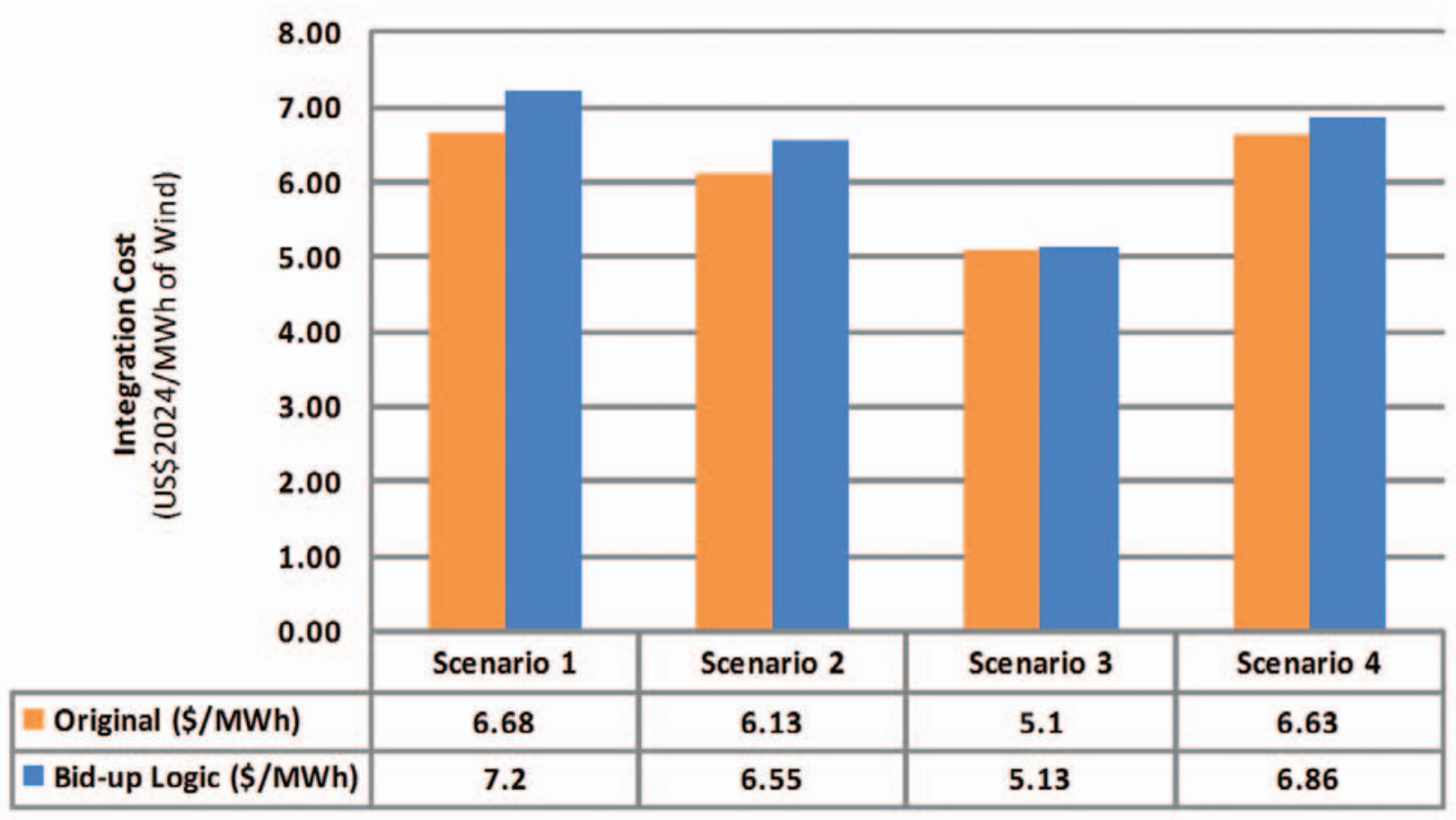

Figure 9-1. Comparison of production simulation results (integration cost) for base unit-commitment algorithm and more sophisticated "bid-logic" approach

\section{INFLUENCE OF HURDLE RATES}

Tariffs, or hurdle rates, are placed on transactions between defined regions in the model to simulate the economic inefficiency that results from independent commitment and dispatch of resources within each region. To assess the effect of these tariffs on production and integration cost, the study team ran production simulations again for two scenarios with hurdle rates set to zero. Under these conditions, the program optimizes the commitment and dispatch of resources across the entire model or, as in this study, the Eastern Interconnection.

Results from these simulations show that the hurdle rates have only a minor impact on production costs (shown in Figure 9-2) and integration costs. 


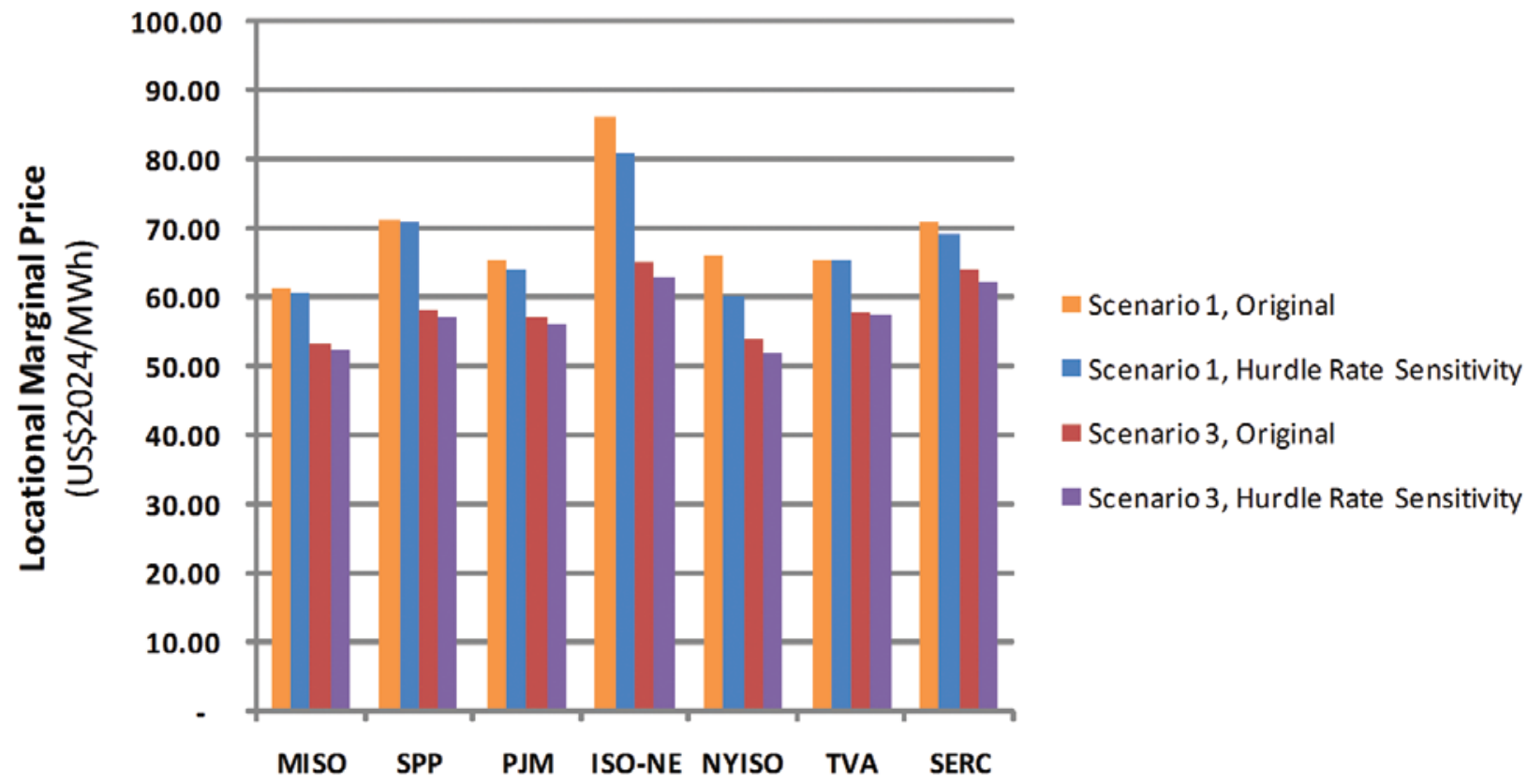

Figure 9-2. Comparison of LMPs for hurdle rate sensitivity

\section{CARBON SENSITIVITY}

No carbon penalties or limits were considered in the base set of assumptions for the study. A single formal sensitivity was defined in the original project scopeevaluating the impacts of carbon penalties or other limitations on the generation expansion, transmission overlay design, production costs, and integration costs associated with wind generation.

The entire analytical methodology, except for the LOLE analysis, was run for a scenario that considered a carbon price of $\$ 100 /$ ton. The high price was determined to be necessary to bring about a significant change in the type of new generation built during the expansion process. Figure 9-3 shows the results of the expansion. Figure 9-4 gives more detail and compares the expansion for this case to the base scenarios and the existing Eastern Interconnection queue. 


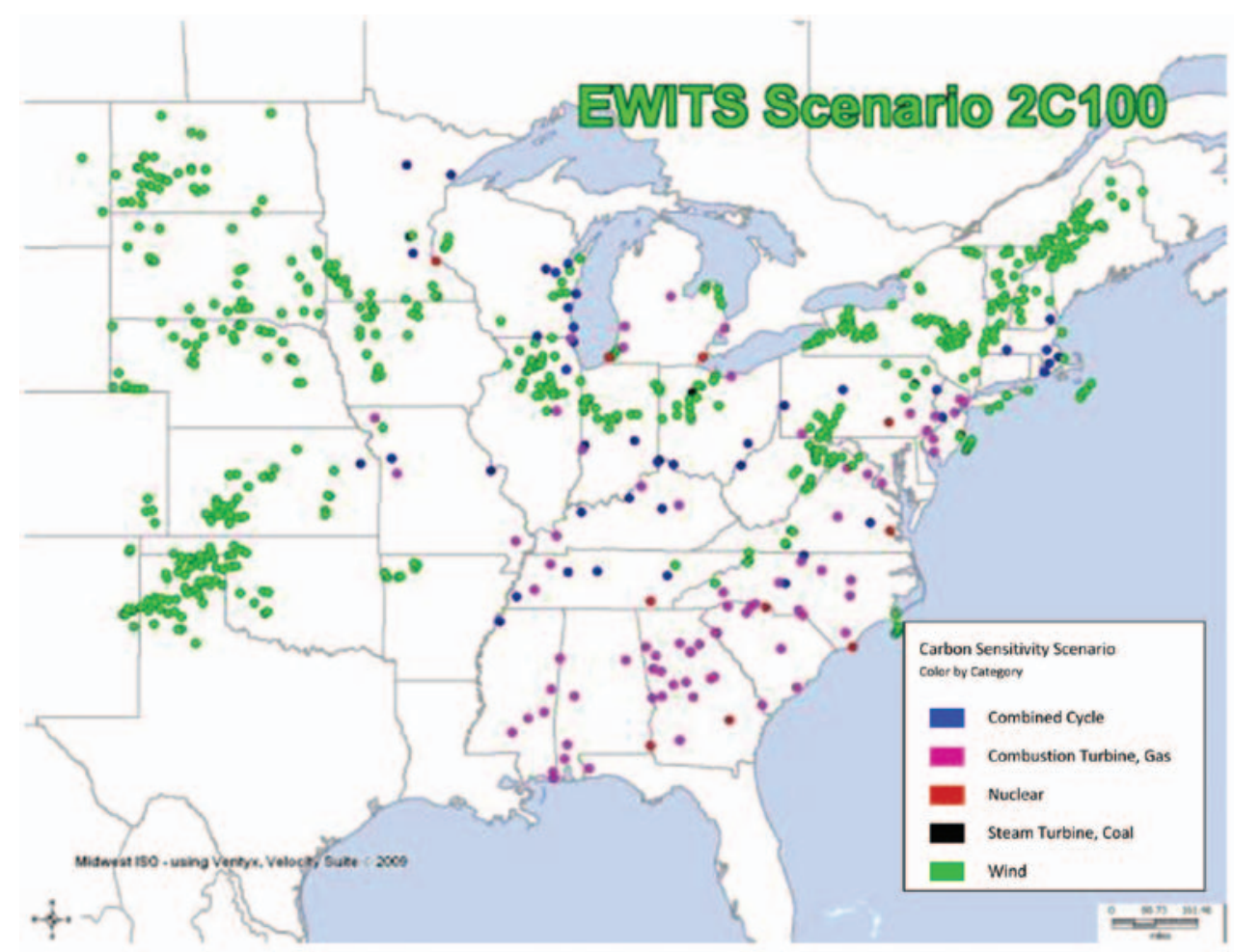

Figure 9-3. Scenario 2, carbon case generation expansion

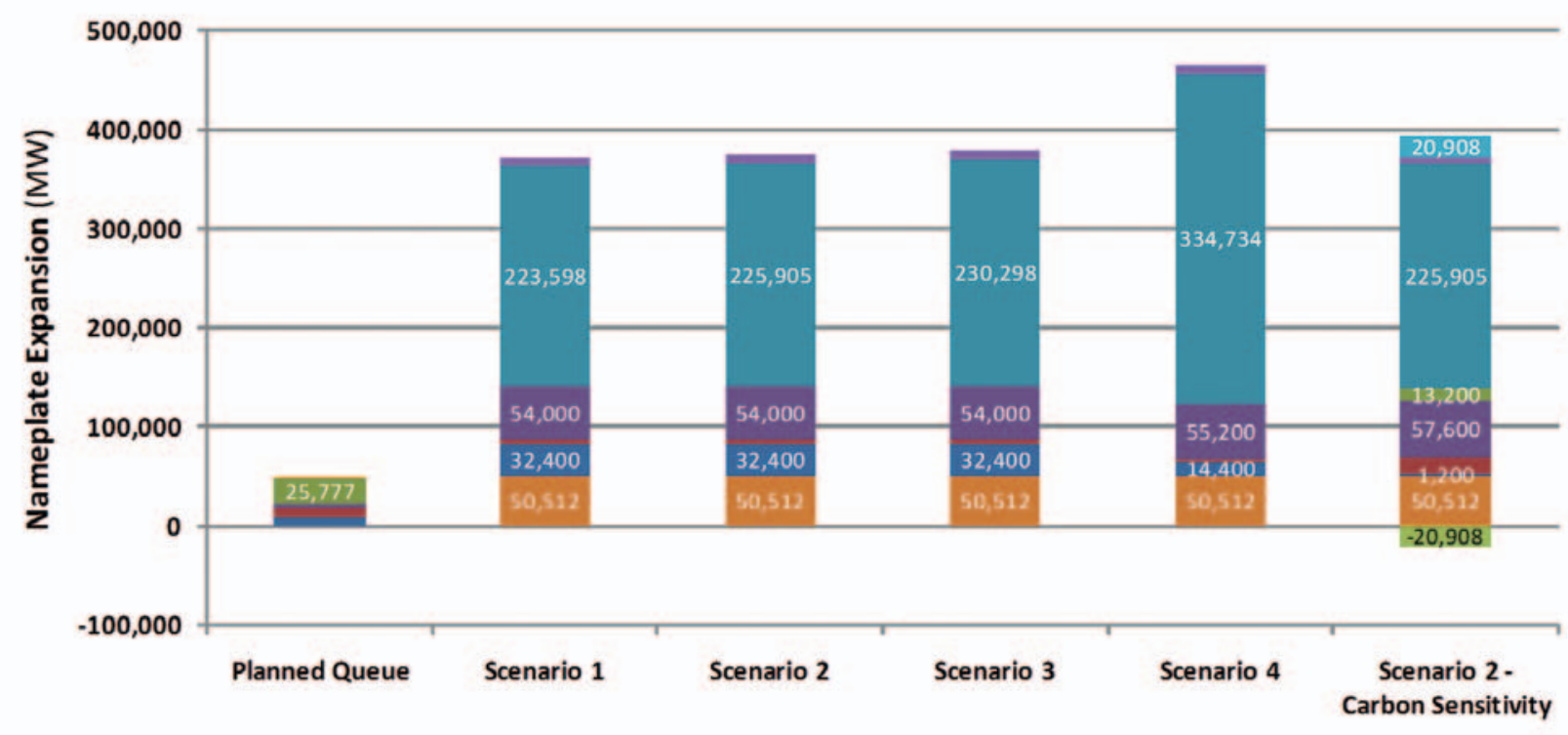

$\equiv$ PlannedQueue $\equiv \mathrm{Coal} \equiv \mathrm{CC} \equiv \mathrm{CT} \equiv$ Nuclear $\equiv$ Wind $\equiv \mathrm{IGCC} \equiv \mathrm{IGCC} / \mathrm{Seq} \equiv \mathrm{CC} / \mathrm{Seq} \equiv \mathrm{DR}=\mathrm{RET}$ Coal $\|$ Replacement CC

Notes: $C C=$ combined cycle; $C T=$ combustion turbine; $D R=$ demand response; $I G C C=$ integrated gas combined cycle; IGCC/Seq = integrated gas combined cycle with sequestration; $C C / S e q=$ combined cycle with sequestration; RET Coal = coal plant retirements; Replacement CC = replacement combined cycle

Figure 9-4. Generation expansion by scenario, 2008-2024 
Results from the production simulations showed that the effect on carbon emissions was substantial. Even though the case was based on Scenario 2 and had wind generation delivering $20 \%$ of the Eastern Interconnection energy, carbon emissions were lower than those from Scenario 4 with 30\% energy generated from wind (Figure 9-5).

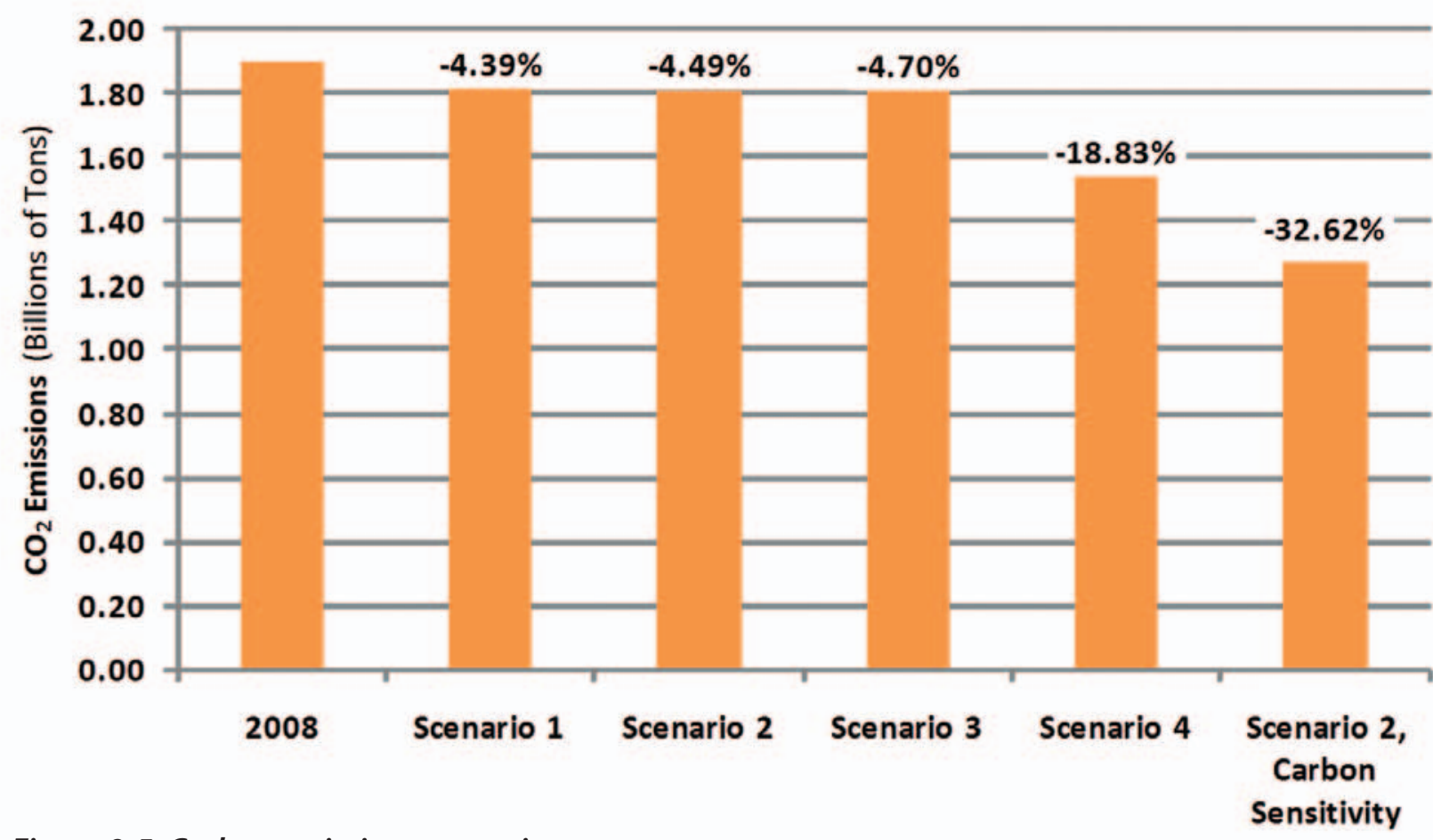

Figure 9-5. Carbon emission comparison

Little effect was observed on wind generation curtailment or integration cost. Fossil generation was reduced relative to the original Scenario 2 (Figure 9-6), and nuclear generation increased because the nuclear share of the new generation expansion was larger. Energy from combined cycle plants also increased as they became the preferred resource for managing variability.

Energy prices increased across the footprint (Figure 9-7). 


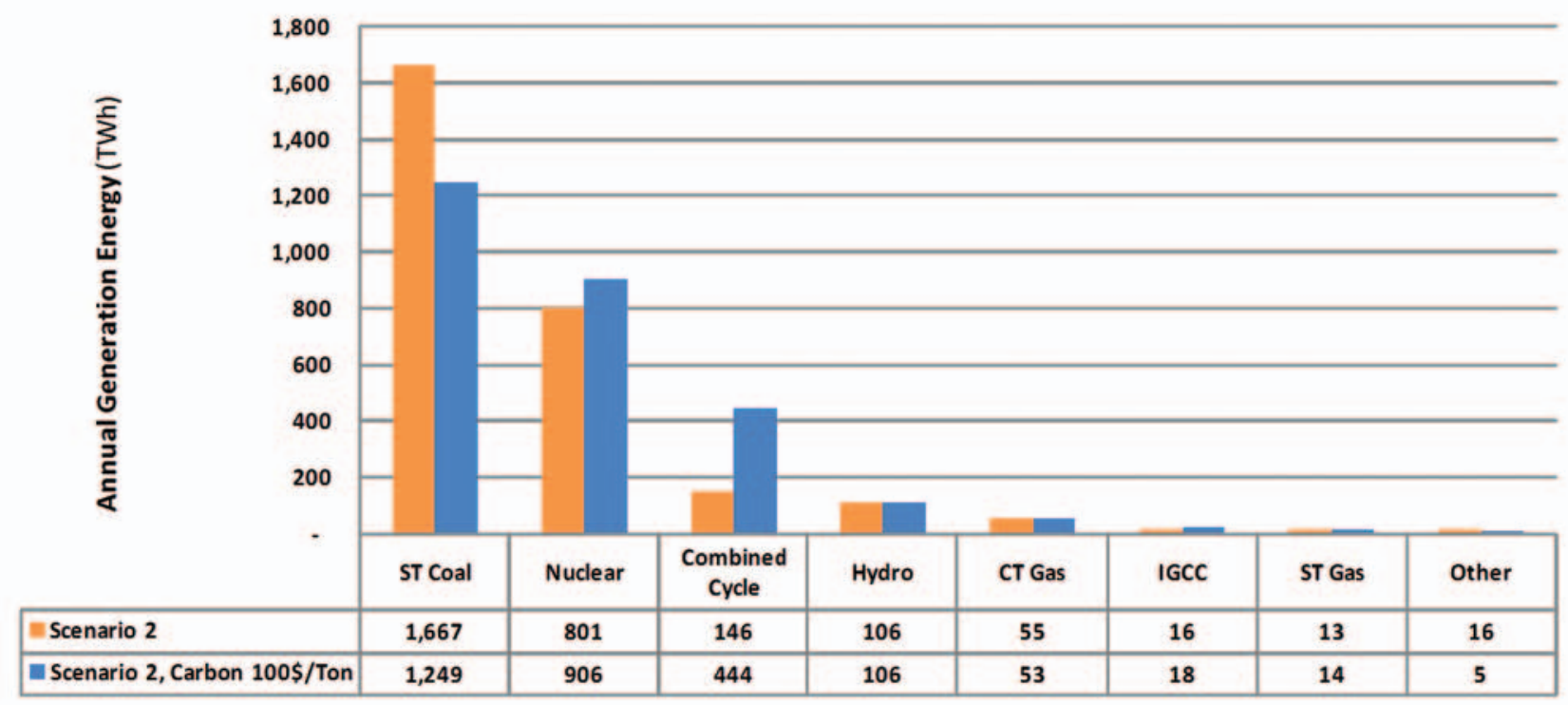

Figure 9-6. Change in generation for carbon sensitivity

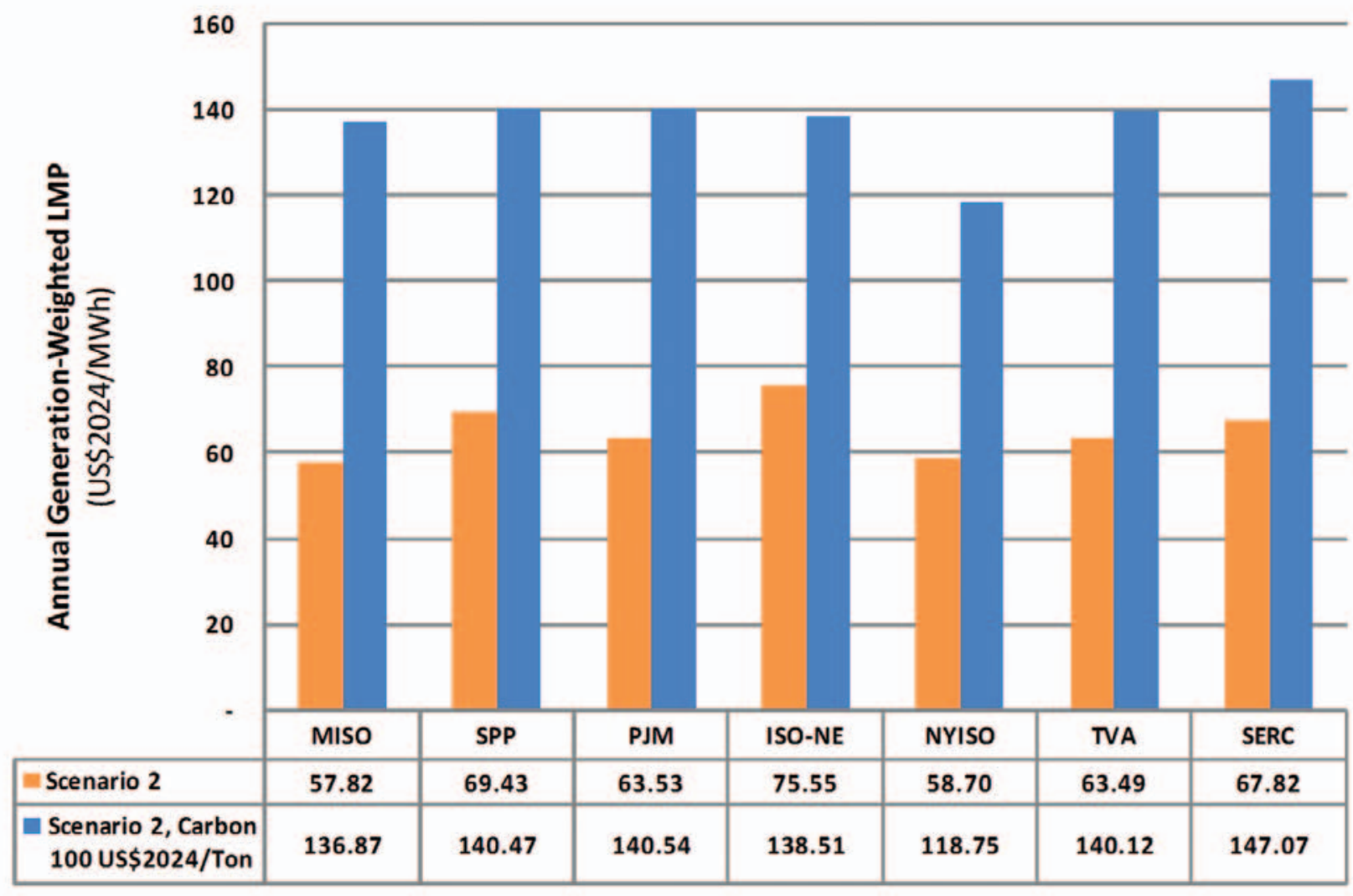

Figure 9-7. Change in LMP for carbon sensitivity

\section{SCENARIO COST COMPARISONS}

Costs for each scenario were calculated as the sum of production-related costs plus annualized amounts for capital investments in new conventional generation, wind plants, and transmission. The results for the Reference Scenario and the 
four high-penetration scenarios developed in this study (Figure 9-8) show that Scenario 1 is the least costly of the $20 \%$ scenarios, and that the increased cost of offshore wind is a major cost element in Scenarios 3 and 4.

Transmission costs are a relatively small fraction for all scenarios, with only a small absolute difference in this component seen in the $20 \%$ scenarios.

None of the scenarios includes any costs associated with carbon.

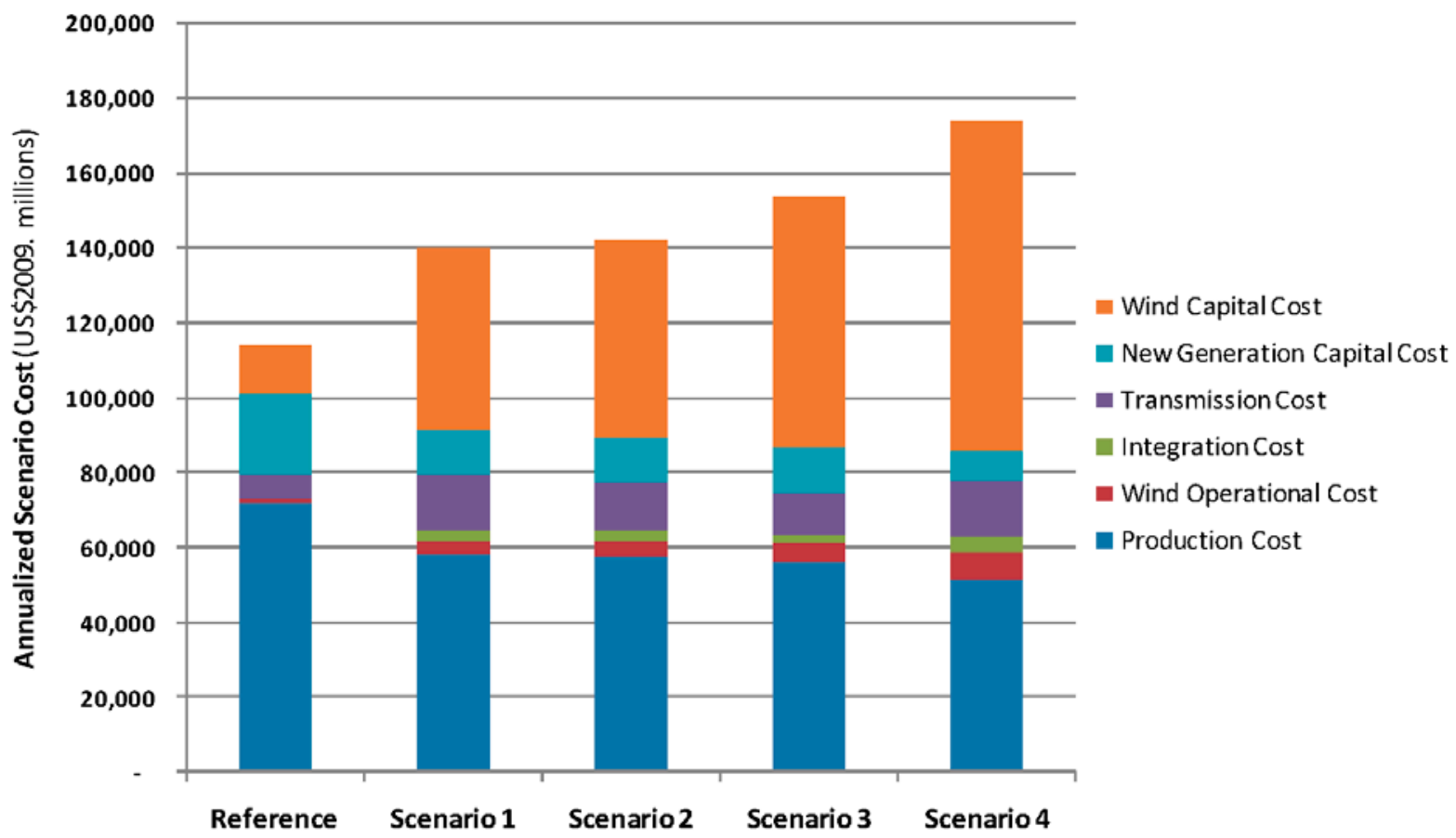

Figure 9-8. Scenario cost comparisons

Other findings and conclusions include the following:

- Achieving 20\% wind energy penetration across the Eastern Interconnection will require very substantial wind development and therefore significant grid expansion.

- A single iteration of the economic transmission expansion methodology gives useful results and insights.

- Wind generation curtailment across the footprint ranges from a low of $3.9 \%$ in Scenario 3 to a high of $10.5 \%$ in Scenario 4.

- Further iterations would allow overlays to be improved and wind curtailment to be minimized. 


\section{SUMMARY}

The significant amount of analytical work performed in this study answers the questions posed at the outset of the project:

1. What impacts and costs do wind generation variability and uncertainty impose on system operations? With large balancing areas and fully developed regional markets, the cost of integration for all scenarios is about \$5 / MWh of wind, or about $\$ 0.005$ per kilowatt-hour ( $\mathrm{kWh}$ ) of electricity used by customers.

2. What benefits accrue from long-distance transmission that accesses multiple and geographically diverse wind resources? The study results show that long-distance (and high-capacity) transmission can assist smaller balancing areas with wind integration, allowing penetration levels that would not otherwise be feasible. Furthermore, all scenarios, including the Reference Case, made use of major transmission upgrades to better interconnect Eastern Interconnection markets for assisting with wind integration.

3. What benefits are realized from long-distance transmission that moves large quantities of remote wind energy to urban markets? Long-distance transmission, along with assumed modifications to market and system operations, contributes substantially to integrating large amounts of wind that local systems would have difficulty managing. In addition, longdistance transmission has other value in terms of system robustness that was not completely evaluated in EWITS.

4. How do remote wind resources compare to local wind resources? In the Eastern Interconnection, the Eastern Wind Data Study database (AWS Truewind 2009) shows that the higher quality winds in the Great Plains have capacity factors that are about $7 \%-9 \%$ higher than onshore wind resources near the high-load urban centers in the East. Offshore plants have capacity factors on par with Great Plains resources but the cost of energy is higher because capital costs are higher.

5. How much does geographical diversity, or spreading the wind out across a large area, help reduce system variability and uncertainty? Quite substantially.

6. What is the role and value of wind forecasting? With significant wind generation, forecasting will play a key role in keeping energy markets efficient and reducing the amount of reserves carried while maintaining system security. 
7. What benefit does balancing area cooperation or consolidation bring to wind variability and uncertainty management? This and other recent studies (see Bibliography) reinforce the concept that large operating areas-in terms of load, generating units, and geography-combined with adequate transmission, are the most effective measures for managing wind generation.

8. How does wind generation capacity value affect supply resource adequacy? Wind generation can contribute to system adequacy, and additional transmission can enhance that contribution.

The scenarios developed for this study do not in any way constitute a plan; instead, they give a top-down, high-level view of four different 2024 futures. The transition over time from the current state of the bulk power system to any one of the scenarios would require much more technical and economic evaluation, including detailed modeling of power flows and a study of the effects on the underlying transmission systems. A more thorough evaluation of the sensitivity of the results from this study to changes in assumptions or scenarios would also be required to guide the development of any specific bottom-up plans.

\section{RECOMMENDATIONS FOR FUTURE STUDY}

The results of this study represent a first detailed look at a handful of future snapshots of the Eastern Interconnection as it could exist in 2024. The analysis was driven primarily through economics-based transmission expansion planning, resource adequacy studies, and hourly modeling simulations. Important technical aspects in the study related to bulk-power system reliability were not studied or were represented approximately or by means of best engineering judgments.

This study is an important step in the uncertain world of long-range planning because it addresses questions such as feasibility and total ultimate costs, and begins to uncover important additional questions that will require answers. Although the Technical Review Committee (TRC) that gave input to EWITS has extensive Eastern Interconnection representation, the study team recognizes that additional key stakeholders must be involved to further develop an interconnection-wide view of transmission system plans.

A complete evaluation of any of the scenarios would require a significant amount of additional technical analysis. The framework established by the scenario definitions and transmission overlay concepts in this study, however, offers a starting point for employing conventional power system planning to further evaluate the feasibility of these high-penetration scenarios and to improve the cost estimates. 
Production simulation results from this study could be used to identify times of binding constraints. The EWITS results could also be used to explore other periods of interest, such as times when there are large changes in wind production, periods of minimum load, and conditions where loss of significant generation would raise questions about the security of the system. For such periods, the state of the system - in terms of, for example, loads, committed generation and dispatch level, and wind generation-would be transferred to an appropriate AC power system model. A variety of power system engineering analyses could then be conducted to determine what additional equipment or operating limitations would be necessary to maintain system reliability. Two examples follow:

- An AC analysis could examine in more detail the power transfer limitations assumed in the production modeling. The production simulations in EWITS used a DC power flow that does not consider the wide range of issues associated with voltage control and reactive power dispatch. This would involve power flows that look at voltage and reactive compensation issues, dynamic and transient stability, and HVDC terminal control. Local and regional transmission needs could then be analyzed in much greater detail.

- Longer term dynamic analysis would allow more detailed simulation and analysis. For example, the actions of automatic generation control (AGC), load tap changing on transformers, and capacitor or reactor switching for voltage control could be simulated and analyzed in much greater detail. This, in turn, would enable examination of subhourly market operation and the response of generation to either AGC or market dispatch instructions. And that examination would allow investigators to consider limitations caused by prime mover or governor response, HVDC control actions, or special protective schemes. These types of analyses could be used to zoom in on the operation of the system in real time, resulting in higher confidence estimates of the operating reserve requirements and policies needed to maintain performance and reliability.

The analysis suggested for the large footprint considered in EWITS would require participation and collaboration from a large number of entities across the interconnection. Personnel engaged in running similar studies with a regional focus would need to be involved, at a minimum, in a review capacity and for interpretation of results. National entities such as the North American Electric Reliability Corporation (NERC) would also need to be engaged to oversee the development of the data sets and models. The size and scope of the system models might also require computational power beyond what is used today in the power industry, and therefore could involve universities or national laboratories with appropriate resources. 
The top-down views of the interconnection produced in this study constitute, in essence, the starting point for a significant amount of subsequent engineering analysis. The analysis would paint a more accurate picture of the total transmission investment necessary, and illuminate what would be required to preserve the security of the bulk power system. As with EWITS, such an effort would be beyond the scope of what has previously been attempted, and would require cooperation and coordination at many levels to succeed.

The results of this study pose some interesting policy and technology development questions:

- Could the levels of transmission, including the Reference Case, ever be permitted and built, and if so, what is a realistic time frame?

- Could the level of offshore wind energy infrastructure be ramped up fast enough to meet the aggressive offshore wind assumption in the EWITS scenarios?

- Would a different renewable profile or transmission overlay arise from a bottom-up process with more stakeholders involved?

- How can states and the federal government best work together on regional transmission expansion and the massive development of onshore and offshore wind infrastructure?

- What is the best way for regional entities to collaborate to make sure wind is integrated into the bulk electrical grid optimally and reliably?

- What is the difference between applying a carbon price versus mandating and giving incentives for additional wind?

As is expected in a study of this type, especially when a wide variety of technical experts and stakeholders are giving ongoing input, a number of important variations on the 2024 future scenario can be envisioned. In addition, a number of technical areas in the study present opportunities for further technical investigation that could deepen understanding or reveal new insights:

- Further analysis of production-cost simulation results: The output from the many annual production simulations performed in this study contains detail on every generator and monitored transmission interface in the Eastern Interconnection. Because of scope and schedule constraints, the analysis conducted in this study was necessarily limited to summary results. Further analysis of this output data would likely generate additional valuable insights on impacts of wind generation on the conventional generation fleet, and help define more detailed analyses that could be conducted going forward.

- Smart grid implications and demand response sensitivities: The Eastern Interconnection load considered in the study was based on regional projections out to the 2024 study year. For the most part, load was considered static. Major industry initiatives are currently exploring means by which at least a portion of the load might respond like a supply 
resource, thereby relaxing the constraints on scheduling and dispatch of conventional generating units. The implications for wind generation are potentially very significant, which is why alternative 2024 scenarios that consider the range of smart grid implications for the bulk electric system merit further study.

- PHEVs (nighttime charging of plug-in electric vehicles): Widespread adoption of electric vehicles has the potential to alter the familiar diurnal shape of electric demand. Because the wind resource is abundant at night and during the low-load seasons, increases in electric demand during these times could ease some of the issues associated with integration.

- Commitment/optimization with high amounts of wind: The approach for scheduling and dispatching generating resources used in the production simulations was based on current practice. In the future, new operating practices and energy market structures might be implemented that take advantage of the fact that uncertainty declines as the forecast horizon is shortened (for both load and wind generation). Intraday energy markets that allow more frequent reoptimization of the supply resources could offer some advantage for accommodating large amounts of variable and uncertain wind energy.

- Fuel sensitivity: In this phase of EWITS, the study team considered a single "future" for prices of other fuels used for electric generation. As history attests, there is much uncertainty and volatility inherent in some fuel markets, especially for natural gas. Alternate scenarios that explore the impacts of other fuel price scenarios on integration impacts and overall costs would be valuable.

- The role and value of electric energy storage: With the substantial transmission overlays and the assumption of large regional markets, the EWITS results show that large amounts of wind generation might be accommodated without deploying additional energy storage resources. The ability to store large amounts of electric energy could potentially obviate the need for some of the transmission and reduce wind integration impacts, though. Analysis of bulk energy storage scenarios with generic storage technologies of varying capabilities would quantify the costs and benefits of an alternate means for achieving high penetrations of renewable energy.

- Transmission overlay enhancement: As described earlier, the analytical methodology was based on a single pass through what is considered an iterative process. Further analysis of the existing results could be used to refine the transmission overlays, which would then be tested in additional production simulations and LOLE analyses, along with AC power flow and stability analysis. This could reduce the estimated costs of the overlay, and bolster the view of the required regional transmission expansion that would be needed to deliver the large amounts of wind energy to load. 
- Sequencing of overlay development: The EWITS team used a top-down perspective to focus on a snapshot of four 2024 scenarios. The resulting transmission overlays and very substantial wind generation would be developed over many years. An analysis over time-beginning now and extending to 2024-would yield important insights into the overall feasibility and costs of an aggressive transmission development future.

- Wind generation curtailment: Selective and appropriate use of wind generation curtailment could have high operational value. Although wind plants cannot increase their output at will without first spilling wind generation, downward movement is easily accomplished with today's wind generation technology, and could have very high economic value under certain circumstances. Wind generation is quite capable of providing "regulation down" ( for example, in an ancillary services market where the regulation service is bifurcated, meaning that regulation up and regulation down are separate services). Additional analysis of the scenarios studied in EWITS could help quantify what such a service would be worth to wind plant operators.

The current installed capacity of wind generation in many areas of the United States, coupled with prospective development over the next several years, requires that assessments of the bulk electric power system take a much broader view than has been typically employed. In addition, the unique characteristics of wind generation as an electric energy supply resource are leading the power industry to new approaches for planning and analyzing the bulk electric power system.

Several of these techniques were demonstrated in this study, and are also being used in other large-scale wind integration analyses. The data sets compiled for the study represent the most detailed view to date of high-penetration wind energy futures. Given the significant changes coursing through the electric power industry, many alternative scenarios for the Eastern Interconnection in 2024 can be postulated. In that sense, EWITS is a solid first step in evaluating possibilities for the twenty-first-century grid in the United States, with many more to follow. 


\section{GLOSSARY}

Area control error (ACE): The instantaneous difference between net actual and scheduled interchange within a control area on the power grid, taking into account the effects of frequency deviations.

Automatic generation control (AGC): A control system that automatically adjusts generation units on regulation duty to compensate for random or sudden changes in demand. Depending on the characteristics of the balancing area, AGC adjustments occur over periods of tens of seconds to a minute.

Adjusted production cost (APC): Captures the actual cost of serving load. The cost of purchases or sales to the outside world is adjusted from the total production cost.

Balancing area (or balancing authority area [BAA]): The collection of generation, transmission, and loads within the metered boundaries of the balancing authority. The balancing authority maintains load-resource balance within this area.

Benefit/cost (B/C): Analysis of the benefits and costs of a given option. In this report, $\mathrm{B} / \mathrm{C}$ is expressed as a ratio.

Bus-bar: The point at which power is available for transmission.

Capability: The maximum load that a generating unit, generating station, or other electrical apparatus can carry under specified conditions for a given period of time without exceeding approved temperature and stress limits.

Capacity: The amount of electrical power delivered or required for which manufacturers rate a generator, turbine, transformer, transmission circuit, station, or system.

Capacity factor: The fraction of the nameplate rating of a wind power plant that can be counted as dependable or firm capacity, expressed as a percentage.

Capacity value: A measure of the productivity of a power plant, calculated as the amount of energy that the plant produces over a set time period, divided by the amount of energy that would have been produced if the plant had been running at full capacity during that same time interval. Most wind power plants operate at capacity factors ranging from $25 \%$ to $40 \%$.

Capital costs: The total investment cost for a power plant, including auxiliary costs. 
CAPX 2020: A joint initiative of 11 transmission-owning utilities in Minnesota and the surrounding region, designed to expand the electric transmission grid.

Copper sheet simulation: Sensitivity analysis with no transmission constraints in the system.

Control Performance Standards 1 and 2 (CPS1 and CPS2): The reliability standards that set the limits of a balancing authority's ACE over a specified time period. CPS1 is a statistical measure of the variability of the ACE and CPS2 is a measure of the magnitude of the ACE.

Curtailment: Shutting down or limiting the output of generators to mitigate a transmission constraint or other binding constraint such as excess electricity supply relative to demand and must-run generation (minimum generation limits); limitations in ramping capability; or availability of adequate operating reserves.

Dispatch: The physical inclusion of a generator's output onto the transmission grid by an authorized scheduling utility.

Distribution: The process of distributing electricity. Distribution usually refers to the series of power poles, wires, and transformers that run between a high-voltage transmission substation and a customer's point of connection.

Dump energy: A term representing the unavoidable surplus generation that cannot be used to serve load because of unit operating or transmission constraints. Dump energy is the result of negative bus locational marginal prices (LMPs). It is conceptual and used only for reporting purposes.

Effective load-carrying capability (ELCC): The amount of additional load that can be served at the target reliability level by adding a given amount of generation. For example, if adding 100 megawatts (MW) of wind could meet an increase of $20 \mathrm{MW}$ of system load at the target reliability level, the turbine would have an ELCC of $20 \mathrm{MW}$, or a capacity value of $20 \%$ of its nameplate value.

Electric Generation Expansion Analysis System (EGEAS): Software from the Electric Power Research Institute (EPRI) that is used for long-term regional resource forecasting. EGEAS performs capacity expansions based on long-term, least-cost optimizations with multiple input variables and alternatives. The software can perform optimizations on a variety of constraints such as reliability (loss-of-load hours), reserve margins, or emissions.

Electricity generation: The process of producing electricity by transforming other forms or sources of energy into electrical energy. Electricity is measured in kilowatt-hours. 
Energy penetration: The ratio of the amount of energy delivered from one type of resource to the total energy delivered. For example, if 200 megawatt-hours (MWh) of wind energy supplies 1,000 MWh of energy consumed, wind's energy penetration is $20 \%$.

European Wind Integration Study (EWIS): An initiative established by the European transmission system operators in collaboration with the European Commission. EWIS partners are developing, where possible and appropriate, common solutions to wind integration challenges. They are also identifying arrangements that will best use the pan-European transmission network to deliver the benefits of wind generation across Europe.

Eastern Wind Integration and Transmission Study (EWITS): A project that evaluated the power system impacts, costs, and conceptual transmission overlays attendant with increasing wind generation capacity to $20 \%$ and $30 \%$ of retail electric energy sales in 2024 for the study area, which includes a large fraction of the U.S. Eastern Interconnection.

Federal Energy Regulatory Commission (FERC): An independent agency that regulates the interstate transmission of electricity, natural gas, and oil.

Financial transmission right (FTR): A right to congestion credits or charges along a specific path during a given time frame for a certain amount of power flow. FTRs are tradable financial instruments that allow market participants to hedge against the cost and uncertainty that can arise from congestion in the market.

GE Energy's Multi-Area Reliability Simulation (GE-MARS): A transportationstyle model based on a sequential Monte Carlo simulation that steps through time chronologically and produces a detailed representation of the hourly loads and wind profiles, generating units, and interfaces between the interconnected areas.

Gigawatt (GW): A unit of power that is instantaneous capability equal to 1 million kilowatts.

Gigawatt-hour (GWh): A unit or measure of electricity supply or consumption of 1 million kilowatts over a period of 1 hour.

Grid: A common term for an electricity transmission and distribution system. See also power system and utility grid.

Hurdle rate: Rates used in the production-cost model to allow regional transactions during the security-constrained unit-commitment and dispatch process. Two separate hurdle rates are defined for dispatch and for unit commitment. The dispatch hurdle rates are the economic adders between 
applicable price zones to reflect either regulatory tariffs or market efficiency impacts. Within a regional transmission organization (RTO), there are no hurdle rates; the hurdle rates are between RTOs. The commitment hurdle rate is a mechanism to commit pool generation for pool load. Commitments to serve load outside the pool are made based on the price differentials.

Kilovolt (kV): One volt is the basic unit of electromotive force, or difference in potential, that causes a current of one ampere to flow through a conductor having a resistance of one ohm. One kilovolt is equal to 1,000 volts.

Kilowatt (kW): A standard unit of electrical power that is instantaneous capability equal to 1,000 watts.

Kilowatt-hour (kWh): A unit or measure of electricity supply or consumption of 1,000 watts over a period of one hour.

Load (electricity): The amount of electrical power delivered or required at any specific point or points on a system. The requirement originates at the consumer's energy-consuming equipment.

Load factor: The ratio of the average load to peak load during a specified time interval.

Load following: An electric system's process of adjusting its generation to follow changes in demand over periods of several minutes to hours. The goal of the practice is to ensure that generators are producing neither too little nor too much energy to supply the utility's customers.

Levelized cost of energy (LCOE): An important measure of wind-resource quality for each facility in the database and for the wind database as a whole. The LCOE allows for direct comparisons among the lifetime costs—on an energy-delivered basis—of facilities with different capital and maintenance costs.

Locational marginal price (LMP): The marginal cost of serving the next megawatt of demand. LMP depends on the system transmission constraints and the performance characteristics of generation resources.

Loss of energy expectation (LOEE): The expected unsupplied energy resulting from generating inadequacy. The LOEE incorporates the severity of the deficiencies.

Loss of load expectation (LOLE): The number of hours in a specified period in which the load exceeds the available generating capacity. 
Loss of load probability (LOLP): The probability that the load will exceed the generation at a given time. When this probability is summed over a time frame ( e.g., 1 year), it is known as LOLE.

Megawatt (MW): The standard measure of power plant electricity-generating capacity. One megawatt is equal to 1,000 kilowatts or 1 million watts.

Megawatt-hour (MWh): A unit of energy or work equal to1,000 kilowatt-hours or 1 million watt-hours.

Mesoscale: Atmospheric phenomena (temperature, pressure, precipitation, and wind, for example) on scales of several kilometers to several hundred kilometers.

Nameplate rating (or nameplate capacity): The maximum continuous output or consumption (in megawatts) of an item of equipment as specified by the manufacturer.

Power: The rate of production or consumption of energy.

Power system: A common term for an electricity transmission and distribution system. See also utility grid.

Production-cost model: A model that captures all the costs of operating a fleet of generators. The model has been developed into an hourly, security-constrained, economic commitment and dispatch simulation. It uses an hourly chronological dispatch algorithm that minimizes costs while simultaneously adhering to a number of operating constraints. It calculates hourly production costs and location-specific market-clearing prices.

Ramp rate: The rate of change in output from a power plant.

Regional Transmission Organization (RTO): An independent organization established to operate the transmission assets and deliver wholesale transmission services within a defined geographic region. Typically, the RTO does not own transmission facilities but operates them on behalf of the transmission-owning utilities. A RTO can operate a central energy market in addition to furnishing transmission services. (Note: RTO can sometimes stand for regional transmission operator, depending on context.)

\section{Reserves}

Contingency Reserves: Reserves to mitigate a contingency, which is defined as the unexpected failure or outage of a system component such as a generator, transmission line, circuit breaker, switch, or other electrical element. In the formal North American Electric Reliability Corporation (NERC) 
definition, this type of reserve is the provision of capacity deployed by the balancing authority to meet the disturbance control standard (DCS) and other NERC and regional reliability organization contingency requirements.

Operating Reserves: That capability above firm system demand required for regulation, load forecasting error, forced and scheduled equipment outages, and local area protection. This type of reserve consists of both generation synchronized to the grid and generation that can be synchronized and made capable of serving load within a specified period of time.

Regulating Reserves: An amount of reserve that is sufficient to allow for normal regulating margins. Regulating reserves, which are responsive to AGC, are the primary tool for maintaining the frequency of the bulk electric system at $60 \mathrm{~Hz}$.

Spinning Reserves: The portion of operating reserve consisting of (1) generation synchronized to the system and fully available to serve load within the disturbance recovery period following the contingency event; or (2) load fully removable from the system within the disturbance recovery period following the contingency event.

Reserve margin: Percentage by which available generating capacity is expected to exceed forecast peak demand.

Security-constrained unit commitment (SCUC): An area-wide optimization process designed to meet electricity demand at the lowest cost, given the operational and reliability limitations of the area's generation fleet and transmission system.

Single largest hazard (SLH): Largest possible single loss of generating capacity resulting from either forced outage of generation or transmission equipment. Also called single largest contingency.

Utility grid: A common term for an electricity transmission and distribution system. See also power system.

Western Electricity Coordinating Council (WECC): The regional entity responsible for coordinating and promoting bulk electric system reliability in the Western Interconnection.

Western Wind and Solar Integration Study (WWSIS): A study examining the planning and operational implications of adding up to $30 \%$ of wind and solar energy penetration to the WestConnect footprint in the WECC. 
Wind integration costs: Incremental costs incurred in operational time frames that can be attributed to the variability and uncertainty introduced by wind generation.

Wind power: Power generated by using a wind turbine to convert the mechanical power of the wind into electrical power.

Wind power plant: A group of wind turbines interconnected to a common utility system.

Wind resource assessment: The process of characterizing the wind resource and its energy potential for a specific site or geographical area.

Wind speed: The rate of flow of wind when it blows undisturbed by obstacles.

Wind turbine: A device that converts wind energy to electricity. 


\section{BIBLIOGRAPHY}

AWS Truewind, LLC. 2009. Development of Eastern Regional Wind Resource and Wind Plant Output Datasets. Prepared under Subcontract No. ACO-8-88500-01. NREL/SR-550-46764. Golden, CO: National Renewable Energy Laboratory (NREL).

Bai, X., K. Clark, G. Jordan, N. Miller, and R. Piwko. July 2007. Intermittency Analysis Project: Appendix B, Impact of Intermittent Generation on Operation of California Power Grid. Prepared by GE Energy Consulting for the California Energy Commission Public Interest Energy Research Program. Schenectady, NY: GE Energy Consulting. http: / / www.energy.ca.gov/2007publications/CEC-5002007-081 / CEC-500-2007-081-APB.PDF.

California ISO. November 2007. Integration of Renewable Resources: Transmission and Operating Issues and Recommendations for Integrating Renewable Resources on the California ISO-Controlled Grid. http:/ / www.caiso.com/1ca5/1ca5a7a026270.pdf.

Corbus, D., D. Lew, G. Jordan, W. Winters, F. Van Hull, J. Manobianco, and R. Zavadil. November/December 2009. "Up with Wind: Studying the Integration and Transmission of Higher Levels of Wind Power." IEEE Power and Energy, 7(6): 36-46.

Corbus, D., M. Milligan, E. Ela, M. Schuerger, and R. Zavadil. September 2009. Eastern Wind Integration and Transmission Study-Preliminary Findings. Preprint. Presented at the 8th International Workshop on Large Scale Integration of Wind Power and on Transmission Networks for Offshore Wind Farms, October 14-15, Bremen, Germany. NREL / CP-550-46505. Golden, CO: NREL. http: / www.nrel. gov/docs/fy09osti/46505.pdf.

Department of Communications, Energy and Natural Resources (Governments of Ireland and Northern Ireland). 2008. All Island Grid Study. http:/ / www.dcenr. gov.ie/Energy / North-South+Co-operation+in+the+Energy+Sector / All+Island+ Electricity+Grid+Study.htm

EERE (U.S. DOE Office of Energy Efficiency and Renewable Energy). July 2008. 20\% Wind Energy by 2030: Increasing Wind Energy's Contribution to U.S. Electric Supply. DOE/GO-102008-2567. Washington: EERE. http:/ / www1.eere.energy. gov/windandhydro/pdfs / 41869.pdf.

EnerNex Corporation. March 2007. Final Report-Avista Corporation Wind Integration Study. Knoxville, TN: EnerNex. http:/ / www.uwig.org/ AvistaWindIntegrationStudy.pdf. 
EnerNex Corporation. November 2006. Final Report-2006 Minnesota Wind Integration Study, Volume I. Knoxville, TN: EnerNex. http: / www.uwig.org/ windrpt_vol\%201.pdf.

EnerNex Corporation and WindLogics Inc. September 2004. Xcel Energy and the Minnesota Department of Commerce Wind Integration Study-Final Report. Knoxville, TN: EnerNex and St. Paul, MN: WindLogics. http: / / www.uwig.org/ XcelMNDOCStudyReport.pdf.

European Wind Integration Study Web site. http:/ / www.wind-integration.eu.

EWEA (European Wind Energy Association). December 2005. Large-Scale Integration of Wind Energy into the European Power Supply: Analysis, Issues and Recommendations. Brussels: EWEA. http:/ / www.ewea.org/index.php?id=178.

GE Energy. March 2008. Attachment A: Analysis of Wind Generation Impact on ERCOT Ancillary Services Requirements. Prepared for the Electric Reliability Council of Texas. Schenectady, NY: GE Energy. http: / / www.ercot.com/content / news / presentations / 2008/Wind_Generation_Impact_on_Ancillary_Services_-_ GE_Study.zip

Interconnection for Wind Energy, Order No. 661, FERC Stats. \& Regs.

IRC (Independent System Operator / Regional Transmission Organization Council). 2009. 2009 State of the Markets Report. http: / / www.hks.harvard.edu / hepg / Papers / 2009/2009\%20IRC\%20State\%20of\%20Markets\%20Report.pdf.

JCSP (Joint Coordinated System Plan). 2008. JCSP'08 Executive Summary; JCSP'08 Report, Volume 1: Economic Assessment; and JCSP'08 Volume 2: Reliability Assessment. http:/ / www.jcspstudy.org/.

Kirby, B., M. Milligan, R. Gramlich, and M. Goggin, July 2009. Impact of Electric Industry Structure on High Wind Penetration Potential. NREL/TP-550-46723. Golden, CO: NREL.

Meibom, P., R. Barth, H. Brand, B. Hasche, D. Swider, H. Ravn, and C. Weber. July 2007. All Island Grid Study, Wind Variability Management Studies, Workstream 2B. Roskilde, Denmark: Risø National Laboratory. http: / / www.uwig.org/Irish_ All_Island_Grid_Study/Workstream_2B.pdf.

Midwest ISO. December 2009. Regional Generation Outlet Study: Phase I Executive Summary Report. http: / / www.midwestmarket.org/publish/ Document/312000_1256e686b3c_-7f210a48324a/RGOS_I_Executive_Summary_ Report_DRAFT_121109.pdf?action=download\&_property=Attachment 
Milligan, M., and B. Kirby. June 2008. Analysis of Sub-Hourly Ramping Impacts of Wind Energy and Balancing Area Size. Preprint. Presented at WindPower 2008, June 1-4, Houston, Texas. NREL/CP-500-43434. Golden, CO: NREL. http:/ / www. nrel.gov / docs/ fy08osti/43434.pdf.

Milligan, M., and B. Kirby. June 2008. “The Impact of Balancing Area Size and Ramping Requirements on Wind Integration." Wind Engineering, 32 (4): 379-398.

Milligan, M., and K. Porter. June 2008. Determining the Capacity Value of Wind: An Updated Survey of Methods and Implementation. Preprint. Presented at WindPower 2008, June 1-4, Houston, Texas. NREL/CP-500-43433. Golden, CO: NREL. http: / / www.nrel.gov / docs / fy08osti / 43433.pdf.

NYISO (New York Independent System Operator). Accessed November 2008. Section 2.23a, Market Services Tariff. http:/ / www.nyiso.com/public/webdocs / documents / tariffs/market_services / services_tariff.pdf

Piwko, R., X. Bai, K. Clark, G. Jordan, N. Miller, and J. Zimberlin. March 2005. The Effects of Integrating Wind Power on Transmission System Planning, Reliability, and Operations. Report on Phase 2: System Performance Evaluation. Prepared for the New York State Energy Research and Development Authority, March 2005. Schenectady, NY: GE Energy. http: / / www.nyiso.com/public/webdocs / services / planning/special_studies/wind_integration_report.pdf.

Potter, C., D. Lew, J. McCaa, S. Cheng, S. Eichelberger, and E. Grimit. 2008. "Creating the Dataset for the Western Wind and Solar Integration Study (U.S.A.)." Wind Engineering, 32(4): 325-338.

Smith, J.C., M. Milligan, E. DeMeo, and B. Parsons. August 2007. “Utility Wind Integration and Operating Impact State of the Art." IEEE Transactions on Power Systems, 22(3): 900-908.

SPP (Southwest Power Pool). 2008. Draft 2008 SPP EHV Overlay Report. http: / / www.spp.org/publications / 2008\%20SPP\%20\%20EHV\%20Overlay\%20Report_ DRAFT_12_26_08_FINAL.pdf.

Wan, Y.-H. September 2004. Wind Power Plant Behaviors: Analyses of Long-Term Wind Power Data. NREL/TP-500-3655. Golden, CO: NREL. http:/ / www.nrel. gov/ wind/systemsintegration/pdfs / 2004/wan_wind_plant_behaviors.pdf

Western Wind and Solar Integration Study Web site. http:/ / www.westonnect. com/planning_nrel.php. 
Wiser, R., and M. Bolinger. July 2009. Wind Technologies Market Report. DOE/ GO-102009-2868. Washington: EERE, July 2009. http: / / eetd.lbl.gov/ea/ems/ reports / 2008-wind-technologies.pdf.

Xcel Energy. March 2007. An Effective Load Carrying Capability Study for Estimating the Capacity Value of Wind Generation Resources: Final Report. http: / / www.xcelenergy.com/SiteCollectionDocuments/docs / PSCoELCCFinalReport030107.pdf

Zavadil, R. 2006. Final Report: Wind Integration Study for Public Service Company of Colorado. Knoxville, TN: EnerNex. http:/ / www.nrel.gov/wind/ systemsintegration/pdfs/colorado_public_service_windintegstudy.pdf 


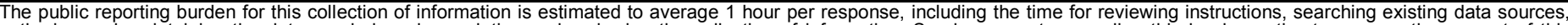

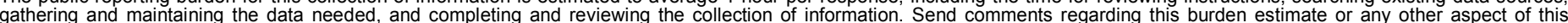

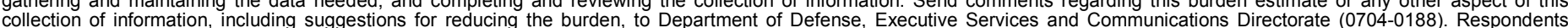

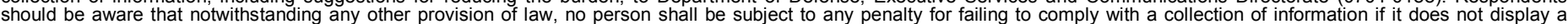

should be aware that notwithstanding

PLEASE DO NOT RETURN YOUR FORM TO THE ABOVE ORGANIZATION.

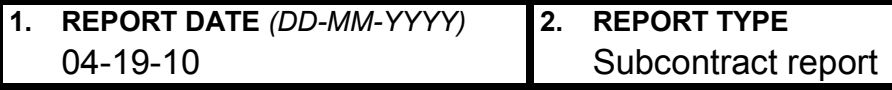

4. TITLE AND SUBTITLE

Eastern Wind Integration and Transmission Study
3. DATES COVERED (From - To)

2007 - 2009

5a. CONTRACT NUMBER

DE-AC36-08G028308

5b. GRANT NUMBER

5c. PROGRAM ELEMENT NUMBER

5d. PROJECT NUMBER

NREL/SR-5500-47078

5e. TASK NUMBER

WE10-4311

5f. WORK UNIT NUMBER
7. PERFORMING ORGANIZATION NAME(S) AND ADDRESS(ES)

EnerNex Corporation, Knoxville, Tennessee
8. PERFORMING ORGANIZATION REPORT NUMBER

AAM-88513-01

9. SPONSORING/MONITORING AGENCY NAME(S) AND ADDRESS(ES)

National Renewable Energy Laboratory

1617 Cole Blvd.

Golden, CO 80401

10. SPONSOR/MONITOR'S ACRONYM(S) NREL

11. SPONSORING/MONITORING AGENCY REPORT NUMBER NREL/SR-5500-47078

12. DISTRIBUTION AVAILABILITY STATEMENT

National Technical Information Service

U.S. Department of Commerce

5285 Port Royal Road

Springfield, VA 22161

13. SUPPLEMENTARY NOTES

NREL Technical Monitor: David Corbus

14. ABSTRACT (Maximum 200 Words)

The Eastern Wind Integration and Transmission Study was designed to answer questions posed by a variety of stakeholders about a range of important and contemporary technical issues related to a $20 \%$ wind energy scenario for the large portion of the electric demand in the Eastern Interconnection.

\section{SUBJECT TERMS}

wind energy integration: wind energy interconnection; transmission study; utility grid;

\begin{tabular}{l} 
16. SECURITY CLASSIFICATION OF: \\
\begin{tabular}{|l|l|l|}
\hline a. REPORT & b. ABSTRACT & c. THIS PAGE \\
Unclassified & Unclassified & Unclassified \\
& & \\
\hline
\end{tabular} \\
\hline
\end{tabular}

\begin{tabular}{l|l} 
17. $\begin{array}{l}\text { LIMITATION } \\
\text { OF ABSTRACT }\end{array}$ & $\begin{array}{l}\text { 18. } \\
\text { NUMBER } \\
\text { OF PAGES }\end{array}$ \\
UL & \\
&
\end{tabular}

19a. NAME OF RESPONSIBLE PERSON

19b. TELEPHONE NUMBER (Include area code) 